\title{
envelapgs
}
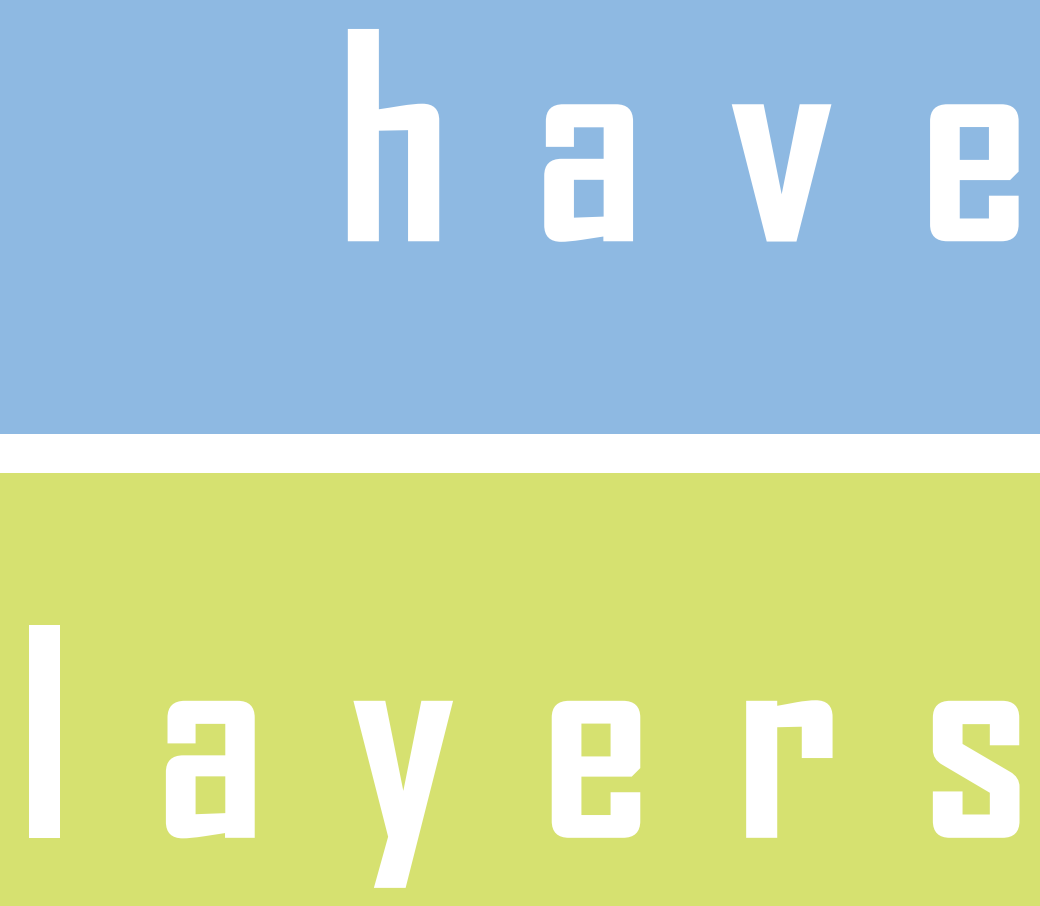

Improving Performante and Legibility of Building Envelope Layers 


\section{envelopes have layers \\ Improving Performance and Legibility of building envelopes}

by

Grace Tennent

A 120-point thesis submitted to the

Victoria University of Wellington

in partial fulfilment of the requirements for the

degree of Master of Architecture (Professional)

Victoria University of Wellington

School of Architecture

2021 


\section{acknowledgements}

Firstly, I would like to thank my parents, who have always encouraged and supported me throughout my study. This would not have been possible without them. I would like to thank my supervisor Hans-Christian Wilhelm for the time and input you have had into this project. To Dr Dave Edkins for answering my never ending questions on hygrothermal analysis. To my work colleagues for providing insight into the realities of the construction industry. I would like to thank my family and friends for the support and patience they have showed during the stresses of thesis life. I need to also mention my black labrador who has literally never left my side. All glory to God! 


\section{$\begin{array}{lllllllllllll}c & 0 & n & t & e & n & t & s\end{array}$}

\section{1 ressarch outline}

1.1 abstract

002

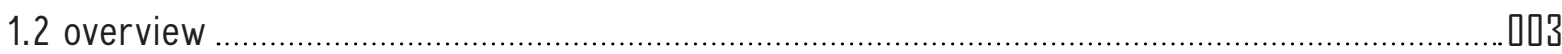

1.3 background and problem statement …….......................................................................... 004

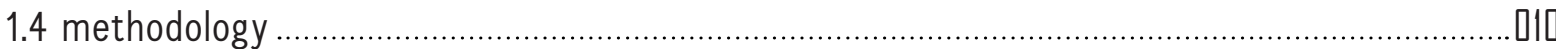

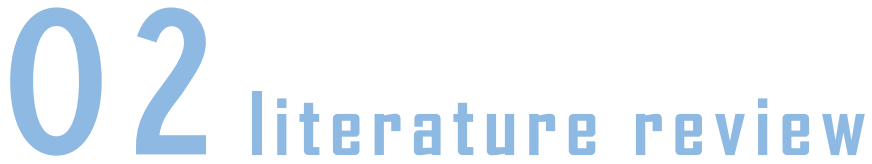

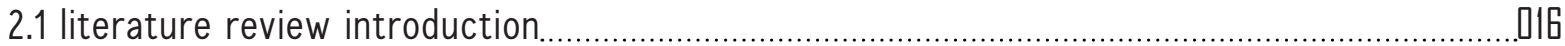

2.2 the building envelope

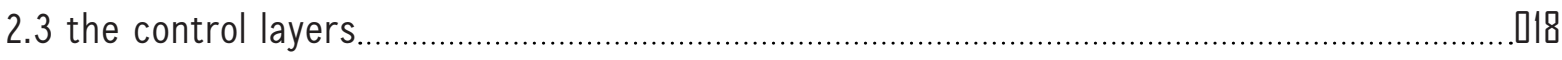

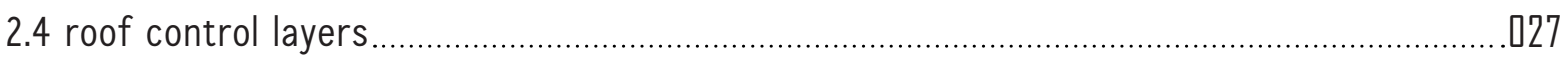

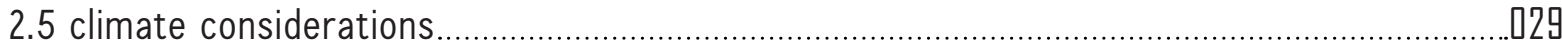

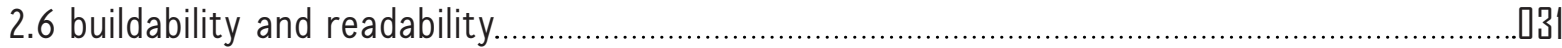

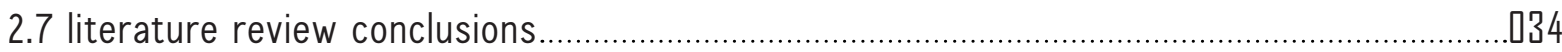

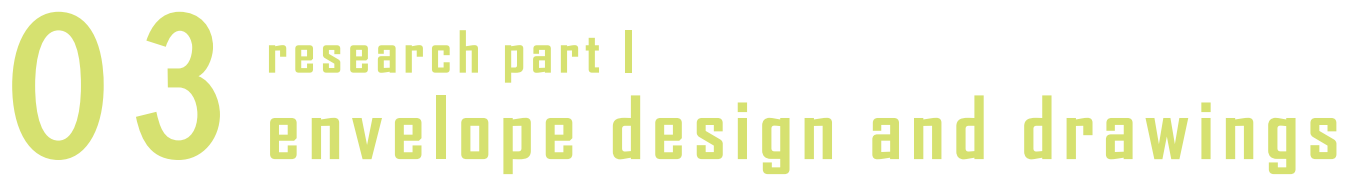

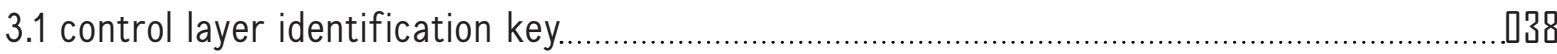

3.2 building envelope science diagrams.................................................................................... .939

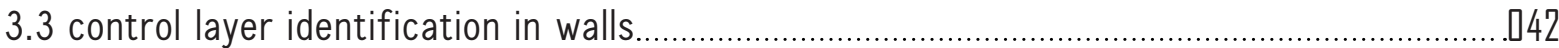

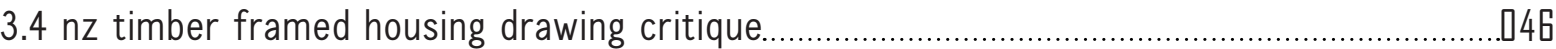

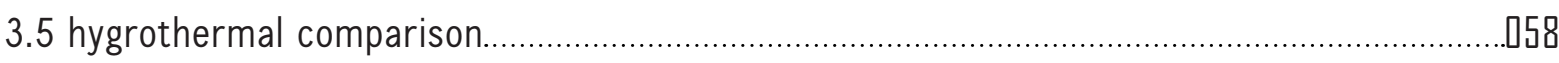

3.6 proposed envelope assembly design.......................................................................................... 


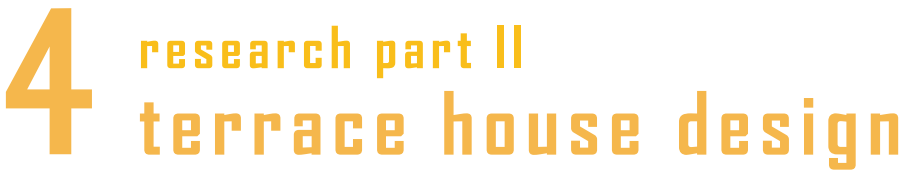

4.1 terrace house design overview.

4.2 terrace house design drawings 092

4.3 terrace house detailed design drawings. .116

\section{optimisation and implications}

5.1 implications 176

5.2 building envelope comparison. 178

5.5 optimisation. 183

reference and figure list 188 


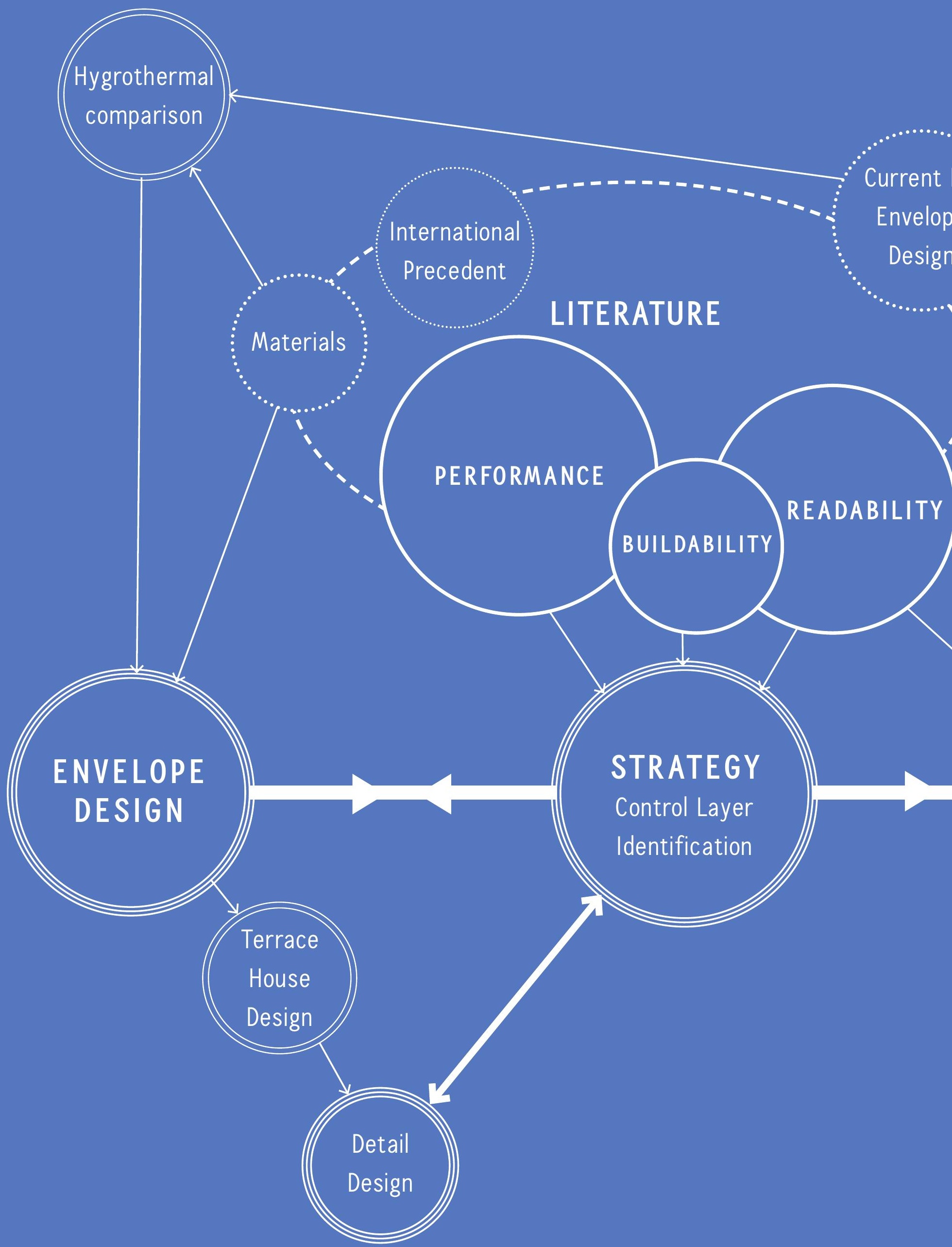




\section{l.I abstract}

Residential timber framed buildings in New Zealand continue to have issues in relation to performance as a result of poor initial building envelope design and a lack of construction quality.

Building envelopes need to be designed in respect to fundamental building envelope science. It is also crucial that drawings and details relating to the building envelope are clear if the desired level of performance is to be achieved. And, ultimately, the architectural drawings that are developed must be practical in respect to buildability - the construction methodology and detailing of the building envelope must be practical and achievable if the desired outcomes are to be achieved.

The legibility and identification of building envelope control layers on architectural drawings communicates building envelope performance and helps to ensure buildability of control layers, particularly in respect to their continuity during construction.

Readable (clarity) and buildable (constructability) architectural details, which respect the fundamentals of building envelope science in regard to rain, air, vapour, and heat control, can improve construction quality in New Zealand, increase building performance, and provide durable, efficient and healthy homes.

This research focuses on building envelopes constructed from timber framing as this is the most common method of residential construction in New Zealand. Common New Zealand building envelope detail drawings from a range of contexts are used to critique current New Zealand building envelope design. This analysis identifies common building envelope problems in regard to drawing readability and performance.
The research proposes a revised set of building envelope details for a timber framed terraced house, which feature an enhanced way of achieving and communicating performance and buildability within building envelope drawings and details. 


\section{I.2 averview}

Background and problem statement. The envelope of a building performs as an environmental separator (Knaack \& Koenders, 2018) and, as such, has a critical function in providing a healthy indoor environment. Whilst building performance relies on many factors this thesis looks at two crucial considerations in relation to building envelope performance. Firstly, the design of the building in relation to hygrothermal performance, including the control of moisture in the envelope (building science aspect). Secondly, the ability for this envelope system to be successfully built and implemented in practice. This will be determined by the clarity and readability of architectural drawings (drawing aspect).

Building envelope performance. Performance looks into what building science principles need to be considered in the design of a building envelope. In New Zealand the majority of building envelope problems are moisture related and controlling moisture entry into the building envelope is therefore the single most important factor to creating durable buildings (Lstiburek, 2019). Moisture related problems have led to mould in New Zealand homes (the BRANZ 2015 house condition survey noted that mould was present in half of the homes visited) and unfortunately the health effects of this are reflected in New Zealand's high rate of asthma and respiratory disease with, on average, 77 New Zealanders dying from asthma every year (BRANZ Research Now, 2019) (Asthma and Respiratory Foundation NZ, 2019).

In New Zealand, residential building envelope assemblies are commonly constructed around structural timber framing with use of various material layers for enclosing the interior space. If designed with reference to the local climate, and in response to the fundamental building envelope science principles, layered wall assemblies can be well suited to meeting the performance requirements of the building envelope in relation to moisture, air-tightness, and heat transmission. However, because the building envelope works as system, it is crucial to understand how the layers of the envelope function together rather than as individual components.

Based on a review of current building envelope science literature the envelope is analysed in reference to the envelope's crucial control layers. The role of each control layer is addressed in respect to how it contributes to the overall performance of the building envelope, and a colour coding system to identify and communicate these control layers is proposed. III-informed layering and poor building envelope design is likely to compromise weather-tightness, air and vapour control, thermal performance and durability of the building envelope. The adoption of the building envelope science principles that are discussed aims to eliminate moisture related performance problems within New Zealand timber framed building envelopes.

Drawing readability. Architectural drawings are the most important form of communication between the architect and builder. The quality and clarity of drawings directly influences the built outcome, including the performance and durability of building envelopes. Additionally, building envelope design which considers the buildability (including, but not limited to, sequencing on site) will minimise the risk of defects during construction. To do this the designer should have a practical understanding of how the detail will be built.

This thesis looks into ways for building envelope performance to be communicated on drawings. A shared understanding between architects and builders about the design and performance strategy for the envelope system, and the location and continuity of envelope layers, encourages a combined commitment to delivering a functional building envelope. 


\section{I.3 background + problem statement}

Overview. It is not uncommon to hear the complaint that new houses in New Zealand do not perform as well as they could, particularly when compared to residential buildings in other jurisdictions. This comment is often made in reference to the prevalence of moisture related problems and mould in relatively new homes in New Zealand.

Whilst 'older' houses were less prone to issues related to mould and moisture it must also be appreciated that, due to significantly less (and sometimes no) insulation, and due to generally high levels of air leakage through the building envelope, these older houses were renowned for being cold in winter and for over-heating in summer.

Higher levels of thermal resistance and airtightness have changed the way houses perform (Lstiburek, 2008). The irony is that, inadvertently, the increased thermal performance and airtightness of building envelopes in New Zealand can result in increased mould and moisture problems. If the building envelope is not designed and detailed correctly then interstitial condensation and mould growth will result in deterioration of the timber framing and a reduction in the overall performance and durability of the building envelope. Moisture is the most prominent damaging function acting upon timber framed building envelopes and in 2008 92\% of New Zealand houses were timber framed (Page, 2009).

The way in which building envelopes are designed and built in New Zealand often ignores important building envelope principles and there is strong evidence that the consequences of ignoring these principles negatively affects a person's physical and physiological well-being (Knaack \& Koenders, 2018).
Personal Experience. While working at a company that provides building envelope systems, part of my job was drawing construction details to allow architects to accurately detail the particular systems into their drawing sets. It was also sometimes necessary to integrate the specific building envelope system into an architect's completed detail set.

Whilst working with the technical team at this company I became aware of how crucial the detailing process is to ensure the performance of the building envelope. There were key issues that consistently occurred when redrawing details. Most details had a focus on weathertightness, however, many failed to achieve continuity in airtightness, vapour or thermal control.

Another issue was in respect to buildability. Whilst a critical flashing may have been detailed correctly, in a technical sense, there was sometimes no appreciation of how that flashing detail could practically be executed on site. This results in the builder changing the construction methodology, with the potential that, in doing so, the performance of the building envelope is compromised.

Change in Energy Flow. Before 1978 insulation was not required in NZ homes (Ministry for Culture and Heritage, 2016). Since then, insulation requirements have gradually increased, corresponding with a focus on making building envelopes more airtight. This increased focus on insulation (and airtightness) has changed the way in which building envelopes perform. Uninsulated and air 'leaky' homes were cold and inefficient to heat but they did not have condensation or mould problems. To understand the reason for this it is necessary to understand how increased 
levels of insulation effect the exchange of energy across the building envelope. Energy exchange is directly related to the flow of energy across the building envelope. It is this energy exchange that allows drying, as drying cannot happen without an exchange of energy. The greater the rate of energy exchange, the greater the rate of moisture movement (Lstiburek, 2008).

Current practice involves significantly increasing thermal insulation (and airtightness) in wall assemblies and this directly results in a reduction in drying potential (Lstiburek, 1999). Prior to 1978, because houses were uninsulated and air leaky, there was a massive energy flow across the building envelope. Because moisture in the air could freely move through the building envelope the wall assembly was constantly being dried out. In most cases this was sufficient to eliminate the risk of moisture being trapped and accumulating within the wall assembly.

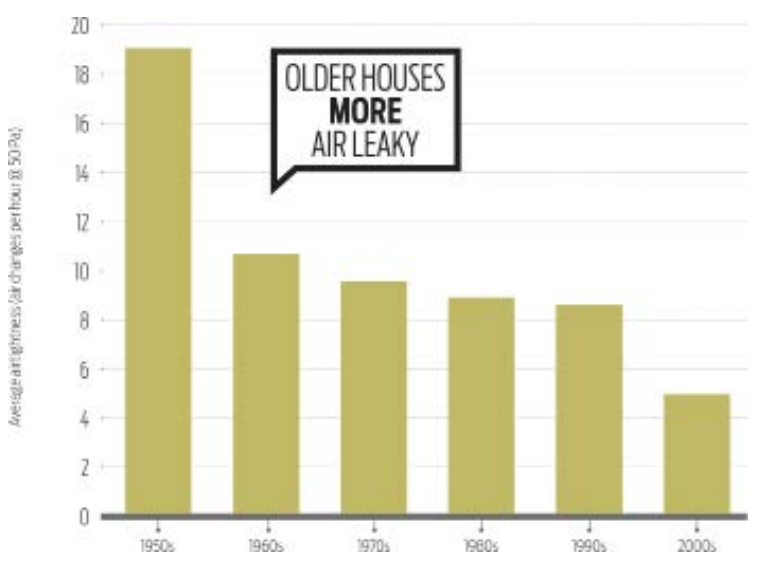

Figure 1.1. The increasing airtightness of New Zealand homes. Combating Internal Moisture (p.47), BRANZ Build, 2015.

Today those wall assemblies are insulated and also more tightly sealed to reduce the rate of air exchange. This results in significantly reduced drying potential. Therefore, when the wall assembly gets wet or damp it is less likely to be able to dry out (Lstiburek, 2008).

So, in an attempt to make houses more efficient to heat we may have increased the potential for moisture related building envelope problems. How then do we insulate (to stay warm), build airtight (to effectively control the interior environment) and eliminate moisture problems (interstitial condensation, mould, corrosion, and structural decay) within the building envelope? It is clear that we cannot continue to build as we are currently, ignoring fundamental building science principles, and hope the problem will go away. The solution is in the correct detailing of the control layers within the building envelope along with appropriate management of the internal environment (humidity, temperature control and ventilation).

Condensation Crisis. Most people in New Zealand will, in some way, be able to relate to houses being damp and cold. This may be from personally living in a damp and/or cold house or from the countless research papers and news articles that draw attention to the severity of New Zealand's housing problem (Science Media Centre, 2008) (Powers, 2019). Since the early 2000s there has been a focus on improving weathertightness in response to the much-publicised leaky building crisis. However, improved weathertightness does not mitigate condensation and mould risk. If this issue is not addressed it has the potential to result in systemic building performance failures with wider implications than the leaky building crisis. 


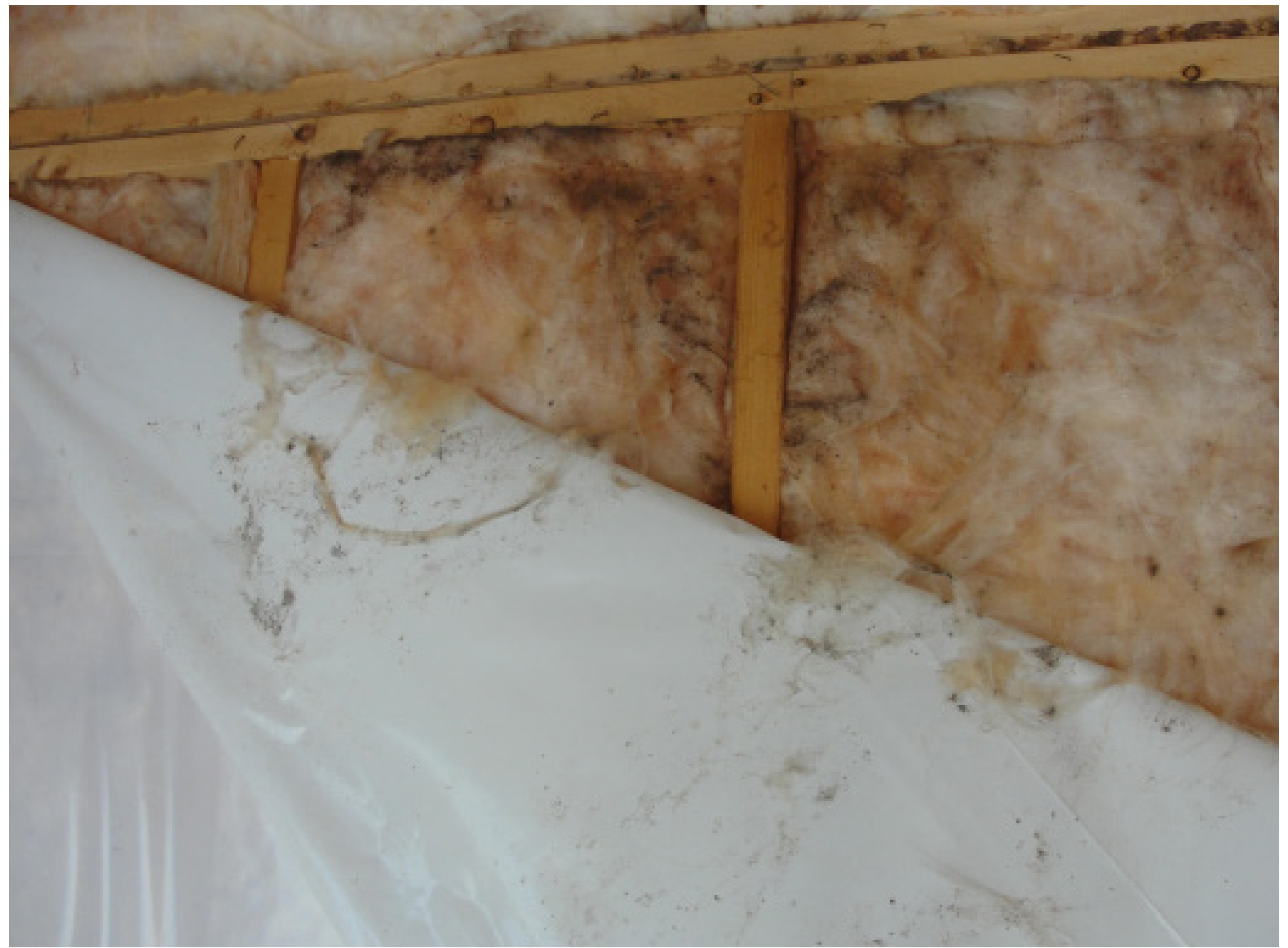

Figure 1.2. Mould in a timber framed building envelope on the building wrap and cavity insulation. Saltzman, 2012.

Whilst the pictures shown may seem to be examples of extreme failures, they are common in New Zealand. Part of the problem is that condensation and mould, which occur within the structural cavity, are hidden until both the health of the internal environment and the structural integrity of the timber framing in compromised.

Health impacts. The implications of poor design of the building envelope have had a significant societal impact, particularly in relation to public health. It is critical that building envelopes are able to provide a living environment that is dry, free of mould and allows us to maintain internal temperatures at levels recommend by the World Health Organisation (WHO) to ensure the health of occupants. WHO recommends a minimum average internal temperature of $18^{\circ} \mathrm{C}$ whilst the average winter temperature in NZ homes is just $16^{\circ} \mathrm{C}$. As the indoor house temperature falls houses become cold and damp, increasing the risk of respiratory illness. Relative humidity will be higher at lower indoor temperatures and mould growth can occur when relative humidity reaches anywhere above 80\% (BRANZ Research Now, 2019). Mould spores are harmful to health and can lead to respiratory illness and allergies, especially when mould growth is long lasting and deep-seated (Knaack \& Koenders, 2018). 


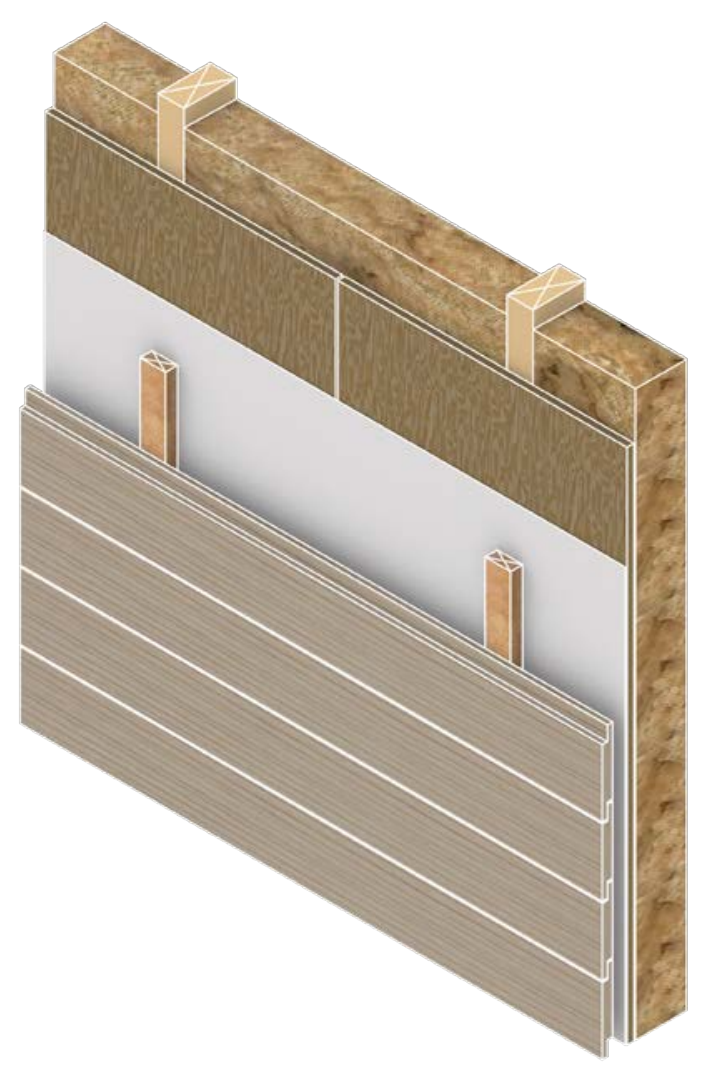

Figure 1.3. Typical New Zealand wall build-up.

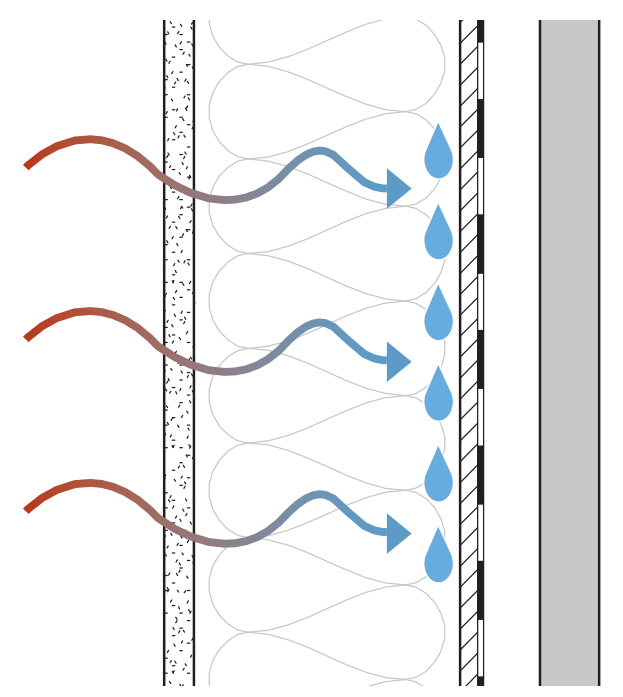

Figure 1.4. Interstitial condensation diagram in typical New Zealand wall.
BRANZ research has also established that New Zealand homes have moisture content and levels of air contamination that exceed recommended levels and therefore compromise the safely and comfort of the occupants (BRANZ Research Now, 2019). According to BRANZ Study SR372 visible mould was evident in $50 \%$ of all houses investigated. In this study non-visible mould (for example, within wall cavities) was not assessed meaning the percentage of properties would, in reality, be much higher (Jones \& White 2017) (Powers, 2019).

The facts are concerning. New Zealand has over 610,000 people who suffer from asthma resulting in 86,457 hospital admissions per year, with those living in poor quality housing disproportionately represented. Hospitalisation rates are 3.5 times more likely for Maori and 2.7 times more likely for Pacifica than that of non-Maori and non-Pacifica (Asthma and Respiratory Foundation NZ, 2018). As can be seen by these statistics, a connection seems clear between the poor quality of New Zealand housing and its disproportionate effect on Maori. Improving the quality of New Zealand building envelopes has the potential to dramatically increase the health and well-being of Maori.

A strong link can be made between poor quality housing and the high rates of asthma and respiratory disease in New Zealand. If people are living in poor quality housing and there are negative health implications, then that is proof that housing needs to be improved through better building envelope design. 


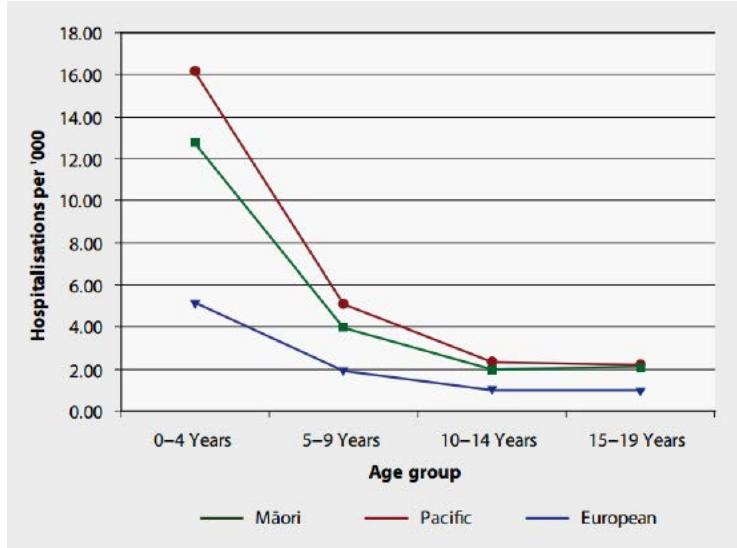

Figure 1.5. Hospitalisations for asthma for year ending May 2007. Best Practice Journal, Special Edition Childhood Asthma (p.2.), Bpac NZ, 2009.

To add to New Zealand's poor housing statistics, it is estimated that $25 \%$ of New Zealand homes are in fuel poverty. The Energy Policy journal attributes this to New Zealand's poor history of housing regulation which has resulted in, among other things, poorly insulated homes (Howden-Chapmen "et al"). Cold houses resulting from fuel poverty is considered to be a cause of New Zealand's high rate of winter mortality (Howden-Chapmen "et al"). Today there is a focus on increased levels of insulation in New Zealand houses, both new and retrofit. Whilst increasing insulation is a positive initiative it is critical that the implications of increased thermal performance is understood within the context of good building envelope design. If this is not considered, then unintended consequences may manifest themselves in the form of hygrothermal imbalance and resulting condensation risk within wall assemblies.

To understand the significance of the problem this issue must be seen, not just as a housing problem, but as a public health crisis. Leilani Farha, former United Nations special rapporteur on adequate housing, says, "If people in New Zealand continue to call it a housing crisis it obfuscates what is going on here... the conditions are really stark," citing damp, mouldy homes that cause chronic illnesses and poverty, and rampant housing discrimination against Maori, Pasifika and those with disabilities (Roy, 2020:online). The poor quality of New Zealand housing has even made international headlines, being referred to as a "human rights crisis" (Roy, 2020).

Indoor air quality. Good indoor air quality is achieved primarily through two mechanisms, summed up in the statement 'build tight and ventilate right.' It is implicit in this statement that, until the building envelope is designed and constructed correctly (build tight), it is not possible to manage indoor air quality (ventilate right). Airtightness and ventilation with fresh outside air is the most effective way to reduce harmful contaminants in the air (BBRANZ Research Now, 2019).

Buildability and readability. Architects will often satisfy themselves with specifying individual components "to manufacturer's specifications" without having a thorough understanding of what they are drawing or specifying (Slater and Radford, 2012). What is actually required is a working knowledge of the basic building science principles that are critical to designing and constructing a functional building envelope. This requires an understanding of the role and placement of the required control layers, the physical properties of those control layers and how they function collectively within the wall assembly. The focus must be on designing the envelope 'system' and not on simply specifying individual products or components which may not have the required properties to function as a system. 
Societal relevance. Better building envelopes have a major impact on the lives of those who live within them. The initial motivation behind this project came from recognising the significance of building envelope design and its direct impact on human well-being.

Tikanga Maori. As mentioned above, New Zealand's poor-quality housing is resulting in high rates of asthma and respiratory disease. Statistics from the NZ Asthma and Respiratory Foundation demonstrates that poor-quality housing disproportionately affect Maori. Better building envelope design has the potential to directly increase the health and overall well-being of Maori.

Practical Relevance. The practical application of the building envelope science reviewed in this project is a key driver of the design outcome. The building envelope science is applied to the design and detail drawings of timber framed building envelopes. Improving the quality of housing is one of the most effective ways to improve the quality of people's lives.

Statement on Sustainability. For this project the most important aspect of sustainability is the durability of the building envelope. Durability is fundamental to designing homes that last. Building envelopes that last and perform in excess of 50 years will be much more sustainable than poorly designed envelopes that fail prematurely. Furthermore, a well-designed building envelope results in a home that is more efficient to heat and ventilate, which will reduce energy use. 


\section{4 methadalogy}

Literature Review. International building envelope science research, in relation to rain and hygrothermal control within building envelopes, is the focus of the literature review. A summary of this literature will provide a basis for addressing common problems in the way we currently design and build residential building envelopes. The literature addresses building envelope performance in respect to rain control, air control, vapour control, and heat control. These four elements form the crucial control layers which are considered together as part of a systems-based approach for building envelope performance. The literature review discusses the first of the key themes in 'Envelopes Have Layers': Building Envelope Performance. The literature review then introduces the remaining key theme which is readability of drawings. Readability, including clarity and buildability of drawings, is also further developed and explored in later chapters.

Representation of control layers. Findings from the literature review are used to analyse the building envelope visually through the medium of architectural drawings. The visual analysis of building envelope performance subsequently develops the themes of buildability and readability. The most important part of this chapter is the colour coding system used to identify and communicate building envelope control layers, a motif which is continued throughout. A series of diagrams are presented in response to building envelope science principles discussed in the literature review. The diagrams aim to visually articulate how the scientific principles engage with different building envelope assemblies.

Drawing Critique. The drawing critique is a review of envelope facade section drawings and details. The drawings are sourced from the public domain (unless stated otherwise); project specific information has been removed to keep drawings anonymous.

The majority of the drawings aim to generally represent typical facade sections of existing New Zealand timber framed building envelopes. Single unit and medium density housing types are used. The selection of facade sections that are analysed aim to cover the broadest range of house types/constructions in residential timber framed construction in New Zealand.

Drawings are critiqued in relation to performance, buildability and readability. Control layer identification is carried out in the existing envelope facade sections and also various wall assemblies. The drawing critique highlights problems within typical New Zealand timber framed construction including condensation risk and incorrect location of control layers. These problems are considered in the literature review and analysed by way of the hygrothermal comparison. The problems will be resolved in the proposed building envelope design and its detail documentation.

\section{Hygrothermal performance comparison and} envelope design. Based on literature review, and in close reference to Lstiburek's 'perfect wall' concept (explained in the literature review), a timber framed building envelope assembly is proposed. In order to assess the hygrothermal performance, the proposed wall and roof assemblies are compared with typical wall and roof assemblies using two types of hygrothermal simulation software - steady state and dynamic. 
The hygrothermal comparison is used to explain the differences between the proposed and typical envelope assemblies and how their control layers and their location affect the overall performance of the envelope. The hygrothermal comparison clearly communicates the importance of building envelope physics in the performance of the building envelope assembly.

The proposed building envelope design that is simulated in the hygrothermal comparison is developed from the findings in the literature review and drawing critique. From this point the wall and roof assemblies are visually represented three-dimensionally and the build-up is explained. This becomes the starting point for the terrace house design. The proposed wall and roof assemblies (with a concrete slab) combine to deliver the complete building envelope system drawn and detailed in the terrace house drawing set.

Terrace house design. In order to explore and develop functional, buildable, and readable building envelope drawings and details, a series of timber framed terrace houses are designed (corresponding to the housing projects reviewed in the drawing critique). Timber framed terrace housing is becoming more popular in New Zealand cities due to housing demand. This provides the opportunity for architectural exploration and spatial arrangement and requires resolution of complex details in respect to exterior walls, party walls and roof design, particularly when continuity of control layers is considered critical. Plan, section, elevation, perspective, and structural diagrams of the terrace houses will be presented along with the design decisions that inform the final terrace house design.
Detailed design drawings. Finally, a drawing set for one of the terrace houses is presented. The drawing set includes three different scales which each have a different role in the theme of readability. The control layer identification key, developed and used in the previous chapter, is used to communicate the building envelope performance on the drawings. The drawing set aims to optimise readability in relation to the building envelope by focusing on control layer continuity on a detail level. The drawings are intended not only as detail documentation of the terrace house but as a template for New Zealand building envelope construction practice.

Implications and optimisation. Finally, a facade section from the drawing critique will be juxtaposed with a facade section from the terrace house design as a way to visually communicate performance and readability differences within the drawings. Implications of the project and further optimisation of the research is discussed. 


\section{objectives}

Based on the methodology, the project objectives are:

- Use building science research in relation to rain and hygrothermal control to draw out the scientific principles required to design functional timber framed building envelopes. These principles will provide a different approach to building envelope design than that currently used in New Zealand and, by doing so, will provide a design that has the potential to significantly reduce moisture related problems within the building envelope.

- Create a method to visually represent performance and buildability of building envelopes on architectural drawings.

- Perform a hygrothermal comparison to demonstrate the performance differences between typical New Zealand walls and the proposed wall design.

- Design and develop a residential timber framed building envelope system that effectively manages rain and hygrothermal load and protects the timber framing. Develop drawings and details of the envelope system which are readable and buildable to enable the building envelope performance design to become a built reality.

- Design a set a of terrace houses. This terrace house design will be the mechanism by which drawings and details reflecting the thesis research can be demonstrated.
- Create final sets of details that can be utilised when designing timber framed residential building envelopes. The buildability and readability of the details will ensure the building envelope can be constructed and performs at a high level providing a durable, sustainable, healthy home.

This thesis provides an alternative way to design residential building envelope details. It proposes a method of designing details which provides an understanding of why and how the details are drawn and provides a clear system of detailing that will provide the best built outcome.

Hypothesis. Readable building envelope drawings that are designed with the correct envelope control layers in regard to building envelope science fundamentals will provide functional and durable building envelope assemblies for timber framed homes in New Zealand. 


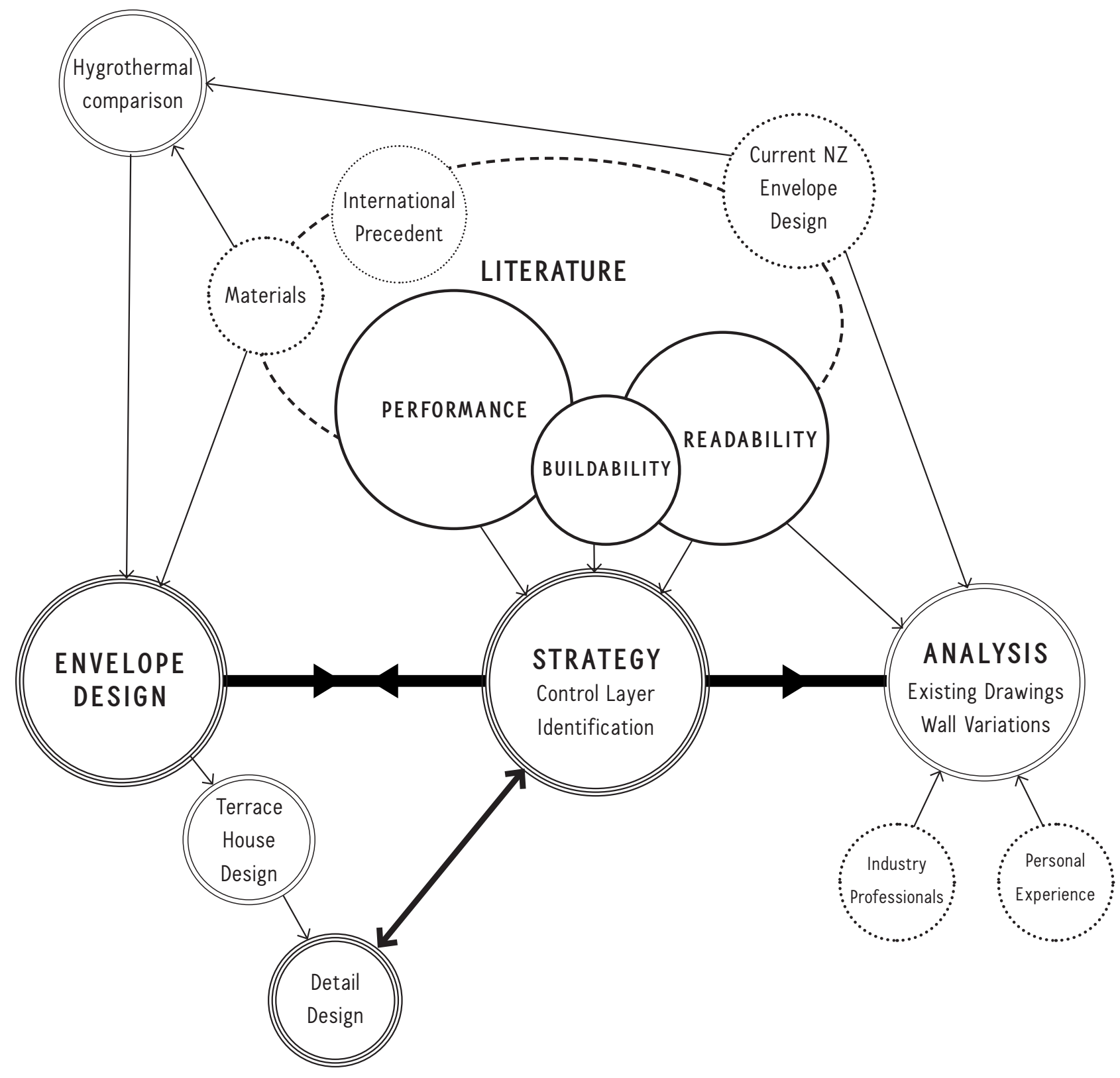

Themes

Figure 1.6. Topical research diagram. 


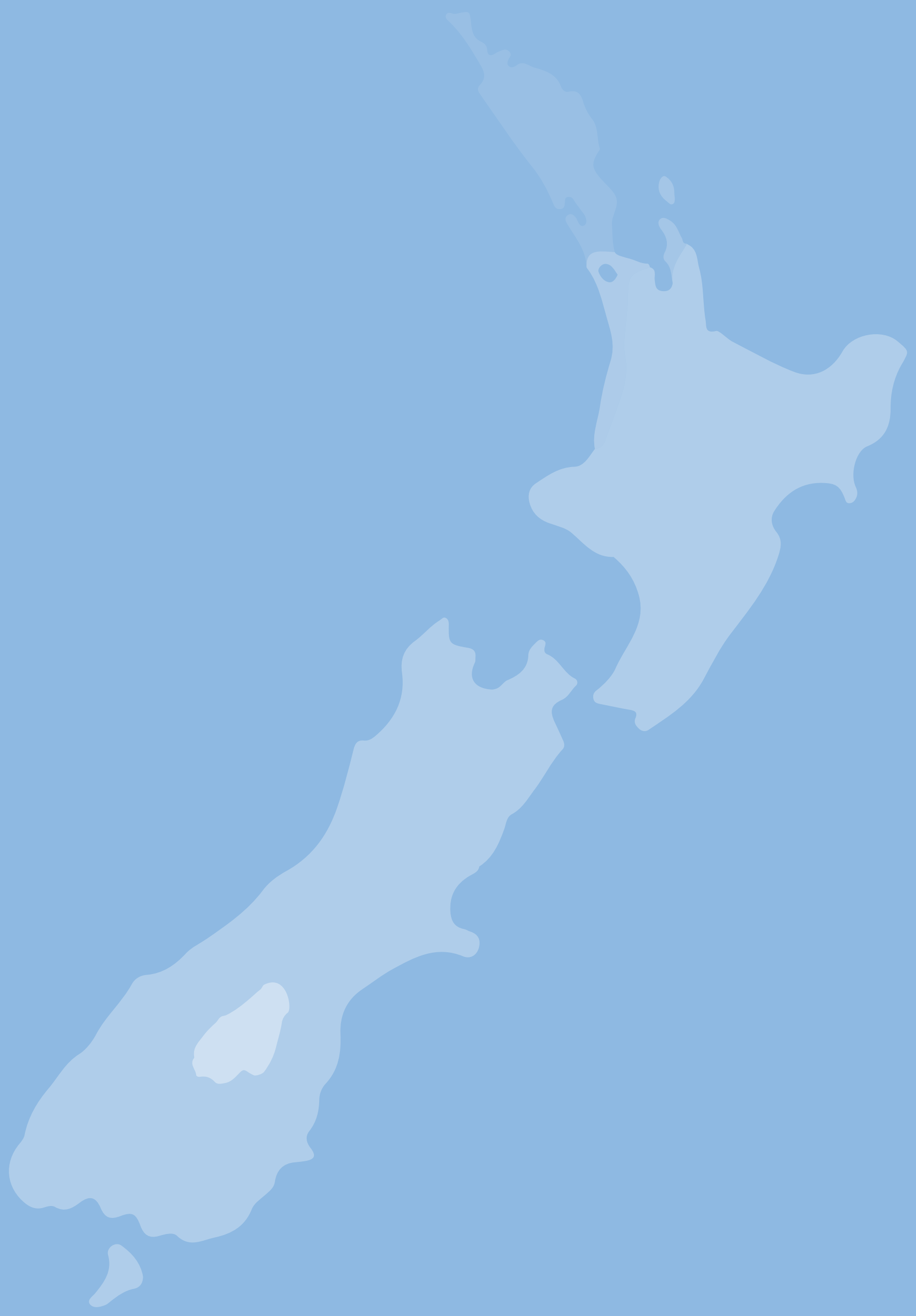




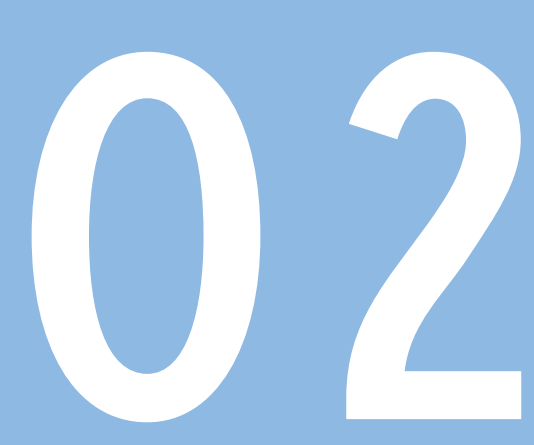

litgraturg revigw 


\section{I literature review introduction}

This literature review examines international research within the field of building envelope science. Burnett and Straube claim building envelope science is a relatively new discipline. (Burnett \& Straube, 2005). "Is it the technical side of architecture?" or "the architectural side of engineering?" are questions often asked in relation to building envelope science.

As a discipline building envelope science is becoming more evident as the analysis of building envelopes in relation to corrosion, condensation, mould and hygrothermal load become more common.

Problems, both existing and historical, with New Zealand building envelopes point to a lack of understanding of well-established building envelope science principles. New Zealand lacks not only its own relevant building envelope science research but also the capability to engage with developments in international building envelope science. Four key literature sources are primarily used in the literature review to consider building envelope control layers and the role of each layer, hygrothermal performance, and practical application of building envelope science principles.

The first of these is Building Science Corporation (founded by Dr Joe Lstiburek) which publishes a vast range of research papers on building envelope science. Lstiburek has become known for his 'perfect wall' concept (Lstiburek, 2010) and in 2001 the Wall Street Journal named him as the "Dean of North American building science". The second is Building Science for Building Enclosures (Straube and Burnett, 2005). Dr Straube and Dr Burnett are both building science consultants and professors at the University of Waterloo, Canada. The third is the Building Enclosure Design Guide (BC Housing, 2020) published by the $B C$ Housing Research Centre. The design guide on wood frame multi-unit residential buildings focuses on how building science research is applied to built assemblies and their details drawings. The final key source is Building Physics of the Envelope: Principles of Construction (Knaack \& Koenders, 2018) which is an overview of building physics parameters and their effect on the building envelope.

The sources come from countries that are most advanced in the building envelope science discipline; United States, Canada, and Germany, covering three different construction and climate contexts. It was important to have literature that was applicable to the New Zealand context, such as the Building Enclosure Design Guide, which concentrates on timber frame construction. The publications all carry a common thread of practical application of the building envelope science they discuss. Central to this project is how building envelope science is translated on architectural drawings and becomes a built reality.

The literature review addresses building science principles by addressing the role of the 'control layers' which exist in the building envelope. The role of each control layer is explained, providing the basis for a building envelope design that is durable, eliminates moisture related problems, and references the current New Zealand building industry.

The review also considers the readability of architectural drawings and details. As Allen states, details which focus on building envelope performance and are buildable and readable are key to creating sustainable buildings (Allen, 2016). 


\section{2 the building envelope}

The building envelope allows us to feel comfortable in a building even under uncomfortable weather conditions. (Knaack \& Koenders, 2018). The overall envelope system is required to balance out the different air and vapour pressure levels on either side of the building envelope. (Knaack \& Koenders, 2018).

Any part of the building that separates the indoor environment from the exterior environment is part of the building envelope (Burnett \& Straube, 2005). It is where the flow of energy is interrupted or deflected. (Knaack \& Koenders, 2018).

The literature review focuses on the building envelope science, particularly in relation to moisture movement through the envelope, including rain control and hygrothermal load as most building envelope problems are a direct result of moisture accumulation. (Lstiburek, 2002).

The typical residential building envelope system in New Zealand consists of the roof, wall, and base floor system as well as the windows and doors. The building envelope controls environmental factors including rain, sound, and light. Designing a building envelope that eliminates moisture related problems inevitably addresses other aspects such a UV protection, acoustic performance, and improves energy efficiency.

The poor quality and lack of durability of New Zealand houses has been well documented. The issues range from poor detailing, poor craftsmanship and material defects. This literature review looks specifically at the performance of the building envelope and the building science principles which should be considered when designing an envelope system. As the architect's role is to design a functioning envelope system it is crucial that they understand how a building envelope functions.

Part of the design process for architects is specifying products that will ensure performance of the envelope system they have designed. Architects need to focus on specifying a building envelope system rather than individual components. As Brand concludes, reliance on specifying products based on their individual performance properties but failing to understand how they work in a system becomes problematic as incorrect assumptions are made as to how materials will perform as a system. (Brand, 1990).

Interstitial condensation. Interstitial condensation causes mould growth, often unseen, that causes deterioration to the structure. When relative humidity reaches $80 \%$, even without the presence of liquid water, mould growth can still be stimulated. (Knaack \& Koenders, 2018). Interstitial condensation is a problem affecting New Zealand building envelopes. This research provides solutions that mitigate this risk. 


\section{3 the 'control layers'}

The 'perfect wall' was popularised by Lstiburek as a template for effectively communicating the role of control layers and their location within a building envelope system (Lstiburek, 2010). The 'perfect wall' is introduced as a concept to understand how building science is applied to envelope assembly design.

The Perfect Wall (Lstiburek, 2010) outlines the four crucial building envelope layers needed in a wall assembly. The crucial layers of the building envelope system are known as the control layers (BC Housing 2020). In order for the wall to separate the outdoor and indoor environments it needs to control rain, air, vapour, and heat. Therefore, a rain, air, vapour, and thermal control layer are required (Lstiburek, 2010). The design of these building envelope layers dictates how the envelope system responds to the environmental factors acting upon it.

Lstiburek explains that the best place to locate control layers is on the outside of structure. It is especially important that timber structure is protected from changing temperatures and moisture as these factors can affect its material properties and compromise its structural integrity (Lstiburek, 2010). Having all control layers on the outside of the structure ensures the structure is protected from temperature extremes, moisture accumulation and UV (Lstiburek, 2010).

Lstiburek then goes on to state that, in a "beautiful bit of elegance and symmetry", by simply changing the position of the 'perfect wall' you get the 'perfect slab' and 'perfect roof' (Lstiburek, 2010, p.2). Hence, the 'perfect wall' concept can be applied to the entire building envelope system.
It should be noted that, whilst Lstiburek was not the first to propose the concept of the perfect wall, his clarity in communicating the concept has been valuable, both academically and for practitioners. As the perfect wall is a concept, the built reality of the wall can exist in many different variations.

A control layer consists of materials and components that are continuous and together form a control function within the building envelope. (BC Housing, 2020).

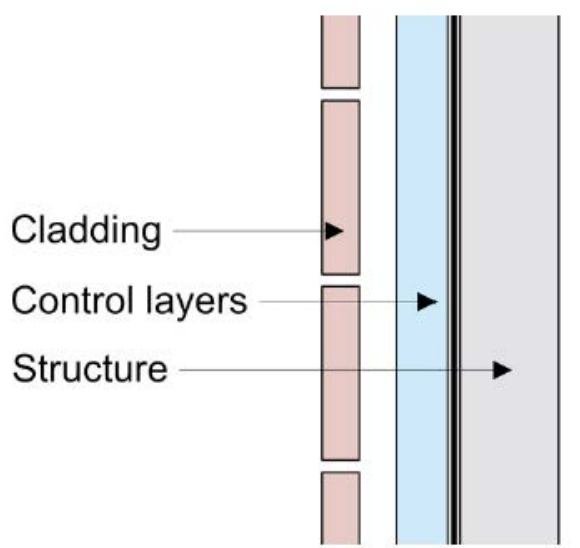

Figure 2.1. The 'perfect wall' concept. Insight: The Perfect Wall (p.1). Lstiburek, 2010.

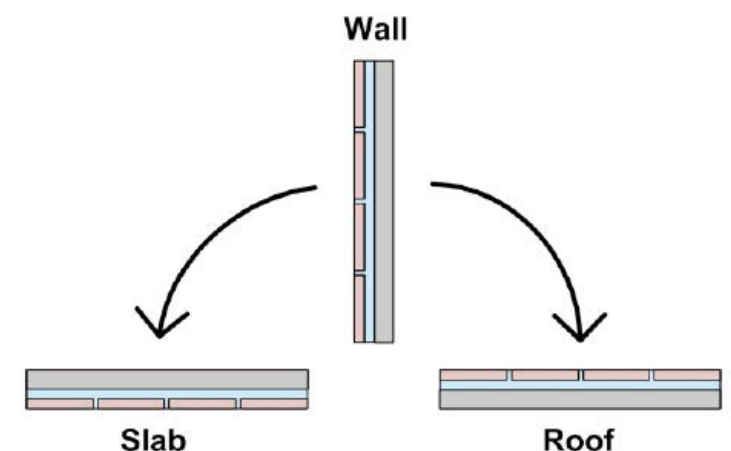

Figure 2.2. The 'perfect wall' conceptually applied to the roof and slab assemblies. Insight: The Perfect Wall (p.2). Lstiburek, 2010. 


\section{cladding (rain shed layer)}

Overview. If you were to ask builders, contractors and even architects where they would perceive the rain control layer to be on a building, the majority would consider it to be the cladding. However, it cannot be assumed that the cladding keeps all water out of a building envelope (Lstiburek, 2019). Performance issues can result if it is assumed that the materials behind the cladding are completely protected from rainwater entry by the cladding. If this is assumed it may mean a rigid air barrier or wall underlay that is not being sufficiently water resistant, or not effectively flashed/detailed, is installed.

Building Science for Building Enclosures claims that cladding should be considered a rain shed layer along with contributing to management of other environmental factors acting on the building envelope including wind, sun, and impact (Burnett \& Straube, 2005).

Emphasising this point further, Lstiburek explains that a cladding should be understood as contributing to the rain shed layer. He asserts, "The claddings function is principally to act as an ultraviolet screen. Oh, and architects might consider the aesthetics of the cladding to be important" (Lstiburek, 2010, p. 1). Water can enter through the cladding, through gaps or joints in the cladding, around penetrations in the cladding, like windows, doors, and anything else that penetrates the cladding. If rain beyond the cladding is to be anticipated then a mechanism needs to be designed to remove it (see rain control layer) (Lstiburek, 2019).

It should also be understood that different cladding types respond to moisture differently so different design approaches are needed. When cladding types that absorb water are used (for example, brick and uncoated timber) the absorbed moisture will be released inwards (towards the interior) when exposed to sun. (Lstiburek, 1999). In these cases, it is crucial that the air space beyond the cladding is sufficient. Burnett and Straube claim an air space of at least $19 \mathrm{~mm}$ is required for adequate ventilation of absorptive claddings (Burnett and Straube, 2005). In these cases, the air space needs to be ventilated with top and bottom openings in order to remove moisture that passes through the cladding (Burnett and Straube, 2005).

Claddings that don't absorb water (e,g., profiled metal cladding) require an air space sufficient to eliminate capillary action (lateral transfer of water). With such claddings an air space of $3 \mathrm{~mm}$ (capillary break) can be sufficient (Lstiburek, 1999).

Due to the above discussion, the rain shed layer is not considered as a "crucial control layer" Rain shed and rain control of the roof assembly is slightly different to walls and discussed in chapter 2.4 (roof control layers).

Rain shed layer definition: The outer most layer of the building envelope that sheds rain, including the cladding, windows, doors, and flashings.

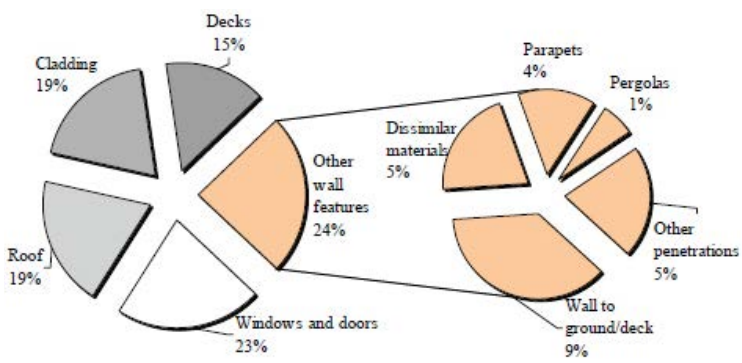

Figure 2.3. Water entry in New Zealand leaking buildings. Selected Papers from Building A Better New Zealand (BBNZ 2014) Conference (p.60), Baird., Bennett \& Easton, 2016. 


\section{rain control layer}

Overview. Controlling rainwater entry is the single most important factor in creating durable buildings (Lstiburek, 2019). Therefore, it is critical that rain is affectively managed. According to BC Housing the rain control layer is the surface farthest into the assembly from the exterior that can accommodate exterior moisture entry in the form of liquid water (BC Housing, 2020).

Role. There are two aspects to rain control. Firstly, reduction of water entry through the cladding (discussed in cladding) and secondly, control of rainwater that enters through the cladding. (Lstiburek, 2019). Assuming some water will get past the cladding (as seen in figure 2.5), a rain control layer is designed within the envelope system to direct it to the exterior.

Lstiburek defines the rain control layer as a sheet membrane (self-adhered or mechanically attached), liquid membrane, or material layer that is water impermeable (Lstiburek, 2019) (Burnett \& Straube, 2005). The rain control layer is interconnected with flashings, windows, and doors to create continuity.

In a layered wall assembly rain control requires a continuous rain control layer and an air space (cavity) in between the cladding and rain control layer for drainage. The rain control layer forms the drainage plane in which water can flow out to the exterior. (Burnett \& Straube, 2005). The air space promotes drainage, ventilation, and moisture redistribution. (Lstiburek, 2019).

Drainage. Drainage is the most effective way of moving rainwater penetration. In a layered wall assembly there are multiple lines of defence against water entry (figure 2.4). Burnett and Straube state water can drain on the back of the cladding, through the air space, and on the face of the rain control layer which provides a continuous drainage plane enabling water to flow out of the wall by gravity (Burnett \& Straube, 2005).

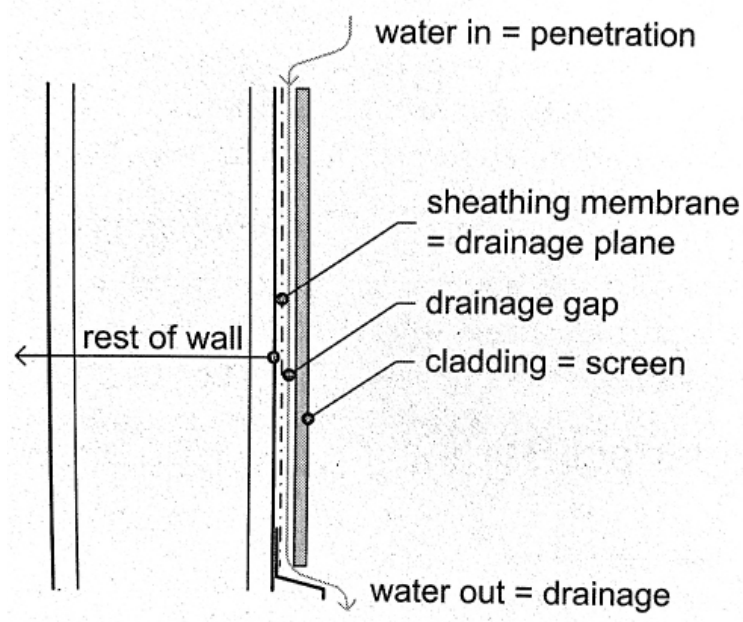

Figure 2.4. Multiple lines of defense against rain in a drained wall assembly. Building Science for Building Enclosures (p.471), Burnett \& Straube, 2005.

The role of the air space is to resist the lateral transfer of water. The air space must be a continuous space. It may be filled with a porous material as long as it fulfils the properties for drainage (Burnett \& Straube, 2005).

Ventilation. Ventilation provides a mechanism for the removal of water that does not drain from behind the cladding. (Burnett \& Straube, 2005). By increasing the flow of air into and through the air space, a relatively large amount of water vapour can be transported from the air space. Achieving sufficient ventilation is the reason to use $19 \mathrm{~mm}$ or larger air spaces behind the cladding. In order to promote ventilation, vent holes must be provided at the top and bottom of walls. (Burnett \& Straube, 2005). 
Rain control layer performance. Materials which form the rain control layer should overlap correctly and be sealed to create a continuous layer (Lstiburek, 2019). The materials should be layered in such a way that water is directed downward and out of the envelope (Lstiburek, 2001). Performance of the rain control layer and its ability to form a drainage plane lies in how it is detailed around windows, doors, penetrations and how it is connected to flashings to remain continuous.
Rain control at windows. The performance of the rain control layer at window openings relies on the use of flashings. Lstiburek argues that windows should have pan flashings. (Lstiburek, 2001). An under-pan flashing works like a gutter in that it redirects water that leaks through the windows back to the exterior. Window details are developed in chapter 4.3.

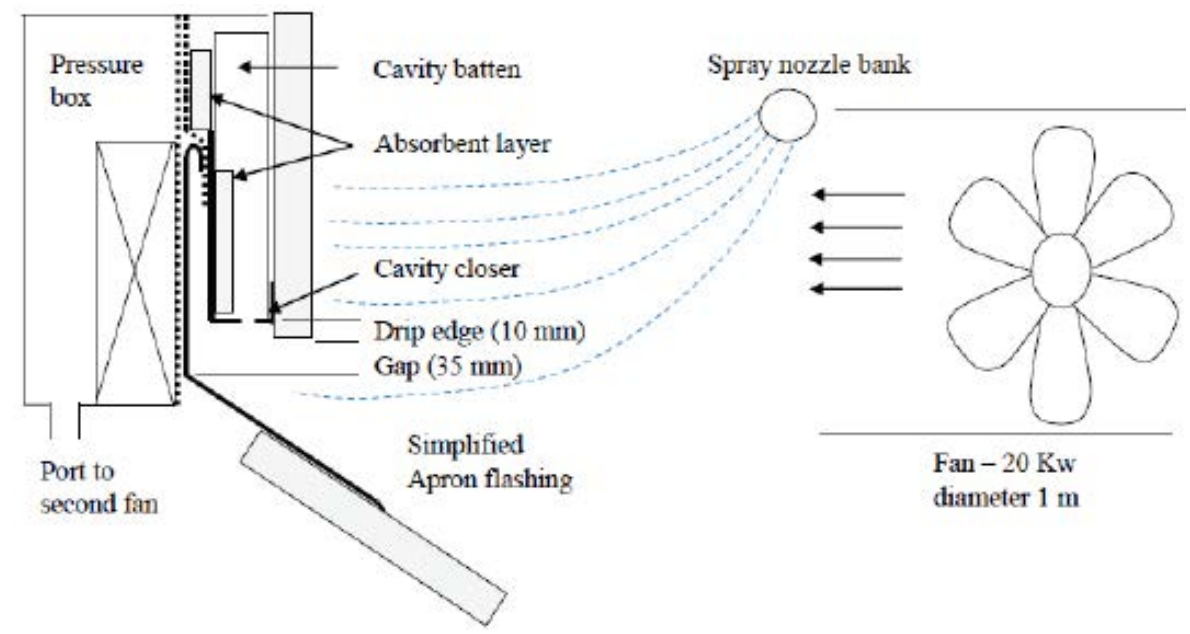

Figure 2.5. Experimental E2 Acceptable Solutions apron flashing between wall and roof revealing locations of water leakage past the cladding. Locations being between the flashing upstand and the cavity closer and up through the vent openings in the cavity closure. Selected Papers from Building A Better New Zealand (BBNZ 2014) Conference (p.73), Baird., Bennett \& Easton, 2016. 


\section{air control layer}

Overview. The air control layer encloses air and controls pressure differences between the internal and external environments. The air control layer creates the 'air barrier system'. Air barriers control air flow between the conditioned space (the interior) and unconditioned space (the exterior). There is general agreement between authors in the importance of an effective air control layer in a functioning building envelope system. Air control layers must be impermeable to air flow and be continuous over the whole building envelope (Lstiburek, 2006).

\section{Rigid and Flexible Air Control Layers. Air barriers} can be either flexible or rigid. The advantage of rigid air control layers is that they can effectively resist air pressure difference (Lstiburek, 2004) and are able to withstand higher wind forces. (Burnett \& Straube, 2005). Both flexible and rigid air barriers need to sealed at joints and seams (Lstiburek, 2006).

Moisture Transport. If movement of moisture into the envelope assembly is to be controlled then the air that transports that moisture must be controlled. Air carries a substantial amount of moisture so the air needs to be kept out of the wall assembly (Lstiburek, 2000). If air moves into an insulated structural cavity and cools till it reaches its dew point, liquid water (condensation) will form. The risks of moisture building up within a structural cavity can be significant. Air transport moves moisture in the air from an area of higher air pressure to an area of lower air pressure (Lstiburek, 2004). In winter, this means that warm air from inside the building is driven through the building envelope towards the exterior.

Indoor Air Quality. In order to efficiently control the quality of indoor air it must be contained. (Lstiburek,
2004). So, like the rain control layer, the best place to control air is outside the timber framing and on the internal side of the insulation so no change in air temperature occurs within the framing (and there is no risk of condensation).

Any amount of air that can leak out of a building envelope compromises the ability to manage indoor air quality. Once the air is contained, air filtration, air change, humidity and temperature can all be controlled. (Lstiburek, 2010). Warm air must be exhausted to the outside and fresh air from the outside must be fed into the building. However, the more air-tight the building, the more attention that needs to be given to targeted ventilation.

(Knaack \& Koenders, 2018). Even with no mechanical ventilation an air-tight building envelope is the most energy efficient. The room volume can be changed through a large ventilation opening (i.e., windows or doors) in just a few minutes. Even though the warm air escapes, indoor construction elements do not cool off, so the indoor air can be heated back to comfortable levels within a short period of time (Knaack \& Koenders, 2018). Mechanical ventilation within an air-tight envelope creates the most ideal indoor environment.

Air control layer performance. Installing the air control layer to the outside of the structure simplifies the installation and reduces the potential for the air control layer to be compromised. Compared to an air control layer installed internally detailing is more straightforward as detailing challenges related to intersecting walls, penetrations and services are overcome (Lstiburek, 2006). This is important when it is understood that large quantities of moisture 
can be transported through relatively small openings by air movement (Lstiburek, 2004). In reality, it is not possible to eliminate all breaches and install a 'perfectly continuous' air barrier. But effort should be made to ensure that joints between materials and penetrations are completely airtight (Knaack \& Koenders, 2018).

The disadvantage of installing air barriers on the outside of the timber framing, as is typical in New Zealand wall assemblies, is that this does not control the entry of air-transported moisture into the insulated structural cavity. This creates a condensation risk. This issue, along with how the perfect wall concept can be shown (with hygrothermal analysis) to eliminate condensation risk, is considered further in chapter 3.5 .

Combined air and vapour control. In all wall assemblies that incorporate a heat control layer, an air control layer is also required. Containing air is a good idea in any climate. In some conditions, in addition to air control, vapour control will also be required (see discussion on vapour control layer). When vapour control is required the air control layer can have properties that enable it to function as the required vapour control layer (Lstiburek, 2006). If this approach is taken then the vapour permeability of the air control layer is crucial.

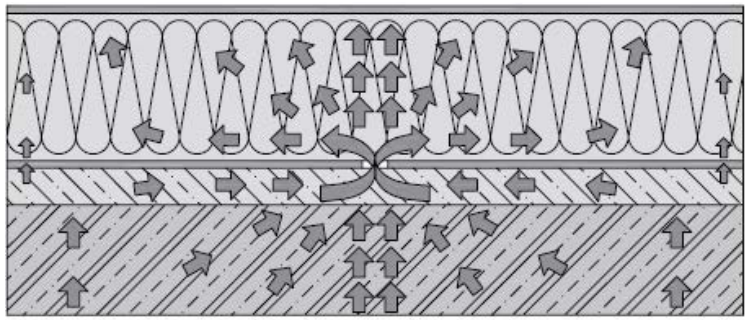

Figure 2.6. Water vapour transport in roof assembly, diffusion bridge is demonstrated where a vapour retarder is perforated. Building and Environment 44 (p.1618), Slanina \& Silarova, 2009.

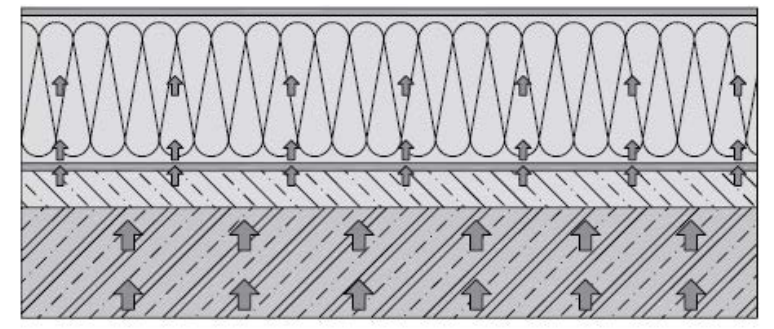

Figure 2.7. Water vapour transport in roof assembly through diffusion. Building and Environment 44 (p.1618), Slanina \& Silarova, 2009.

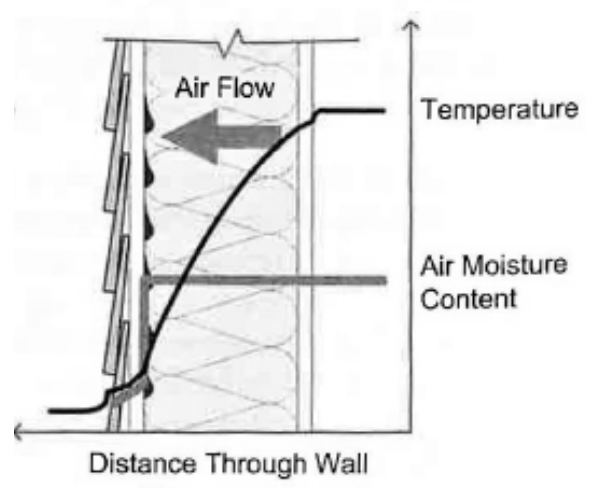

Figure 2.8. Water vapour transported by air flow can create interstitial condensation on cold surfaces within walls. Building Science for Building Enclosures (p.406), Burnett \& Straube, 2005. 


\section{heat control layer}

Overview. The thermal control layer is not only crucial for thermal comfort but also in mitigating moisture related problems within the building envelope. Insulation (with air control) keeps us warm and ensures our homes are efficient to heat. In the perfect wall concept the heat control also goes on the outside of the structure and over the other control layers. This means the heat control layer is continuous (no thermal bridging) and the condensing surface temperature is controlled.

Condensing surface temperature. The heat control layer controls the condensing surface temperature of the exterior sheathing eliminating condensation risk. In layered building envelope assemblies it is possible for condensate to be deposited on more than one layer as moisture evaporates from one surface and re-condenses on another (Knaack \& Koenders, 2018).

As air moves though insulating materials it cools down creating a temperature gradient throughout the insulation. The key is to keep the condensing surface sufficiently warm throughout the year and thereby avoid a change of phase, eliminating condensation risk. The required level of exterior insulation will depend on outdoor climate.

Condensation will occur whenever air contacts a surface with a temperature below its dew point (Burnett \& Straube, 2005). Water vapour can move to an interstitial surface by diffusion and air flow. The insulation causes the temperature of the air moving within it to drop (Knaack \& Koenders, 2018). The water vapour must contact the cold surface for condensation to occur (Burnett \& Straube, 2005).
The greater the insulation thickness and the lower the thermal conductivity, the greater the heat transmission resistance ( $\mathrm{R}$-value). As the thickness of the exterior insulation increases so does the condensing surface temperature (sheathing temperature) and therefore, the class of interior vapour control required becomes less restrictive (Lstiburek, 2004).

The cladding attachment system should be designed and installed in a way which has the least effect on reducing the performance of the insulation (BC Housing, 2020).
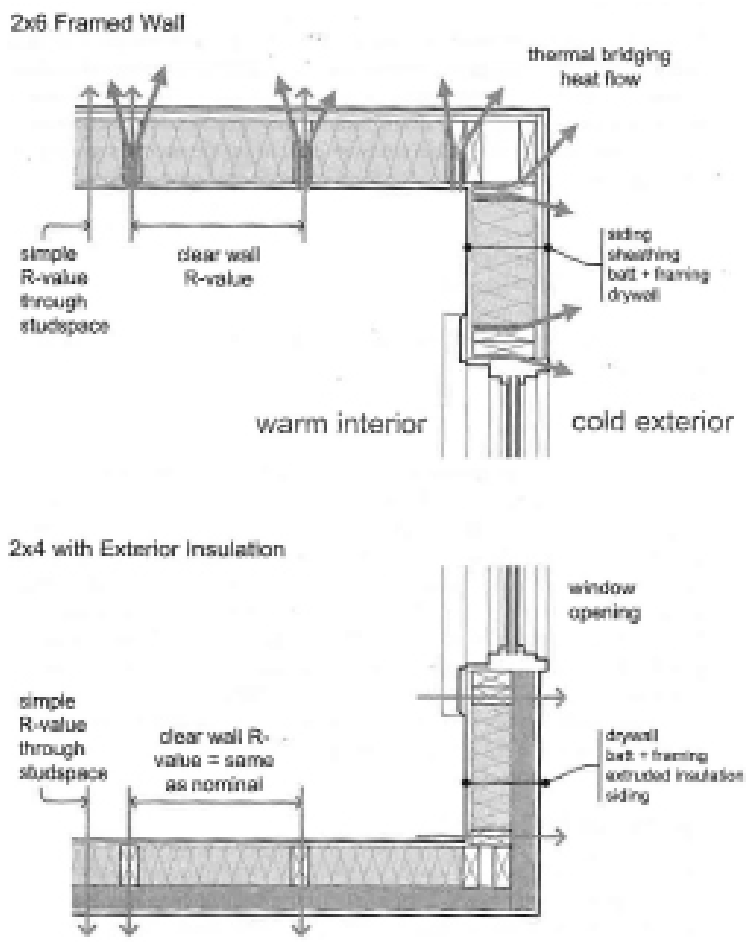

Figure 2.9. Thermal bridges and the effect of continuous exterior insulation on timber framed envelopes. Building Science for Building Enclosures (p.213), Burnett \& Straube, 2005 
vapour control layer

Overview. The function of a vapour control layer is to retard the entry of water vapour into the building envelope through vapour diffusion (Lstiburek, 2011). Vapour diffusion is the movement of water in the vapour state through a material as a result of vapour pressure difference. Vapour pressure is directly related to the concentration of moisture at a specific location (Lstiburek, 2004). Moisture flow by diffusion obeys the second law of thermodynamics - vapour moves from 'more to less' and 'warm to cold' (thermally driven diffusion) (Lstiburek, 2000).

The vapour control layer is only relevant once air is controlled. Vapour movement only occurs two ways - through air transport and through vapour diffusion. These two mechanisms work independently of each other. A vapour control layer (sometimes referred to as a vapour barrier or vapour retarder) controls the diffusion of water vapour. The location of the vapour control layer within the building envelope assembly and the required permeability of the vapour control layer will depend on the material properties of the components within the envelope system and on the climate the building is designed for (Lstiburek, 2011).

Role. There is often confusion between the role of the air control layer and role of the vapour control layer. When air moves (due to air pressure differences) the vapour in the air moves with it. So an effective air control layer will, even though it may not qualify as a vapour control layer, control the movement of vapour. In fact, the movement of water vapour through air transport is far more significant that the movement of water vapour through diffusion.

An air control layer will still allow vapour to move through it by diffusion. However, an air control layer with high vapour resistance can also function as a vapour control layer. A vapour control layer, when it is continuous and impermeable to airflow, will also function as an air control layer.

Vapour drive direction. Regardless of the climate, building enclosures need to control the movement of moisture as a result of air transport and vapour diffusion (Lstiburek, 2004).

The direction of vapour drive changes depending on the specific climate. Therefore, when designing building envelope assemblies, it is sometimes necessary to have different strategies depending on climate (Lstiburek, 2004).

Due to New Zealand's climate, in most parts of the country (and for most of the year), the direction of vapour drive will be from inside to outside as the relatively warm and humid interior air has a higher vapour pressure than the outside air (which is mostly colder and has less absolute humidity). It is important that the vapour control layer is not located where it could result in moisture being trapped within the wall assembly (the hygrothermal comparison in chapter 3.5 explains this further).

Within the perfect wall concept the control layers are on the outside of the timber framing at the same location so the wall is able to dry in both directions. As stated in Insight: The Perfect Wall the assembly will dry from the control layers inwards and from the control layers outwards (Lstiburek, 2010).

Vapour control layer classes. There is a lot of confusion around the language of vapour control. Names and terms are interchanged and used incorrectly. And to add to the confusion, vapour permeance 
can be measured in multiple ways. Vapour control layers are variously described as vapour barriers and vapour retarders without a clear understanding of exactly what is being described or what needs to be specified (Lstiburek, 2011).

Vapour control layers have different vapour resistances depending on the building envelope requirements. Classes of the vapour control layers are defined depending on the vapour permeability of the vapour control layer.

These vapour control layer classes, listed below, appear in the IBC (International Building Code), IRC (International Residential Code) and 2004 ASHRAE Journal Moisture Control for Buildings (Lstiburek, 2011).

The IBC and IRC include vapour control requirements which are widely adopted in the US and Canada. The NZBC does not define vapour retarders, barriers, or control layers with any precision and no requirements or recommendations for vapour control in residential buildings is defined.

A Class I vapour control layer is described as vapour impermeable and is a vapour barrier. Examples are extruded polystyrene with polypropylene facing, foil faced PIR, polyethylene and glass. A class II vapour control layer is described as being vapour semi-impermeable. Examples are coated structural sheathing, vinyl wall coverings and unfaced extruded polystyrene. A class III vapour control layer is described as vapour semi-permeable. Examples are plywood, OSB, bitumen impregnated paper, unfaced expanded polystyrene and most latex paints. Materials that have less vapour resistance than a class III vapour retarder are described as vapour permeable. Examples are unpainted/unfaced gypsum board, fiberglass insulation, and lightweight building papers.

Most building papers and wall underlays (if they are continuous) can act as effective air barriers but their properties mean they are vapour permeable and not an affective vapour control layer (Lstiburek, 2004). Furthermore, hygroscopic materials (such as plywood) change their permeability as relative humidity increases and these material properties must also be considered (Lstiburek, 2004).

The amount of water that can diffuse through a building component is a direct function of area. If $90 \%$ of the envelope surface is covered in a vapour control layer, then the vapour control layer is 90\% effective (Lstiburek, 2004). This is unlike the performance of an air control layer which must be free from holes. This explains how the air and vapour control layer can differ.

\begin{tabular}{l|l|l|l}
\multicolumn{1}{c|}{ Vapour control layer class } & \multicolumn{1}{|c|}{ I } & \multicolumn{1}{c}{ III } \\
\hline US Perms (permeance) & $0-0.1$ & $0.1-1.0$ & $1.0-10$ \\
\hline Vapour diffusion resistance factor $(\mu)$ & $>35,000$ & $35,000-3500$ & $3500-350$ \\
\hline MNs/g & $>175$ & $175-17.5$ & $17.5-1.75$ \\
\hline MNs/gm & $>175,000$ & $175,000-17,500$ & $17,500-1.750$ \\
\hline Sd $(m)$ & $>35$ & $35-3.5$ & $3.5-0.35$ \\
\hline Material example & polyethelene & vinyl wall covering & bitumen impregnated paper
\end{tabular}

Table 2.1. vapour permeability unit conversions of vapour control layer classes. 


\section{4 roof control layers}

Overview. Of any element of a building, the roof has the most consistent and extreme level of exposure to the environment and will be exposed to all environmental forces in a given location all the time. For this reason, roof assemblies must be designed with a focus on managing condensation and mould risk. In site surveys BRANZ has observed that mould has been found on structural timber and roofing underlay in a number of new houses (BRANZ Facts, 2018).

The ideal roof design will follow the same building science principles that have been discussed previously in this chapter. In the most basic sense, the control layers will be located continuously on the outside of the structure in order to protect it and ensure optimal system performance and durability. The metal roof cladding or membrane roofing will then be installed above these control layers.

However, there are some key differences between wall and roof construction which will determine exactly where each control layer will be located within the roof system and also determine how these control layers will be detailed to ensure that on site installation is practical. Consideration must also be given to the transition between the wall and roof, both in terms of understanding the criticality of continuity at this junction and also to ensure that a focus on buildability is maintained.

As is the case with the wall assembly, air flow is the primary moisture transport mechanism. In roof assemblies it is crucial air is controlled if moisture related problems are to be avoided. Vapour diffusion should be considered a secondary moisture transport mechanism when designing roofs (as is the case with walls). However, the vapour pressure relative to a roof assembly will be much higher than that of a wall assembly (Lstiburek, 2004). For this reason, in roof construction, the vapour control layer plays a more crucial role than in wall construction.

Roofs can be designed and constructed to either be vented or unvented (Lstiburek, 2004). As condensation and mould within roof systems in New Zealand has become more evident in recent years, the most common industry response has been to introduce ventilation. The premise is that, whilst condensation cannot be eliminated, sufficient ventilation in a roof system will ensure that condensation is removed from the roof (BRANZ Facts, 2018).

$B C$ Housing makes the point that designing a vented roof system does present some risk (BC Housing, 2020). One risk is being able to assess how much ventilation is required to remove the condensation that forms. Establishing the appropriate amount of ventilation in a roof system, with the complex range of variables that need to be factored, is extremely difficult. Another risk is in respect to buildability.

Depending on the actual design, a vented roof system will often require control layers (e.g., airtightness, insulation) to be detailed around the structural elements. This means maintaining control layer continuity is difficult. Failure of the control layers will increase the vapour load within the roof assembly meaning the allowance made for ventilation in the design may be insufficient.

The geometry of many roofs may also restrict air movement in the ventilation space to the point that effective ventilation is not possible (BC Housing, 2020). BC housing concludes, where possible, the 
best solution may be to avoid the use of vented roof assemblies altogether and instead use roofs with exterior insulation and continuous control layers (BC Housing, 2020).

When designing an unvented roof there are two key elements to address - control of the condensing surface temperature and vapour entry into the roof system.

A continuously externally insulated roof assembly enables the roof substrate (the condensing surface) to be kept sufficiently warm throughout the year to mitigate the risk of condensation in the roof assembly (Lstiburek, 2004). This is done by locating a continuous heat control layer (insulation) above the structure of the roof (on top of the roof substrate) (Lstiburek, 2004). This results in the control of a condensing surface where warm air from inside does not come into contact with a cold surface where condensation can occur (Lstiburek, 2001). The thermal resistance of the roof insulation (thickness) necessary to control condensation depends on the climate (Lstiburek, 2004). For example, a roof in Queenstown would require more thermal resistance to control the condensing surface throughout the year than a roof in Auckland as demonstrated in figure 2.13.

Continuity of air and vapour control layers on the outside of the structure, but underneath the heat control layer, is crucial to ensure vapour cannot move into the roof system (the same concept described in the perfect wall) (Lstiburek, 2001). Condensation will not occur unless the dew point temperature of the interior air is reached.
In the system described above the risk of condensation is eliminated by the control layers. In contrast, a ventilated roof system is designed with the intention of removing (by ventilation) condensation that may occur. In chapter 3.5 a hygrothermal comparison is used to compare the performance of a typical New Zealand roof assembly.

A membrane roof assumes that the waterproof membrane is completely watertight. Vapour movement into the roof assembly is controlled by the vapour control layer that is installed on the interior side of the insulation.

In respect to buildability, detailing of the drains, scuppers and penetrations is a significant factor in overall performance and durability (BC Housing, 2020). Detailed design of the proposed roof assembly is developed in 4.3 .

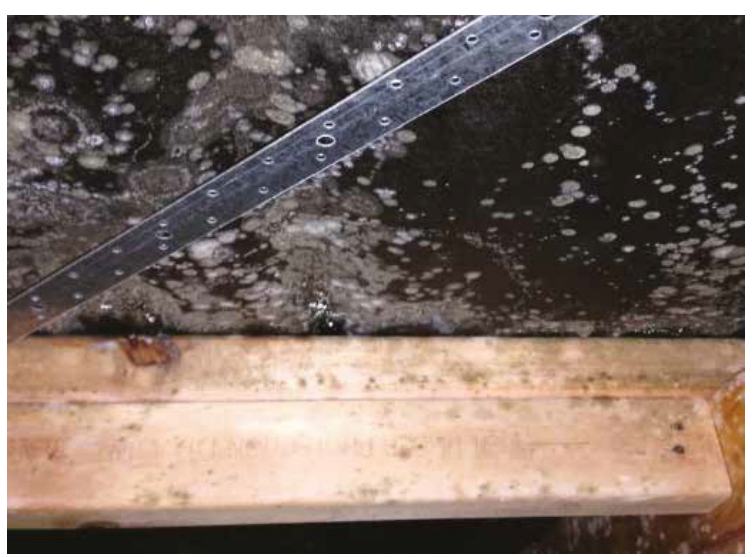

Figure 2.10. Mould growing on roof framing timber and roofing underlay in a vented roof in an Auckland house. BRANZ Facts Roof Ventilation \#1: Roof Space Ventilation in New Zealand houses (p.1), BRANZ, 2018. 


\section{5 climate considerations}

It is important to consider the hygrothermal region, the rainfall rate and the internal environmental conditions when considering how a building envelope is designed and what it is built from (Lstiburek, 1999).

Overall, New Zealand sits within a mixed humid region, has moderate to high rainfall and will ideally have a temperature-controlled environment. In a mixed humid hygrothermal region, building envelope assemblies should be designed to be able to dry to both the interior and exterior. With moderate to high rainfall areas claddings require a drainage plane and air space. To ensure a temperature-controlled environment the building should be air-tight, have heating and mechanical ventilation (Lstiburek, 1999).

The perfect wall concept works in all climates. In cold climates condensation risk is eliminated on the interior side of the vapour control layer due to the continuous insulation layer being installed on the exterior side of the control layers. The above will be true for New Zealand for most of the year, where vapour movement is most common from the inside to outside. In summer, in some parts of New Zealand, vapour drive may change from outside to inside. In this scenario, moisture that condenses on the exterior side of the control layers will be drained to the exterior (Lstiburek, 2011).

The concept of the perfect wall works in any climate due to its ability to effectively separate the indoor and outdoor environments, allowing the wall to dry outwards from the control layers and inwards from the control layers. New Zealand has high indoor humidity which is created by our high outdoor humidity combined with activities within the home that add moisture into the air. The 'perfect envelope' will manage the negative impact of moisture in the envelope system by eliminating interstitial condensation mould risk. However, mechanical ventilation is still critical to maintaining a comfortable and healthy indoor environment.

Exterior insulation levels will depend on the outdoor temperatures. For example, in Queenstown a higher level of exterior insulation is required compared to Auckland. As Queenstown has much colder outdoor temperatures, more thermal resistance is required to keep the condensing surface (sheathing or roof substrate) above the dew point of the interior air.

Due to New Zealand's moderate temperatures the timber cavity can also be insulated as long as the $\mathrm{R}$-value remains lower than that of the exterior insulation.

Mixed-humid climate: A region that receives more than $500 \mathrm{~mm}$ of annual rain and where the monthly average temperature drops below 7.2 degrees Celsius during the winter months (Building Science Corporation, 2003). 


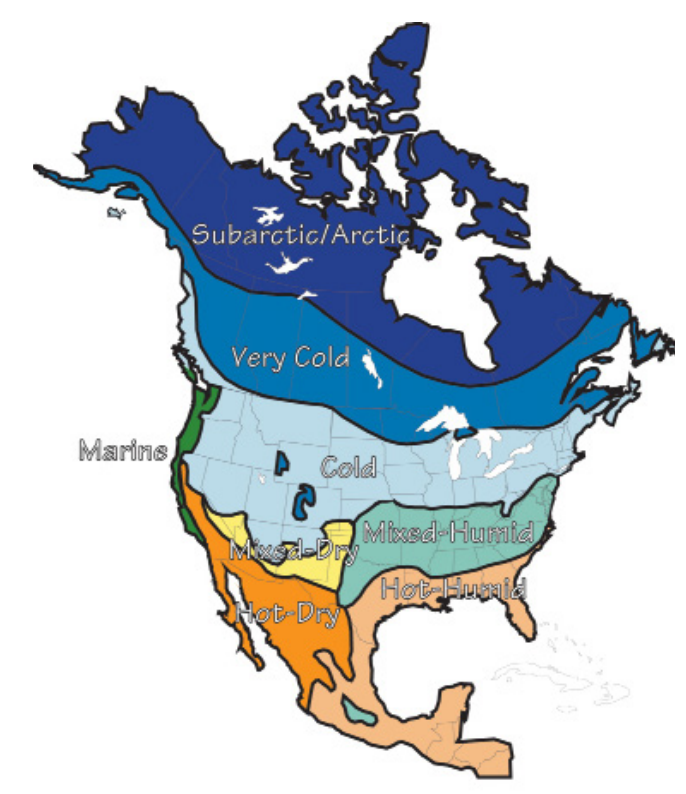

Figure 2.11. Hygrothermal Regions developed by Building Science Coorporation. BSC Information-310: Vapor Control Layer Recommendations for all climates (p.1), Buiding Science Corporation, 2003.

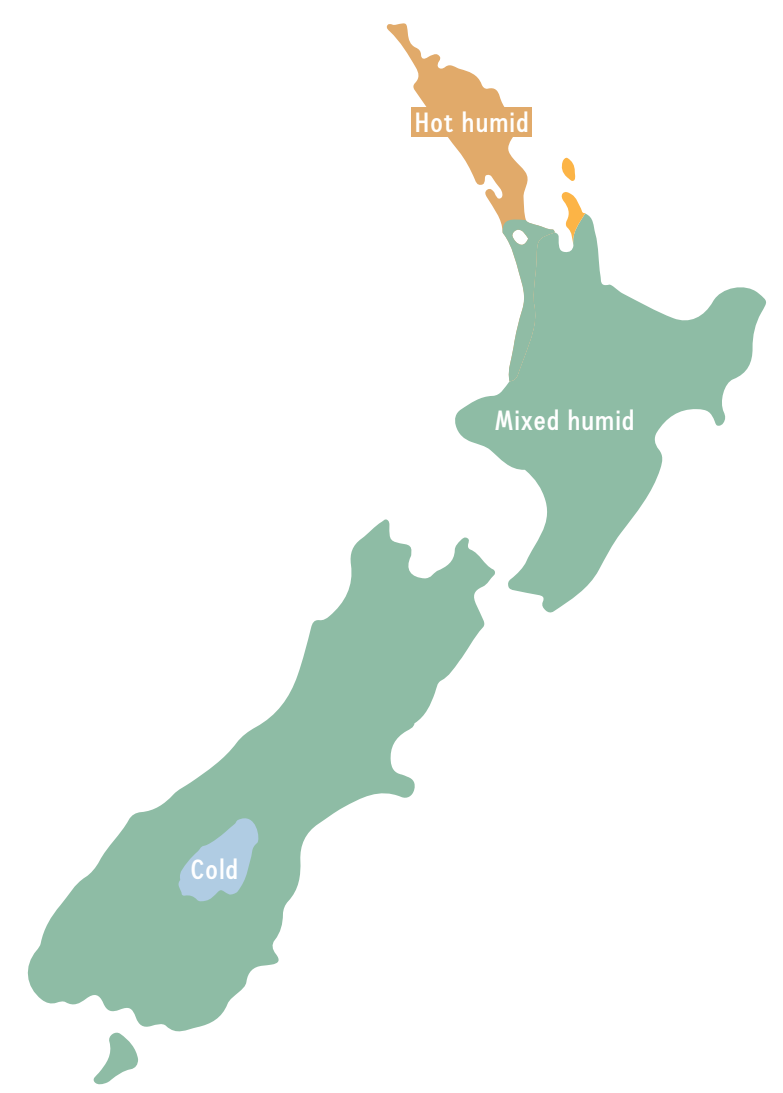

Figure 2.12. Hygrothermal Regions in New Zealand. Regions developed by Building Science Corporation.

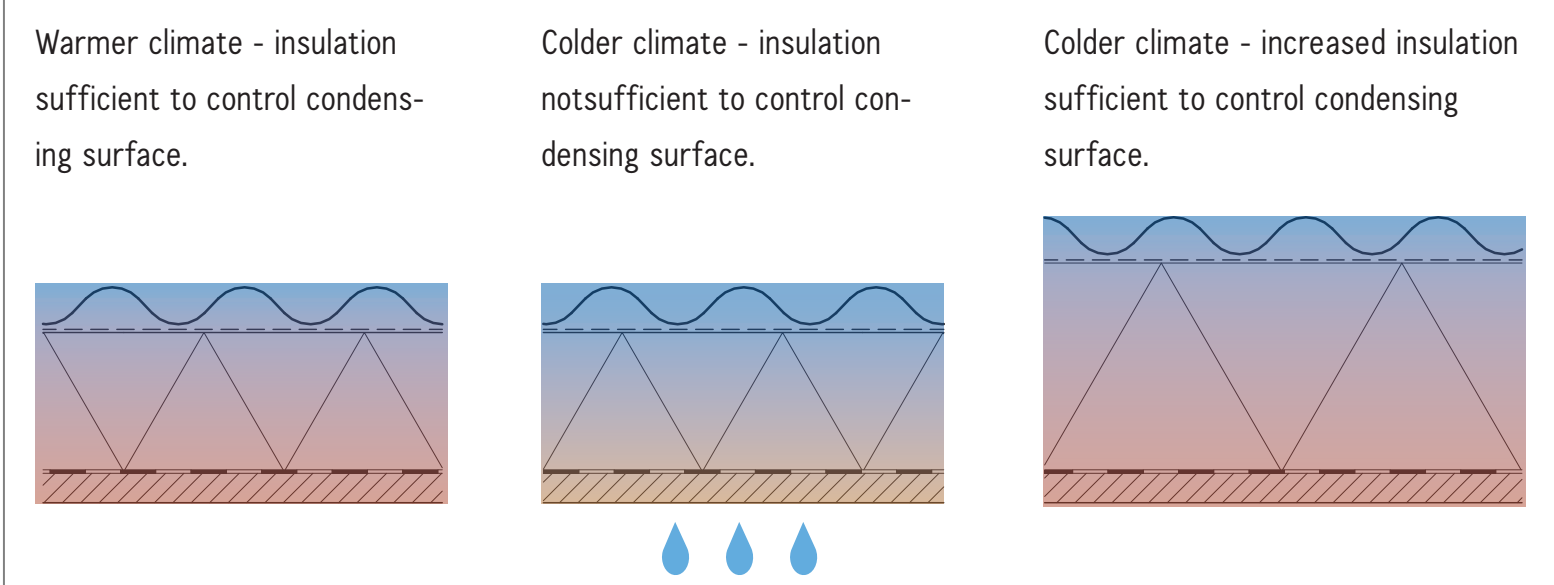

Figure 2.13. Different outdoor temperatures determining varying amounts of insulation used in roof assemblies. 


\section{6 buildability and readability}

Overview. The importance and performance of control layers (rain, air, vapour, and heat) has been considered.

When the architect is confident that the correct principles of envelope building science have been implemented into the envelope design, Allen poses the question of how will the drawn details achieve the desired results on site? (Allen, 2016). The drawings need to be sound in respect to building envelope science, be readable (clarity) and be buildable. All detailed design drawings should be unambiguous, coherent, accurate and complete (Slater \& Radford, 2012). For a building to function well its details must function well (Allen, 2016).

Consistency within drawings is crucial to their readability. Representation of control layers should be consistent and reflect the function of the control layer. The current way air control layers (e.g., flexible air barrier and flashing tapes) are often shown is with a thin dashed line on drawings yet the cladding is shown as a thicker solid line. The dashed line used to represent the air control layer intuitively indicates the layer is discontinuous or perforated or has a high degree of permeability or is much less significant than the cladding because of its thinner, dashed line. However, the literature review has made clear the role of the air control is crucial and its continuity paramount. The air control layer must be completely air impermeable whereas gaps withing the cladding are expected and designed for. It makes common sense for the representation of the air control layer to be a solid, thicker line and easily recognisable.

Allen considers that it is important to use patterns when drawing details. These detail patterns are based on building physics, common sense, and the realities of human performance. An architect should employ these patterns automatically when designing details (Allen, 2016). Patterns create consistency withing drawings and details. The consistent drawing of the air control layer is a pattern. Correct overlapping (Allen, 2016) of materials forming the rain control so water flows out of the envelope is another pattern. Detail patterns create consistency and help to ensure satisfactory execution on site.

Buildable details. Buildable details should be easy to assemble, be forgiving of small inaccuracies (tolerances) and should use efficient construction techniques. A detail may work perfectly in response to building science fundamentals but is flawed if it is hard to construct and unnecessarily expensive (Allen, 2016).

The builders and contractors have a right to understand how a building is put together without a great level of difficulty. A builder's knowledge and experience of construction and materials means they often have insights about a detail that would be beneficial to an architect (Allen, 2016). If the designer and builder can share an image of what is to be achieved the details will be more achievable (Brand, 1990). As builders will fully understand, a well-conceived detail is not fully understood until it is built (Allen, 2016).

Readability of control layers. Detail drawings should clearly identify and label the rain control layer including all associated flashings, tapes, and joints. This includes identifying slopes and drip edges on flashings (Burnett \& Straube, 2005). The drainage plane should also be clearly identified. Burnett and Straube state that the integrity of too many building 
envelope joints relies solely on the performance of a single-stage sealant. Proper joint design will provide multiple lines of protection against water. This will mean the exterior does not necessarily have to be watertight as long as the inward seal connects to the drainage plane, directing water to the exterior (Burnett \& Straube).

The air control layer should also be clearly identified on the drawings and details along with the method of insulation and the materials required to ensure its continuity. Water vapour will always search for the path of least resistance so it is crucial that all joints in the air control layer are structurally sound to resist the air pressure differences. (Knaack \& Koenders, 2018).

Insulation should be as continuous as possible with minimal thermal breaks at windows and doors (Burnett \& Straube, 2005).

Control layer continuity and materiality. All control layers must be present and be continuous across the entire building envelope, inclusive of all openings and penetrations (BC Housing, 2020). This is one of the most common challenges faced by both designers and builders.

For the designer, the challenge is to produce architectural details which are clear and consistent across the building envelope. An important aspect of this is ensuring that it is clear which components are associated with and responsible for which control layer within the building envelope assembly (BC Housing, 2020).

This problem can be seen in relation to prefabricated buildings or prefabricated wall and roof panels. If not carefully resolved it is possible for prefabricated components to preclude the opportunity for control layers to be made continuous, even when all controls layers are present.

A control layer can be made up of several materials or components and the designer has a seemingly endless range of options available to them when selecting control layers within the building envelope. Burnett and Straube make the important point that there are not necessarily materials that are "good" or "durable" in themselves but all materials must be used in a durable way (Burnett and Straube, 2005.) For example, a rain control layer can be made of a flexible membrane, flashing tapes and metal flashings but it is important that these separate materials are compatible with each other and detailed correctly to ensure that they stop water from entering the building envelope.

Material layers can also perform more than one control layer function. For example, an air control layer can also perform as a vapour control layer depending on its location within the envelope system and its material properties. Another example would be where the air control layer can also function as the rain control layer. However, if the air control layer is to provide a rain control function it must be detailed to reflect this. An air control layer must always be taped and flashed to be continuous but, if it is also to function as the rain control layer, those tapes and flashings must be installed and layered correctly to ensure an effective drainage plane is achieved.

These examples demonstrate that building envelope design creates the opportunity to consider how to incorporate the four critical control layers (rain, air, vapour, and thermal control) within a functioning 
building envelope assembly. This will be considered further in chapter 3 where the author will present the concept of the 'perfect wall' where a single control layer will be proposed that provides rain control, air control and vapour control in conjunction with a continuous external heat control layer.
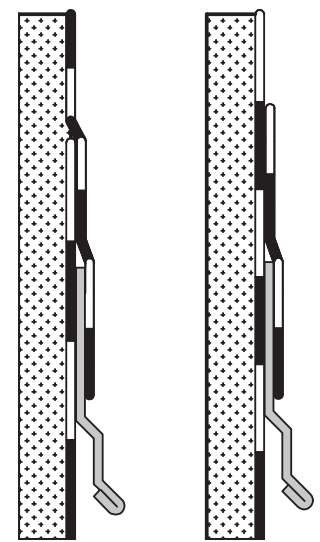

Figure 2.15. Detail Pattern - overlapping of rain control layer at flashing. Left is correct overlapping to drain water to the exterior. Right is incorrect overlapping.

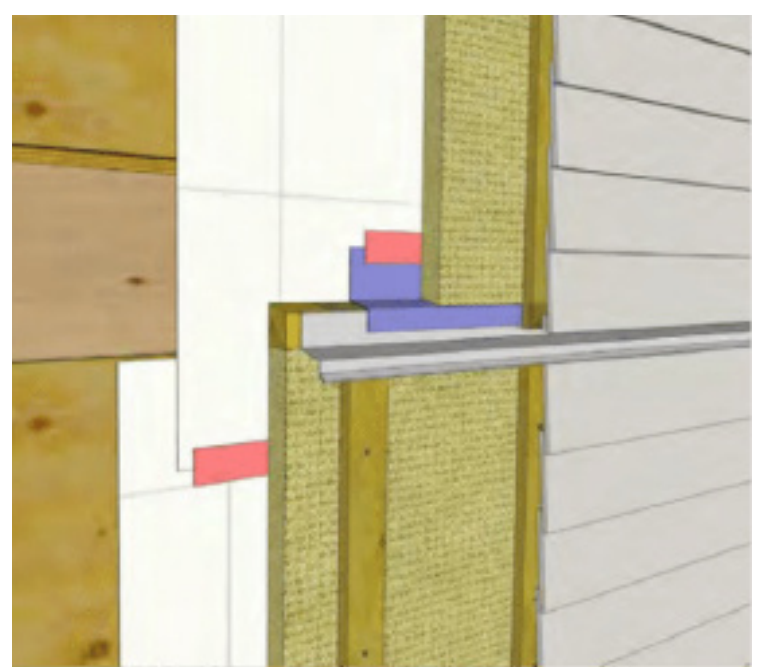

Figure 2.14. Matreriality of control layers in 3D cutaway of interstorey junction. Building Enclosure Design Guide: WoodFrame Multi-Unit Residential Buildings (2nd ed) (p.6-24), BC Housing, 2020

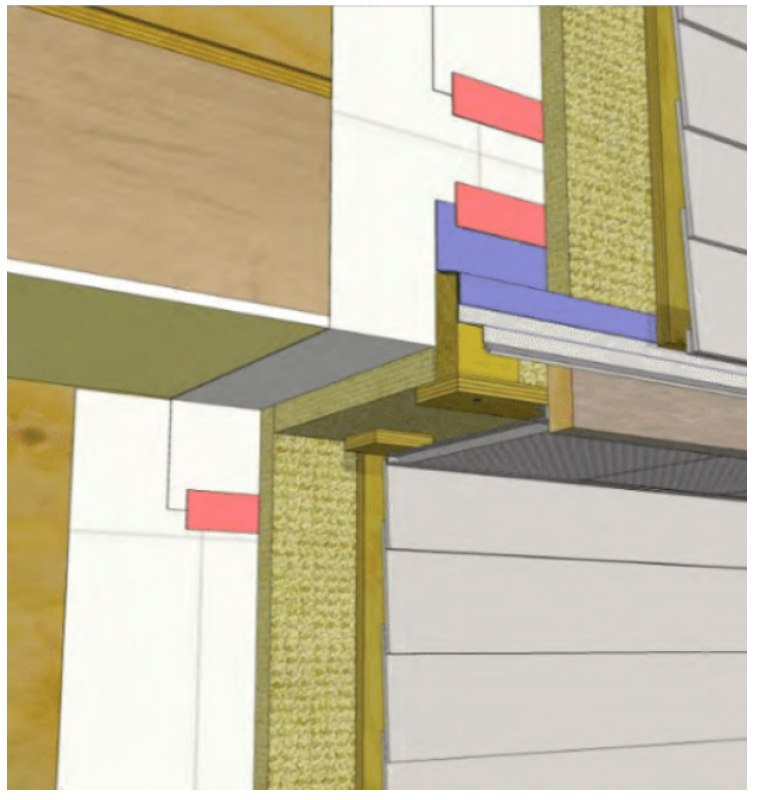

Figure 2.15. Matreriality of control layers in 3D cutaway of cantilevered floor. Building Enclosure Design Guide: WoodFrame Multi-Unit Residential Buildings (2nd ed) (p.6-16), BC Housing, 2020.

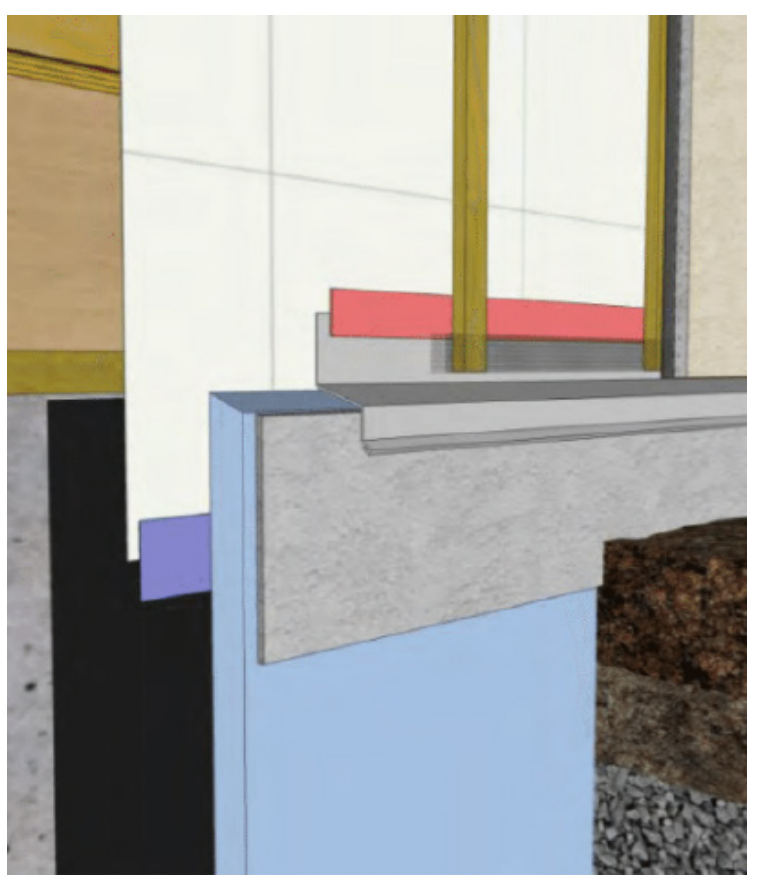

Figure 2.16. Matreriality of control layers in 3D cutaway of insulated slab edge. Building Enclosure Design Guide: WoodFrame Multi-Unit Residential Buildings (2nd ed) (p.6-31), BC Housing, 2020. 


\section{7 literature view canclusians}

The 'perfect wall' concept presented by Lstiburek is a tool that helps explain how fundamental building envelope science principles can be applied in the design of timber framed building envelopes (Lstiburek, 2010). The perfect wall, at a theoretical level, will work in all situations. However, the built reality of the perfect wall will look different depending on the specific requirements of the project and the climate zone.

The concept of the perfect wall may not necessarily be applicable to every project. However, the building envelope science principles upon which the perfect wall is based should be understood and applied in all building envelope designs.

To develop a building envelope system for a timber framed house in New Zealand the envelope must contain all four crucial control layers. Whilst there is flexibility in regard to the materiality of these control layers, and even their location within the wall assembly, the design must always be guided by building envelope science fundamentals.

With the perfect wall the rain, air and vapour control layer are in the same location and these control layer functions are able to be achieved with the use of one physical layer. This is unique when compared to other wall assemblies.

If a self-adhered or mechanically attached air control layer is installed over rigid sheathing, and that layer is water impermeable and fulfils the vapour resistance requirements, it can, when appropriately detailed, form the rain control layer and, by definition, the drainage plane.
With the perfect wall a single layer performing these three control layer functions is attached to rigid sheathing. This sheathing provides wind and seismic load resistance and provides support for the attachment of the control layers.

The heat control layer will be rigid insulation in the form of high-density rock fibre. This insulation is not water sensitive and therefore can be left exposed to the air space. The air space is located behind the cladding and in front of the heat control layer. The interior linings should be vapour permeable to allow drying to the interior (Lstiburek, 2000).

The idea of the wall being perfect is a conceptual designation. Due to the nature of on-site construction, the wall will be built with small inaccuracies. The perfect wall can be designed to be functional even when these inaccuracies are present. The design manages these inaccuracies because it allows drying to both the interior and exterior. A practical example of this is that rain control is managed at three separate locations - the cladding, air space and drainage plane. Another example based on the building envelope science is that the wall assembly is designed to dry both from the control layers inwards and the control layers outwards.

As a result of having conducted a review of literature relating to building envelope performance, the author has formed the view that the 'perfect wall' provides an approach to building envelope design and construction which is ideally suited to timber framed residential houses in New Zealand.

It is conceded that a literature review that explores concepts and solutions in a field as vast and complex 
as building envelope design will not be able to consider all views or potential approaches. Every potential method of constructing a functional building envelope cannot be considered. Every material that is, or could be, used in the construction of a building envelope cannot be evaluated. There are a vast number of such products and products are constantly being developed and changed.

In some respects, the 'perfect wall' may be seen as being a radical departure from traditional/current methods of envelope construction in New Zealand. Taking this view, some would argue that more consideration should be given to "tweaking" the status quo to improve envelope performance rather than proposing something that is so fundamentally different.

In the literature, the fundamental building science principles that inform the concept of the perfect wall are generally well settled and agreed upon. There are one or two minor points of discussion still evident in the literature - for example, what is the ideal dimension of the airspace within the wall assembly? - but there is no debate or disagreement as to the functionality of the perfect wall in principle.

The authors view, based on the review of the literature, is that the concept of the perfect wall is well suited to residential, timber framed construction in New Zealand. It is based on sound building science principles, it is simple and intuitive to understand, design and build, and has a high level of redundancy. There is no question that many existing building envelope designs do not function well at the most fundamental level, evidenced by their inability to manage condensation, mould and corrosion risk. The 'perfect wall' provides an opportunity to build better in New Zealand. 


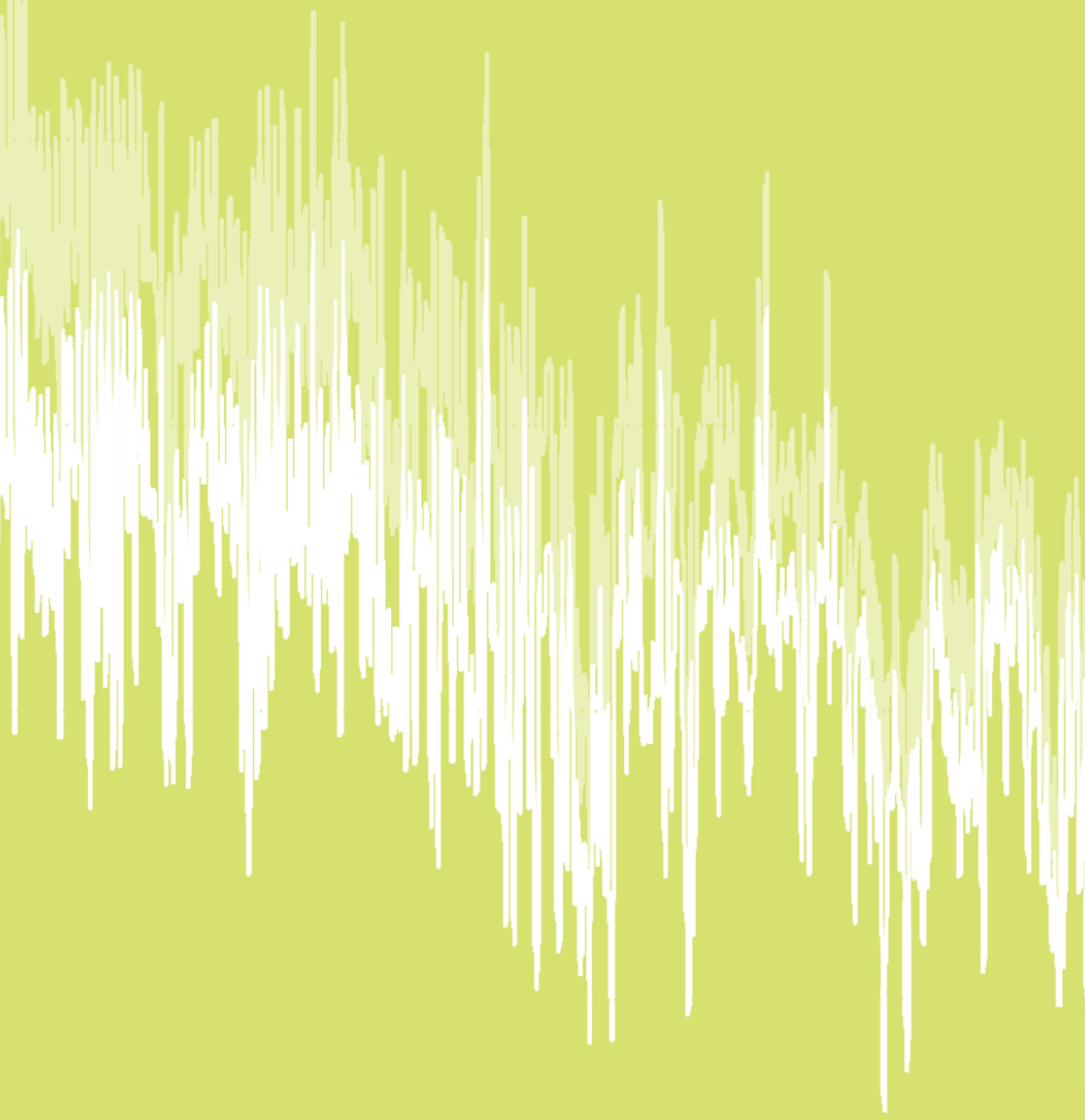




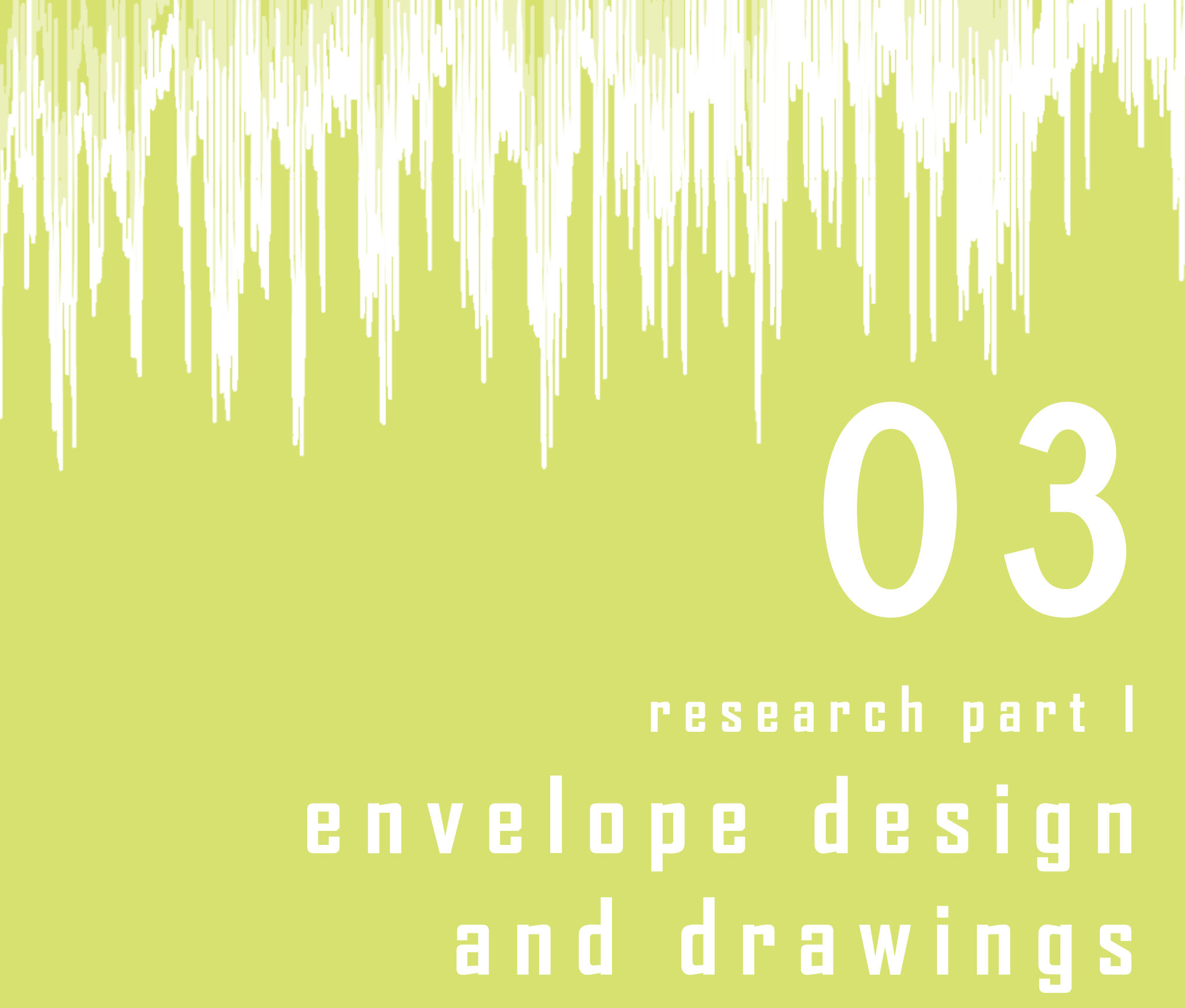




\section{I control layer identification key}

In order to analyse and design building envelope systems a control layer identification key is developed. The key includes the four crucial control layers required to control moisture in the building envelope. The cladding layer protects the building envelope from driving rain and ultraviolet radiation. The rain control layer is watertight, it forms a continuous drainage plane that directs any water that makes it way past the cladding to the exterior. The air control layer separates the conditioned air (interior air) from the unconditioned air (exterior air) and is impermeable to air flow. Hence, the air control layer controls the movement of water vapour through the process of air flow. The heat control layer ensures energy efficiency of the interior environment and controls the temperature of the condensing surface. The vapour control layer controls the movement of water vapour through the process of diffusion.
As made clear in the literature review, the air control layer controls the movement of vapour through air flow. To the extent that it controls vapour it is also a vapour control layer. The control layer key distinguishes the air control layer and vapour control layer. In some cases, there are physically separate air and vapour control layers whilst in other cases the air control layer has properties which manage vapour diffusion allowing it to function as the air and vapour control layer.

Through the control layer identification key, building envelopes in the drawing critique (chapter 3.4) are analysed based on how they function as an envelope system and not just as individual components. The detail patterns described in chapter 2.6 can also be used to critique and understand existing architectural drawings and details (Allen, 2016).

\section{$\begin{array}{ll}\text { CLADDING } & \text { DRIVING RAIN, WIND, UV PROTECTION }\end{array}$}

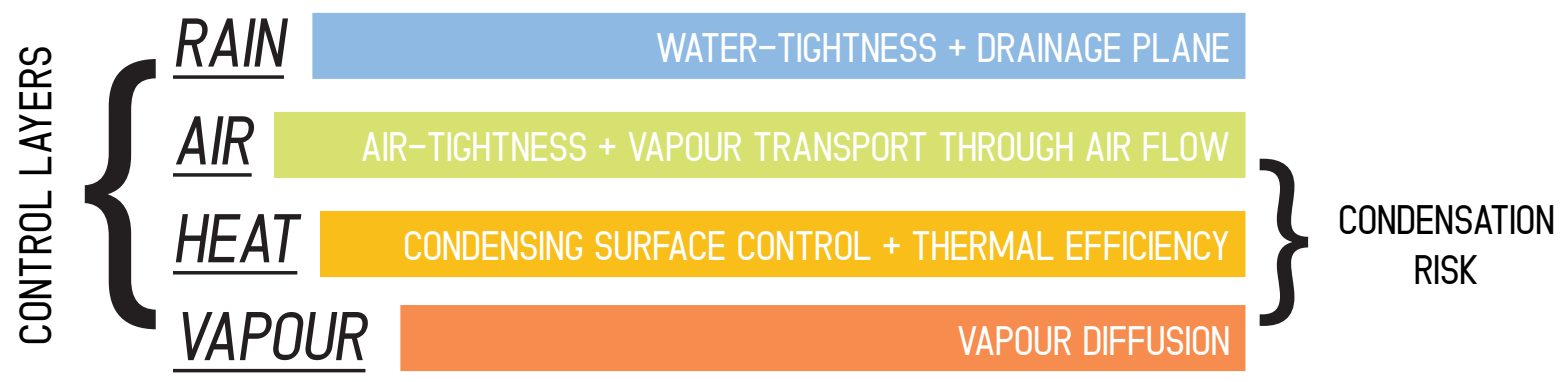

Figure 3.1. Control layer identification key. 


\section{2 building envelope science diagrams}

The diagrams represented on the following pages are in realtion to a typical NZ wall assembly and the propsed wall assembly. The proposed wall assembly has rain, air and vapour control layers on the outside of the structure followed by the heat control layer.

\section{typical wall assembly}

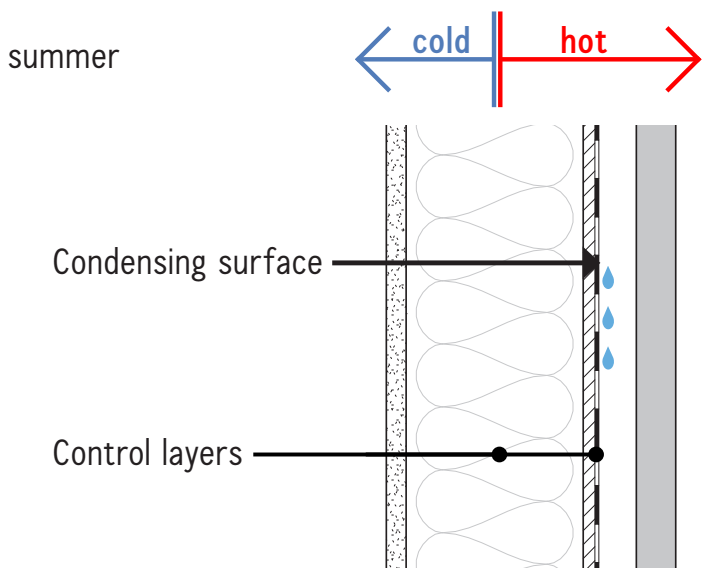

Figure 3.2. Intersitial condensation diagram: typical NZ wall in summer.

In summer, condesation is limited to the outside of the structure. If condensation was to form, it drains to the exterior given the rain control layer is effectively detailed to form the drainage plane. winter
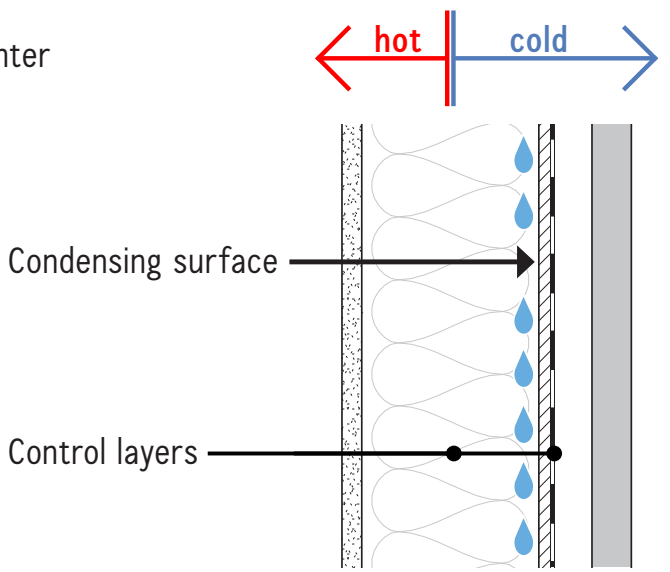

Figure 3.3. Intersitial condensation diagram: typical NZ wall in winter.

In winter, interior air can move into the structuaral cavity where condesation risk will occur if it comes into contact with a surface colder than its dew point. 


\section{proposed wall assembly}

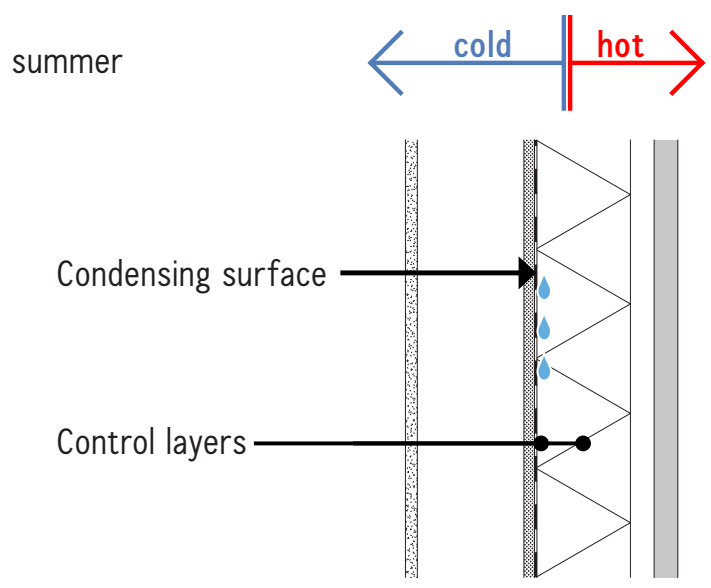

Figure 3.4. Intersitial condensation diagram: 'perfect wall' concept in summer.

In summer, condensation is rare. If condensation was to form, it is limited to the outside of the structure and can drain given the rain control layer is effectively detailed to form the drainage plane.

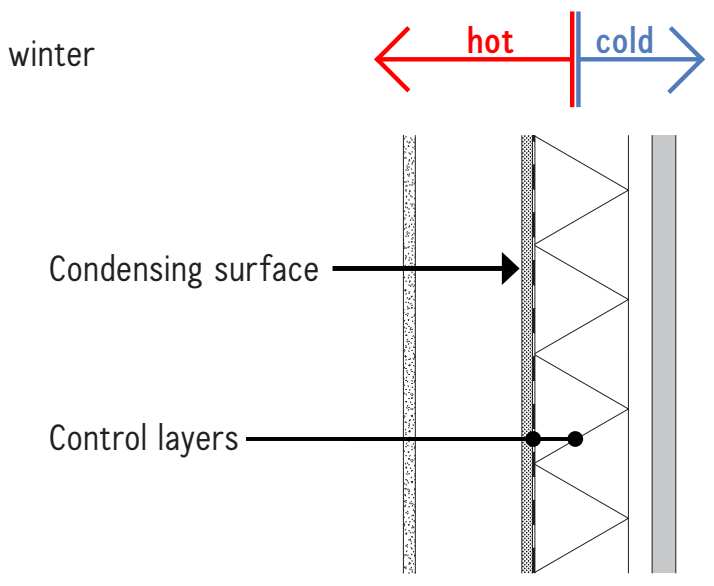

Figure 3.5. Intersitial condensation diagram: 'perfect wall' concept in winter.

In winter, the exterior sheathing, which is the condensing surface, is kept warm by the continuous insulation (above the dew point temperature). Condensation risk is able to be eliminated.

\section{vapour control layer vs. air control layer}

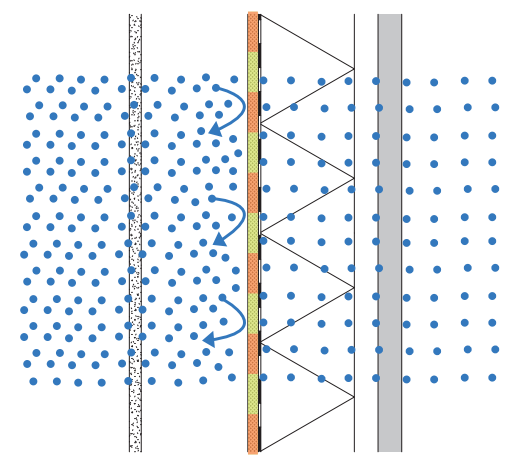

no water vapour diffusion

Figure 3.6. Vapour control layer vs air control layer. Role of vapour control layer.

The diagrams above demonstrate the difference between the role of the air control layer and the role of the vapour control layer. Vapour drive is shown from the inside to outside. In figure 3.6 water vapour

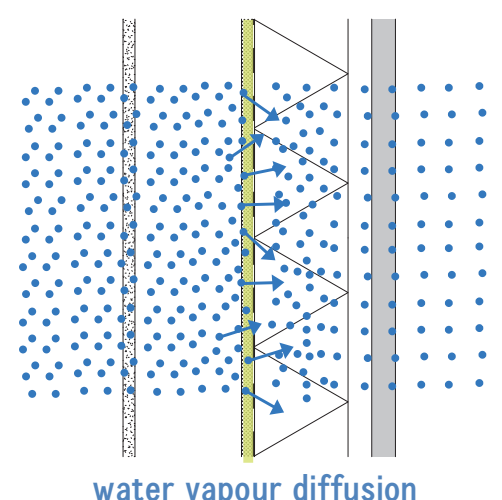

Figure 3.7. Vapour control layer vs air control layer. Role of air control layer.

(shown as blue dots) cannot move past the vapour control layer. Figure 3.7 has an air control layer but no vapour control layer. Water vapour can move by the process of diffusion through the air barrier. 
vapour control layer vs air control layer in typical wall assemblies

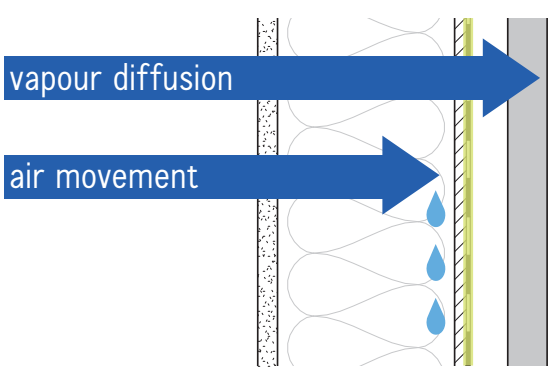

Figure 3.8. Role of air control layer on exterior side of typical wall assembly.

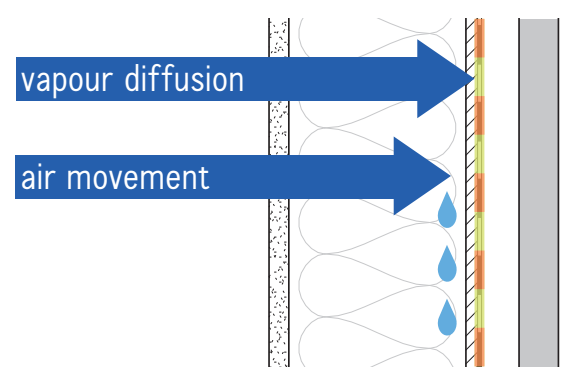

Figure 3.9. Role of vapour control layer on exterior side of typical wall assembly.

The use of an air and/or vapour control layer on the exterior of a typical wall assembly (figure 3.10 and figure 3.11) creates a risk of condensation at the interior face of the exterior sheathing.

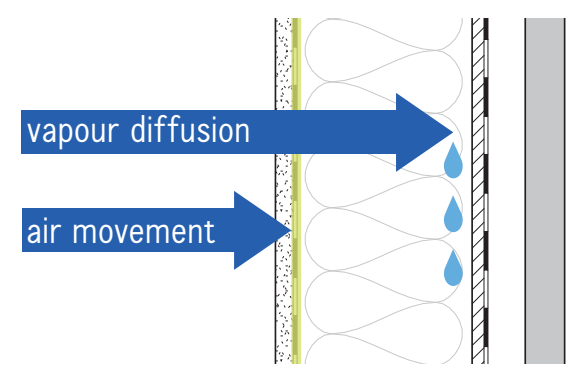

Figure 3.10. Role of air control layer on the interior side of a typical wall assembly.

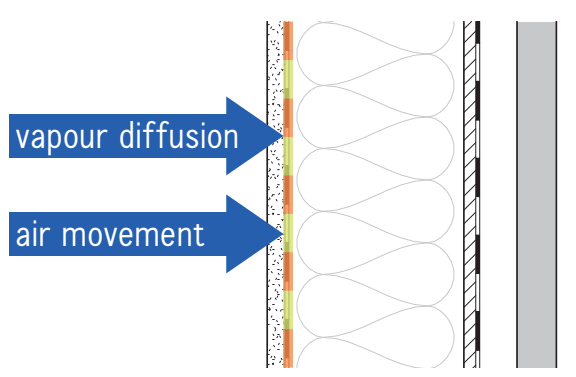

Figure 3.11. Role of vapour control layer on interior side of typical wall assembly.

The use of an air control layer on the interior side of a typical wall assembly in figure 3.12 poses a risk of condensation as water vapour diffuses through the air control layer and moves into the insulated cavity. Figure 3.13 has air and vapour control layers on the interior side of the wall assembly. This prevents vapour movement through both air transport and diffusion and condensation risk can be eliminated within the insulated wall cavity. 


\section{3 control layer identification in walls}

\section{pгior 1978 uninsulated NZ wall}

The following images demonstrate the use of the control layer identification key. Control layers are identified on four different wall assemblies.

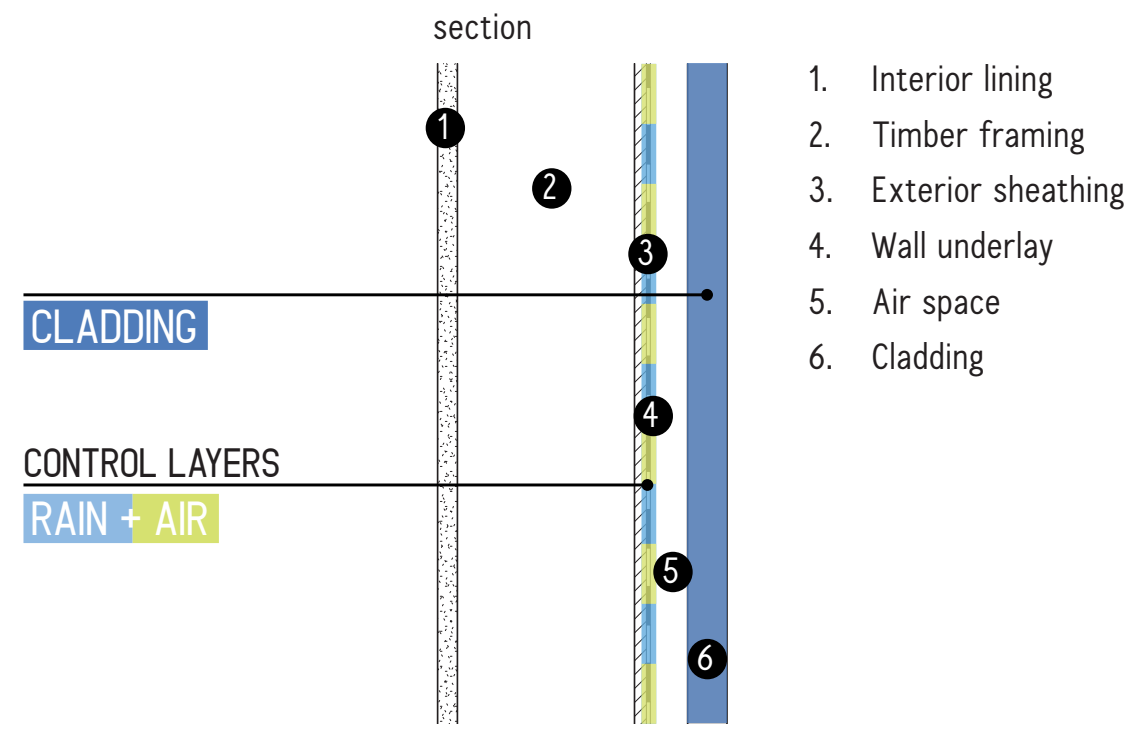

Figure 3.12. Control layer identification in uninsulated wall in section.

plan

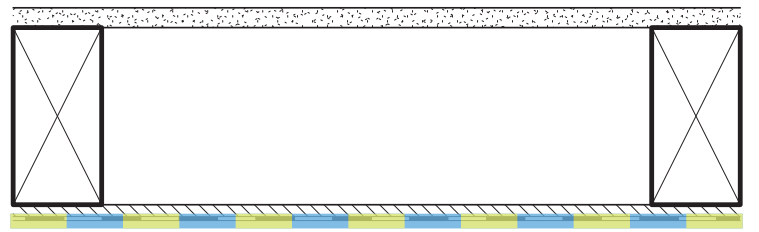

Figure 3.13. Control layer identification in uninsulated wall in plan.

\section{CLADDING}

$\underline{\text { RAIN }}$

$\underline{\text { AlR }}$

VAPOUR 
typical NZ wall

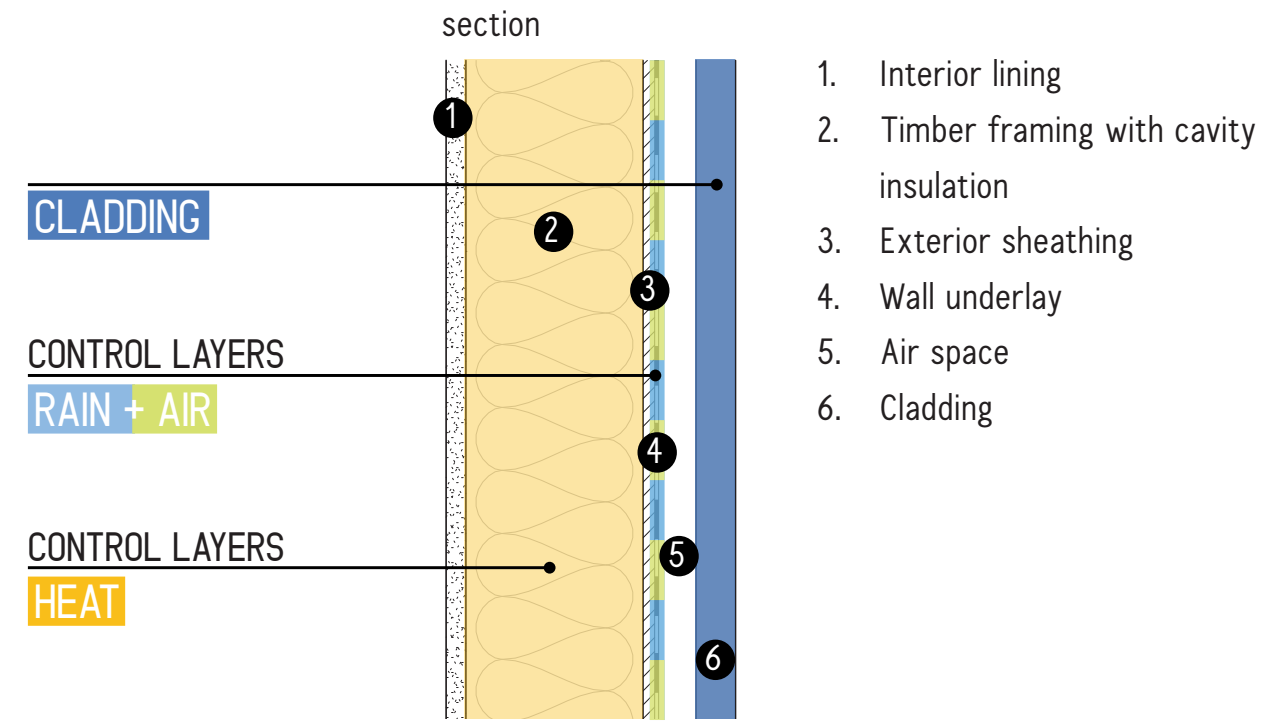

Figure 3.14. Control layer identification in typical NZ wall in section.

plan

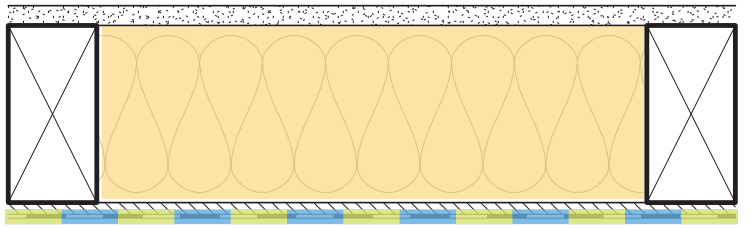

Figure 3.15. Control layer identification in typical NZ wall in plan.

CLADDING

RAIN

AIR

HEAT

VAPOUR 
typical wall with internal vapour control

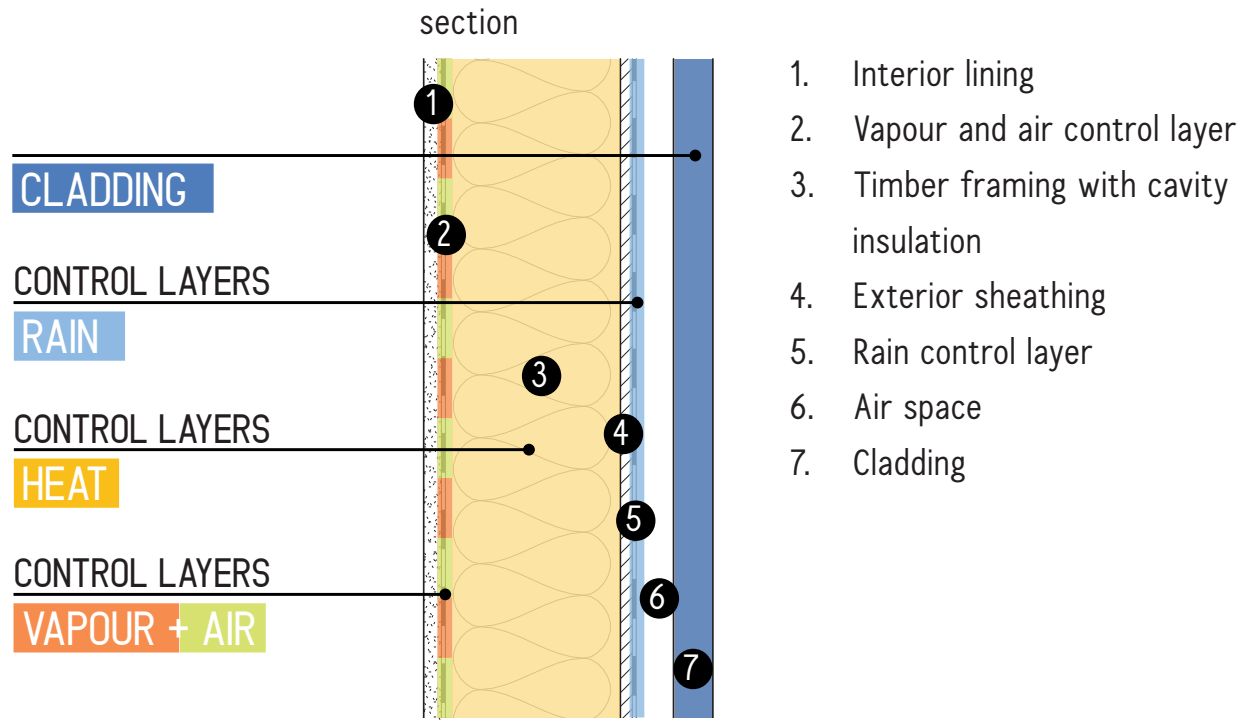

Figure 3.16 Control layer identification in wall with internal vapour control in section.

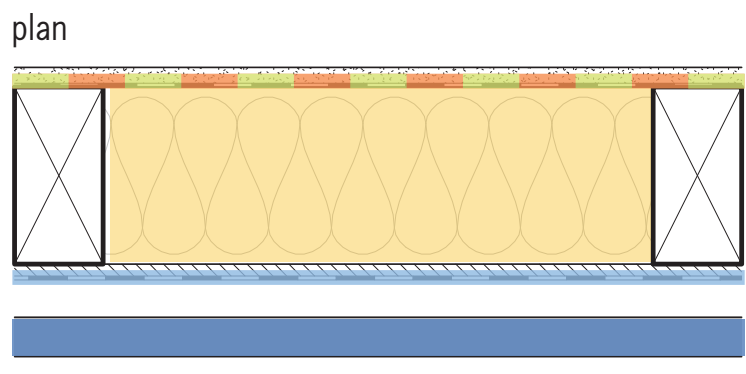

Figure 3.17. Control layer identification in wall with internal vapour control in plan.

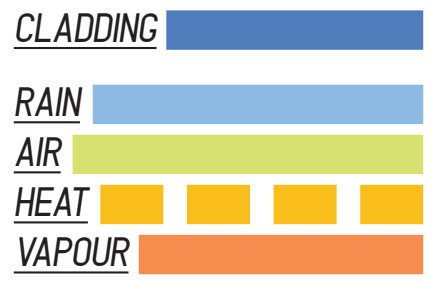


proposed wall assembly

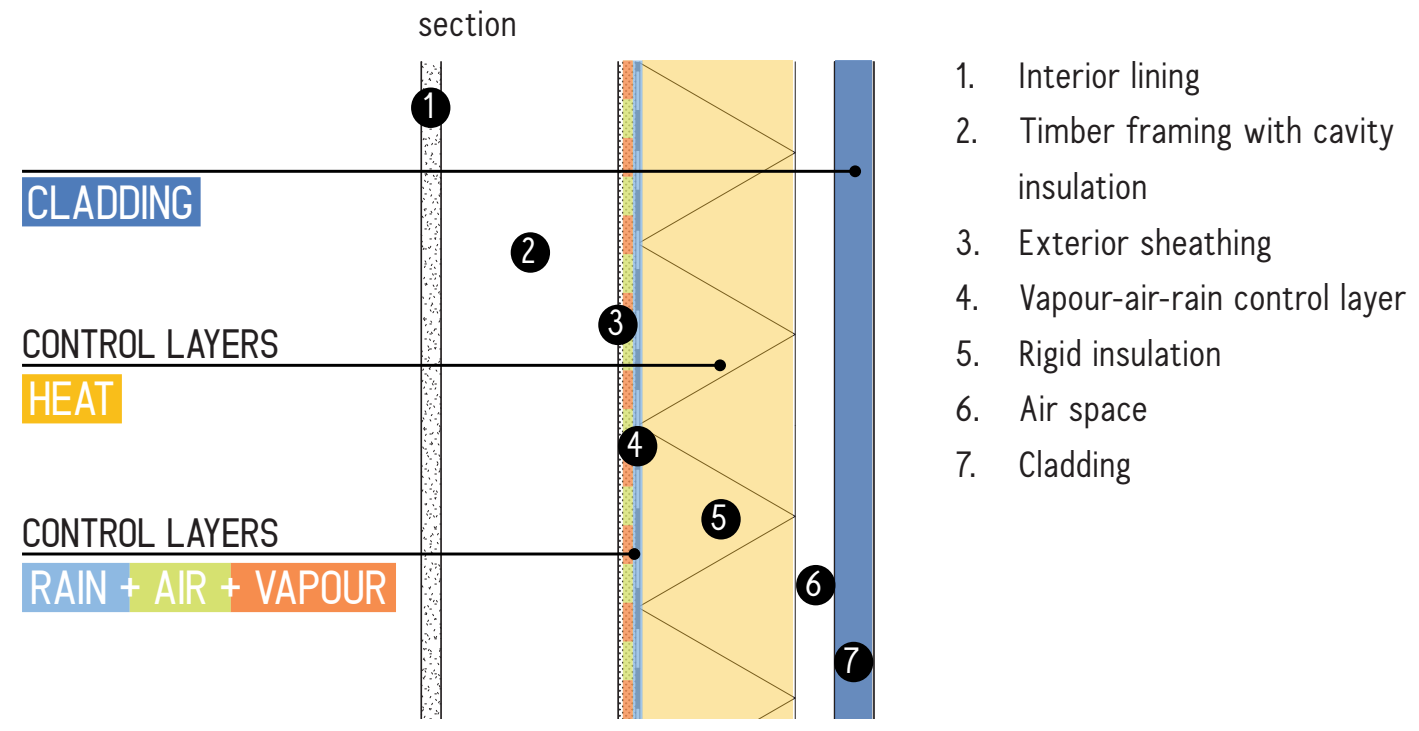

Figure 3.18. Control layer identification in wall with external control layers in section.

plan

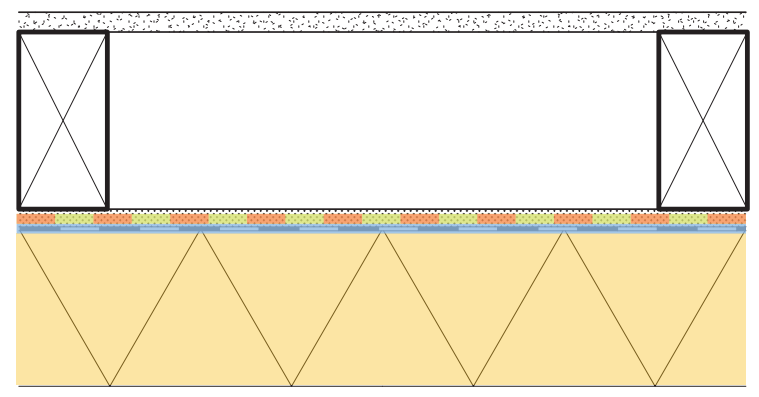

Figure 3.19. Control layer identification in wall with external control layers in plan.

\section{CLADDING}

RAIN

AIR

HEAT

VAPOUR 


\subsection{New Zealand timber framed hausing drawing critique} wall one
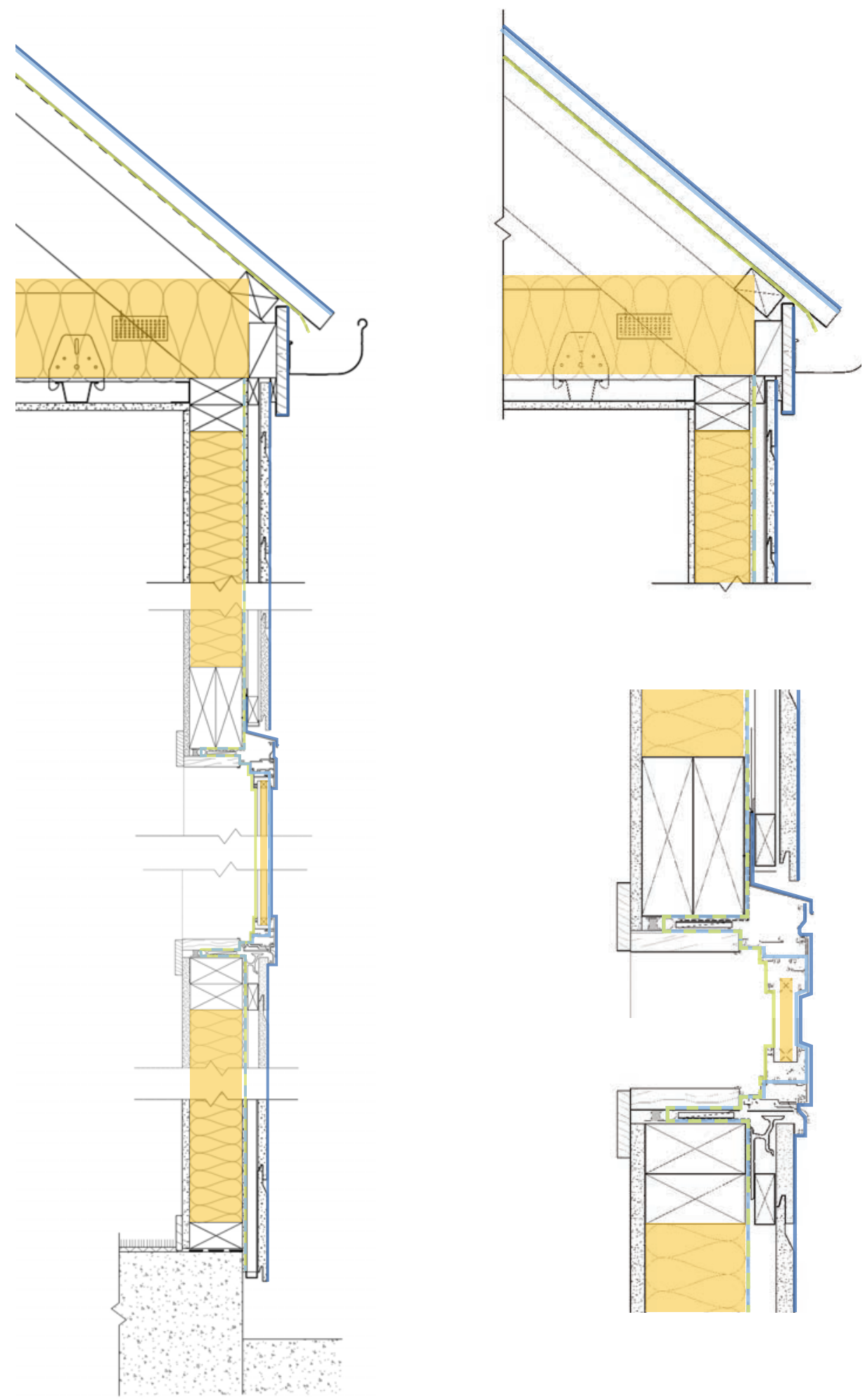

Figure 3.20. Wall one, typical NZ facade design. Public View Building Information, Search, Hutt City Council, 2020. 
Control layer identification. Cladding, rain, air and heat contol layers discontinuous. No vapour control.

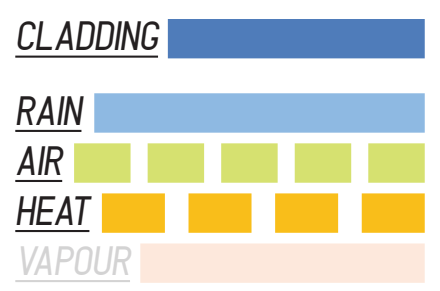

This wall represents the most typical way houses are built in New Zealand. The critiques observed are present in the majority of New Zealand homes including most new builds. The building envelope assembly is comprised of gypsum board interior lining, structural timber framing, fiberglass cavity insulation and a fibre cement rigid air barrier. Polypropylene cavity battens are then installed over the rigid air barrier followed by the mechanical attachment of the fibre cement cladding through the batten and in to the structural timber frame.

Rain control layer. The fibre cement rigid air barrier provides rain control within the system. If this control layer is carefully detailed with jointing and flashing tapes, in conjunction with the flashings that are shown, it will provide rain control. The cavity batten is non-structural so all mechanical fixings for both the batten and cladding will penetrate the rain control layer and fix through to the structural frame. All fixings represent a potential risk of water entry in to the structure.

Heat control layer. Insulation is not continuous. Thermal bridges exist along every stud line, at the window head and sill, and wall to roof junction. The window glazing is offset from the heat control layer reducing the thermal performance.
Air control layer. There is no evidence of air control to the interior side of the thermal insulation meaning that there is potential for air to move in to the insulated structural cavity resulting in condensation risk. The rigid air barrier, that has been detailed on the outside of the structural frame, is discontinuous with the flexible air barrier that has been detailed as part of the roof assembly. Obviously, if it is discontinuous is cannot be airtight.

Vapour Control layer. There is no evidence that vapour control has been considered in this wall assembly. 
wall two

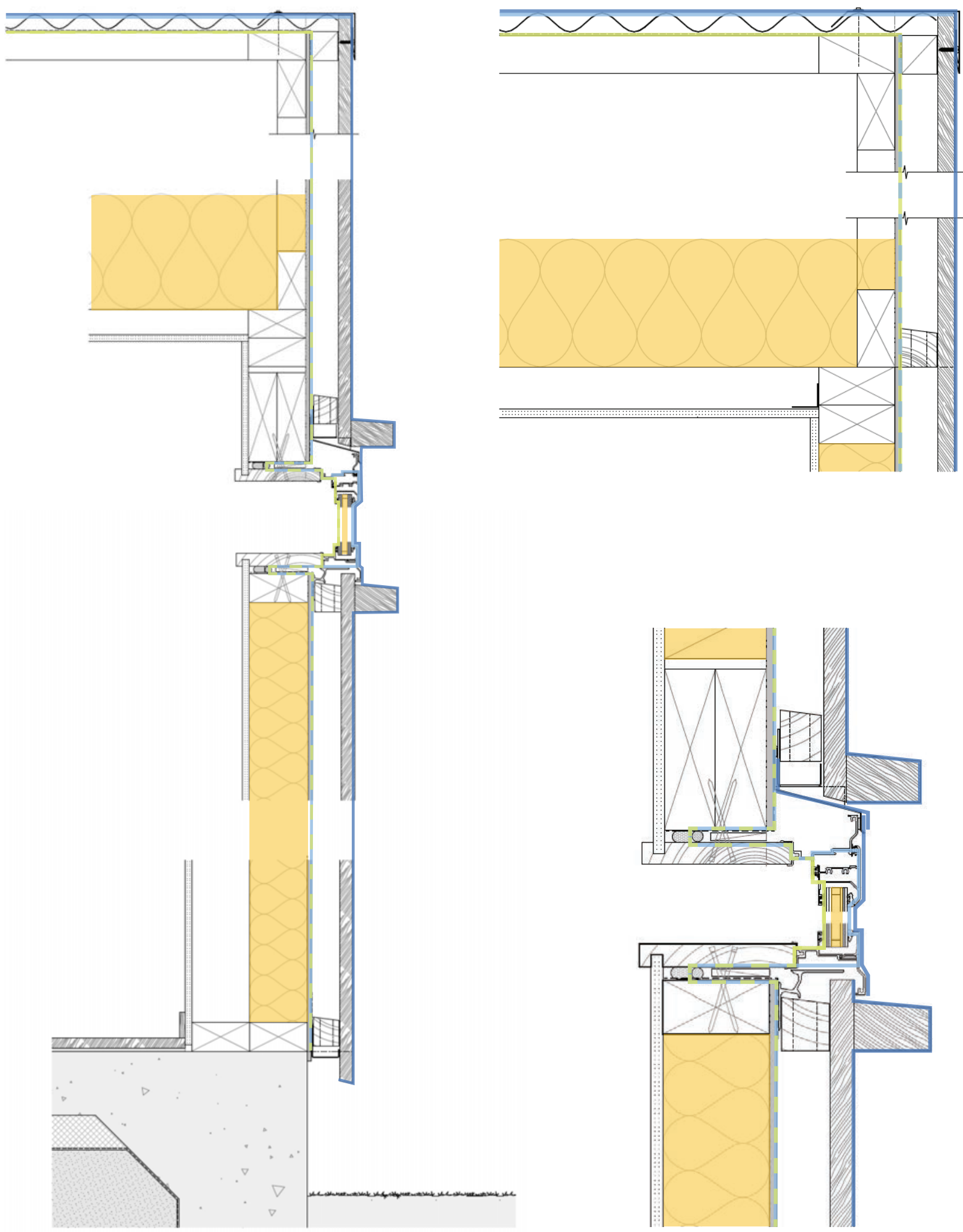

Figure 3.21. Wall two, typical NZ facade design. Public View Building Information, Search, Hutt City Council, 2020. 
Control layer identification. Cladding, rain, air and heat contol layers discontinuous. No vapour control.

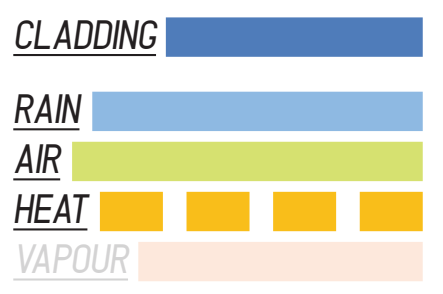

This wall represents the typical way houses are built in New Zealand. The critiques observed are present in the majority of New Zealand homes, including new builds. The building envelope assembly is comprised of gypsum board interior lining, structural timber framing, fiberglass cavity insulation and a fibre cement rigid air barrier. Structural castellated cavity battens are then installed over the rigid air barrier followed by the mechanical attachment of the timber cladding through the batten and in to the structural timber frame.

Rain control layer. The fibre cement rigid air barrier provides rain control within the system. If this control layer is carefully detailed with jointing and flashing tapes, in conjunction with the flashings that are shown, it will provide rain control. The cavity batten is structural so only mechanical fixings for the batten will penetrate the rain control layer and fix through to the structural frame. All fixings represent a potential risk of water entry in to the structure.

Air control layer. There is no evidence of air control to the interior side of the thermal insulation meaning that there is potential for air to move in to the insulated structural cavity resulting in condensation risk. The rigid air barrier that has been detailed on the outside of the structural frame is continuous with the flexible air barrier at the roof.

Heat control layer. Thermal control is not continuous. Thermal bridges exist along every stud line, at the window head and sill, and wall to roof junction. The window glazing is offset from the heat control layer reducing the thermal performance.

Vapour control layer. There is no evidence that vapour control has been considered in this wall assembly. There is also no evidence of vapour control being considered in the roof assembly and there is a significant condensation risk with this roof construction. 
wall three
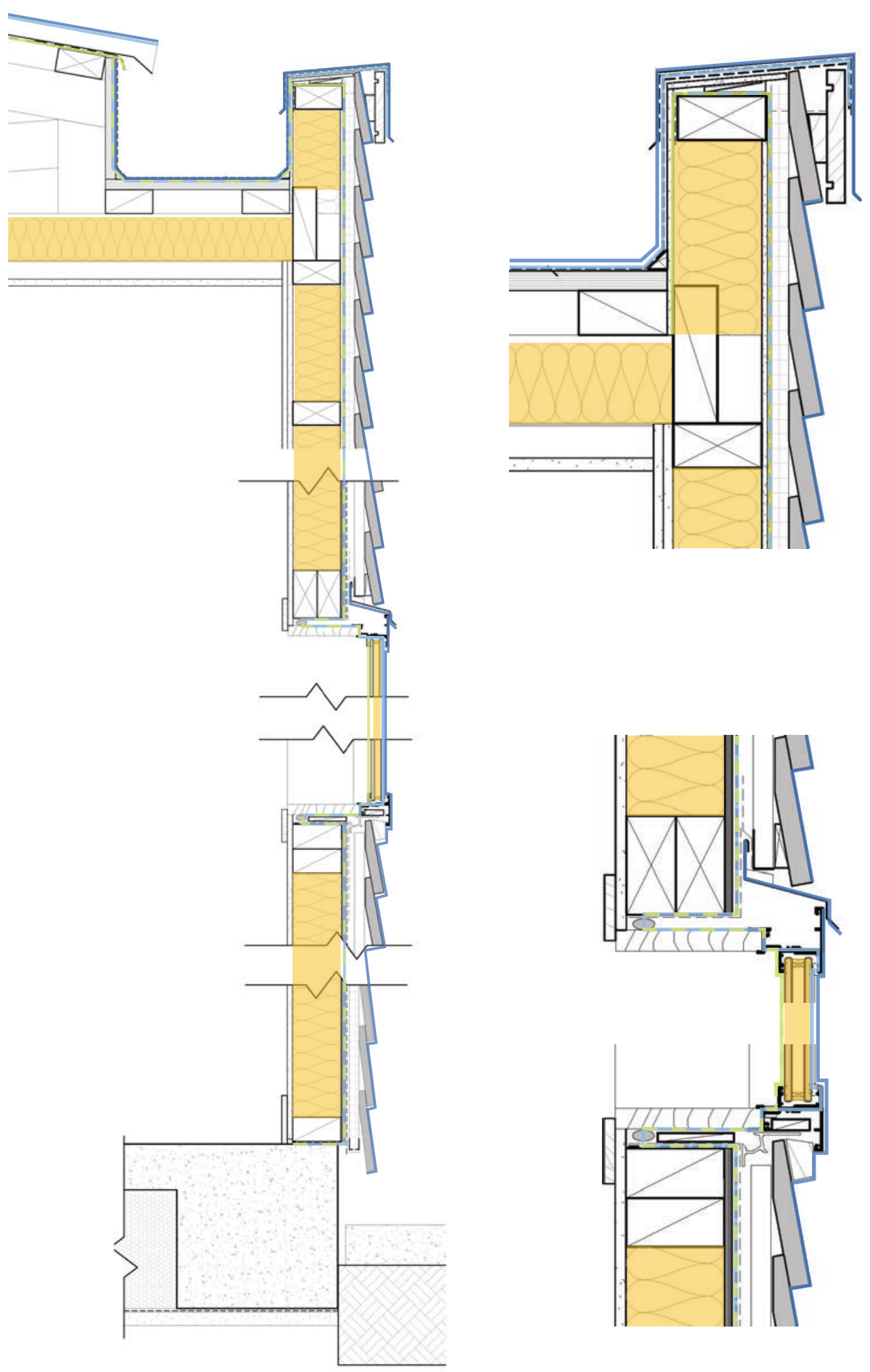

Figure 3.22. Wall three, typical NZ facade design. Public View Building Information, Search, Hutt City Council, 2020. 
Control layer identification. Cladding, rain, air and heat contol layers discontinuous. No vapour control.

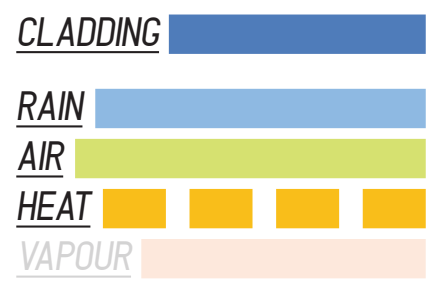

This wall construction is similar to the previous wall (wall 2) but with the addition of an internal gutter which sits within the building envelope. This is a common roof and gutter construction for new house design in NZ and presents some additional challenges in respect to the correct detailing of control layers.

Rain control layer. The fibre cement rigid air barrier provides rain control within the system. If this control layer is carefully detailed with jointing and flashing tapes, in conjunction with the flashings that are shown, it will provide rain control. The cavity batten is non-structural so all mechanical fixings for both the batten and cladding will penetrate the rain control layer and fix through to the structural frame. All fixings represent a potential risk of water entry in to the structure. The detailing of the roofing membrane and associated parapet flashing is critical to maintaining rain control layer continuity.

Air control layer. There is no evidence of air control to the interior side of the thermal insulation meaning that there is potential for air to move in to the insulated structural cavity resulting in condensation risk. The air control layer has been detailed to be continuous from the wall across and down the parapet at which point it connects with the roof membrane in the gutter and then to the metal roof underlay.
Heat control layer. Insulation is not continuous. Thermal bridges exist along every stud line, at the window head and sill, and wall to roof junction. The window glazing is offset from the heat control layer reducing the thermal performance.

Vapour control layer. There is no evidence that vapour control has been considered in this wall assembly. There is also no evidence of vapour control being considered in the roof assembly and there is a significant condensation risk with this roof construction. The absence of effective vapour control creates a specific risk in relation to the internal gutter.

Whilst there is no vapour control on the interior, the gutter membrane effectively forms a "vapour control layer" on the outside face of the plywood substrate. This results in specific condensation and mould risk to the underside of the plywood substrate. 
wall four

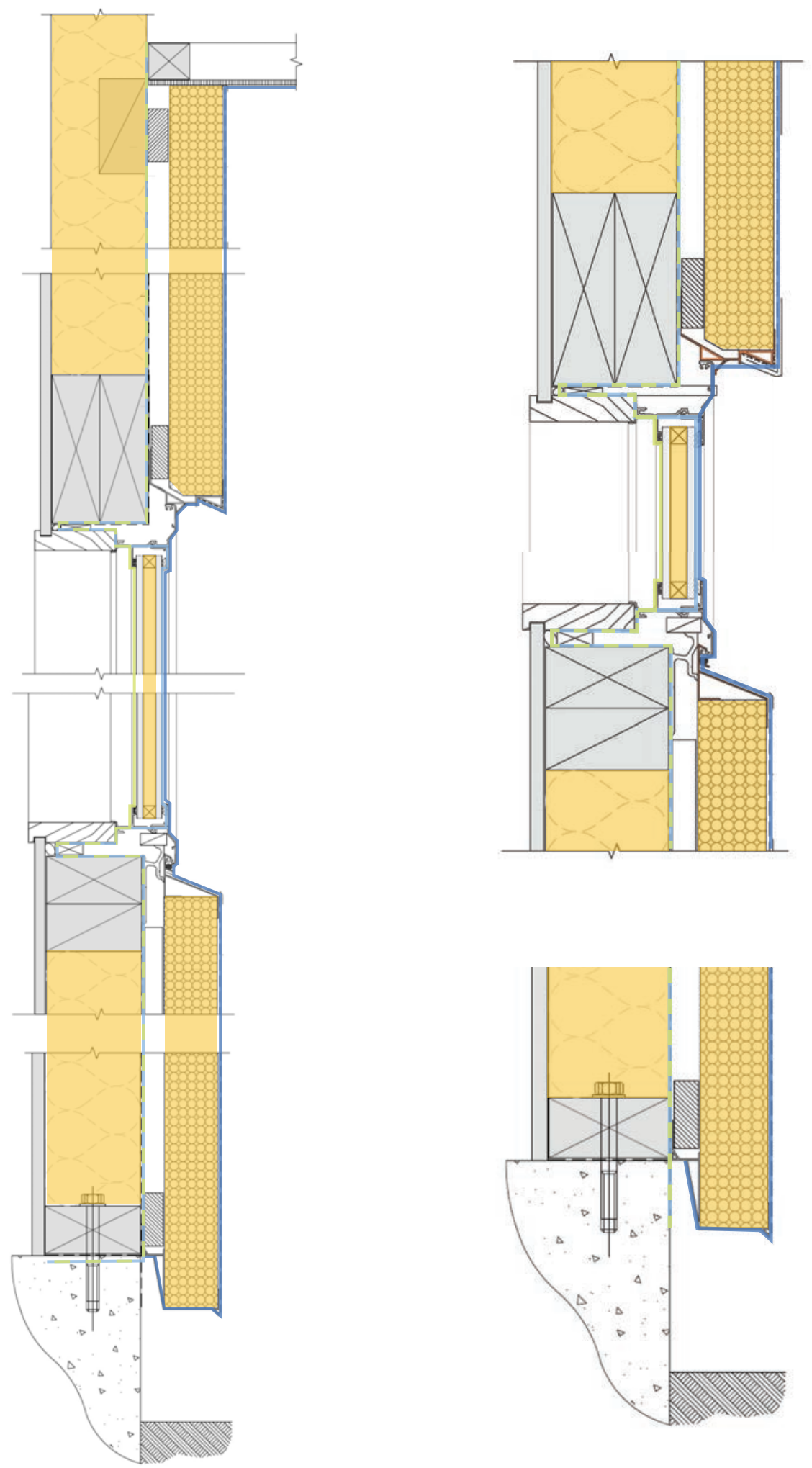

Figure 3.23. Wall four, NZ facade design. Public View Building Information, Search, Hutt City Council, 2020. 
Control layer identification. Cladding, rain, air and heat contol layers discontinuous. No vapour control.

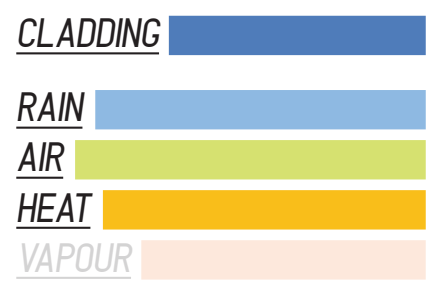

The building envelope assembly is comprised of gypsum board interior lining, structural timber framing, fiberglass cavity insulation and a flexible wall underlay for air control. Continuous expanded polystyrene insulation is then installed over vertical EPS cavity battens and mechanically attached to the timer structure. The polystyrene has a monolithic plaster coating applied.

Rain control layer. The plaster coating, in conjunction with proprietary flashing components and sealants, is intended to be the rain control layer. If there is partial failure of any one of these components then rain control is compromised. For example, plaster coating cracking due to thermal, structural or seismic movement or lack of maintenance of sealants. If it is assumed that the flexible wall underlay will contribute to rain control it is unclear, based on the drawings, how drainage of the air space is achieved.

Air control layer. There is no evidence of air control to the interior side of the thermal insulation meaning that there is potential for air to move in to the insulated structural cavity resulting in condensation risk. The system's flexible air control layer is reliant on seam tapes to achieve airtightness. This can be compromised in high wind zones.
Heat control layer. The same thermal discontinuities are present as in Walls 1-3. The air space behind the EPS insulation layer will provide minimal thermal benefit to the system.

Vapour control layer. No evidence of vapour control. It is not clear how the air space is ventilated (see soffit) so there is potential for vapour to accumulate within the air space. 
wall five
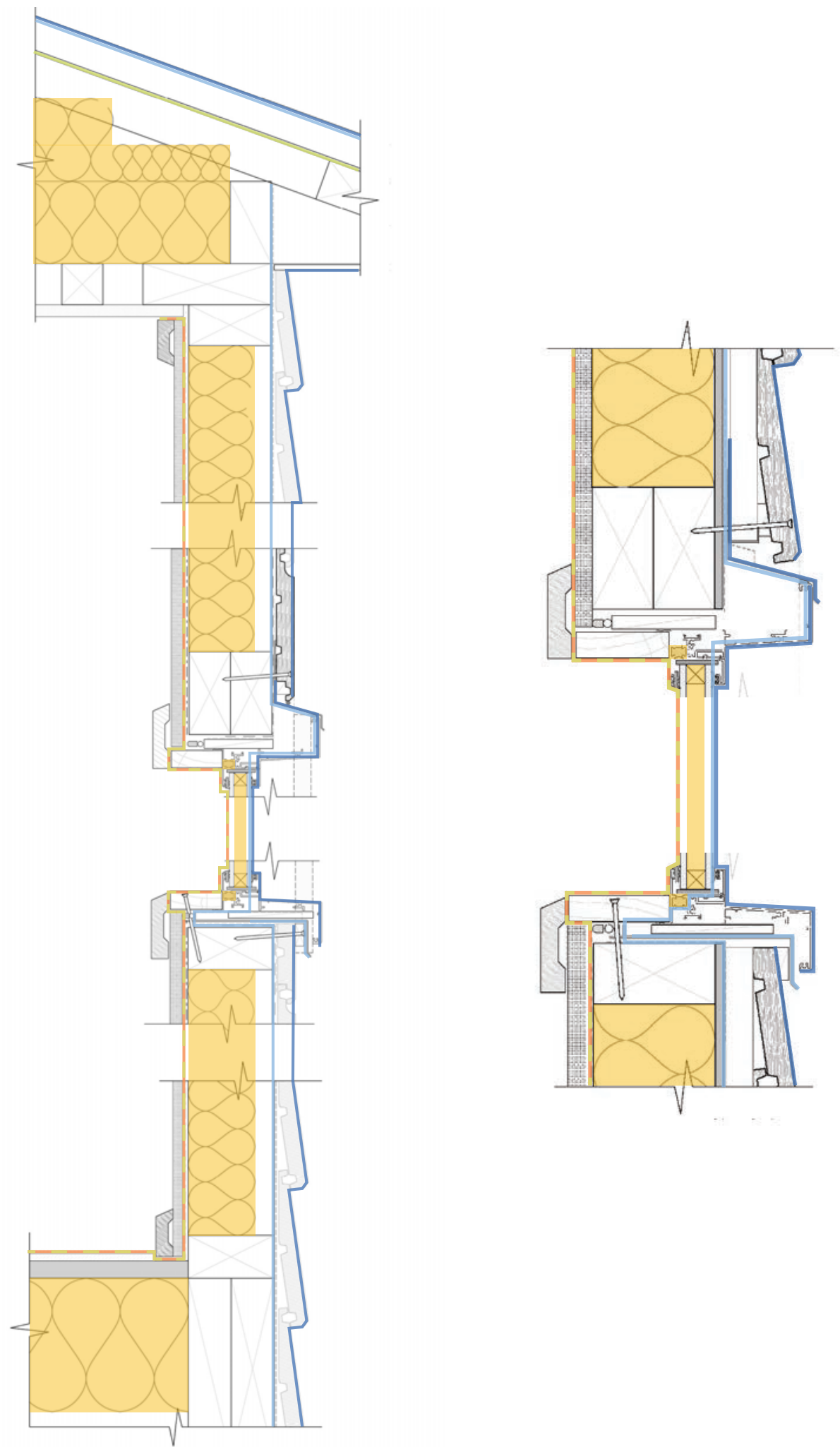

Figure 3.24. Wall five, typical NZ facade design with internal air and vapour control. Public View Building Information, Search, Hutt City Council, 2020. 
Control layer identification. All control layers are present.

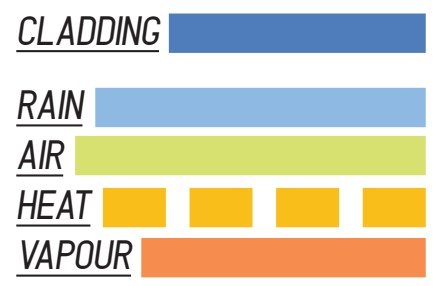

This wall reflects typical New Zealand wall construction with the addition of air and vapour control layers installed on the interior. It is comprised of gypsum board interior lining, mechanically attached membrane taped at joins, timber framing structure, fiberglass cavity insulation and a fibre cement rigid air barrier taped at joins. $20 \mathrm{~mm}$ timber cavity battens are then installed over the rigid air barrier followed by the mechanical attachment of the timber weatherboard cladding through the batten and into the structural timber frame.

Rain control layer. As per walls 1-3 but with the additional of a sill tray flashing to manage water penetration beyond cladding and drain it to the exterior as well as sloping end dams and $8 \mathrm{~mm}$ upstand.

Air control layer Air control exists at both the interior and exterior. It is achieved internally through the installation of a flexible membrane mechanically attached to timber framing prior the installation of the gypsum board interior lining. Air control in this location mitigates condensation risk within the insulated structural cavity as moisture in the air cannot move into the assembly where it has the potential to contact a colder exterior surface and condensate. As stated in chapter 2, continuity of air control is crucial. From a buildability perspective interior air control continuity is difficult. For example, power sockets, pipe penetrations, internal wall junctions and other services create penetrations within the membrane that then have to be flashed and joined to create continuity. This has become so problematic from a buildability/detailing perspective that many wall designs incorporating an internal air/ vapour control layer now include an additional framed services cavity internally to protect the control layer. The presence of air control on both sides of the wall assembly also prevents drying of the structural cavity. If moisture was to appear in the cavity it would not be able to dry out.

Heat control layer. Thermal bridges exist along every stud line and wall to roof junction. The window glazing is thermally broken and set back into the thermal control layer increasing thermal performance.

Vapour control layer. A 'smart' vapour control layer is installed on the interior of the wall assembly. The idea of 'smart' vapour control layers is that they retard the entry of vapour during winter but allow the assembly to dry out during summer. The permeance of the 'smart' vapour control layer changes when exposed to different relative humidities. When it is more humid they are more permeable and when its less humid they are less permeable. In winter, when interior vapour resistance is desirable, if the interior is 'too' humid the 'smart' membrane may not provide the necessary resistance. Interior environments are always changing in relative humidity due to household activities like showering, cooking and washing which all add moisture into the air. 
wall six

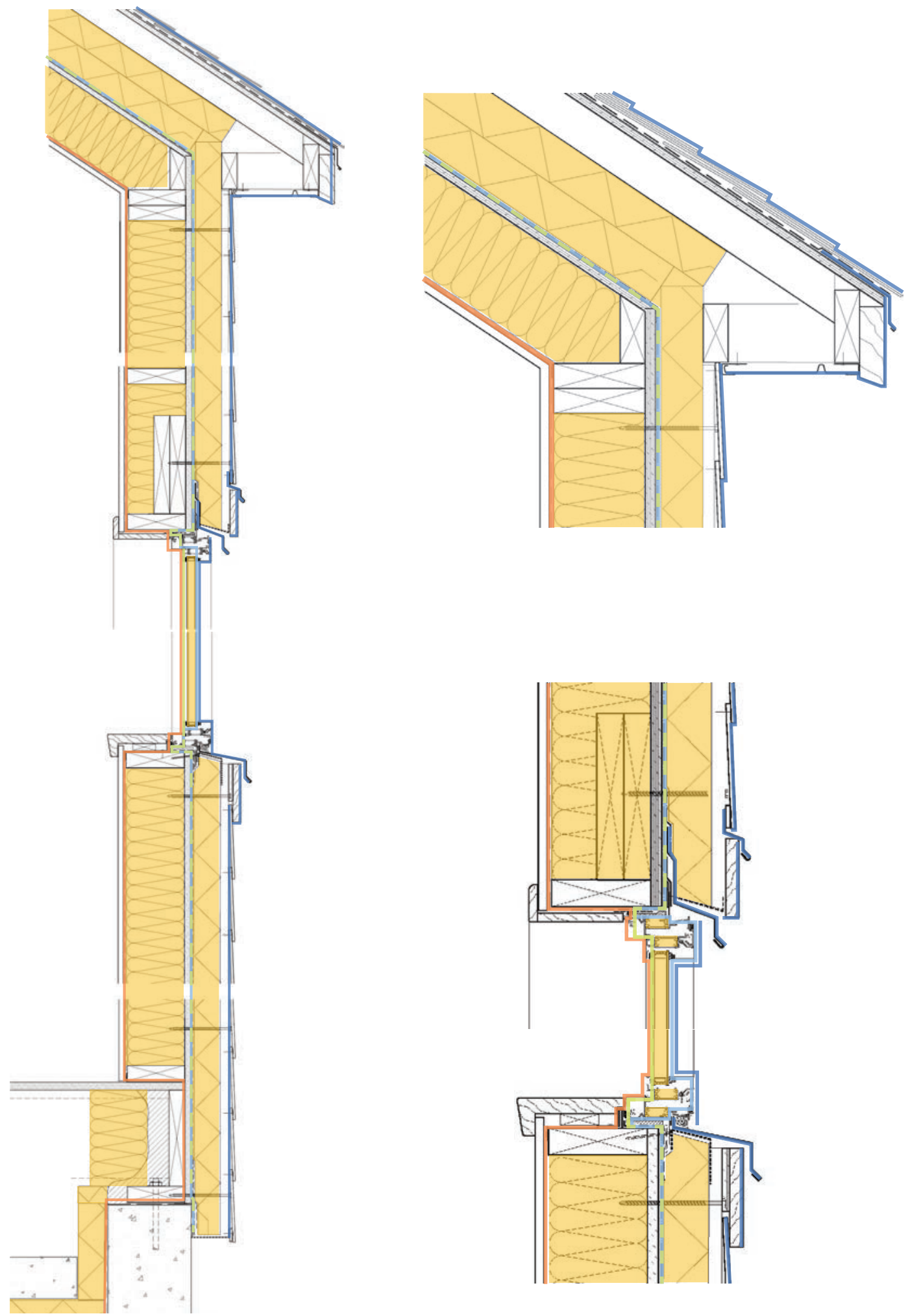

Figure 3.25. Wall 6, high performance wall facade. Rockwool wood frame construction up to 4 storeys construction details, Rockwool, 2029. 
Control layer identification. All control layers shown and continuous.

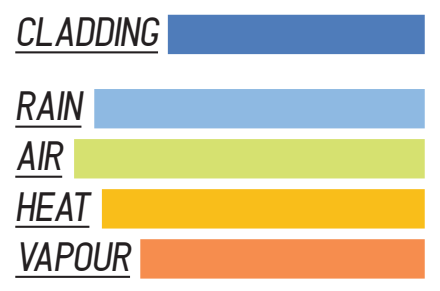

This wall represents a high-performance assembly in respect to building science in that consideration has been given to each of the four crucial control layers. The wall is comprised of interior gypsum lining, an interior vapour control layer, timber framing with rock fibre cavity insulation, plywood exterior sheathing with an air and water resistant barrier, $65 \mathrm{~mm}$ of exterior rigid rock fibre insulation, $18 \mathrm{~mm}$ cavity followed by light weight horizontal cladding.

Rain control layer. The water-resistant barrier with appropriate flashing tapes to the exterior face of the plywood provides continuous rain control and forms the drainage plane. There is continuity of this rain control at the junction between the wall and roof.

Air control layer. Air control exists both on the interior side and exterior side of the structure. Air control is kept continuous at the wall to roof junction. As explained in relation to Wall 5 , maintaining continuity of the interior air control layer is difficult. Leaks or gaps within the interior air control layer could create a condensation risk if moisture in the air was to move into the structural cavity. This is because there is less thermal resistance on the exterior (65mm rock fibre) compared to the thermal resistance with the structural cavity $(140 \mathrm{~mm}$ rock fibre).
Heat control layer. The insulation is continuous at both the wall to roof junction and wall base due to the use of exterior insulation. Windows are thermally broken and sit within the geometry of the thermal control layer. The exterior insulation eliminates the risk of condensation within the structural cavity. The nature of rock fibre means it is not sensitive to moisture.

Vapour Control Layer. The vapour control layer is on the interior side of the structure limiting the movement of vapour into the structural cavity. 


\section{5 hygrothermal comparison}

Overview. Determining how assemblies behave in response to moisture (hygro) and heat flow (thermal) is a challenging task. A hygrothermal analysis can be used to establish condensation and mould risk within building envelope assemblies. This has been done as a way of comparing different assemblies.

\section{A typical pre-1978 New Zealand wall, a typical New} Zealand wall of today, and the proposed wall assembly are analysed and contrasted. The typical wall assemblies that are analysed are constructed in line with the walls that were critiqued in chapter 3.3. The proposed wall assembly consists of internal gypsum board lining, timber framing, Class II vapour control layer to the outside of the framing (providing rain, air and vapour control), rigid rock fibre insulation, airspace and metal cladding.

Comparative hygrothermal analysis is also conducted on a typical New Zealand roof assembly and compared with the proposed roof assembly. The typical roof assembly is comprised of internal gypsum board lining, timber purlins within infill insulation, airspace, roof underlay and metal roof cladding. The proposed roof assembly consists of plywood substrate, Class I vapour control layer, high density rock fibre insulation, roof underlay, and metal roof cladding.

The comparisons are not intended to be definitive proof that one particular system works and another doesn't but are intended to establish what causes a wall or roof assembly to perform differently from a hygrothermal perspective. The comparison is helpful in graphically explaining the building envelope science literature reviewed in chapter 2 and how it applies to the hygrothermal performance of the building envelope.
Interstitial condensation and mould growth. Interstitial condensation occurs when water vapour moving through the building envelope comes into contact with a material which is below the dew point of the water vapour. Mould growth can be stimulated when humidity is $80 \%$ or more. (Knaack \& Koenders, 2018). Mould growth and interstitial condensation can cause deterioration to different layers of the building envelope and an unhealthy internal environment.

Code Requirements. The New Zealand Building Code (NZBC) does not give methods for determining interstitial condensation. E3 'Internal Moisture' does state that buildings must be constructed in a way to avoid the likelihood of fungal growth and damage to building elements caused by the presence of moisture.

Simulation inputs. The comparison includes both a static model (JPA Designer) and dynamic model (WUFI). While WUFI can more accurately reflect the exterior environmental conditions, both models are limited in how they reflect the interior conditions. In building envelopes with air control the water vapour released and generated by the occupant (for example, by respiration and transpiration, cooking and washing, showering and bathing and from house plants) will contribute to the overall humidity. This will mean, in the absence of ventilation, that the indoor relative humidity can become high, especially in winter (Pro Clima, 2011). This results in high water vapour pressure acting on the wall assembly as the humid air pushes to the outside. Because the interior environment is constantly subject to change it is virtually impossible to simulate an accurate indoor environment over a period of time.

For the JPA designer comparison, material properties 


\section{JPA Designer hygrothermal comparison}

and climate data are used as inputs. The material layer properties are shown in the following tables. The JPA model evaluates a summer and winter condition. The limitation to this is that the changing environmental conditions which occur throughout the year are not taken into consideration.

The internal temperature is set at $18^{\circ} \mathrm{C}$ as this is the recommended minimum indoor temperature by WHO (The World Health Organisation.) Recommended indoor humidity's are between $40-60 \%$ so the indoor relative humidity is set at $60 \%$ as the worst-case scenario. The internal environmental data is used for the winter and summer analysis.

It should be noted that high indoor humidity levels are common in New Zealand homes with levels over $60 \%$ RH often reached (see chapter 2). It should be assumed that indoor humidity higher than $60 \%$ would produce worse results. It is also unrealistic to assume all New Zealand homes are kept at $18^{\circ} \mathrm{C}$ (see chapter 2). A lower internal temperature further increases the indoor relative humidity.

Outdoor temperatures were determined by the lower average monthly temperatures in Wellington as the worst-case scenario. The average low temperature for winter is $7^{\circ} \mathrm{C}$ (average low for July) and the average low temperature for summer is $14^{\circ} \mathrm{C}$ (average low for January) (Weather Spark, 2020). The outdoor humidity inputs correspond to the average outdoor humidity in Wellington for July (86.3\%) and January (81\%) (NIWA, 2020). It is important to use the lower average temperature to ensure the proposed wall construction performs in all possible conditions.
The JPA software provides two graphs, one for summer and one for winter. The graphs contain a visual representation of the materials, which are numbered, and the numbers correspond with the material layer property tables. Each graph contains a red and blue line. The red line represents the surface temperature and the blue line represents the dew point temperature. If these two lines touch, condensation forms. If condensation does form the output will also state the amount of condensation built up over a 60-day period.

All materials are taken from the JPA database with the exception of the metal cladding. The metal cladding layer assumes a gap of $0.3 \mathrm{~mm}$ at each lap joint (Latona \& Pinon, 2013). This ensures vapour permeability of the layer within the simulation which would be the case in reality.

The calculations were done using JPA Designer version $6.04 \mathrm{a} 1$, developed by JPA TL Ltd based in the United Kingdom.

Winter creates the most extreme difference between the indoor and outdoor environments and the highest risk of condensation. For this reason graphs for winter have been discussed.

\begin{tabular}{l|c|c} 
Wellington & $\begin{array}{c}\text { Average Low } \\
\text { Temperature }\left({ }^{\circ} \mathrm{C}\right)\end{array}$ & $\begin{array}{c}\text { Average Relative } \\
\text { Humidity (\%) }\end{array}$ \\
\hline Summer & 14 & 81 \\
\hline Winter & 7 & 86.3
\end{tabular}

Table 3.1. Climate data used in JPA hygrothermal comparison. NIWA \& Weather Spark, 2020. 


\section{рге 1978 uninsulated wall}

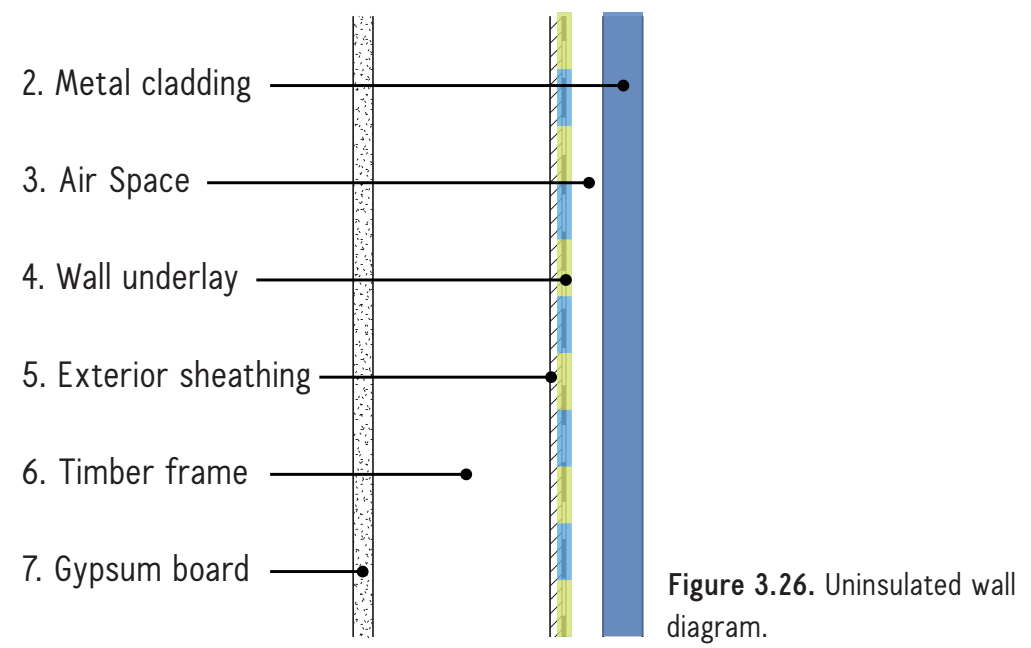

\begin{tabular}{l|l|l|l|l|l}
\multicolumn{1}{c|}{ Material Layer } & $\begin{array}{c}\text { Thickness } \\
(\mathrm{mm})\end{array}$ & $\begin{array}{c}\text { Thermal } \\
\text { Conductivity } \\
(\mathrm{W} / \mathrm{mk})\end{array}$ & $\begin{array}{c}\text { Thermal } \\
\text { Resistance } \\
\left(\mathrm{m}^{2} \mathrm{~K} / \mathrm{W}\right)\end{array}$ & $\begin{array}{c}\text { Vapour } \\
\text { Resistivity } \\
(\text { MNs/gm })\end{array}$ & $\begin{array}{c}\text { Vapour } \\
\text { Resistance } \\
(\text { MNs/g) }\end{array}$ \\
\hline 1. External surface resistance & - & - & 0.040 & - & - \\
\hline 2. Metal Cladding (vapour gaps) & 0.6 & 3.003 & 0.000 & 1.67 & 0.001 \\
\hline 3. Air Space & 20 & - & 0.180 & - & 0.00 \\
\hline 4. Wall Underlay & 1.0 & - & - & 2500 & 2.5 \\
\hline 5. Plywood $\left(700 \mathrm{~kg} / \mathrm{m}^{3}\right)$ & 7.0 & 0.170 & 0.041 & 1100.00 & 7.70 \\
\hline 6. Timber framing & 90 & - & 0.180 & - & 0.001 \\
\hline 7. Gypsum board $\left(700 \mathrm{~kg} / \mathrm{m}^{3}\right)$ & 10 & 0.210 & 0.048 & 50.00 & 0.50 \\
\hline 8. Internal surface resistance & - & - & 0.040 & - & - \\
\hline Total thickness & 128.6 & & & &
\end{tabular}

Table 3.2. Material properties used in JPA Designer simulation of pre 1978 uninsulated wall.

- No account is taken for thermal bridges. The timber frame is modelled as a clear cavity.

- Metal cladding is assumed to have vapour gaps of $0.3 \mathrm{~mm}$ as each lap. (Latona \& Pinon, 2013). As the cladding comes after an air space, the vapour permeability of the cladding effectively becomes redundant in the calculation.

- All values are taken from the JPA database unless stated otherwise. 


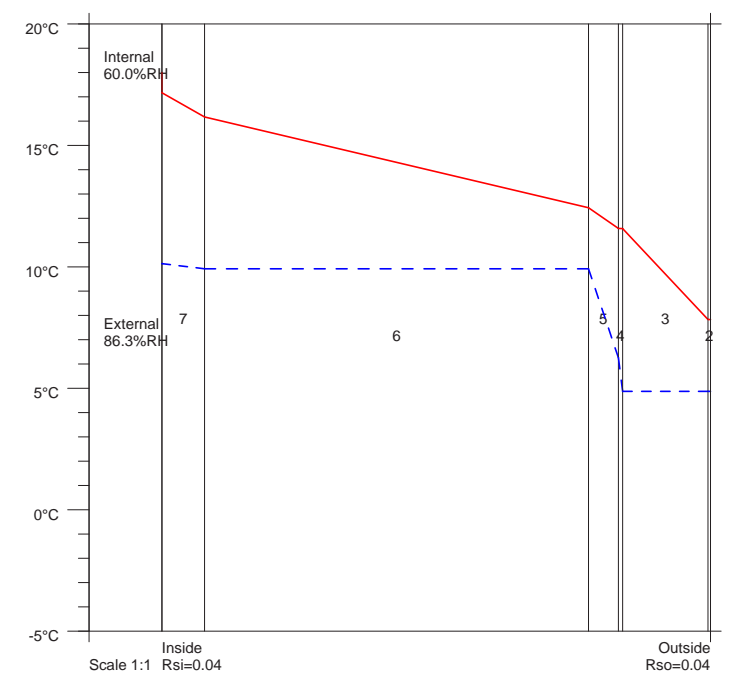

Figure 3.27. Uninsulated wall condensation risk analysis graph in winter.

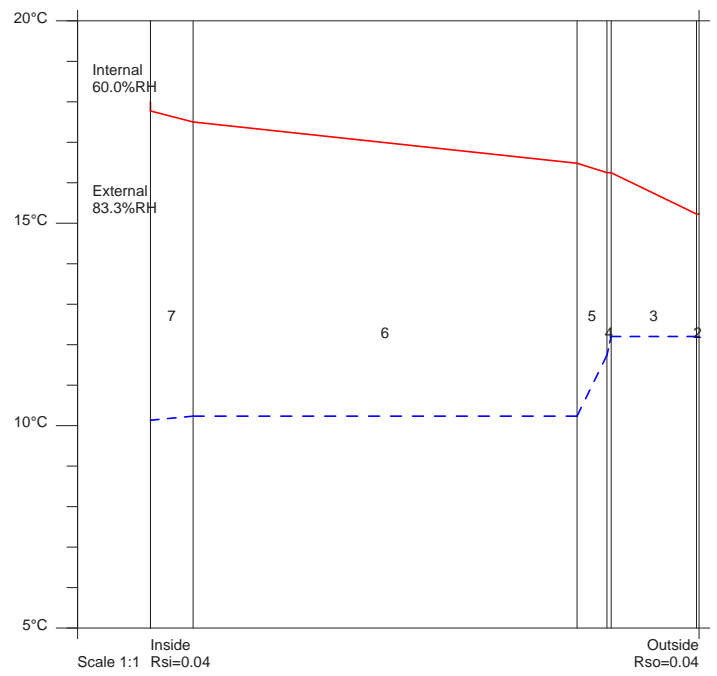

Figure 3.28. Uninsulated wall condensation risk analysis graph in summer.

Condensation Risk Analysis (no account taken of thermal bridges)

Internal / External Conditions : $18.0^{\circ} \mathrm{C} @ 60.0 \% \mathrm{RH} / 7.0^{\circ} \mathrm{C} @ 86.3 \% \mathrm{RH}$ Buildup period 60 days

\begin{tabular}{|c|c|c|c|c|c|c|c|}
\hline & $\begin{array}{l}\text { Interface } \\
\text { Temp. } \\
\text { oc }\end{array}$ & $\begin{array}{l}\text { Dewpoint } \\
\text { Temp. } \\
\text { oc }\end{array}$ & $\begin{array}{l}\text { Vapour } \\
\text { Pressure } \\
\text { (kPa) }\end{array}$ & $\begin{array}{l}\text { Saturated } \\
\text { V.P. } \\
\text { (kPa) }\end{array}$ & $\begin{array}{l}\text { Winter } \\
\text { Buildup } \\
\left(\mathrm{g} / \mathrm{m}^{2}\right)\end{array}$ & $\begin{array}{l}\text { Annual } \\
\text { Buildup } \\
\left(\mathrm{g} / \mathrm{m}^{2}\right)\end{array}$ & $\begin{array}{l}\text { Conden- } \\
\text { sation }\end{array}$ \\
\hline $\begin{array}{l}1 \text { Outside surface resistance } \\
2 \text { Metal Cladding (with vapour gaps) } \\
3 \text { Air Space } \\
4 \text { Wall Underlay } \\
5 \text { Plywood }\left(700 \mathrm{~kg} / \mathrm{m}^{3}\right) \\
690 \mathrm{~mm} \text { Timber Frame } \\
7 \text { Gypsum plasterboard }\left(700 \mathrm{~kg} / \mathrm{m}^{3}\right) \\
8 \text { Inside surface resistance }\end{array}$ & $\begin{array}{l}7.8 \\
7.8 \\
11.6 \\
11.6 \\
12.4 \\
16.2 \\
17.2\end{array}$ & $\begin{array}{r}4.9 \\
4.9 \\
4.9 \\
6.3 \\
9.9 \\
9.9 \\
10.1\end{array}$ & $\begin{array}{l}0.86 \\
0.86 \\
0.86 \\
0.95 \\
1.22 \\
1.22 \\
1.24\end{array}$ & $\begin{array}{l}1.06 \\
1.06 \\
1.36 \\
1.36 \\
1.44 \\
1.84 \\
1.96\end{array}$ & 要 & 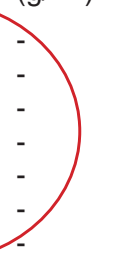 & $\begin{array}{l}\text { No } \\
\text { No } \\
\text { No } \\
\text { No } \\
\text { No } \\
\text { No } \\
\text { No }\end{array}$ \\
\hline
\end{tabular}

Figure 3.29. Condensation risk analysis. No risk of condensation.

Pre 1978 uninsulated wall. As seen in the graphs above, the two lines don't touch and the output indicates there is no condensation. Hygrothermally, a claim could be made that the wall performs well (although obviously it does not perform well in respect to thermal comfort). The uninsulated wall can dry out in both directions. As there is no insulation, the surface temperature line and dew point temperature line stay relatively straight within the framing cavity. The blue line (dew point temperature) drops at the plywood layer as this is acting as the air control layer. Humidity is different on either side of the air control layer therefore different dew point temperatures also exist on either side of the air control layer. The red line (surface temperature) gradually declines throughout the assembly as the air cools down and then it drops steeply as it reaches the cavity and is quickly cooled by the outside air conditions. The red line (surface temperature) stays above the blue line (dew point temperature) avoiding risk of interstitial condensation. 


\section{typical New Zealand wall}

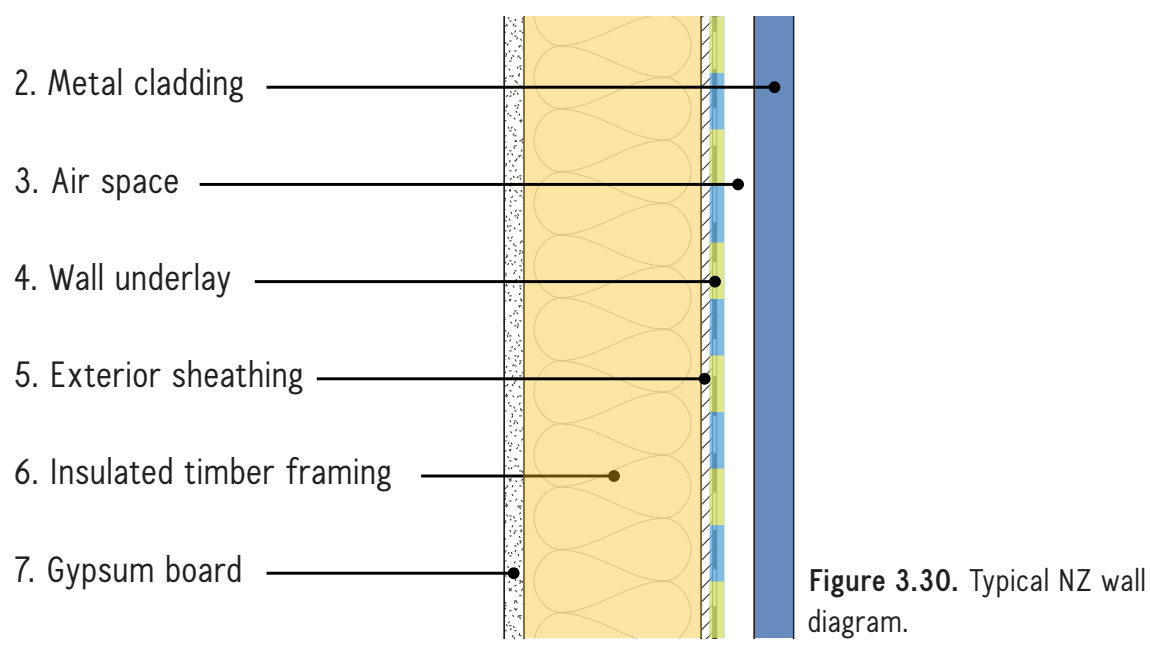

\begin{tabular}{l|l|l|l|l|l}
\multicolumn{1}{c|}{ Material Layer } & $\begin{array}{c}\text { Thickness } \\
(\mathrm{mm})\end{array}$ & $\begin{array}{c}\text { Thermal } \\
\text { Conductivity } \\
(\mathrm{W} / \mathrm{mk})\end{array}$ & $\begin{array}{c}\text { Thermal } \\
\text { Resistance } \\
\left(\mathrm{m}^{2} \mathrm{~K} / \mathrm{W}\right)\end{array}$ & $\begin{array}{c}\text { Vapour } \\
\text { Resistivity } \\
(\text { MNs/gm })\end{array}$ & $\begin{array}{c}\text { Vapour } \\
\text { Resistance } \\
(\text { MNs/g })\end{array}$ \\
\hline 1 External surface resistance & - & - & 0.040 & - & - \\
\hline 2 Metal cladding (vapour gaps) & 0.6 & 3.003 & 0.000 & 1.670 & 0.001 \\
\hline 3 Air space & 20 & - & 0.180 & - & 0.00 \\
\hline 4 Wall underlay & 1.0 & - & - & 2500 & 2.5 \\
\hline 5 Plywood $\left(700 \mathrm{~kg} / \mathrm{m}^{3}\right)$ & 7.0 & 0.170 & 0.041 & 1100.00 & 7.70 \\
\hline 6 Insulated timber frame & 90 & 0.043 & 2.10 & 5.00 & 0.45 \\
\hline 7 Gypsum board $\left(700 \mathrm{~kg} / \mathrm{m}^{3}\right)$ & 10 & 0.210 & 0.048 & 50.00 & 0.50 \\
\hline 8 Internal surface resistance & - & - & 0.040 & - & - \\
\hline Total thickness & 128.6 & & & &
\end{tabular}

Table 3.3. Material properties used in JPA Designer simulation of typical NZ wall.

- No account is taken for thermal bridges. Timber frame is modelled as equivalent to the cavity insulation.

- Metal cladding is assumed to have vapour gaps of $0.3 \mathrm{~mm}$ as each lap (Latona \& Pinon, 2013).
As the cladding comes after an air space, the vapour permeability of the cladding effectively becomes redundant in the calculation.

- All values are taken from the JPA database unless stated otherwise. 


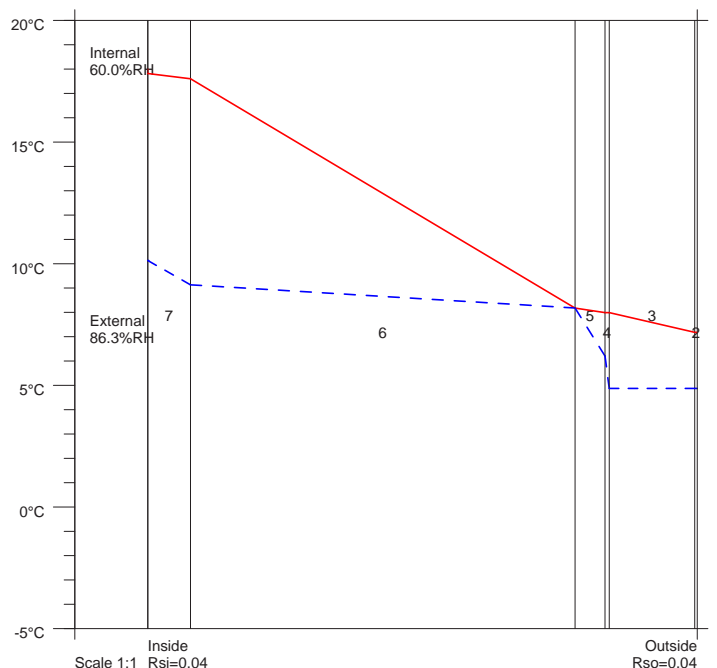

Figure 3.31. Typical NZ wall condensation risk analysis graph in winter.

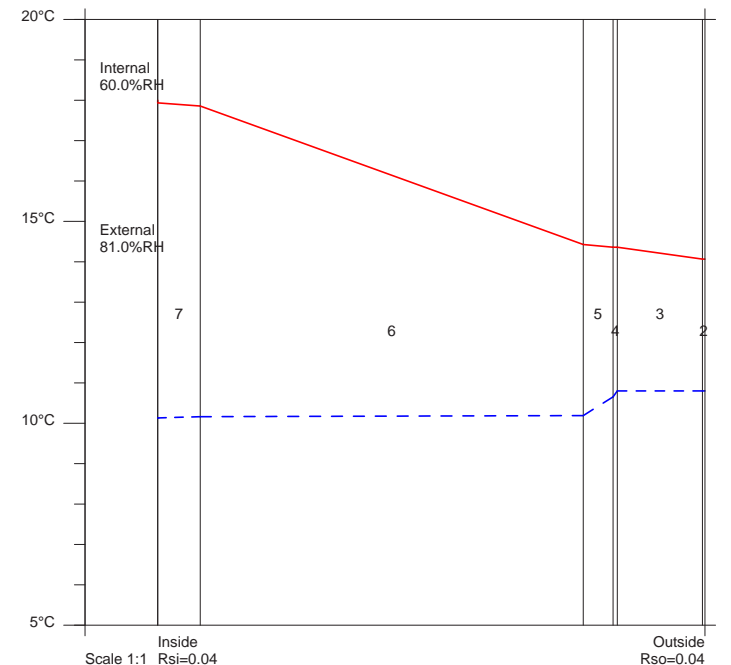

Figure 3.32. Typical NZ wall condensation risk analysis graph in summer.

Condensation Risk Analysis (no account taken of thermal bridges)

Internal / External Conditions : $18.0^{\circ} \mathrm{C} @ 60.0 \% \mathrm{RH} / 7.0^{\circ} \mathrm{C} @ 86.3 \% \mathrm{RH}$ Buildup period 60 days

\begin{tabular}{|c|c|c|c|c|c|c|}
\hline $\begin{array}{l}\text { Interface } \\
\text { Temp. } \\
\text { oc }\end{array}$ & $\begin{array}{l}\text { Dewpoint } \\
\text { Temp. } \\
\text { oC }\end{array}$ & $\begin{array}{l}\text { Vapour } \\
\text { Pressure } \\
\text { (kPa) }\end{array}$ & $\begin{array}{l}\text { Saturated } \\
\text { V.P. } \\
\text { (kPa) }\end{array}$ & $\begin{array}{l}\text { Winter } \\
\text { Buildup } \\
\left(\mathrm{g} / \mathrm{m}^{2}\right)\end{array}$ & $\begin{array}{l}\text { Annual } \\
\text { Buildup } \\
\left(\mathrm{g} / \mathrm{m}^{2}\right)\end{array}$ & $\begin{array}{l}\text { Conden- } \\
\text { sation }\end{array}$ \\
\hline $\begin{array}{l}7.2 \\
7.2 \\
8.0 \\
8.0 \\
8.2 \\
17.6 \\
17.8\end{array}$ & $\begin{array}{r}4.9 \\
4.9 \\
4.9 \\
6.2 \\
8.2 \\
9.1 \\
10.1\end{array}$ & $\begin{array}{l}0.86 \\
0.86 \\
0.86 \\
0.95 \\
1.09 \\
1.16 \\
1.24\end{array}$ & $\begin{array}{l}1.01 \\
1.01 \\
1.07 \\
1.07 \\
1.09 \\
2.01 \\
2.04\end{array}$ & - & $\begin{array}{ll}- & \\
- & \\
- & \\
& -1666 \\
- & \end{array}$ & $\begin{array}{l}\text { No } \\
\text { No } \\
\text { No } \\
\text { No } \\
\text { Yes } \\
\text { No } \\
\text { No }\end{array}$ \\
\hline
\end{tabular}

1 Outside surface resistance

2 Metal Cladding (with vapour gaps) 7.2

3 Air Space

4 Wall Underlay

5 Plywood $\left(700 \mathrm{~kg} / \mathrm{m}^{3}\right)$

$690 \mathrm{~mm}$ Insulated Timber Frame

7 Gypsum Plasterboard $\left(700 \mathrm{~kg} / \mathrm{m}^{3}\right) \frac{17.6}{17.8}$

8 Inside surface resistance

Figure 3.33. Condensation risk analysis. Condensation is present.

Typical NZ Wall. The cavity insulation provides thermal resistance. This is seen in the graph as the red line (surface temperature) gradually declines throughout the insulation layer. As warm air from the inside moves through the insulation it cools down. While the red line (surface temperature) gradually declines throughout the insulation, the blue line (dew point temperature) stays consistent. The blue line (dew point temperature) drops rapidly at the sheathing as this is the air control layer where indoor and outdoor humidity's are separated. As the warm air moves through the insulation its temperature drops from $17.8^{\circ} \mathrm{C}$ to $8.9^{\circ} \mathrm{C}$ yet the dew point temperature only drops $1^{\circ} \mathrm{C}$. The red line (surface temperature) and blue line (dew point temperature) touch at the interior face of the sheathing. At this location the dew point temperature remains similar to that of the internal environment, however, the surface temperature has significantly dropped. As the cooled (but relatively humid) air contacts the sheathing it condenses forming liquid water. It is the location of envelope layers within the wall system that causes the condensation risk. The location of the air control layer within the assembly is important to consider in order to mitigate condensation risk. 
proposed wall assembly

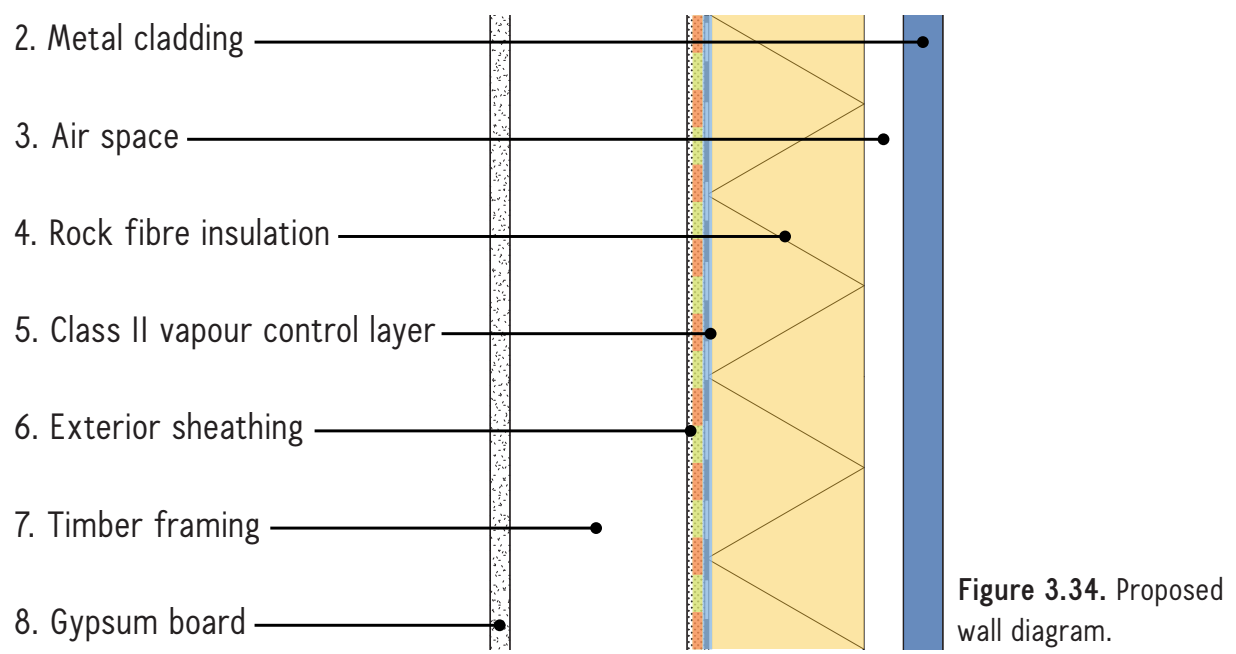

\begin{tabular}{l|l|l|l|l|l} 
Material Layer & \multicolumn{1}{|c|}{$\begin{array}{c}\text { Thickness } \\
(\mathrm{mm})\end{array}$} & $\begin{array}{c}\text { Thermal } \\
\text { Conductivity } \\
(\mathrm{W} / \mathrm{mk})\end{array}$ & $\begin{array}{c}\text { Thermal } \\
\text { Resistance } \\
\left(\mathrm{m}^{2} \mathrm{~K} / \mathrm{W}\right)\end{array}$ & $\begin{array}{c}\text { Vapour } \\
\text { Resistivity } \\
(\text { MNs/gm })\end{array}$ & $\begin{array}{c}\text { Vapour } \\
\text { Resistance } \\
(\text { MNs/g) }\end{array}$ \\
\hline 1 External surface resistance & - & - & 0.040 & - & - \\
\hline 2 Metal cladding (vapour gaps) & 0.6 & 3.003 & 0.000 & 1.670 & 0.001 \\
\hline 3 Air space & 20 & - & 0.180 & - & 0.00 \\
\hline 4 Rock fibre insulation & 80 & 0.036 & 2.200 & 5.00 & 0.40 \\
\hline 5 class II vapour control layer & 1.0 & - & - & 17500 & 17.5 \\
\hline 6 Exterior gypsum board & 12 & 0.210 & 0.057 & 50.00 & 0.60 \\
\hline 7 Timber framing & 90 & - & 0.180 & - & 0.001 \\
\hline 8 Gypsum board & 10 & 0.210 & 0.048 & 50.00 & 0.50 \\
\hline 9 Internal surface resistance & - & - & 0.040 & - & - \\
\hline Total thickness & 213.6 & & & &
\end{tabular}

Table 3.4. Material properties used in JPA Designer simulation of proposed wall.

- No account is taken for thermal bridges. Timber frame is modelled as a clear cavity.

- Metal cladding is assumed to have vapour gaps Of $0.3 \mathrm{~mm}$ as each lap (Latona \& Pinon, 2013). As the cladding comes after an air space, the vapour permeability of the cladding effectively becomes redundant in the calculation.

- All values are taken from the JPA database unless stated otherwise. 


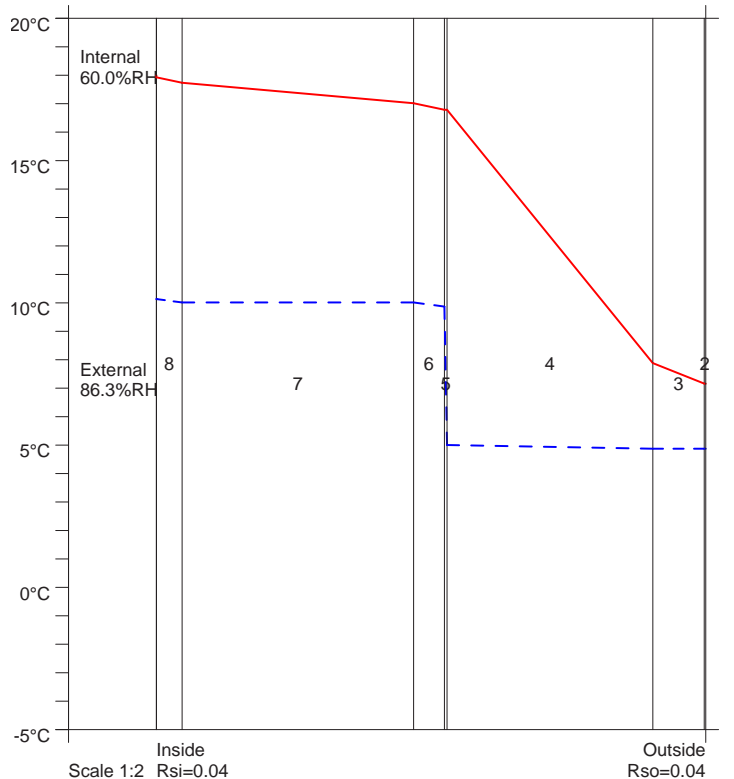

Figure 3.35. Proposed wall condensation risk analysis graph in winter.

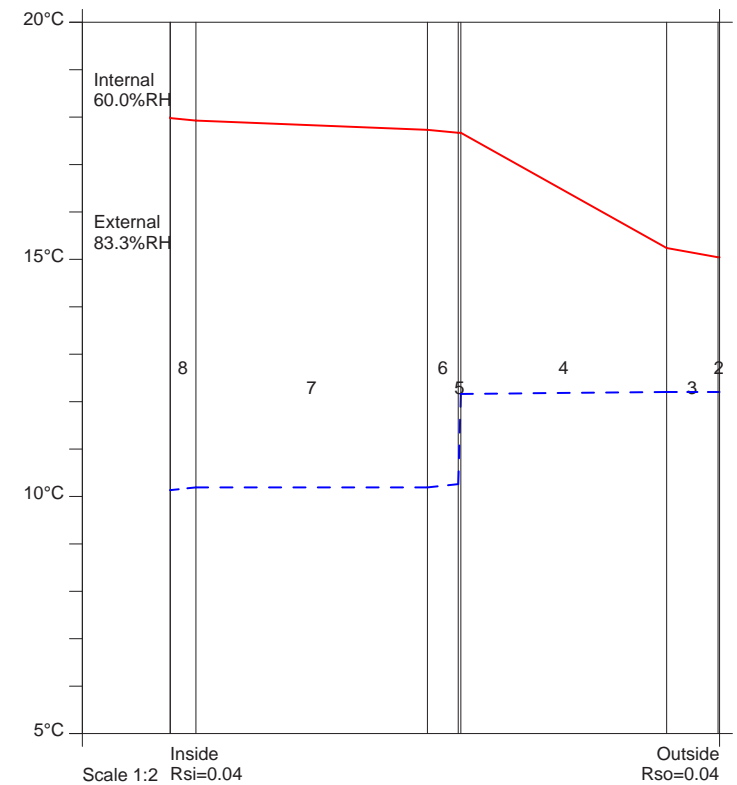

Figure 3.36. Proposed wall condensation risk analysis graph in summer.

\section{Condensation Risk Analysis (no account taken of thermal bridges)}

Internal / External Conditions : $18.0^{\circ} \mathrm{C} @ 60.0 \% \mathrm{RH} / 7.0^{\circ} \mathrm{C} @ 86.3 \% \mathrm{RH}$ Buildup period 60 days

\begin{tabular}{|c|c|c|c|c|c|c|c|}
\hline & $\begin{array}{l}\text { Interface } \\
\text { Temp. } \\
\text { oC }\end{array}$ & $\begin{array}{l}\text { Dewpoint } \\
\text { Temp. } \\
\text { oC }\end{array}$ & $\begin{array}{l}\text { Vapour } \\
\text { Pressure } \\
(\mathrm{kPa})\end{array}$ & $\begin{array}{l}\text { Saturated } \\
\text { V.P. } \\
(\mathrm{kPa})\end{array}$ & $\begin{array}{l}\text { Winter } \\
\text { Buildup } \\
\left(\mathrm{g} / \mathrm{m}^{2}\right)\end{array}$ & $\begin{array}{l}\text { Annual } \\
\text { Buildup } \\
\left(\mathrm{g} / \mathrm{m}^{2}\right)\end{array}$ & $\begin{array}{l}\text { Conden- } \\
\text { sation }\end{array}$ \\
\hline $\begin{array}{l}1 \text { Outside surface resistance } \\
2 \text { Metal Cladding (with vapour gaps) } \\
3 \text { Air Space } \\
4 \text { Rock Fibre Insulation } \\
5 \text { Class II vapour control layer } \\
6 \text { Gypsum Plasterboard }\left(700 \mathrm{~kg} / \mathrm{m}^{3}\right) \\
790 \mathrm{~mm} \text { Timber F rame } \\
8 \text { Gypsum Plasterboard }\left(700 \mathrm{~kg} / \mathrm{m}^{3}\right) \\
9 \text { Inside surface resistance }\end{array}$ & $\begin{array}{l}7.2 \\
7.2 \\
7.9 \\
16.8 \\
16.8 \\
17.0 \\
17.7 \\
17.9\end{array}$ & $\begin{array}{r}4.9 \\
4.9 \\
4.9 \\
5.0 \\
9.9 \\
10.0 \\
10.0 \\
10.1\end{array}$ & $\begin{array}{l}0.86 \\
0.86 \\
0.86 \\
0.87 \\
1.22 \\
1.23 \\
1.23 \\
1.24\end{array}$ & $\begin{array}{l}1.01 \\
1.01 \\
1.06 \\
1.91 \\
1.91 \\
1.94 \\
2.03 \\
2.05\end{array}$ & - & - & $\begin{array}{l}\text { No } \\
\text { No } \\
\text { No } \\
\text { No } \\
\text { No } \\
\text { No } \\
\text { No } \\
\text { No }\end{array}$ \\
\hline
\end{tabular}

Figure 3.37. Condensation risk analysis. Condensation is present.

Proposed Wall Concept. The perfect wall has all control layers on the outside of the timber framing. Changes to the red line (surface temperature) and blue line (dew point temperature) occur on the outside of the timber framing. This means there is no condensation risk within the framing cavity. The key difference between this wall and the typical wall is that the blue line (dew point temperature) rapidly drops before the red line (surface temperature) declines. The dew point temperature line drops at the self-adhered membrane (the air and vapour control layer) where interior and exterior humidity's are effectively separated. The red line (surface temperature) declines after the blue line (dew point temperature) has dropped, eliminating the risk of the two lines touching. As the thermal resistance (insulation) is located on the outside of the air control layer the dew point temperature and surface temperature can only meet outside the timber structure. The condensing surface (the sheathing) is kept above the dew point of the interior air. 


\section{typical New Zealand roof}

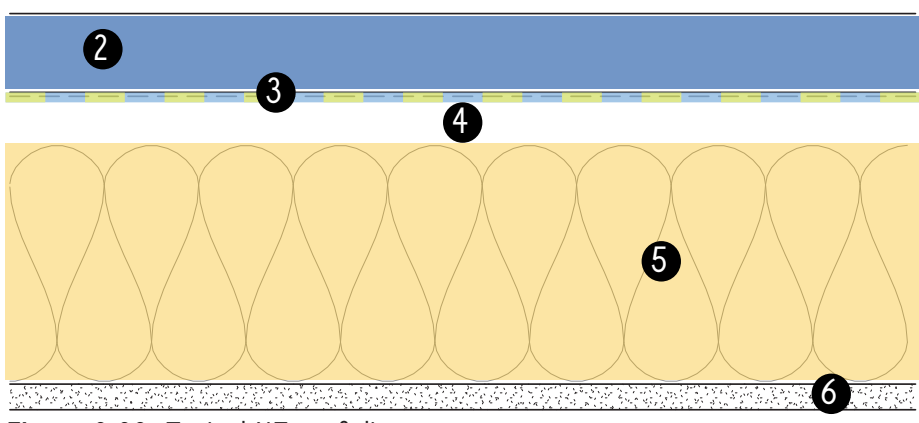

Figure 3.38. Typical NZ roof diagram.
2. Metal cladding

3. Roof underlay

4. Air space

5. Insulation (between timber purlins)

6. Gypsum board

\begin{tabular}{l|l|l|l|l|l}
\multicolumn{1}{c|}{ Material Layer } & $\begin{array}{c}\text { Thickness } \\
(\mathrm{mm})\end{array}$ & $\begin{array}{c}\text { Thermal } \\
\text { Conductivity } \\
(\mathrm{W} / \mathrm{mk})\end{array}$ & $\begin{array}{r}\text { Thermal } \\
\text { Resistance } \\
\left(\mathrm{m}^{2} \mathrm{~K} / \mathrm{W}\right)\end{array}$ & $\begin{array}{r}\text { Vapour } \\
\text { Resistivity } \\
(\text { MNs/gm) }\end{array}$ & $\begin{array}{c}\text { Vapour } \\
\text { Resistance } \\
(\text { MNs/g) }\end{array}$ \\
\hline 1 External surface resistance & - & - & 0.040 & - & - \\
\hline 2 Metal cladding (vapour gaps) & 0.6 & 3.003 & 0.000 & 111667 & 67.00 \\
\hline 3 Roof underlay & 1.0 & - & - & 1000 & 1.00 \\
\hline 4 Air space & 25.0 & - & 0.160 & - & 0.00 \\
\hline 5 Insulation (between purlins) & 120.0 & 0.043 & 2.750 & 5.00 & 0.60 \\
\hline 6 Gypsum board (700kg/m³) & 13.0 & 0.210 & 0.062 & 50.00 & 0.65 \\
\hline 7 Internal surface resistance & - & - & 0.100 & - & - \\
\hline Total thickness & 159.6 & & & &
\end{tabular}

Table 3.5. Material properties used in JPA Designer simulation of typical NZ roof.

- No account is taken for thermal bridges. Timber purlins are modelled as equivalent to the cavity insulation.

- Air space is calculated as not having ventilation as this is often not the case in reality.
- Metal cladding is assumed to have vapour gaps of $0.3 \mathrm{~mm}$ as each lap (Latona \& Pinon, 2013).

- All values are taken from the JPA database unless stated otherwise. 


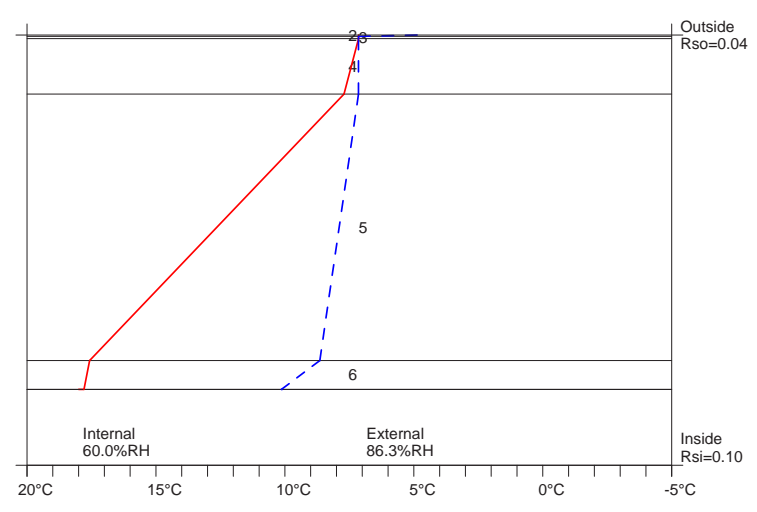

Figure 3.39. Typical NZ roof condensation risk analysis graph in winter.

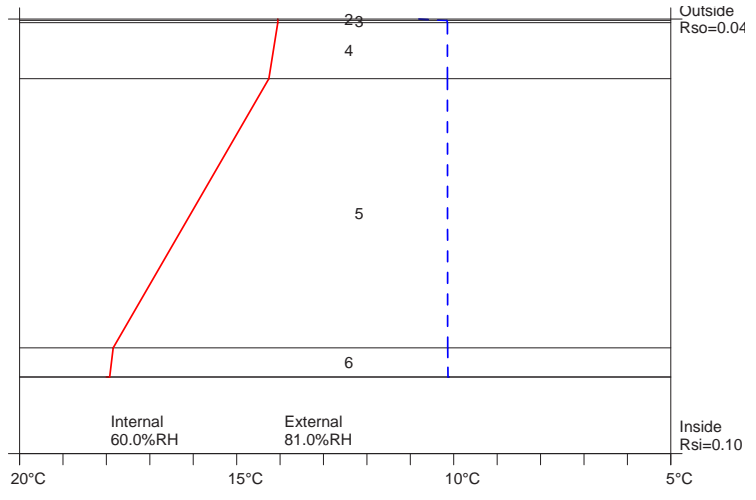

Figure 3.40. Typical NZ roof condensation risk analysis graph in summer.

Condensation Risk Analysis (no account taken of thermal bridges) Internal/ External Conditions : $18.0^{\circ} \mathrm{C} @ 60.0 \% \mathrm{RH} / 7.0^{\circ} \mathrm{C} @ 86.3 \% \mathrm{RH}$ Buildup period 60 days

$\begin{array}{ll}\text { Interface } & \text { Dewpoint } \\ \text { Temp. } & \text { Temp. } \\ \text { o } C & \text { oC }\end{array}$

Vapour
Pressure
$(\mathrm{kPa})$
0.86
1.01
1.01
1.01
1.12
1.24

Saturated Winter Buildup

Annual Buildup Conden$\stackrel{\circ}{ }$ $\left(\mathrm{g} / \mathrm{m}^{2}\right)$ sation

1 Outside surface resistance

7.1

7.1

7.1

7.7

4 Airspace $25 \mathrm{~mm}$

6 Gypsum plasterboard $\left(700 \mathrm{~kg} / \mathrm{m}^{3}\right) \begin{array}{ll}17.6 \\ 17.8\end{array}$

4.9
7.1
7.1
7.1
8.6
10.1

7 Inside surface resistance

10.1

( $\mathrm{KPa})$ $\left(\mathrm{g} / \mathrm{m}^{2}\right)$

Figure 3.41. Condensation risk analysis. No risk of condensation.

The cavity insulation provides thermal resistance - this is indicated on the graph by the red line (surface temperature). As warm air from the inside moves through the insulation it cools down and condensation forms as it comes into contact with the relatively cool roof underlay. More explanation on this is previously explained in the JPA analysis of the typical wall
The typical roof design calculates a winter condensation build up of $940 \mathrm{~g} / \mathrm{m}^{2}$ in contrast to the winter condensation build of the wall was $721 \mathrm{~g} / \mathrm{m}^{2}$. This is expected with higher vapour pressures acting on the roof. 


\section{proposed roof assembly}

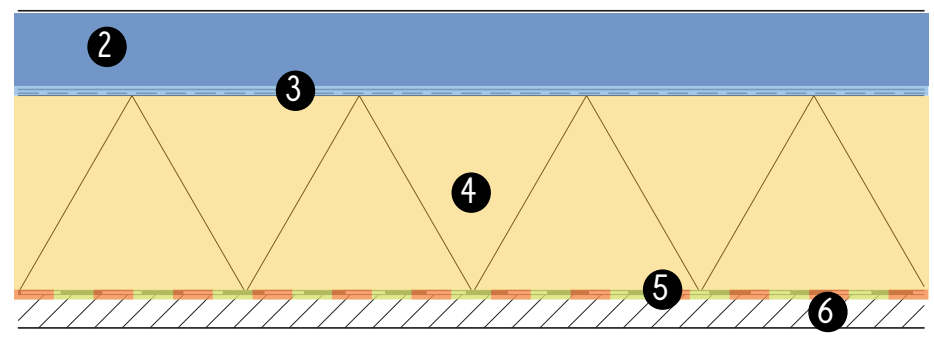

2. Metal cladding

3. Roof underlay

4. Rock fibre insulation

5. Class I vapour control layer

Figure 3.42. Proposed roof diagram.

6. Plywood

\begin{tabular}{l|l|l|l|l|l} 
Material Layer & $\begin{array}{c}\text { Thickness } \\
(\mathrm{mm})\end{array}$ & $\begin{array}{c}\text { Thermal } \\
\text { Conductivity } \\
(\text { W/mk })\end{array}$ & $\begin{array}{l}\text { Thermal Resis- } \\
\text { tance (m²/W) }\end{array}$ & $\begin{array}{c}\text { Vapour } \\
\text { Resistivity } \\
(\text { MNs/gm) }\end{array}$ & $\begin{array}{c}\text { Vapour } \\
\text { Resistance } \\
\text { (MNs/g) }\end{array}$ \\
\hline 1 External surface resistance & - & - & 0.040 & - & - \\
\hline 2 Metal cladding (vapour gaps) & 0.6 & 3.003 & 0.000 & 111667 & 67.00 \\
\hline 3 Roof underlay & 1.0 & - & - & 1000 & 1 \\
\hline 4 Rock fibre insulation & 100 & 0.036 & 2.75 & 5.00 & 0.50 \\
\hline 5 Class I vapour control layer & 1.0 & - & - & 175,000 & 175.00 \\
\hline 6 Plywood (700kg/m $\left.{ }^{3}\right)$ & 18 & 0.170 & 0.106 & 1100 & 19.80 \\
\hline 9 Internal surface resistance & - & - & 0.100 & - & - \\
\hline Total thickness & 120.6 & & & &
\end{tabular}

Table 3.6. Material properties used in JPA Designer simulation of typical NZ roof.

- Metal cladding is assumed to have vapour gaps of $0.3 \mathrm{~mm}$ as each lap (Latona \& Pinon, 2013).
- All values are taken from the JPA database unless stated otherwise. 


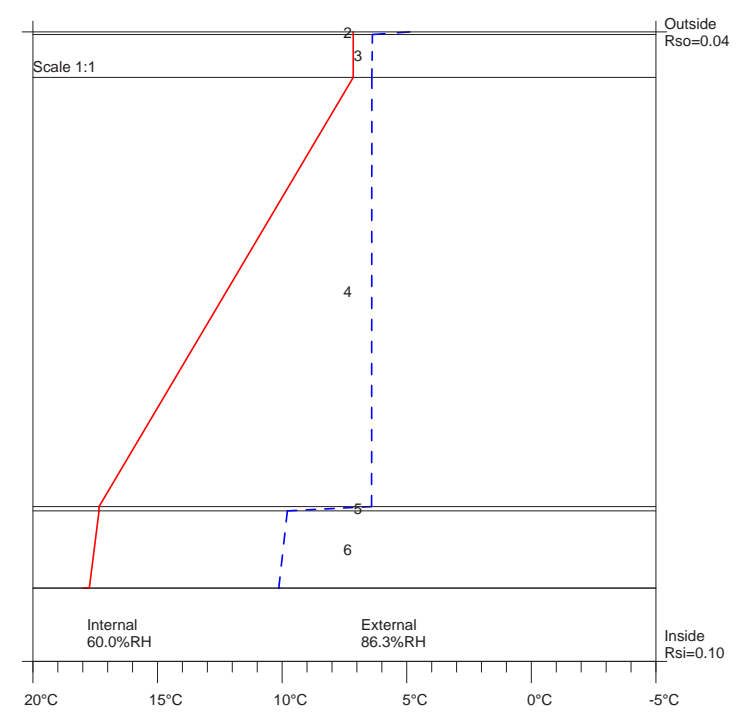

Figure 3.43. Proposed roof condensation risk analysis graph in winter.

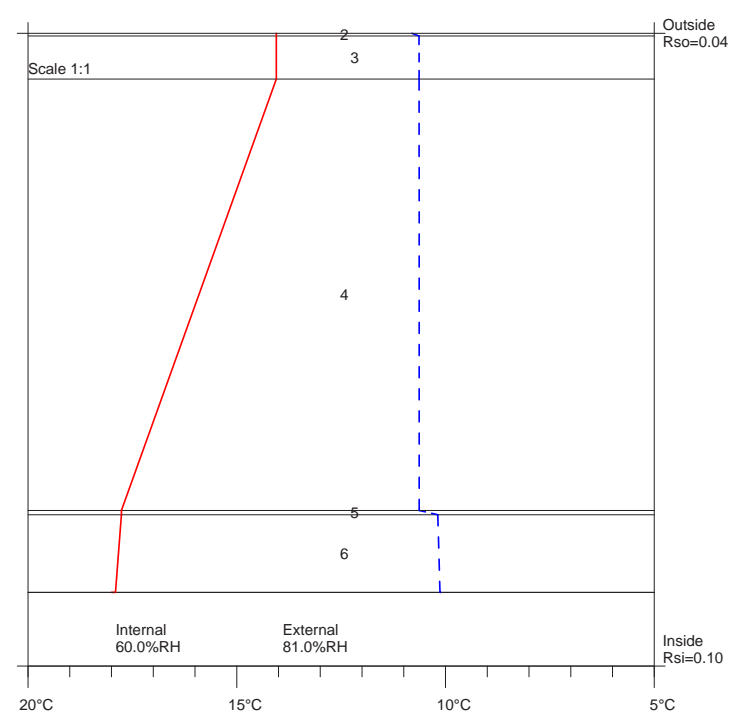

Figure 3.44. Proposed roof condensation risk analysis graph in summer.

\section{Condensation Risk Analysis (no account taken of thermal bridges)}

Internal / External Conditions : $18.0^{\circ} \mathrm{C} @ 60.0 \% \mathrm{RH} / 7.0^{\circ} \mathrm{C} @ 86.3 \% \mathrm{RH}$ Buildup period 60 days

\begin{tabular}{|c|c|c|c|c|c|c|}
\hline $\begin{array}{l}\text { Interface } \\
\text { Temp. } \\
\text { oc }\end{array}$ & $\begin{array}{l}\text { Dewpoint } \\
\text { Temp. } \\
\text { oC }\end{array}$ & $\begin{array}{l}\text { Vapour } \\
\text { Pressure } \\
(\mathrm{kPa})\end{array}$ & $\begin{array}{l}\text { Saturated } \\
\text { V.P. } \\
(\mathrm{kPa})\end{array}$ & $\begin{array}{l}\text { Winter } \\
\text { Buildup } \\
\left(\mathrm{g} / \mathrm{m}^{2}\right)\end{array}$ & $\begin{array}{l}\text { Annual } \\
\text { Buildup } \\
\left(\mathrm{g} / \mathrm{m}^{2}\right)\end{array}$ & $\begin{array}{l}\text { Conden- } \\
\text { sation }\end{array}$ \\
\hline $\begin{array}{l}7.1 \\
7.1 \\
7.1 \\
17.3 \\
17.3 \\
17.7\end{array}$ & $\begin{array}{r}4.9 \\
6.4 \\
6.4 \\
6.4 \\
9.8 \\
10.1\end{array}$ & $\begin{array}{l}0.86 \\
0.96 \\
0.96 \\
0.96 \\
1.21 \\
1.24\end{array}$ & $\begin{array}{l}1.01 \\
1.01 \\
1.01 \\
1.98 \\
1.98 \\
2.03\end{array}$ & - & - & $\begin{array}{l}\text { No } \\
\text { No } \\
\text { No } \\
\text { No } \\
\text { No } \\
\text { No }\end{array}$ \\
\hline
\end{tabular}

Figure 3.45. Proposed roof condensation risk analysis. No risk of condensation.

No condensation risk exists in the proposed roof.

The high level of vapour resistance in the class I vapour control layer restricts vapour from moving into the roof where it is at risk of condensing. 


\section{WUFI hygrothermal comparison}

WUFI is a dynamic simulation. This means the calculation relates to the actual temperature and humidity, sunlight absorption, changes in seasons and atmospheric conditions. WUFI simulation can reveal interstitial condensation risk as well as moisture accumulation within building materials and whether this accumulated moisture dries out or not. The WUFI models are helpful in gauging how the wall will perform over longer time periods

Wellington weather data embedded in the system was used for the comparison (Wellington, BRANZ test site, 2005). For the internal environment the embedded standard from ISO 13788 was used. The mean air temperature was set at $18^{\circ} \mathrm{C}$ at humidity class 3. (humidity class 3 indicates dwellings with low occupancy, ISO 13788, 2012).

Model inputs. The model was calculated for a two-year time period. In order to simulate the least favourable conditions the following parameters were chosen - building orientation: south, initial construction moisture content: $60 \%$, short wave radiation absorptivity: bright.

The proposed wall concept in the WUFI analysis has been modelled with insulation within the structural cavity. This is to evaluate the performance with added thermal resistance on the internal side of the air control layer. The thermal resistance of the cavity must not exceed that of the exterior insulation (Lstiburek, 2011). Cavity insulation will further increase the thermal efficiency and acoustic performance. In reality, the proposed wall can be constructed with or without cavity insulation, depending on the project requirements.
All materials were taken from the WUFI database with minor adjustments made to reflect JPA input properties. As with the JPA comparison the metal cladding assumes a vapour gap of $0.3 \mathrm{~mm}$ every lap (Latona \& Pinon, 2013). WUFI uses the water vapour diffusion factor $(\mu)$ for vapour permeability inputs. The tables also include the equivalent vapour resistance (MNs/g) values which were used in the JPA comparison. To convert MNs/g to $\mu$ the value is multiplied by 0.2 (the permeability of air) and divided by the thickness of the material in metres. Some materials, such as air spaces, don't have values that are easy to convert between units. For these materials, properties may slightly differ depending on the programmes default units and parameters.

The graphical outputs used in the comparison are dew point and relative humidity at the sheathing (condensing surface) and total water content of the assembly. These graphical outputs were chosen as they clearly and visually demonstrate fundamental differences between the wall in respect to interstitial condensation and overall performance.

The calculations were done using WUFI Pro 4.5 developed by the Fraunhofer Institute for Building Physics in Holzkirchen, Germany. 


\section{WUFI wall assembly comparison}

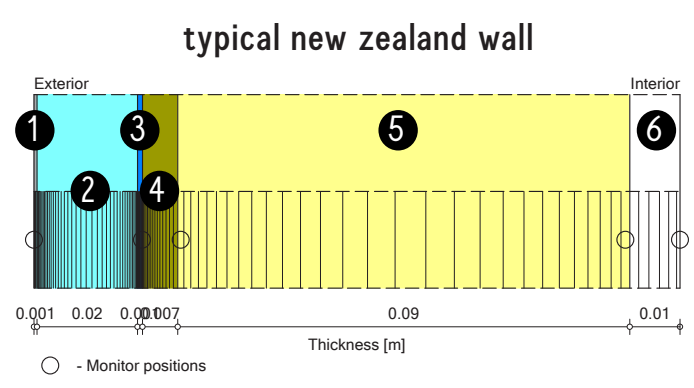

Figure 3.46. WUFI representation of typical NZ wall assembly simulated. Total R-Value of assembly $2.34(\mathrm{~m} 2 \mathrm{~K}) / \mathrm{W}$.

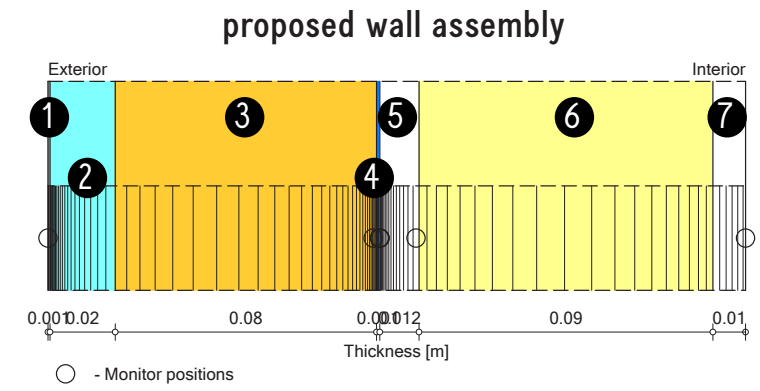

Figure 3.47. WUFI representation of proposed wall assembly simulated. Total R-Value of assebmly $4.86(\mathrm{~m} 2 \mathrm{~K}) / \mathrm{W}$.

\section{typical New Zealand wall}

\begin{tabular}{l|l|l|l|l}
\multicolumn{1}{c|}{ Material Layer } & $\begin{array}{c}\text { Thickness } \\
(\mathrm{mm})\end{array}$ & $\begin{array}{c}\text { Thermal } \\
\text { Conductivity } \\
(\mathrm{W} / \mathrm{mk})\end{array}$ & $\begin{array}{c}\text { Water Vapour } \\
\text { Diffusion Resistance } \\
\text { Factor }(\mu)\end{array}$ & $\begin{array}{c}\text { Vapour } \\
\text { Resistance } \\
(\text { Mns/g) }\end{array}$ \\
\hline 1. Metal cladding (vapour gaps) & 1.0 & 3.003 & 0.6 & 0.001 \\
\hline 2. Air space & 20 & 0.13 & 0.56 & 0.00 \\
\hline 3. Wall underlay & 1.0 & 2.3 & 500 & 2.5 \\
\hline 4. Plywood & 7.0 & 0.170 & 220 & 7.70 \\
\hline 5. Insulated timber frame & 90 & 0.43 & 1.21 & 0.45 \\
\hline 6. Gypsum board & 10 & 0.21 & 8.3 & 0.5 \\
\hline Total thickness & 128.6 & & & \\
\hline
\end{tabular}

Table 3.7. Material properties used in WUFI simulation of typical NZ wall.

\section{proposed wall assembly}

\begin{tabular}{l|l|l|l|l} 
Material Layer & $\begin{array}{c}\text { Thickness } \\
(\mathrm{mm})\end{array}$ & $\begin{array}{c}\text { Thermal } \\
\text { Conductivity } \\
(\mathrm{W} / \mathrm{mk})\end{array}$ & $\begin{array}{c}\text { Water Vapour } \\
\text { Diffusion Resistance } \\
\text { Factor }(\mu)\end{array}$ & $\begin{array}{c}\text { Vapour } \\
\text { Resistance } \\
(\text { Mns/g })\end{array}$ \\
\hline 1. Metal cladding (vapour gaps) & 0.6 & 3.003 & 0.6 & 0.001 \\
\hline 2. Air space & 20 & 0.13 & 0.56 & 0.00 \\
\hline 3. Rock fibre insulation & 80 & 0.036 & 1.1 & 0.40 \\
\hline 4. Self-adhered membrane & 1.0 & 2.3 & 3500 & 17.50 \\
\hline 5. Exterior gypsum board & 12 & 0.21 & 8.3 & 0.60 \\
\hline 6. Insulated timber frame & 90 & 0.043 & 1.21 & 0.45 \\
\hline 7. Gypsum board & 10 & 0.21 & 8.3 & 0.50 \\
\hline Total thickness & 213.6 & & &
\end{tabular}

Table 3.8. Material properties used in WUFI simulation of proposed wall. 
wall assembly dew point temperature comparison

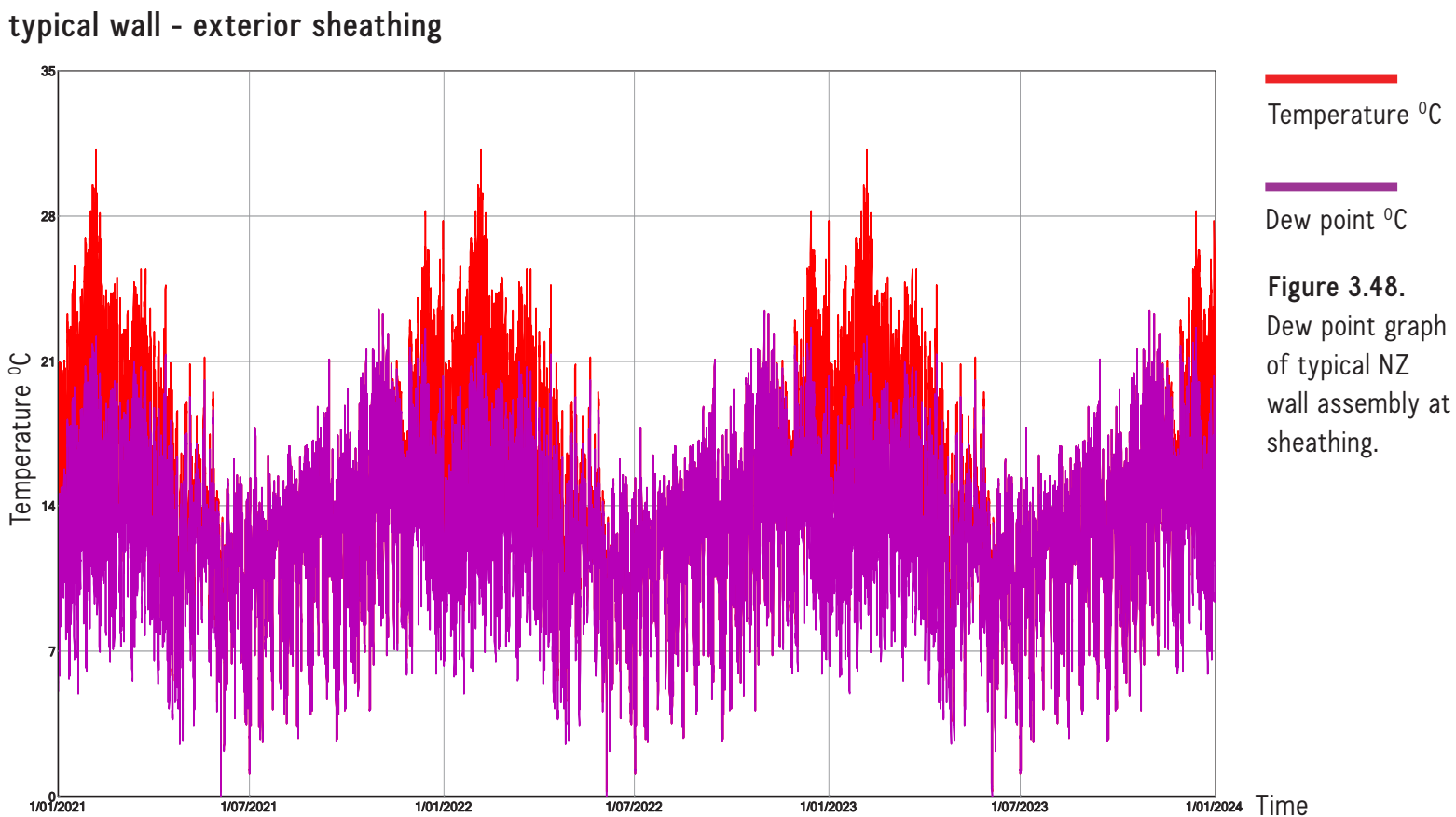

proposed wall - exterior sheathing

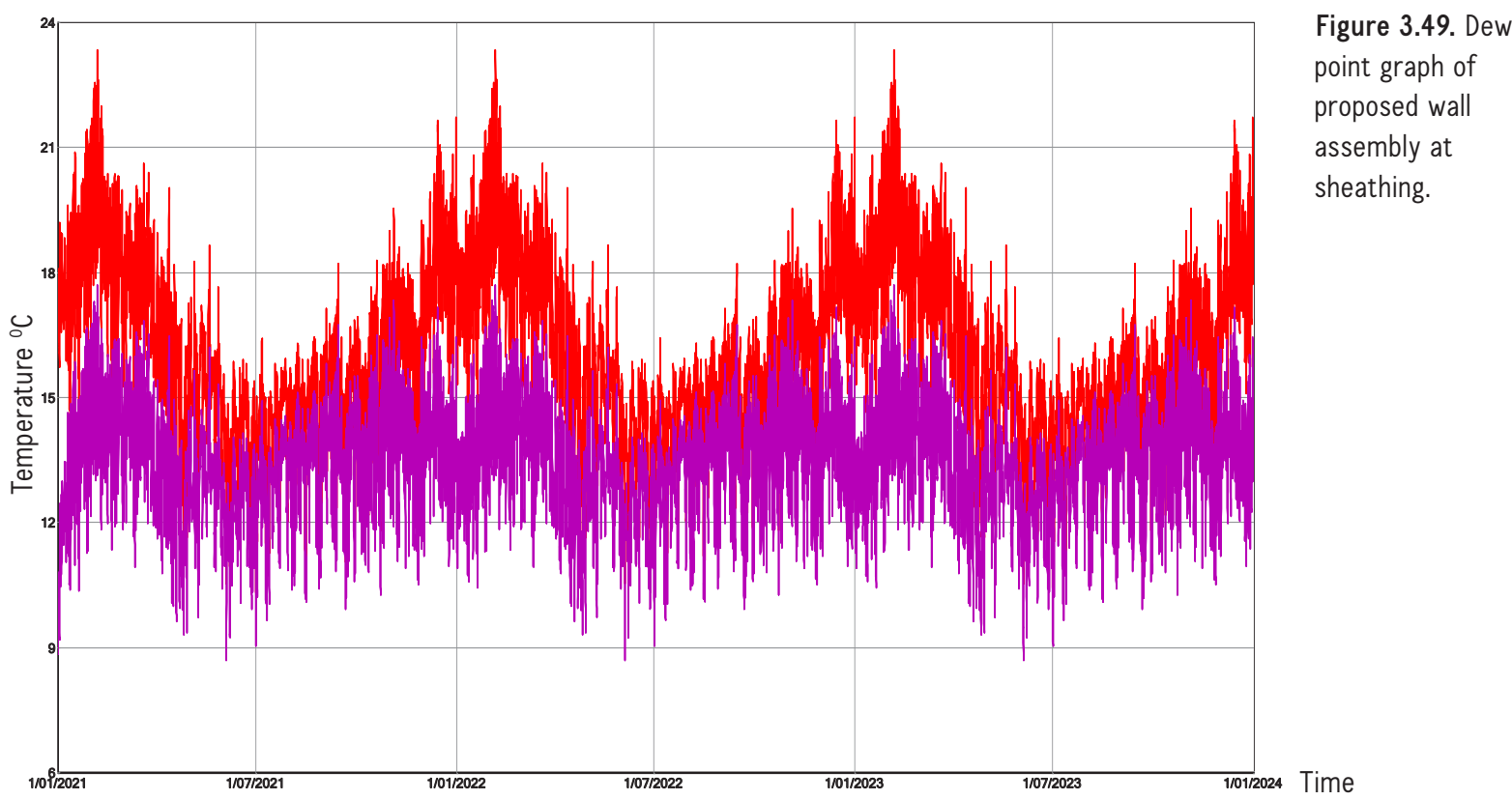

Dew point comparison. The red line represents the surface temperature and the purple line represents the dew point temperature. As explained previously, when the two lines overlap this is evidence of a risk of condensation forming. In the typical New Zealand wall the purple line covers the red line during winter months. 
wall assembly relative humidity comparison

typical wall - exterior sheathing

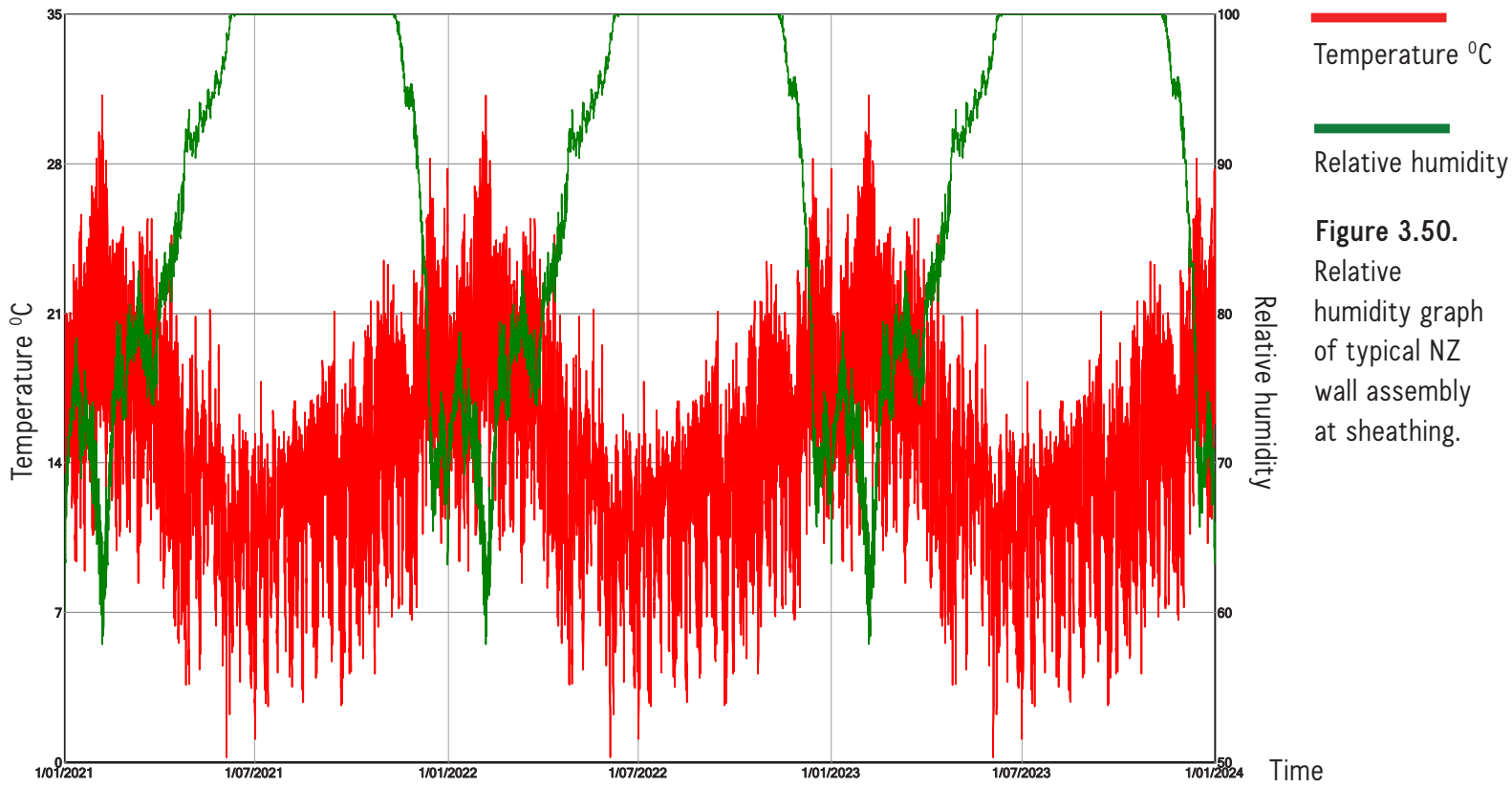

proposed wall - exterior sheathing

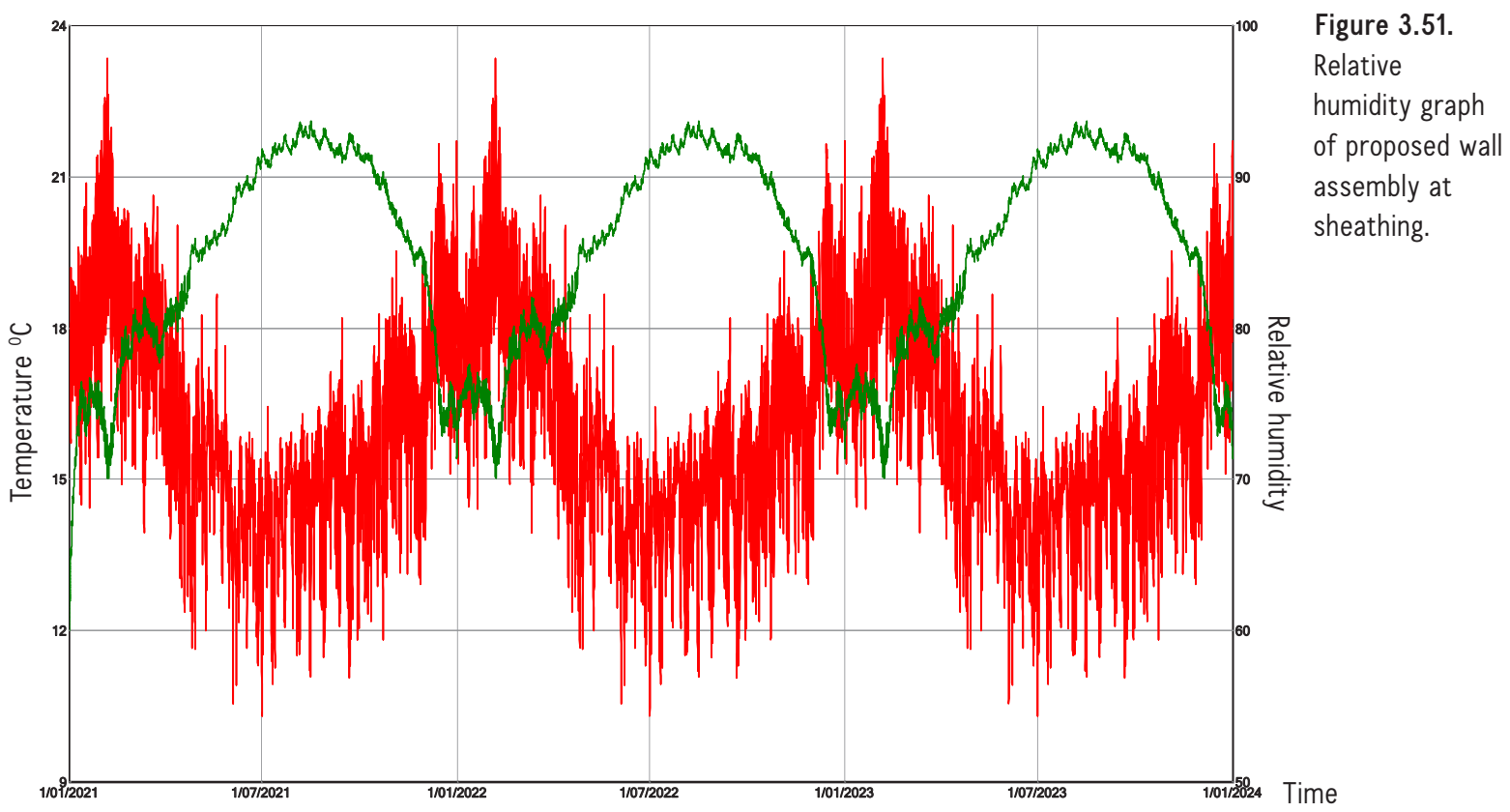

Relative humidity comparison. The red line represents temperature and the green line represents relative humidity. When relative humidity reaches $100 \%$ condensation forms as the air reaches saturation. As you can see the typical New Zealand wall is shown reaching $100 \%$ relative humidity during the winter months. 


\section{wall assembly total water content comparison}
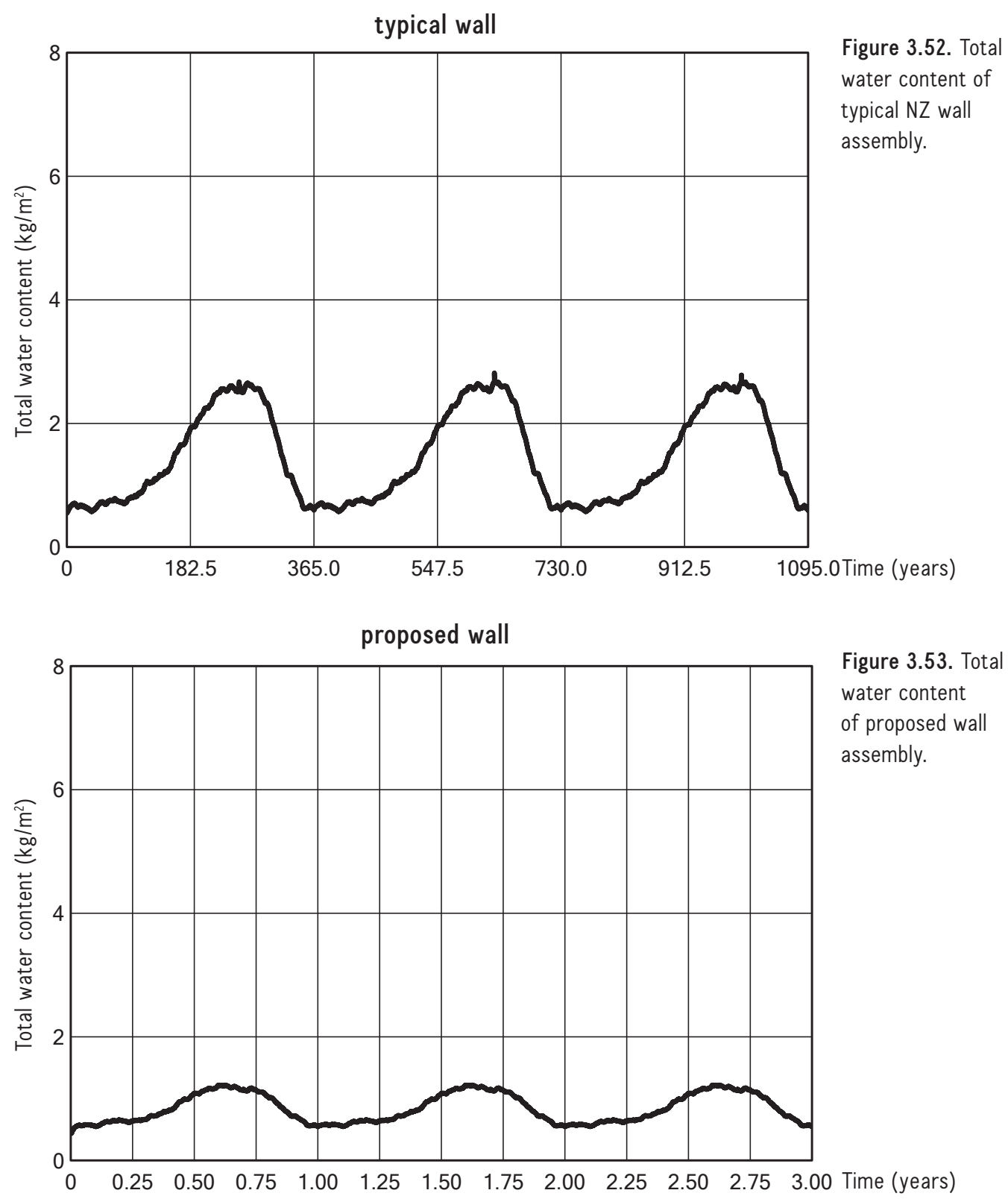

Total water content comparison. The above graphs represent the total water content within the wall assemblies over a period of three years.

As can be seen, the typical New Zealand wall develops a much higher water content than that of the proposed wall assembly. This is particularly noticeable in the winter period where water content rises sharply. However, what is most concerning about the traditional wall is that water content is higher in the second winter than in the first (previous) winter. This indicates that the assembly is retaining some of its water content and not entirely drying out over the summer period. In the proposed wall the water content stays consistant for the three year period. However, the peak winter water content in the wall remains constant over the three years of the simulation. This indicates that any moisture accumulated in the wall over winter completely dries out over summer. 


\section{WUFI roof assembly comparison}

typical New Zealand roof

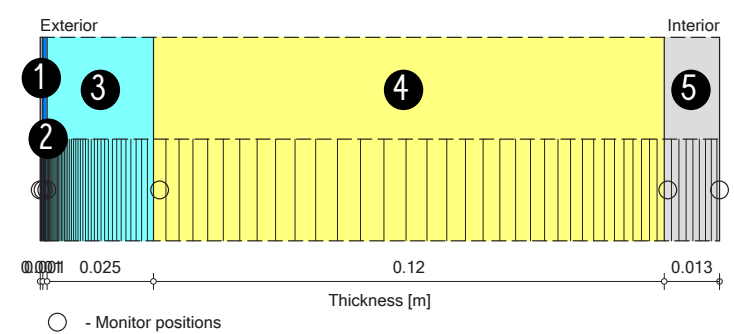

Figure 3.54. WUFI representation of typical NZ roof assembly simulated. Total R-Value of assembly $3.03(\mathrm{~m} 2 \mathrm{~K}) / \mathrm{W}$.

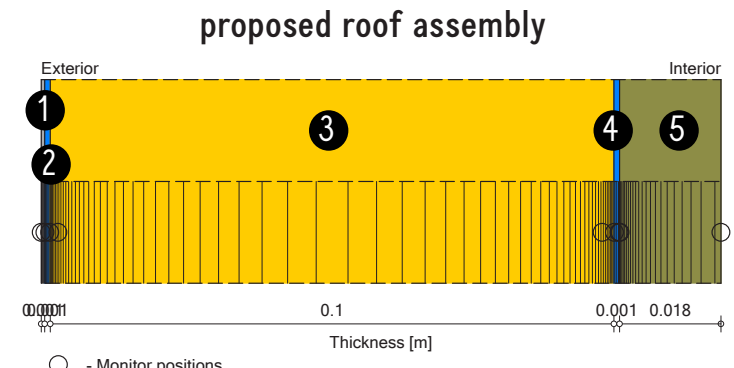

- Monitor positions

Figure 3.55. WUFI representation of proposed roof assembly simulated. Total R-Value of assembly $3.30(\mathrm{~m} 2 \mathrm{~K}) / \mathrm{W}$.

typical New Zealand roof

\begin{tabular}{|c|c|c|c|c|}
\hline Material Layer & $\begin{array}{c}\text { Thickness } \\
\text { (mm) }\end{array}$ & $\begin{array}{c}\text { Thermal } \\
\text { Conductivity } \\
\text { (W/mk) }\end{array}$ & $\begin{array}{c}\text { Water Vapour } \\
\text { Diffusion Resistance } \\
\text { Factor }(\boldsymbol{\mu})\end{array}$ & $\begin{array}{c}\text { Vapour } \\
\text { Resistance } \\
\text { (Mns/g) }\end{array}$ \\
\hline 1. Metal cladding (vapour gaps) & 1.0 & 3.003 & 2000 & 67.00 \\
\hline 2. Roof underlay & 1.0 & 2.3 & 200 & 1.0 \\
\hline 3. Air space & 25 & 0.13 & 0.56 & 0.001 \\
\hline 4. Insulation (between purlins) & 120 & 0.043 & 1.3 & 0.60 \\
\hline 5. Gypsum board $\left(700 \mathrm{~kg} / \mathrm{m}^{3}\right)$ & 13 & 0.210 & 8.3 & 0.65 \\
\hline Total thickness & 159.6 & & & \\
\hline
\end{tabular}

Table 3.9. Material properties used in WUFI simulation of typical NZ roof.

\begin{tabular}{l|l|l|l|l}
\multicolumn{1}{c}{ Material Layer } & $\begin{array}{c}\text { Thickness } \\
(\mathrm{mm})\end{array}$ & $\begin{array}{c}\text { Thermal } \\
\text { Conductivity } \\
(\text { W/mk })\end{array}$ & $\begin{array}{c}\text { Water Vapour } \\
\text { Diffusion Resistance } \\
\text { Factor }(\boldsymbol{\mu})\end{array}$ & $\begin{array}{c}\text { Vapour } \\
\text { Resistance } \\
(\text { Mns/g) }\end{array}$ \\
\hline 1. Metal cladding (vapour gaps) & 0.6 & 3.003 & 2000 & 67.00 \\
\hline 2. Roof underlay & 1.0 & 2.3 & 200 & 1.0 \\
\hline 3. Rock fibre insulation & 100 & 0.036 & 1.1 & 0.50 \\
\hline 4. Self-adhered membrane & 1.0 & 2.3 & 35,000 & 175.00 \\
\hline 5. Plywood (700kg/m 3 ) & 18 & 0.170 & 220 & 19.8 \\
\hline Total thickness & 120.6 & & & \\
\hline
\end{tabular}

Table 3.10. Material properties used in WUFI simulation of proposed roof. 
roof assembly dew point temperature comparison

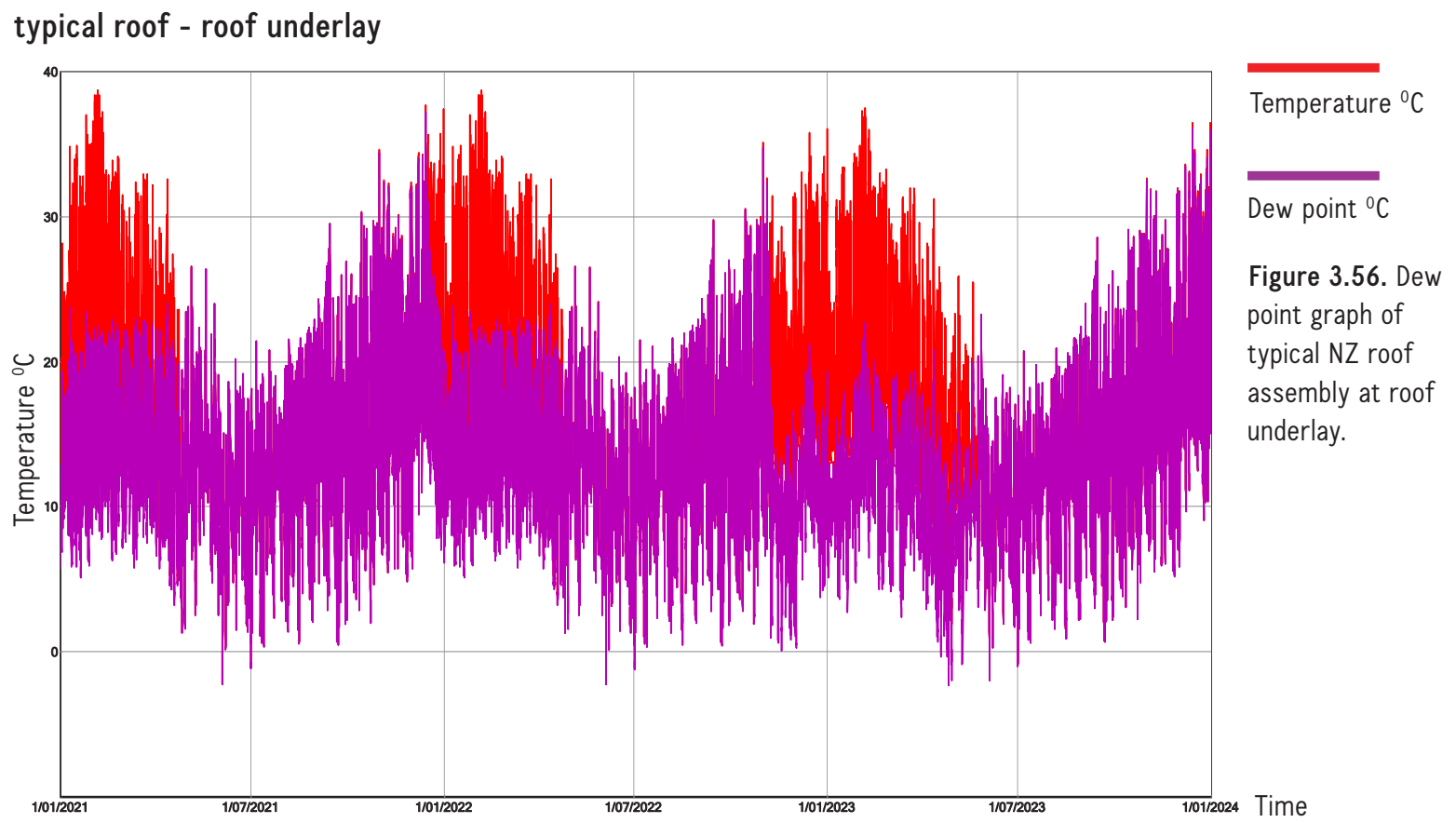

proposed roof - plywood substrate

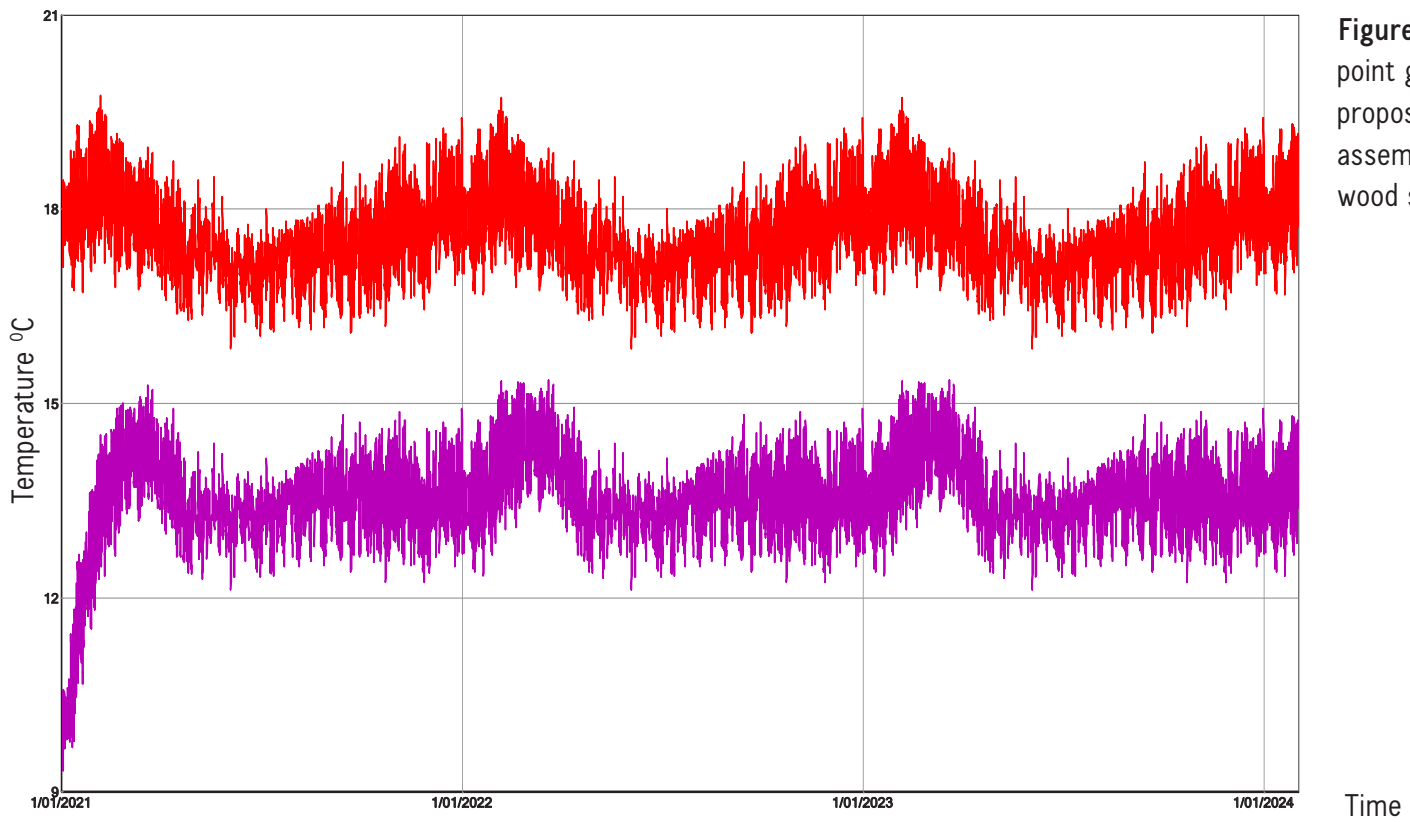

The red line represents the surface temperature and the purple line represents the dew point temperature. As explained previously, when the two lines overlap this is evidence of risk of condensation
Figure 5.57. Dew point graph of proposed roof assembly at at plywood subsrrate. 
rouf assembly relative humidity comparison

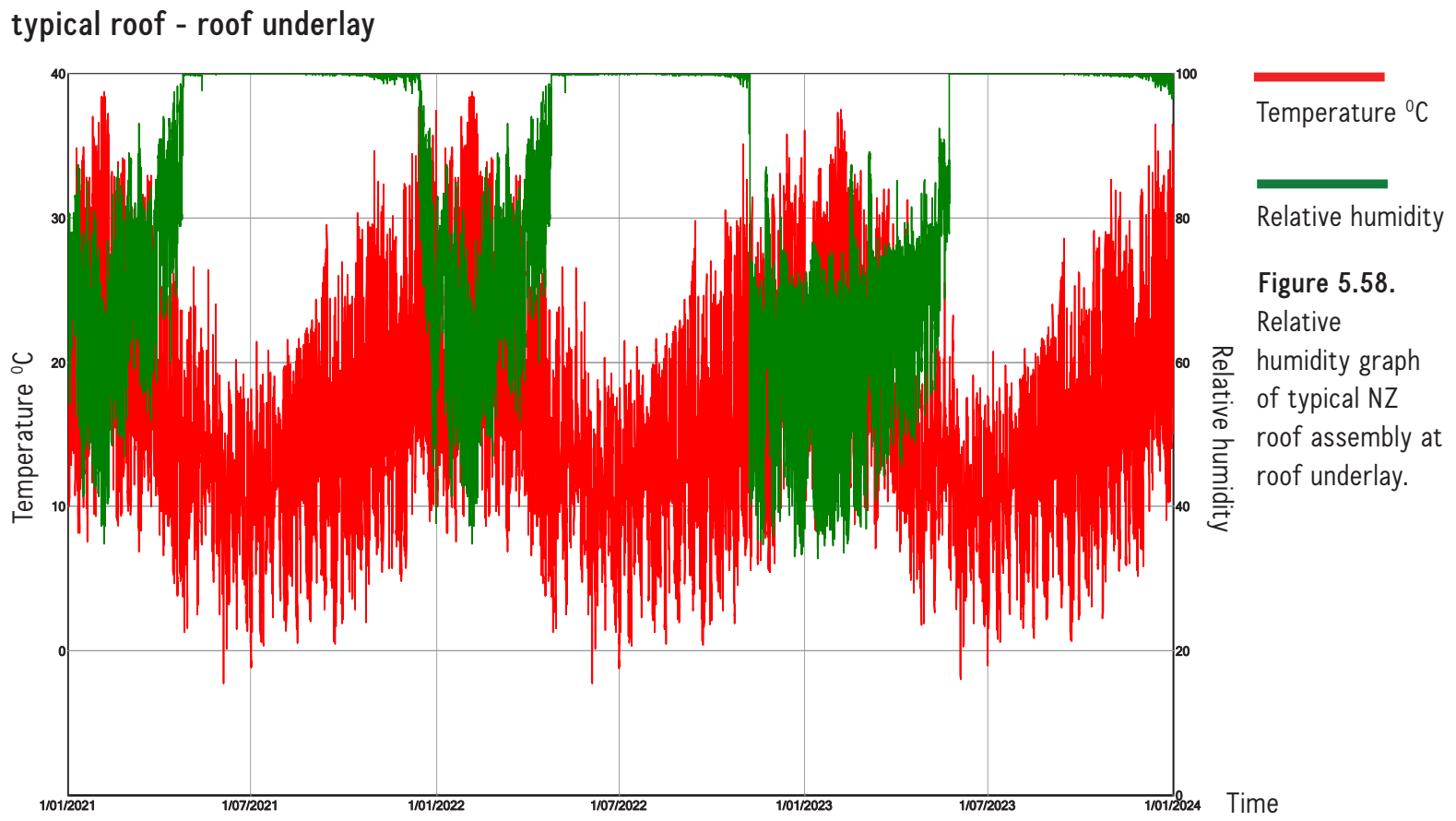

proposed roof - plywood substrate

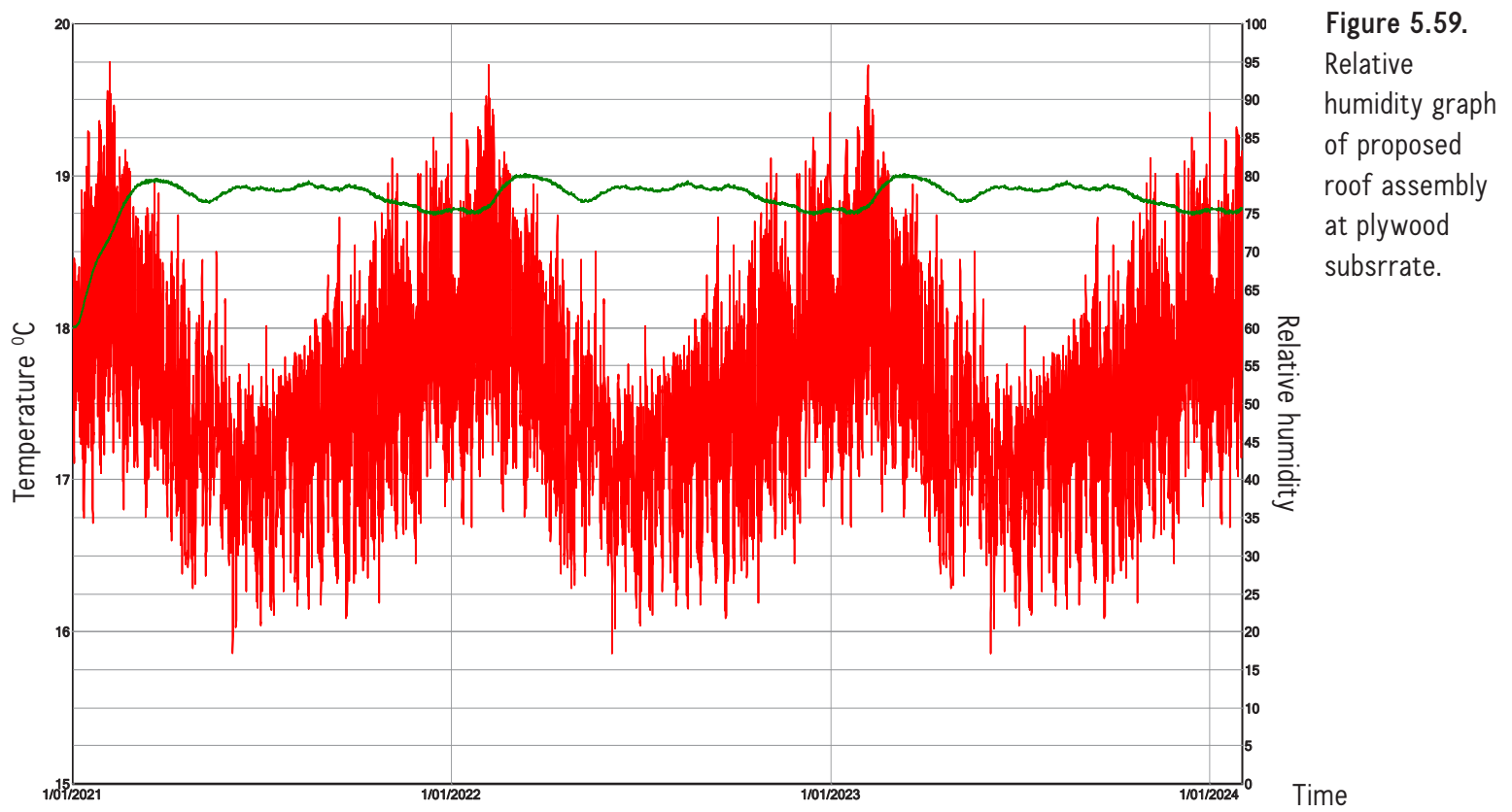

The red line represents temperature and the green line represents relative humidity. When relative humidity reaches $100 \%$ (saturation point) condensation forms. As you can see the typical New Zealand roof is shown reaching $100 \%$ relative humidity during the winter months. 
roof assembly total water content comparison

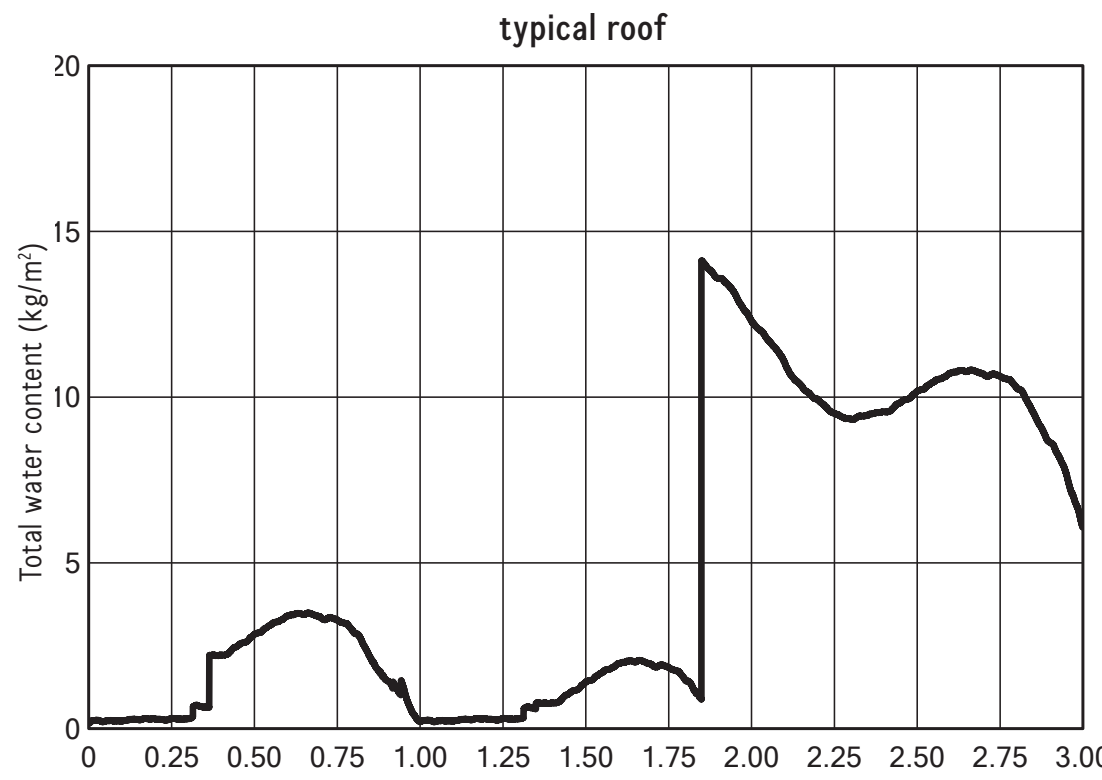

Figure 5.60. Total water content of typical NZ roof assembly.

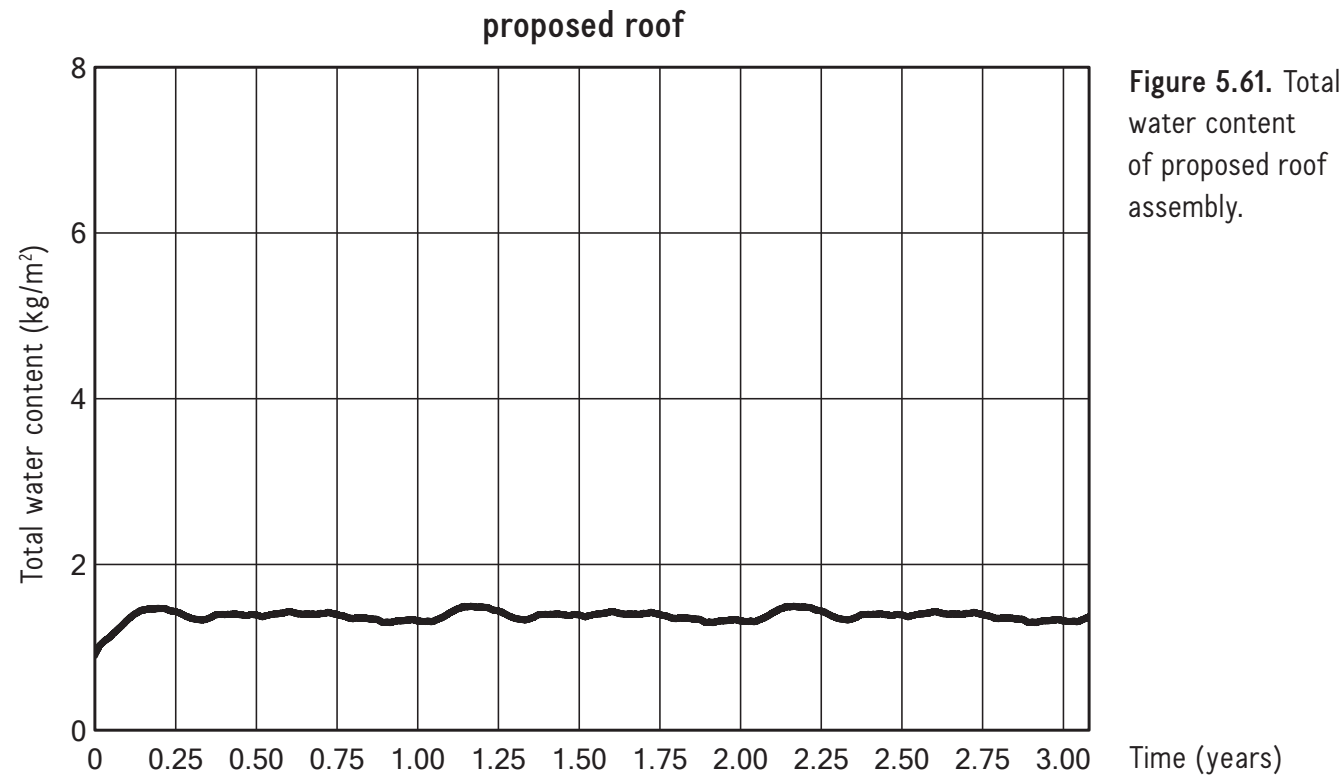

The above graphs represent the total water content within the wall assemblies over the period of three years. In comparison with the proposed roof assembly, the total water content of the roof over the three year period stays more consistent. This is attributed to the increased vapour resistance of the class I vapour control layer and indictes minimal drying of the assembly inbetween seasons.

In the typical roof assembly, the total water content rises dramatically. The condensation forming potential of the roof assembly is greater than the drying potential each year. This is by the fact that each year the total water content in the roof assembly significantly increases. 


\section{hygrothermal comparison conclusions}

While this analysis was undertaken using Wellington climate data, the results can be applied to other parts of the country as the principles are the same. Minor climate differences would result in minor changes in the outputs but the same patterns would be observed. If a climate zone such as Queenstown was used the results would be even more dramatic, particularly in regard to the failure of a typical wall and roof assembly. Similarly, if the proposed wall was being designed for Queenstown, the much colder external environment would require an increase in the external insulation.

New Zealand homes have high indoor humidity and most homes do not have constant heating. With these statistics, along with the way we currently build our envelopes, it is inevitable that hidden mould within wall and roof cavities is, and will continue to be, an issue for New Zealand if changes are not made.

Surface mould is already observed in New Zealand homes and interstitial condensation will exacerbate the mould problem. The consequences of interstitial condensation remain hidden within the framing cavity, hence the deterioration caused is hard to identify.

While the hygrothermal simulations may not precisely represent how a building envelope assembly will perform, they provide comparative data to assess the performance qualities of different walls and enable a qualitative judgment to be made in respect to the proposed wall.

It should be noted that the 'as built' assembly will never exactly replicate the hygrothermal analysis based on material layer inputs due to human craftsmanship and the nature of the construction processes (e.g. that fixings are needed to hold elements together). As well as material layer inputs, there are countless other inputs and assumptions made within the software in an attempt to replicate performance reality. Hygrothermal load is not static and so it is impossible to have all inputs right all of the time. For this reason, a hygrothermal analysis does not produce an exact measure of interstitial condensation or moisture accumulation but it does give a helpful comparison between different wall types. The comparison allows fundamental differences in the wall's performance to be expressed.

The results from the simulation, combined with the previous research in the literature review, gives confidence in the performance of the proposed wall that will be used in the design of the building envelope for the terrace houses.

The simulations cannot account for construction defects, lack of craftmanship or appropriate design and buildability of control layers and their continuity. This emphasises the importance of the readable and buildable drawings which are developed through the terrace house design drawings in the next chapter. 


\section{6 proposed envelope assembly design}

\section{wall and roof design}

The proposed wall. As explored in the literature review, a better performing wall for New Zealand timber framed envelopes consists of a rain, air, vapour and heat control layer on the exterior side of the structure. A vapour control layer that controls vapour movement, an air control layer that is impermeable to air flow and a rain control layer that is detailed to drain water to the exterior. The heat control layer, comprised of continuous rigid insulation, is installed over the other control layers. This is followed by an air space with a structural batten and the selected cladding.

In this wall assembly the envelope will dry from the control layers inwards and from the control layers outwards (Lstiburek, 2011).

Wall design. A building envelope system has been designed which is detailed in the terrace house design drawings. Each material is chosen based on how it performs within the entire envelope system. Several variations will be presented to demonstrate the opportunities and flexibility that are available within the 'perfect wall' concept.

The structure consists of $90 \times 45 \mathrm{~mm}$ timber framing, with recycled fiberglass cavity insulation providing additional thermal and acoustic performance, and a gypsum board interior lining.

Rain-air-vapour control layers. A gypsum board with fibreglass coating has been selected as the exterior sheathing. This sheathing is water and fire resistant and does not support mould growth in the way a timber sheathing does. It provides bracing and is not compromised by being left exposed to moisture on site. (USG Boral, 2020).
The exterior sheathing will be followed by a self-adhered membrane. The fiberglass coating provides an appropriate substrate for the membrane. The membrane will form the continuous rain-air-vapour control layer. It is water proof and, when correctly detailed, will form the drainage plane. The self-adhered membrane provides sufficient vapour resistance (vapour control layer class II - vapour semi-impermeable) and is air impermeable. The nature of the product means it can be easily detailed to be continuous. The self-adhered membrane simplifies the detailing of windows, doors and penetrations by removing the need for multiple flashing tapes to maintain continuity of control layers and eliminates the need for mechanical fixings for its attachment.

Other rain-air-vapour control layers could be:

- Self-adhered membrane over a plywood or OSB exterior sheathing.

- Exterior sheathing followed by a mechanically attached membrane taped at the joints.

- A flexible membrane (such as polyethylene) mechanically attached to the structure and taped at the joins.

- A waterproof sheathing taped at the joints. Sheathings can act as drainage planes if joins are flashed appropriately. In this case an additional flexible control layer (membrane/paper/ wrap) may not be necessary (Lstiburek, 1999). The rain-air-vapour control layers must be waterproof and air impermeable.

Heat control layer. Rigid rock fibre insulation will form the continuous heat control layer. Rock fibre is not affected by moisture so can be left exposed to the air space. Its porous properties also mean that water can drain through the material. It is 
non-combustible. The advantages of this insulation is its fire performance, durability, high vapour permeability (similar to air), thermal stability, dimensional stability, and acoustic performance.

The heat control layer is mechanically fixed back into the structure. Other heat control layers could be:

- PIR (polyisocyanurate) board

- Extruded polystyrene

- Expanded polystyrene

- Phenolic board

If the insulation is sensitive to moisture (e.g., wood fibre and straw bale) the rain control layer is located on the exterior side of the insulation and this would then form the drainage plane. The air control and vapour control layers would still be located on the interior side of the insulation. This exterior rain control layer must be vapour permeable to allow drying to the exterior.

Air space and cladding. A structural cavity batten will be used. The cladding can then be fixed to the batten without having to be fixed back into the structure, reducing the amount of fixings penetrating the rain-air-vapour control layer. A metal batten forms a $20 \mathrm{~mm}$ air space where ventilation is possible. An advantage of metal battens is that they can provide a structural connection for cladding at $20 \mathrm{~mm}$ depth compared to timber structural battens which are required to be a lot deeper $(40 \mathrm{~mm})$.

The proposed terrace house design will have two different cladding types - corrugate metal cladding and panelled timber cladding.
The corrugate metal cladding is installed vertically on horizontal battens. The corrugate cladding provides venting even on a horizontal batten as a function of its profile (Lstiburek, 2004).

The timber cladding is attached horizontally on vertically attached battens. Wood cladding should be primed on all sides to avoid water absorption.

Thermally broken aluminium joinery will be specified. As $B C$ Housing states, aluminium windows may be prone to relatively poor thermal performance and condensation resistance if the frame does not include a sufficient thermal break (BC Housing, 2020). The windows will be set within the geometry of the heat control layer to improve thermal performance.

Roof design. The rain-air-vapour control layer will be a foil faced self-adhered membrane installed over an $18 \mathrm{~mm}$ structural plywood substrate which is installed over the timber purlins. It is desirable to have a greater vapour resistance due to the higher vapour load on the roof. Therefore, the rain-air-vapour control layer will be a Class I vapour control layer which is classified as vapour impermeable.

The self-adhered membrane will incorporate an adhesive mass of approximately 500 microns which will enable it to self-seal around any fixings that are required to penetrate the membrane and connect to structure.

As discussed in the literature review, the roof assembly is slightly different to the wall assembly due to its location within the building envelope. The roof assembly design differs slightly to the wall assembly in that there is no designated air space because of 
the role of the cladding (metal and membrane) in respect to rain control. (Reasons for this are discussed in chapter 2).

The heat control layer will be $100 \mathrm{~mm}$ rock fibre insulation and is selected for the same reasons as the wall. An additional advantage of using rock fibre insulation in the roof assembly is its vapour permeability, as observed in the hygrothermal comparison. Having a similar permeance to that of air, the risk of vapour becoming trapped within the system is reduced.

The pitched roof. In order to reduce the amount of fixings that penetrate the self-adhered membrane, timber battens are included within the roof buildup. The metal roof cladding is then fixed into the battens meaning the only fixings that penetrate the self-adhered membrane are those used to fix the timber batten to the plywood.

The standing seam metal cladding stops liquid water entering the roof assembly. The standing seam profile is attached to the roof through a concealed clip system. This means there are no fixings through the standing seam profiles. The metal flashings that are installed in conjunction with the standing seam profile are also designed so that they do not require any exposed fixings. As stated previously, metal cladding naturally provides some degree of air flow due to the shape of the profile and is not vapour permeable due to the way the profiles overlap.

The flat roof. The flat roof assembly has a high-density gypsum roof board which is installed over the insulation and to which the single ply membrane is adhered. A single fixing is used to attach both the insulation and roof board back into the timber substrate reducing the number of fixing penetrations in the vapour-air-rain control layer. Compared to the vapour-air-rain control layer the single ply membrane that has been selected is relatively vapour permeable. This, combined with the high vapour permeance of rockwool, means vapour is unlikely to become trapped within the system.

Roof layering. The roof assemblies described above mitigate condensation risk through the control of vapour on the interior side of the insulation. As is the case with the perfect wall, all the control layers are outside the structure in order to protect it (Lstiburek, 2010). The vapour and air control layer is installed to the plywood substrate followed by the heat control layer. The 'perfect wall' concept is therefore still functional in roof assemblies.

As previously explained, the roof assembly differs from the wall assembly in that it combines the rain shed and rain control into one layer. The roof cladding that has been proposed is able to perform more effectively as a rain control layer than the wall cladding. This is because the roof cladding has very few complex openings or penetrations in the way that a facade does and also because the specified roof cladding (and associated flashings) is installed without exposed fixings penetrating the cladding layer (i.e. concealed clip system). In saying this, if moisture was to enter into the assembly from the outside, the structure would still remain protected by the continuous vapour control layer which is installed to the plywood substrate.

The detail drawings will provide more information of the material assemblies, their connection and construction. 
As mentioned above, the perfect wall (and roof) concept can, in practice, take many forms. The wall and roof systems described above could have elements substituted, added or removed and still deliver a functioning building envelope system. The building envelope chosen is just one way of interpreting the 'perfect wall' concept.
The choices the architect makes when designing the building envelope will be subject to project performance requirements, climate, budget, access and availability and aesthetics.

\begin{tabular}{|c|c|c|c|c|c|c|c|c|}
\hline & 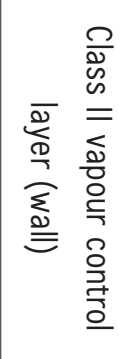 & 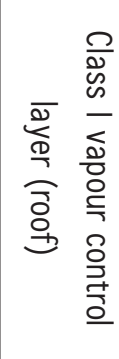 & 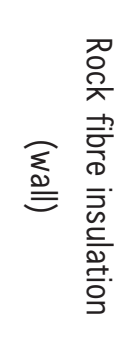 & 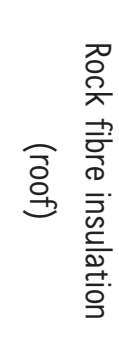 & 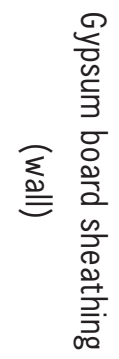 & 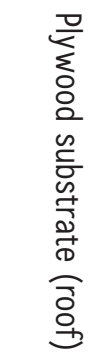 & 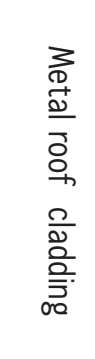 & 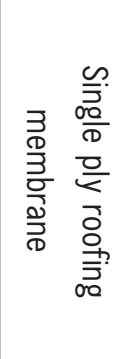 \\
\hline Thickness (mm) & 1 & 1 & 80 & 100 & 12.7 & 18 & 0.6 & 1.2 \\
\hline Density $\left(\mathrm{kg} / \mathrm{m}^{3}\right)$ & - & - & 73 & 73 & 700 & 700 & 7800 & - \\
\hline Thermal conductivity (W/mk) & 2.3 & 2.3 & 0.036 & 0.036 & 0.210 & 0.170 & 3.003 & - \\
\hline Thermal resistance $\left(\mathrm{m}^{2} \mathrm{~K} / \mathrm{W}\right)$ & - & - & 2.2 & 2.8 & 0.57 & 0.106 & - & - \\
\hline $\begin{array}{l}\text { Vapour diffusion resistance } \\
\text { factor }(\mu)\end{array}$ & 3500 & 35,000 & 1.1 & 1.1 & 50 & 220 & 2000 & 16000 \\
\hline Vapour resistance (MNs/g) & 17.50 & 175.00 & 0.5 & 0.5 & 0.6 & 19.8 & 67.00 & 100 \\
\hline
\end{tabular}

Table 3.11. Material properties of control layers used in proposed envelope design. 


\section{wall assembly construction}

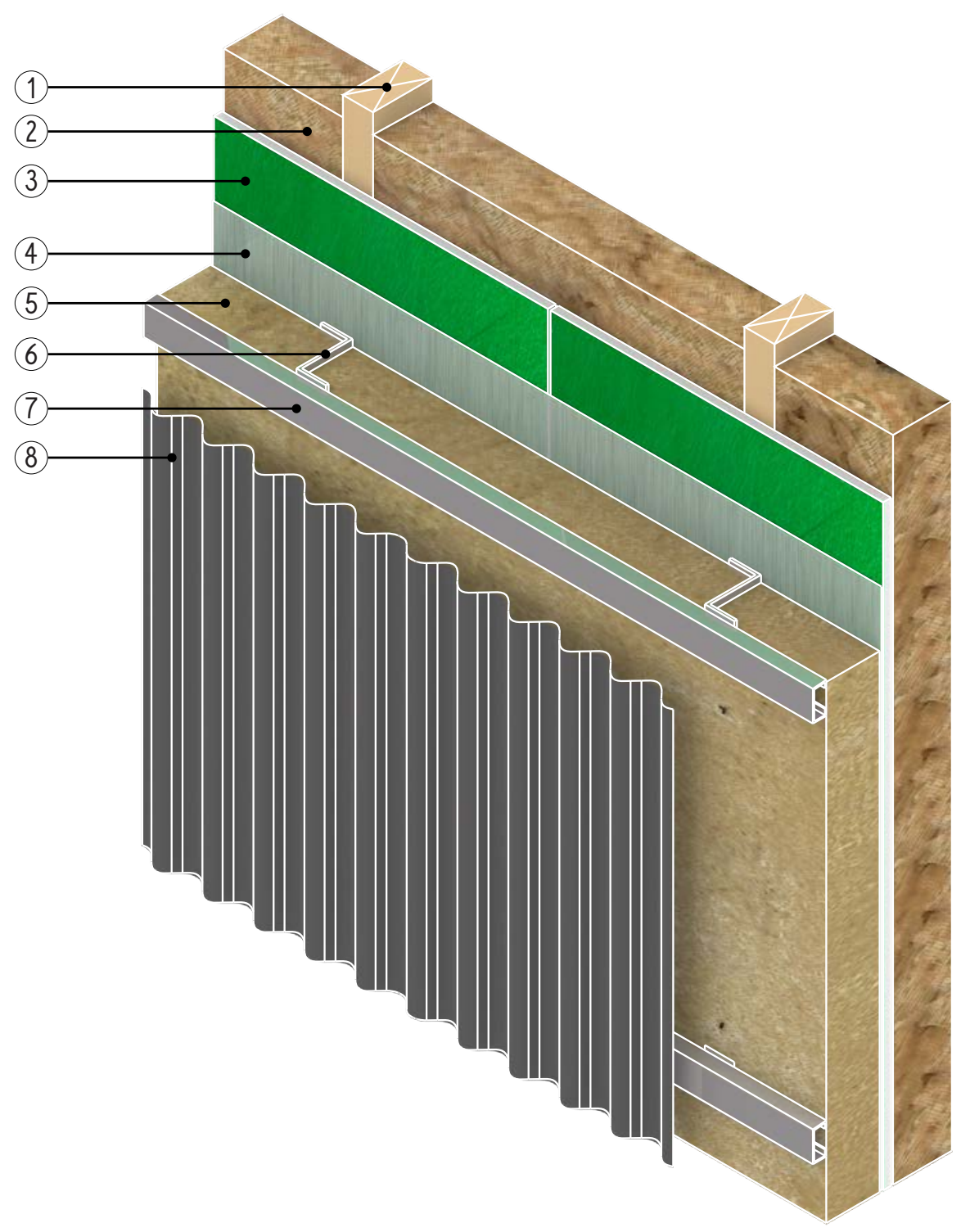

Figure 3.62. Ground floor wall assembly.

1. $90 \mathrm{~mm} \times 45 \mathrm{~mm}$ timber framing

2. Cavity insulation (R-value less than external insulation)

3. Exterior gypsum sheathing with fibreglass coating fixed back to timber framing

4. Class II vapour control layer - air barrier and drainage plane (self-adhered to sheathing)
5. Metal bracket fixed back to timber framing

6. $80 \mathrm{~mm}$ rock fibre insulation fixed back to timber framing

7. Metal structural cavity batten fixed horizontally to metal bracket

8. Metal corrugate cladding fixed to structural cavity battens 


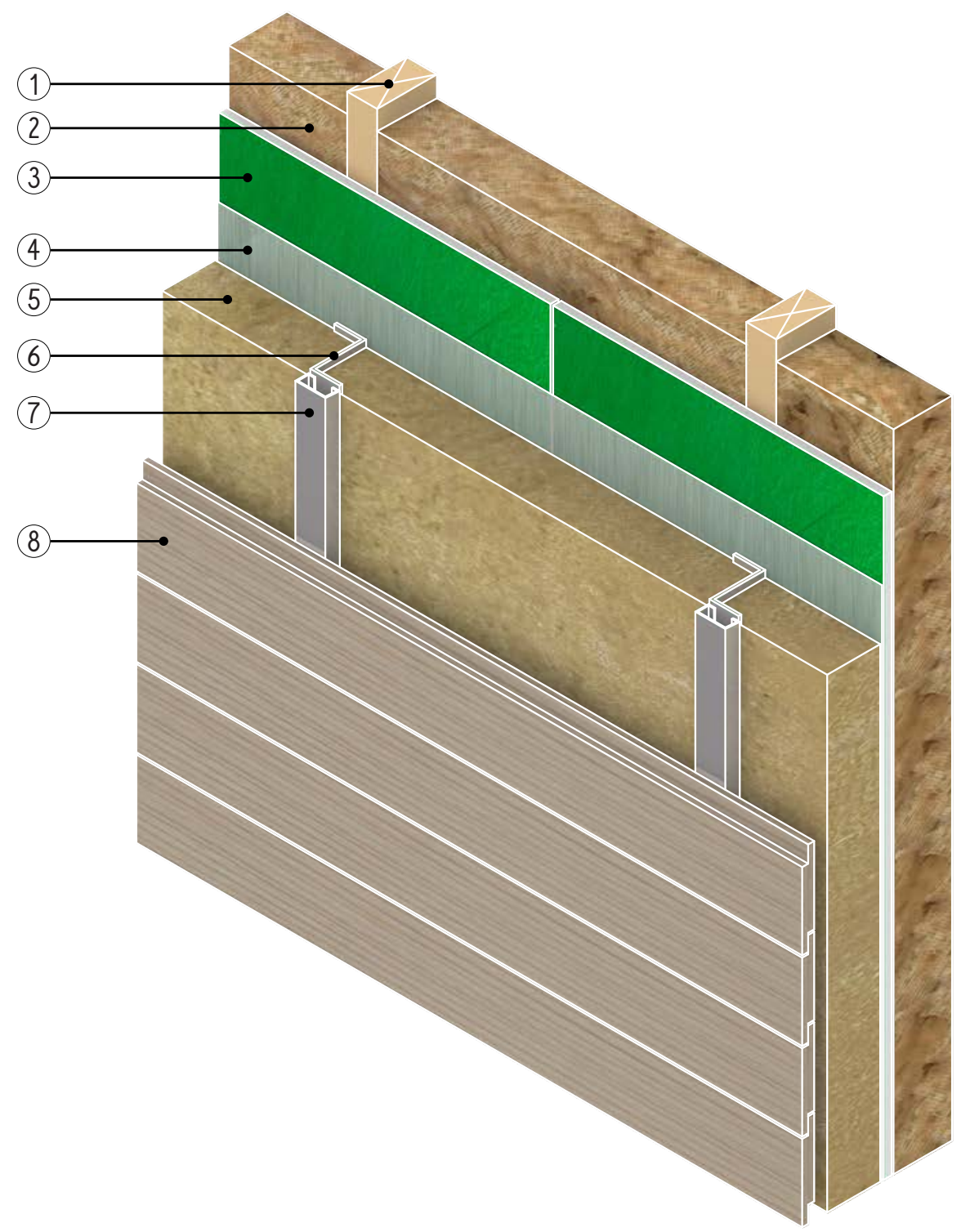

Figure 3.63. First floor wall assembly.

1. $90 \mathrm{~mm} \times 45 \mathrm{~mm}$ timber framing

2. Cavity insulation (R-value less than external insulation)

3. Exterior gypsum sheathing with fibreglass coating fixed back to timber framing

4. Class II vapour control layer - air barrier and drainage plane (self-adhered to sheathing)
5. Metal bracket fixed back to timber framing

6. $80 \mathrm{~mm}$ rock fibre insulation fixed back to timber framing

7. Metal structural cavity batten fixed vertically to metal bracket

8. Horizontal shiplap timber cladding fixed to structural battens 


\section{roof assembly construction}

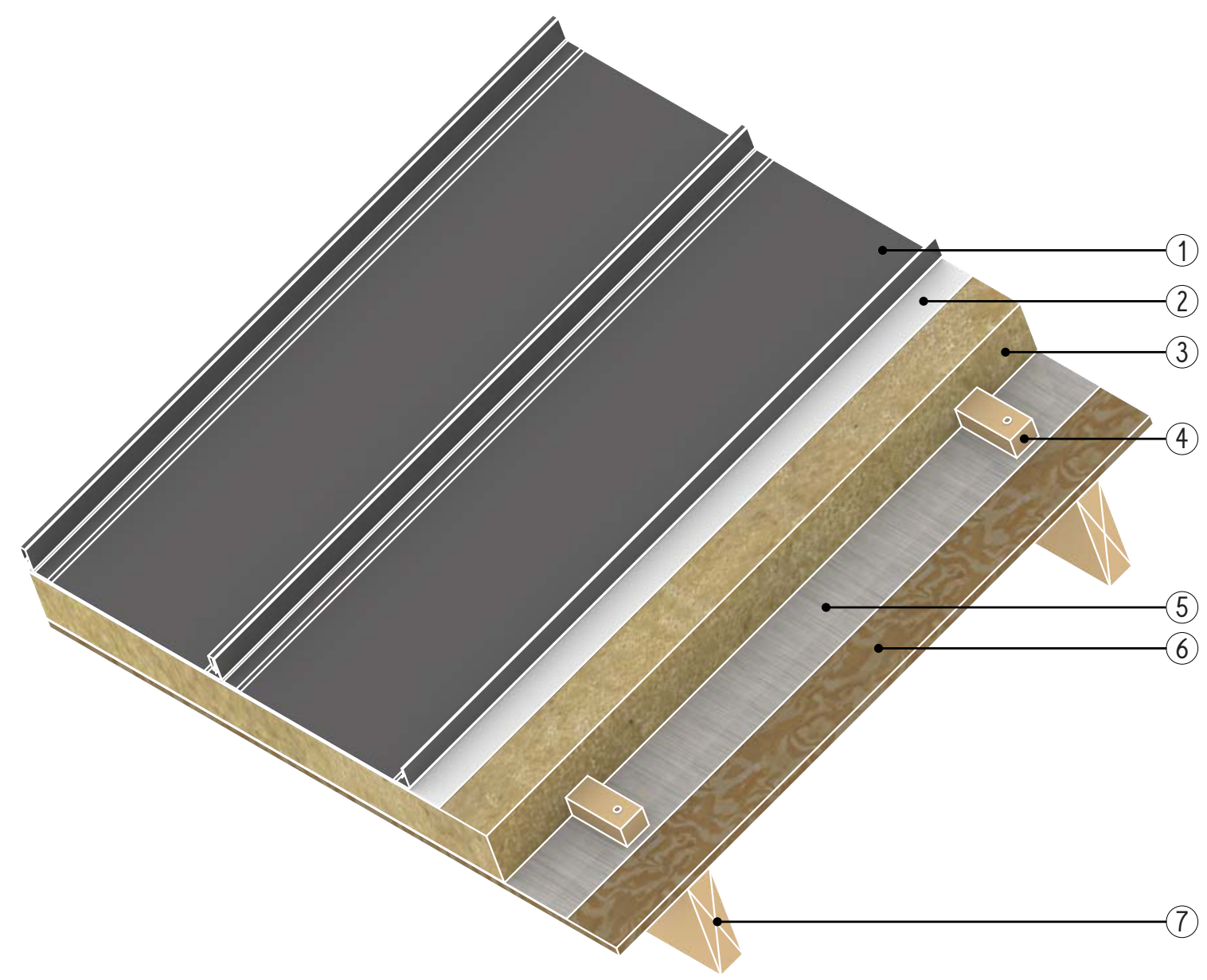

Figure 3.64. Pitched roof assembly.

1. Metal standing seam cladding (concealed clip fixed through to timber battens)

2. Roof underlay

3. $100 \mathrm{~mm}$ rock fibre insulation

4. Timber battens fixed through to purlin
5. Class I vapour control layer - air barrier (self-adhered to plywood)

6. $18 \mathrm{~mm}$ plywood

7. Timber purlin 
1. Single ply roofing membrane

2. Gypsum fibreglass coated roof board

3. $100 \mathrm{~mm}$ rock fibre insulation

4. Class I vapour control layer - air barrier (self adhered to plywood)

5. $18 \mathrm{~mm}$ plywood

6. Timber purlin

Figure 3.65. Flat roof assembly.

Envelope design and drawings conclusion. Chapter 3 researches envelope performance by means of the control layer identification key, the NZ timber framed housing critique and the hygrothermal comparison. The findings from these research methods have ultimately lead to confidence in the performance of the building envelope assembly that will be used in the terrace house design in chapter 4. The building envelope roof and wall assemblies described above will be drawn and detailed in order to explore control layer continuity within detail drawings. The control layer identification key demonstrates that the proposed envelope assemblies contain all the crucial control layers. The NZ timber framed housing critique explained how typical building envelopes lack appropiate location of control layers and their continuity. The proposed wall design considers the location of control layers and the exterior location of these ensures control layer continuity is achieveable. The hygrothermal comparison clearly proved the high level of hygrothermal performance and no risk of condensation was present in the wall or roof asemblies. The findings of chapter 3 are developed in the detailed design of a timber framed terrace house design. It's crucial the findings are able to be translated into built realities and that is the aim of the following chapter. 


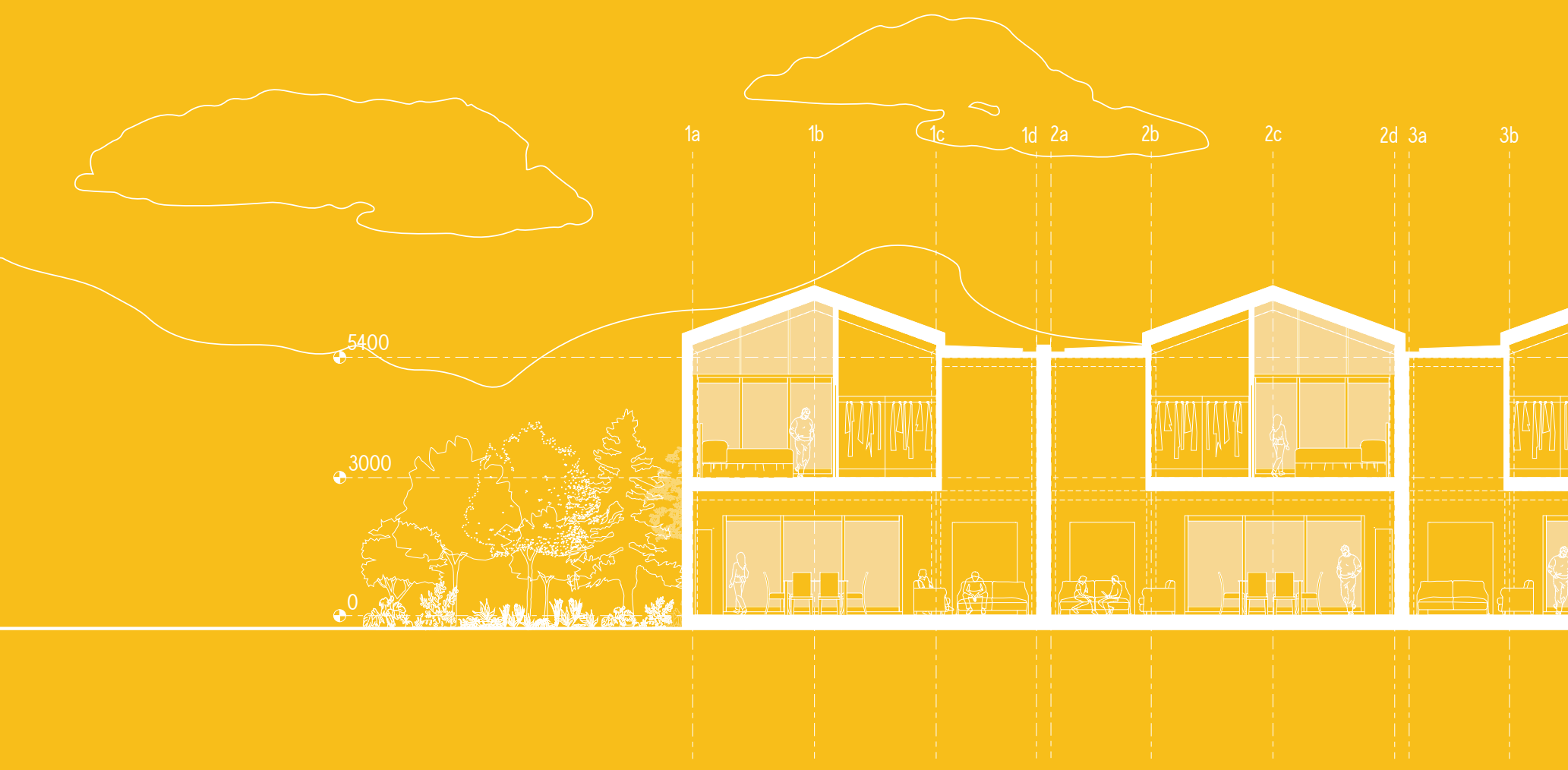



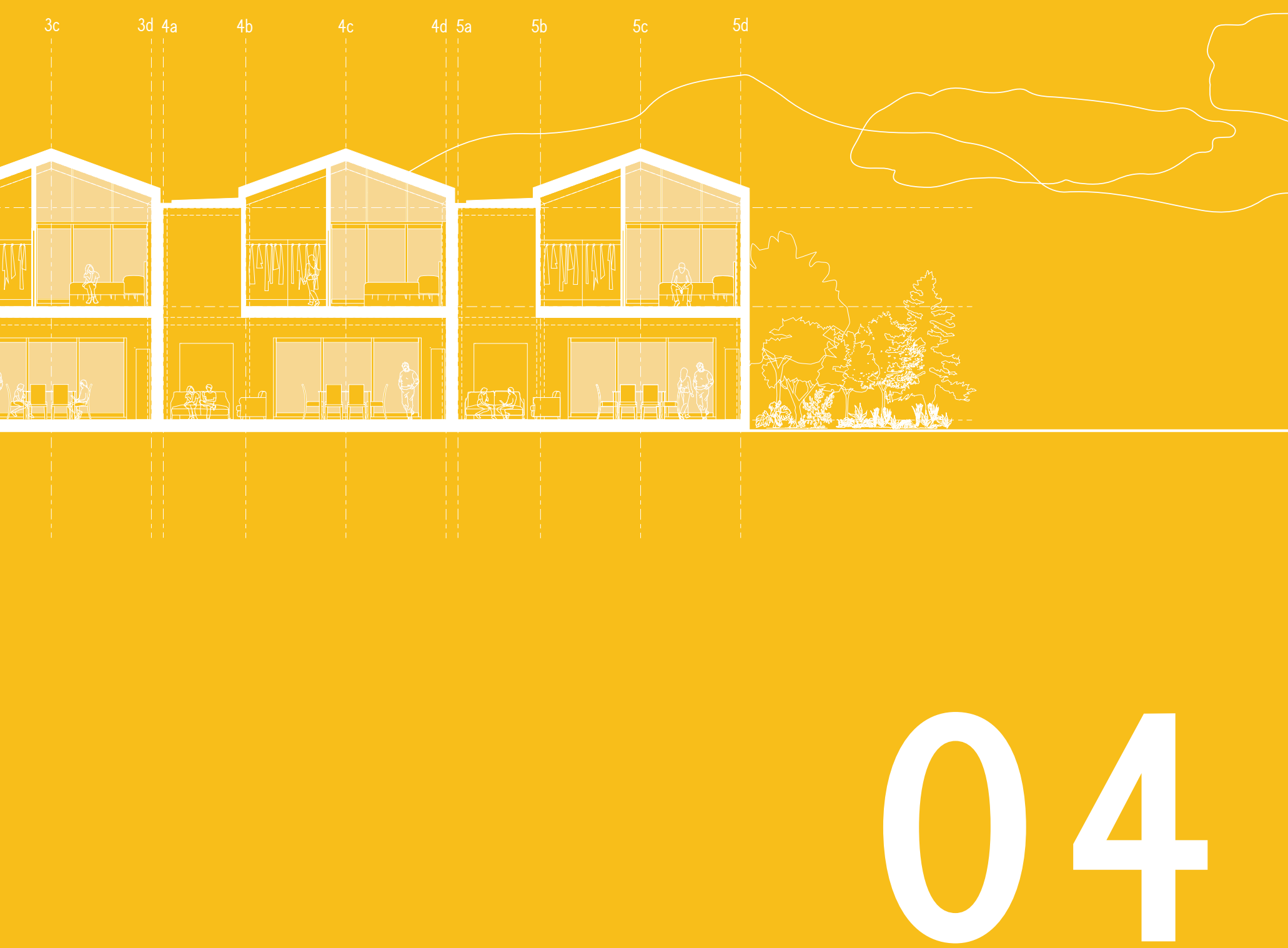

researgh part II terrated house design 


\section{I terrace house design averview}

Overview. The scientific performance of the building envelope can only be accomplished through adequate construction. The primary link between design and construction is the drawings. Drawings enable the design to be transformed into a built reality as they communicate between architects and builders.

In regard to control layer continuity, envelope performance is truly 'in the detail'. Junctions, penetrations, windows and corners are where control layer continuity has the potential to be compromised and therefore readability in relation to these details is essential to the performance outcome.

Terrace houses. A series of timber framed terrace houses have been designed and drawn. Due to recent housing demands, the demand for terrace housing is increasing but so is the need for functional and efficient envelope design. A site has been chosen in Copeland Street, Lower Hutt in order to introduce a sense of reality to the terrace house design.

The nature of terrace housing often results in a repeated design. For the chosen site a set of five repeatable terrace houses have been designed. Besides considering sun orientation, the design is not definitively site specific. The terrace house is used as a mechanism to develop a set of drawings and details which effectively communicate the design of the building envelope.

The drawing set is the outcome of all previous design and research. The drawings begin with an explanation of the building envelope assembly. A singular terrace house is presented in plan and section. Each plan or section is shown in 1:50 scale, and in 1:10 scale where the control layers are identified through the colour coding system. Following each drawing is a series of relevant details in 1:5 scale. Each detail contributes to emphasising the key themes in 'Envelopes Have Layers': performance, readability and buildability.'

For performance, the details are focused on keeping control layer continuity at junctions and interfaces. For buildability, details will be drawn with consideration for on-site sequencing and construction. For readability, the details are to be clear and consistent. The drawing set will not only be applicable to the terrace house design in this thesis but has potential to influence a range of housing projects.

The envelope system. As previously expressed, the building envelope operates as a system and not as individual materials or products. This is rarely communicated in drawings. The building envelope system should be conveyed on drawings with improved clarity so that builders are able to identify the control layers within the building envelope. If a builder has no concept of how an air control layer is required to function and the need for its continuity is not well communicated in detail drawings, less care is likely to be taken to maintain the continuity of that layer, particularly at critical junctions.

How the drawings work. The key to clear and readable drawings is consistency. Consistency between building components, material textures, and scales. The building envelope system and its materials should be easily identifiable on all drawings. The drawing scales allow for greater context as to how the building envelope fits within the building as a whole. 
When collecting drawing sets of other medium density housing projects for use in the drawing critique it was noticed that the majority of the drawing sets went from the scale 1:50 directly to 1:5. This dramatic change in scale creates the potential for valuable information to be missed. In 1:50 scale detail is minimal (e.g., at windows and penetrations) but in 1:5, where it is understood how the detail is built, how the detail fits within the context of the entire building envelope system is lost. Including drawings in 1:10 scale allows representation of the complete building envelope whilst retaining sufficient detail information.

Limitations. It would have been valuable to test the effectiveness of the drawings. However, this is outside the scope of this research. A survey amongst builders asking how they perceive and understand the drawings could be one way to achieve this.
The terrace design characteristics.

- Each terrace house has three bedrooms, one garage, open plan living and dining with double height space, outdoor dining and backyard.

- The double height space allows additional natural light into the living space.

- The large areas of opaque walls allow for better energy efficiency with overall better air-tightness and continuous insulation.

- Skylights add natural light to the hallway and first floor bathroom.

- A large stacker door connects the indoor living to the outdoor living.

- The terrace house arrangement allows for privacy while being open to the landscape.

- The cantilever design gives patio users privacy from the adjacent terrace house.

- The horizontal cladding on the first floor aims to visually emphasise the cantilever.

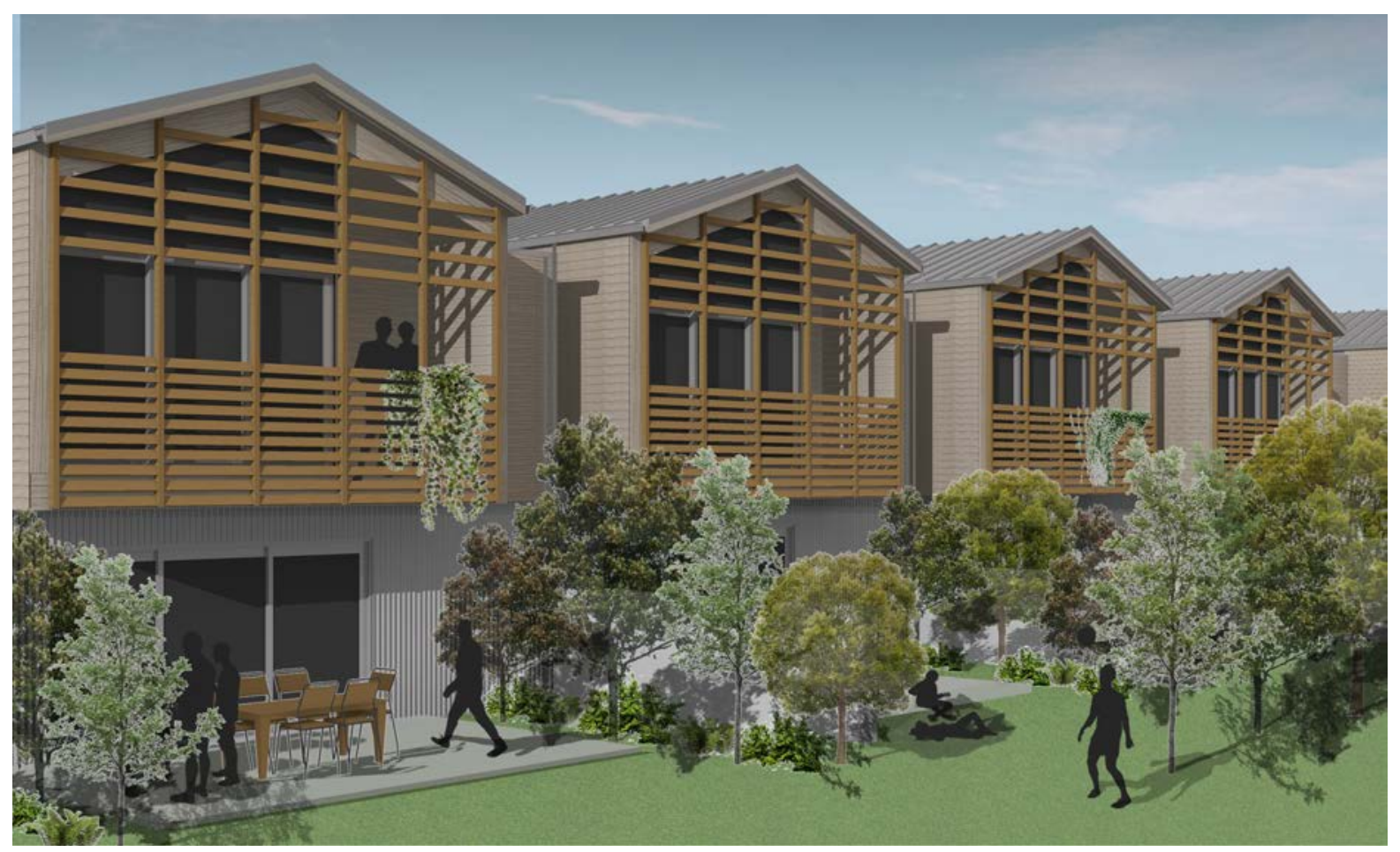

Figure 4.1. Perspective view of the terrace houses. 


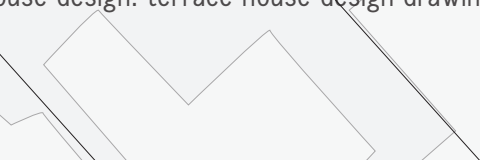

4.2 terrace house design drawings

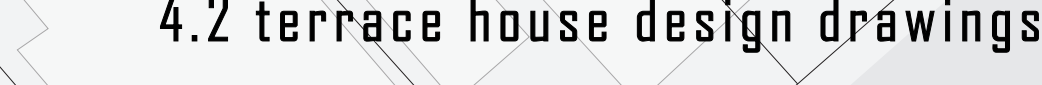





\section{ground floor plan}




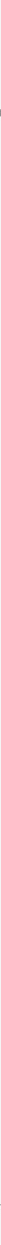




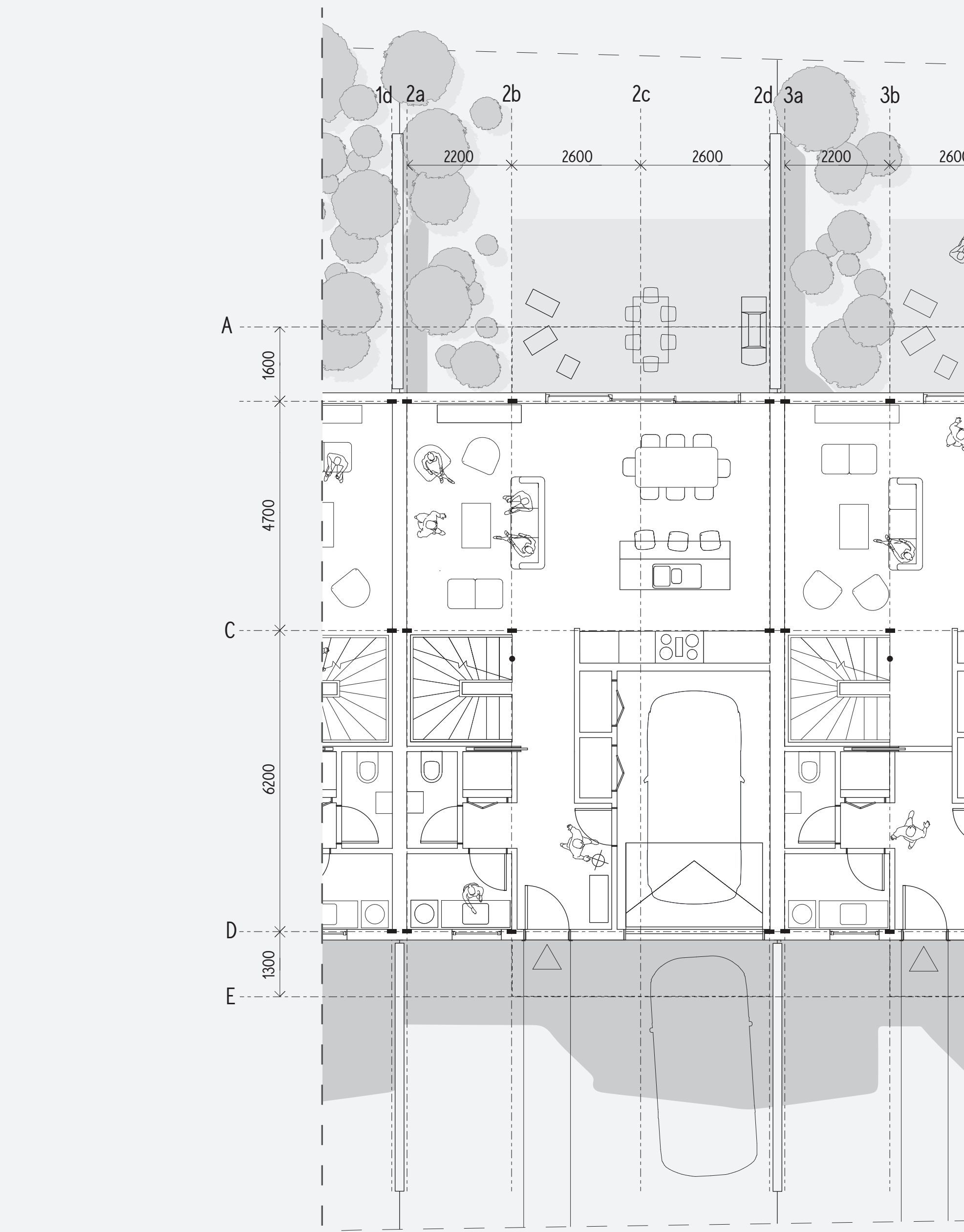

Figure 4.4. Ground floor plan 1:100. 
first floor plan 

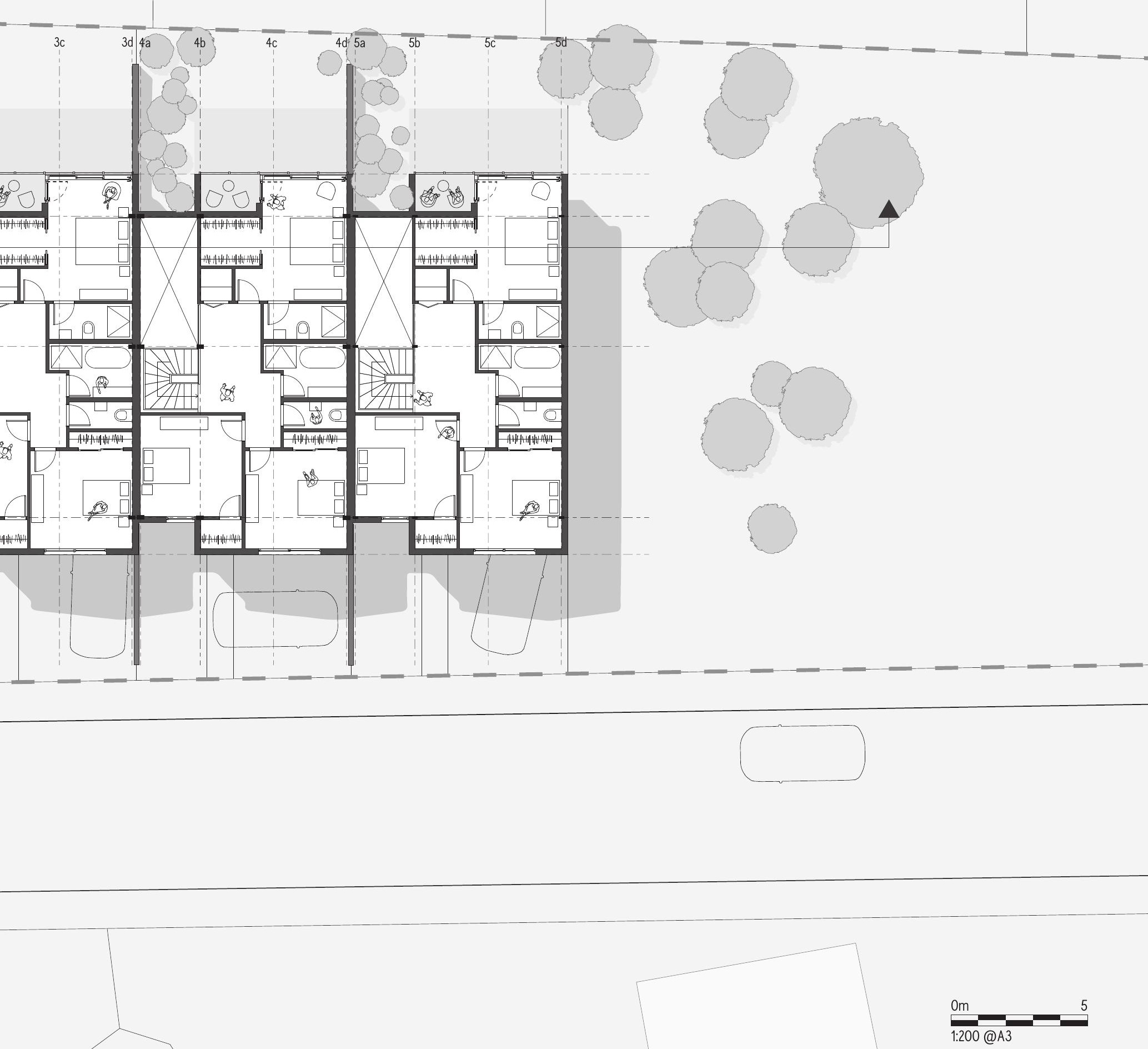


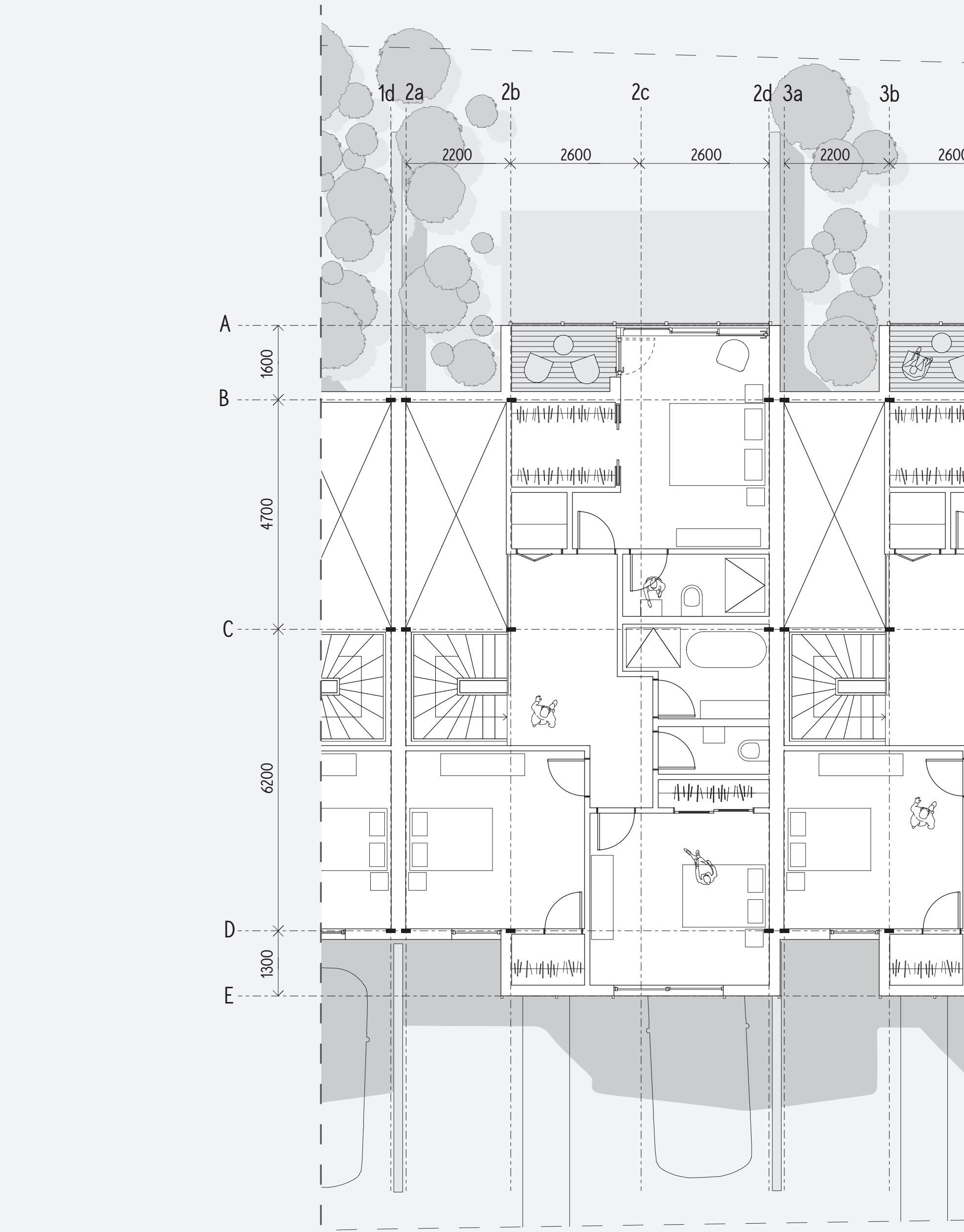

Figure 4.6. First floor plan 1:100. 
site section

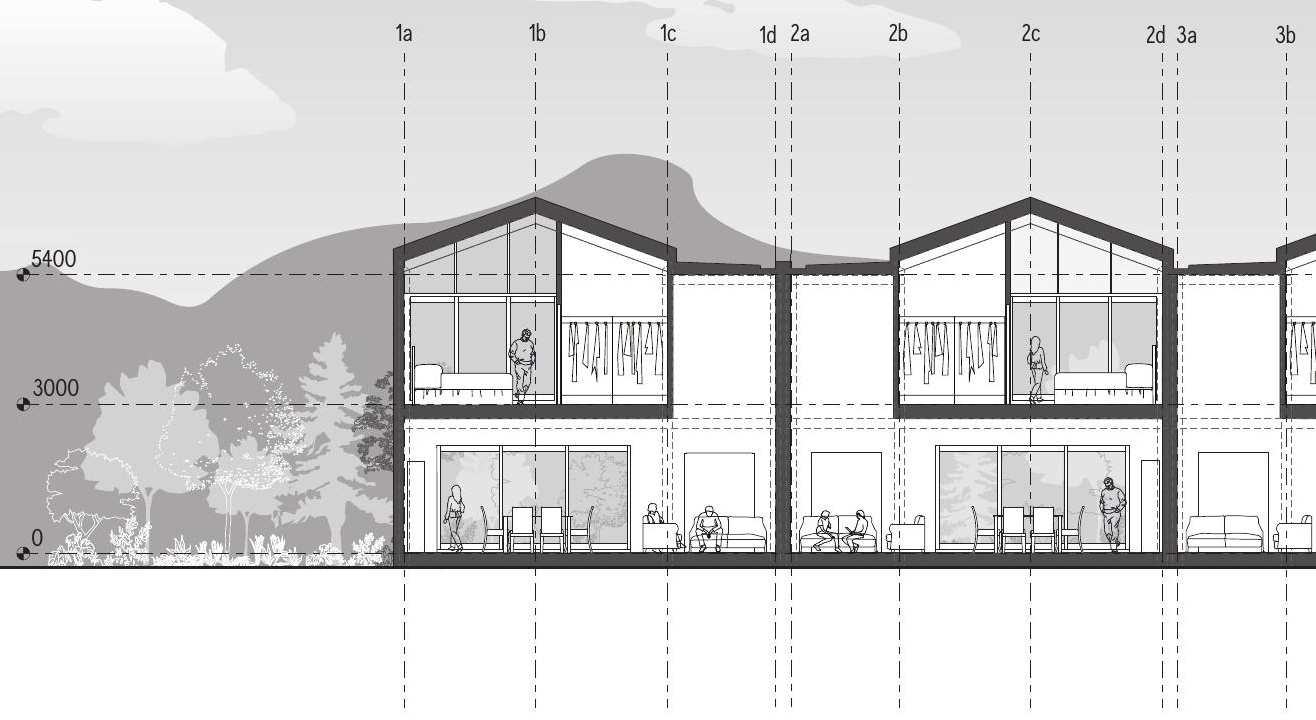




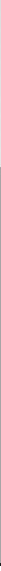


$1 a$

$1 b$

$1 c$

1d 2a

$2 b$

2c

$2 d 3 a$

$3 b$

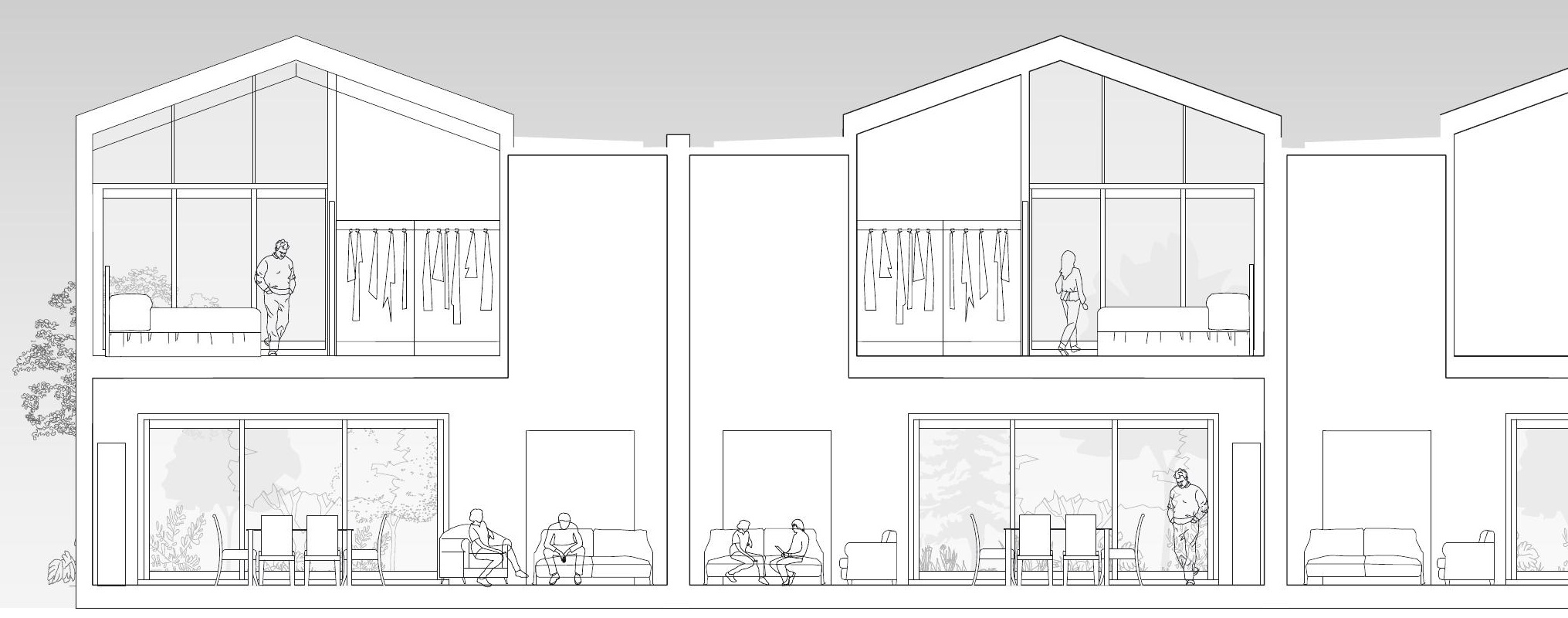


south elevation

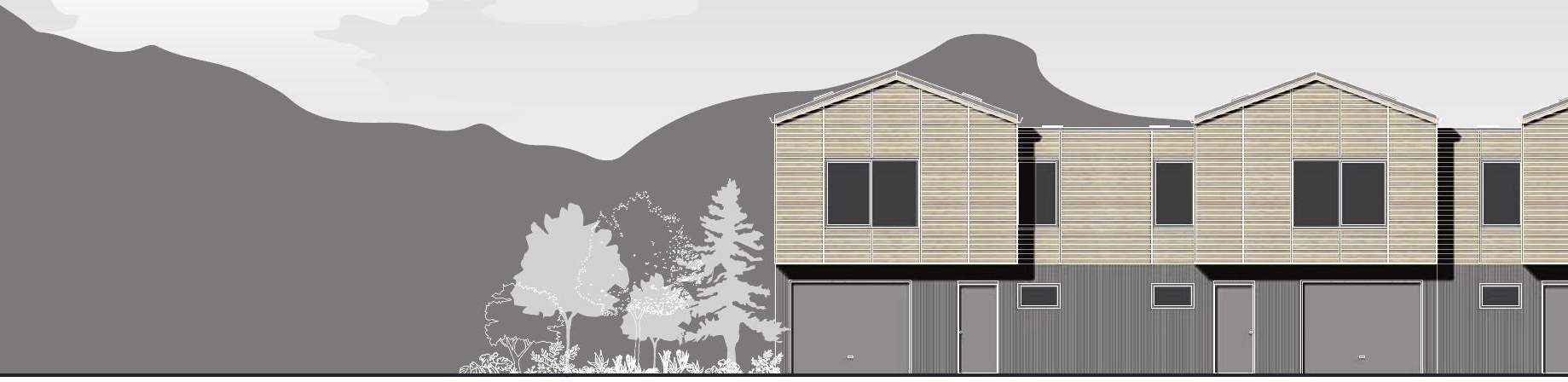


|
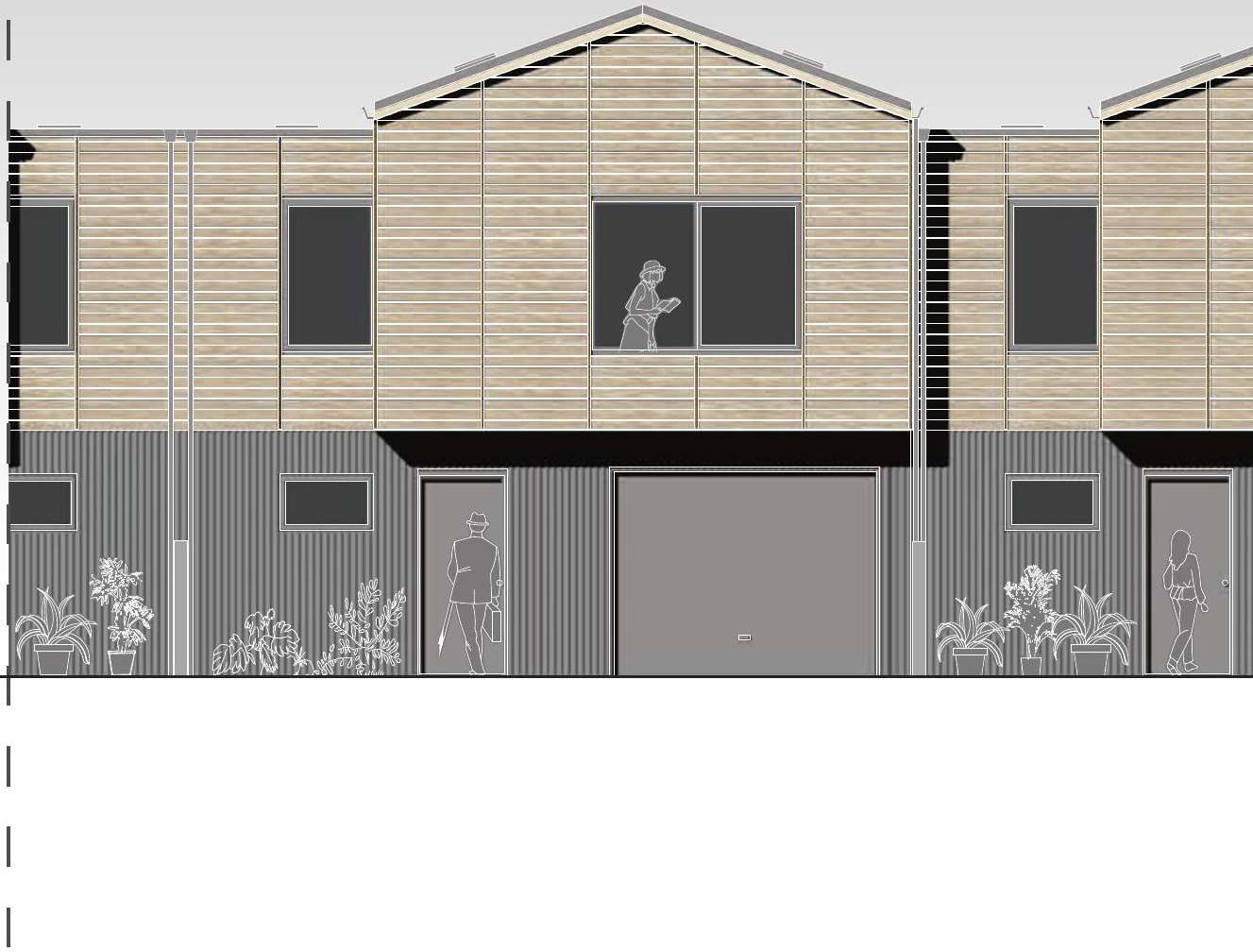

Figure 4.10. South elevation 1:100

page 108 
north elevation

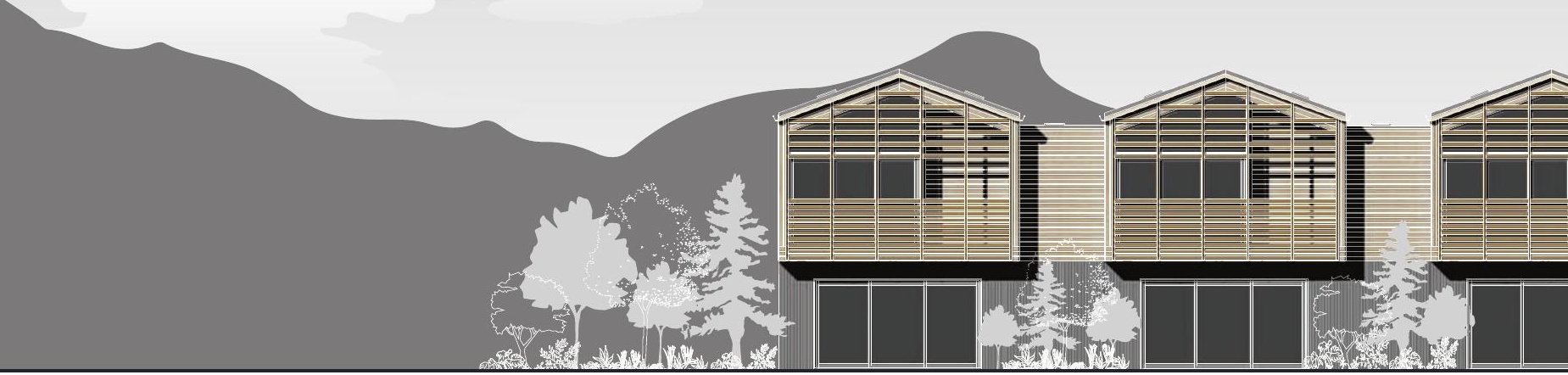




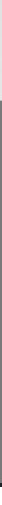




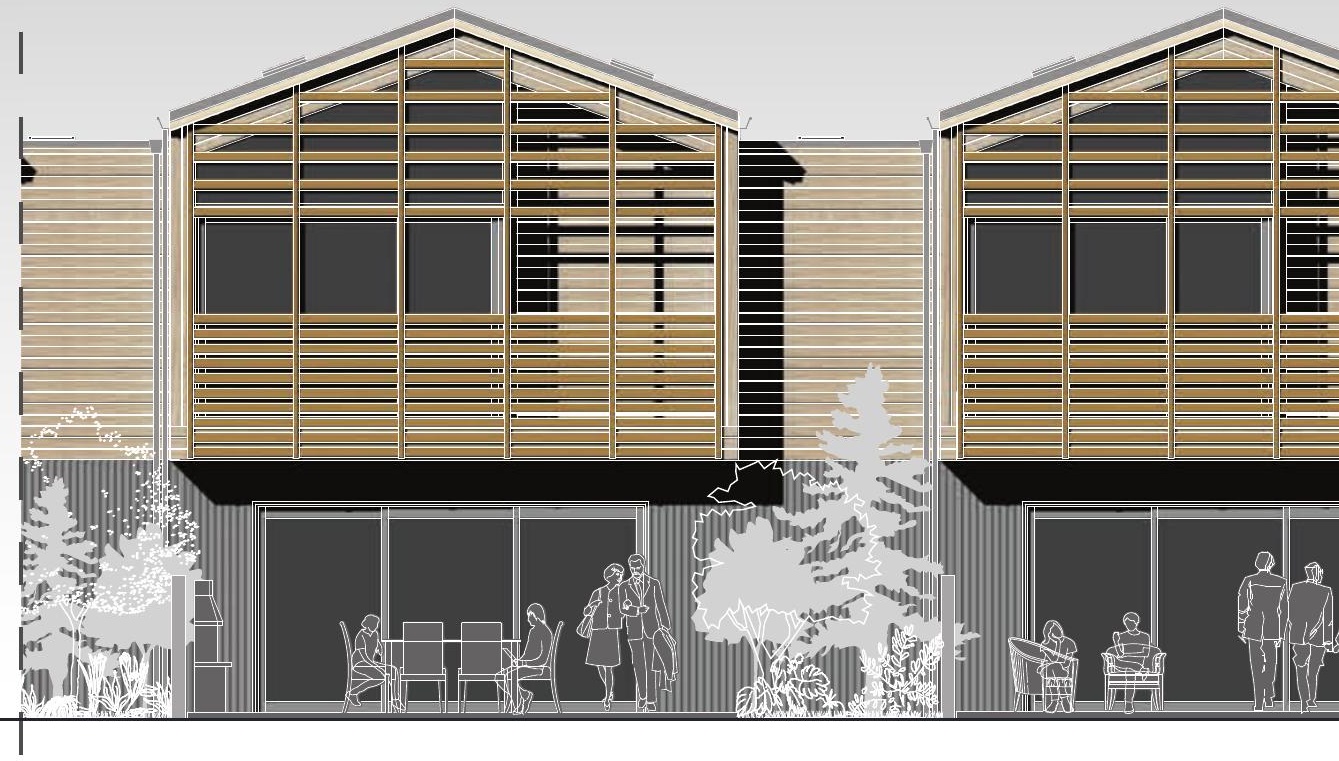




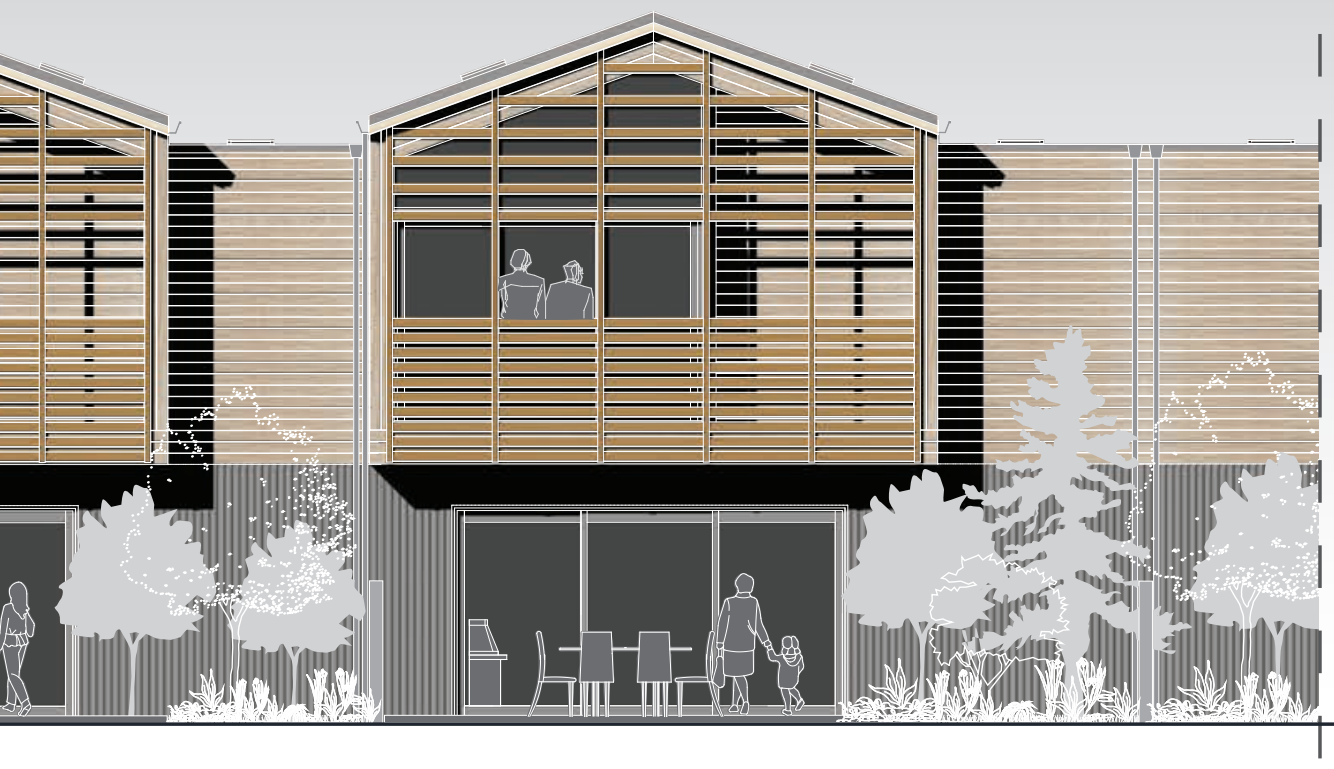




\section{structural design}

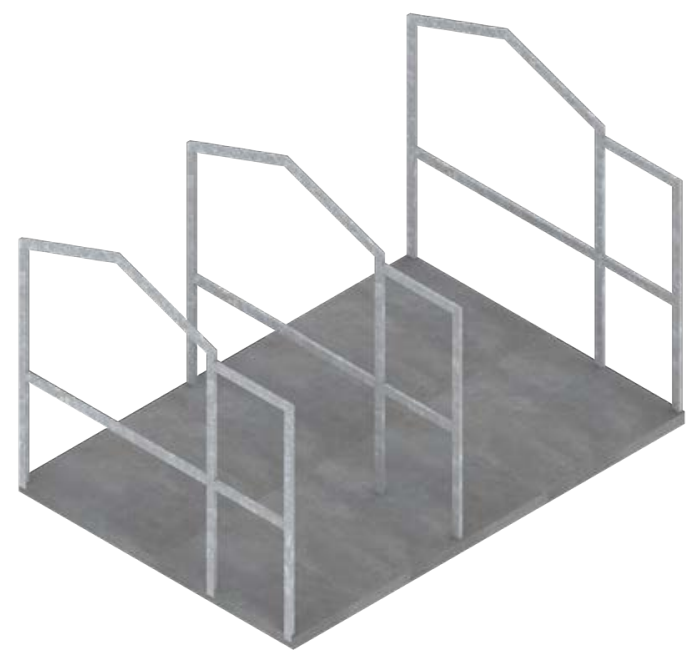

Figure 4.13. Steel structure.

1. Steel structure. $90 \mathrm{~mm} \times 200 \mathrm{~mm}$ rectangular hollow section columns and beams.

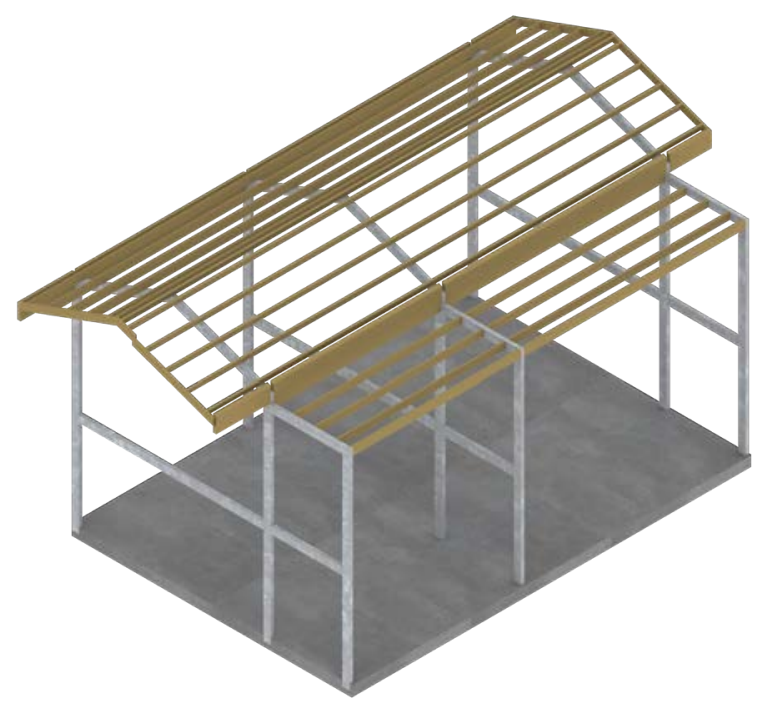

Figure 4.15. Steel structure and roof structure.

3. Timber roof structure. $180 \mathrm{~mm} \times 45 \mathrm{~mm}$ timber purlins installed over steel structure of pitched roof. $200 \mathrm{~mm} \times 45 \mathrm{~mm}$ timber purlins installed between steel structure of flat roof.

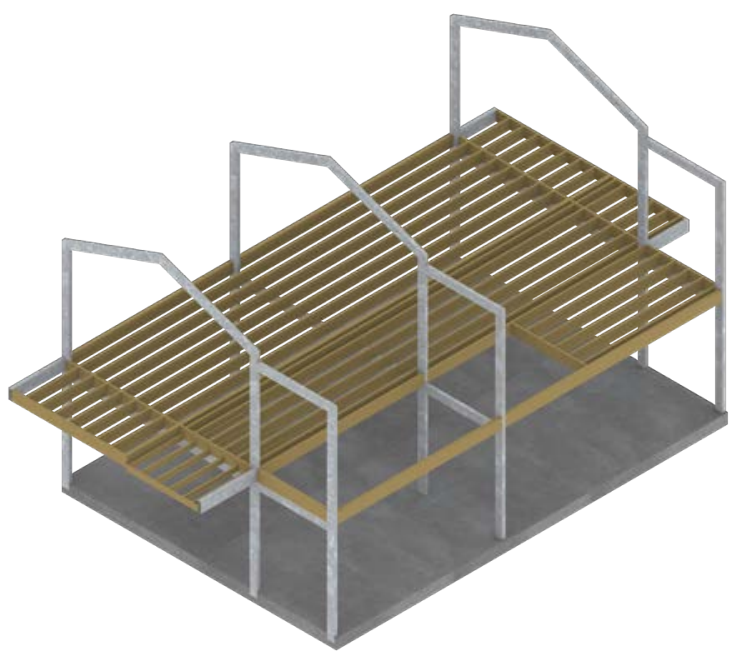

Figure 4.14. Steel structure and floor structure.

2. Timber floor structure. $290 \mathrm{~mm} \times 45 \mathrm{~mm}$ timber joists. $140 \mathrm{~mm} \times 45 \mathrm{~mm}$ cantilever joists for deck framing (deck joists fixed to floor joists).

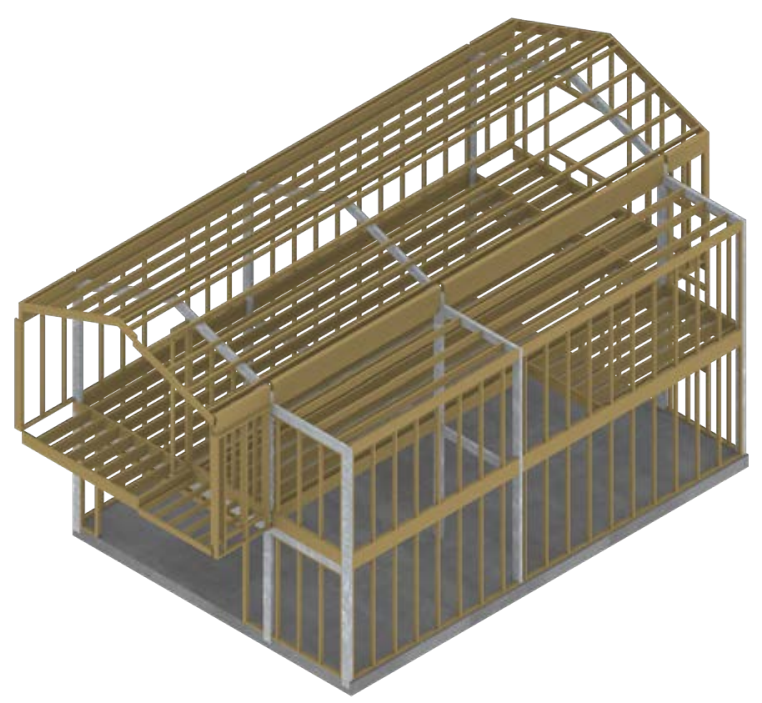

Figure 4.16. Steel structure, floor structure, roof structure and wall framing.

4. Timber framing. $90 \mathrm{~mm} \times 45 \mathrm{~mm}$ timber studs. $90 \mathrm{~mm} \times 45 \mathrm{~mm}$ top and bottom plates. 


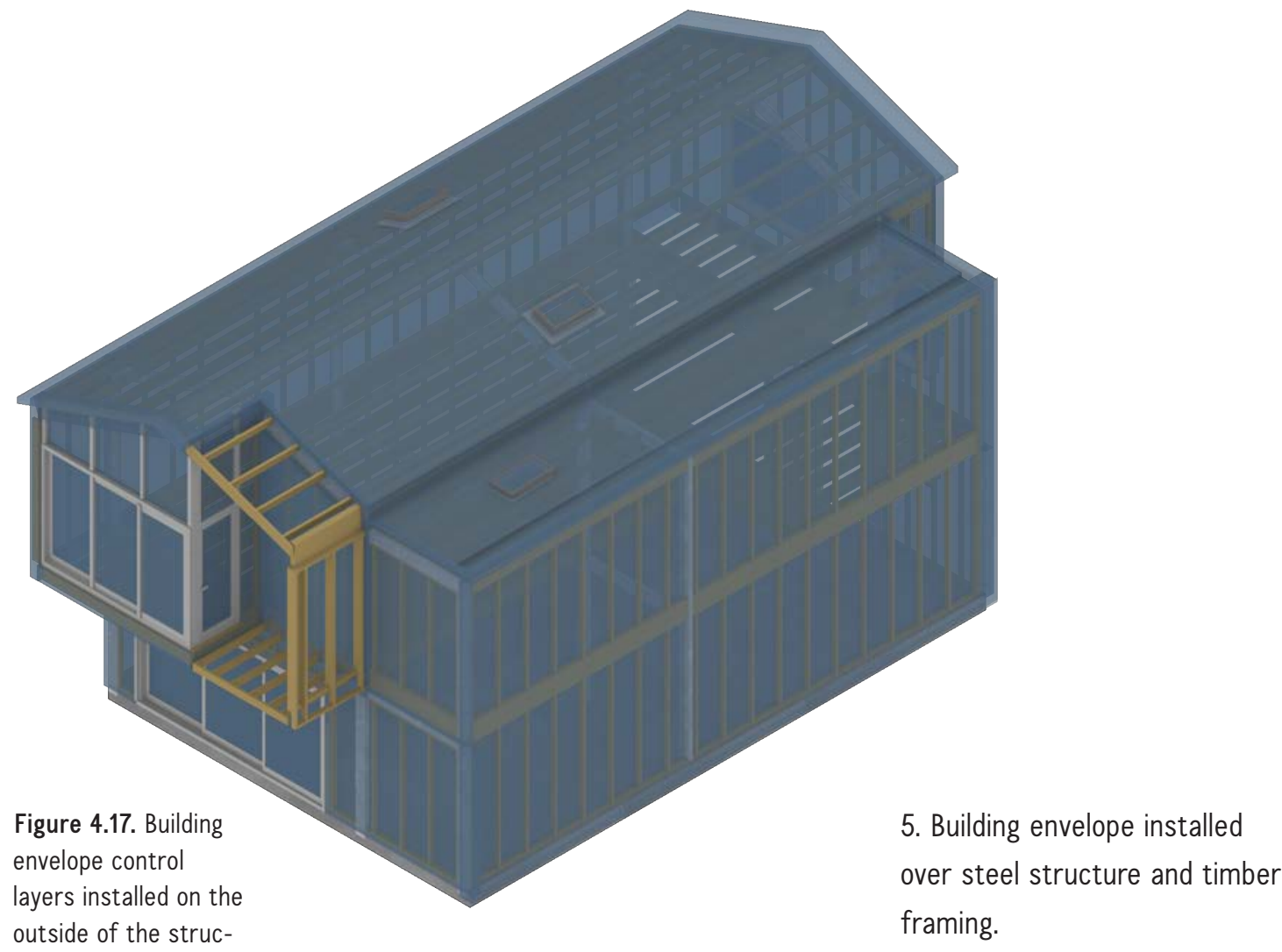

shown in blue).

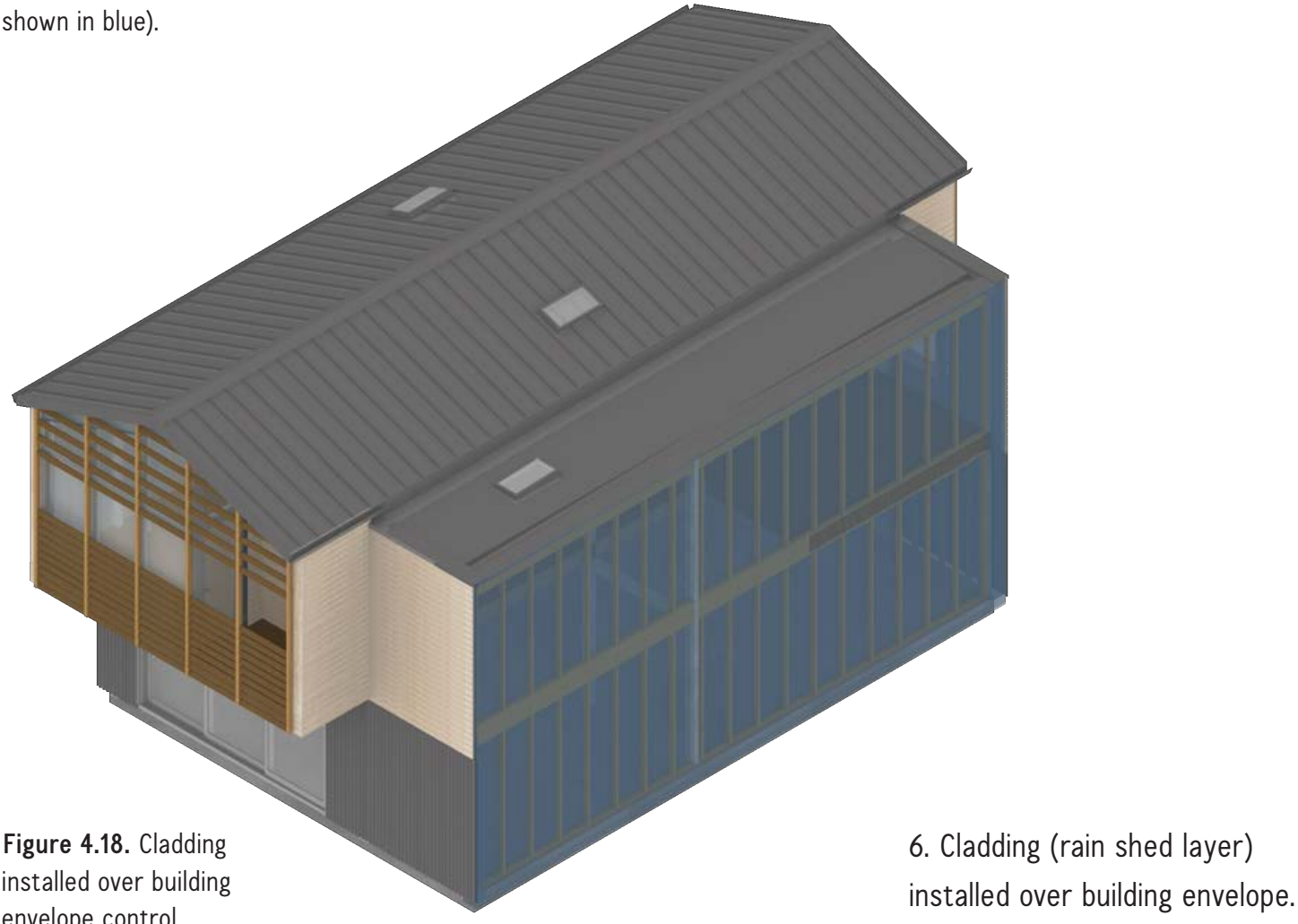

envelope control

installed over building envelope.

layers. 


\section{3 detail design}

Drawing consistencies. To ensure optimum drawing readability all detail drawings at each represented scale should be consistent in the way materials and building information is expressed. The representation of control layers in the same in every scale.

Drawing colour. While in some cases, colour may add valuable information to detail drawings (for example the control layer identification key), it is understood that builders may not have access to colour drawings on site. It is therefore important that identification of materials and construction sequencing is not reliant on colour.

Detail key. The detail key applies to all drawings. It allows users to quickly identify materials on drawings. A key at the start of a drawing set makes viewers aware of the range of materials involved in the project.

Detail annotations. In order to achieve clarity of the drawn detail, the addition of written information on the drawing is keep to a minimum. For this reason, a numbered key is used to annotate relevant aspects of the details.

Line weights. In 1:5 scale line weights play an important role in drawing clarity. Line weights should aim to communicate the importance of components. Structural elements have the thickest line. The rain-air-vapour control layer is shown as a thick continuous element. The individual laps of the layer are represented this way to demonstrate their equal importance to the layer itself.

Exploded details. Typical NZ details are often drawn will the elements slightly exploded with the purpose of bringing clarity to the individual components. However, by having small gaps between the components, the scale of the detail is no longer accurate. This can be misleading as parts of assemblies appear out of proportion to the built reality. The following detail drawings have been drawn to an accurate scale. In the case where a flashing tape is shown, this will overlap the element next to it to remain at an accurate scale.

The following drawings and details focus on control layer continuity of envelope control layers while delivering a functional and buildable design. 
detail key

Recycled fibreglass insulation

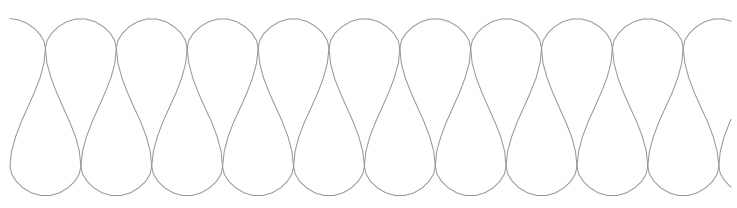

Rigid rock fibre insulation

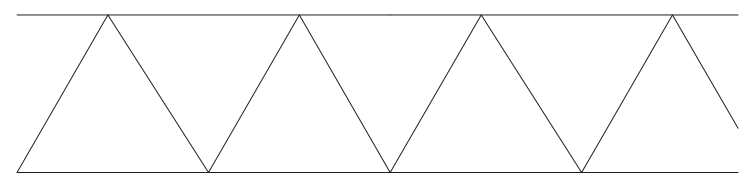

Extruded polystyrene

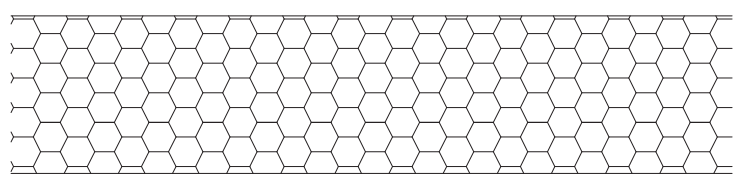

Exterior gypsum sheathing

Rain, air and vapour control layers

Single ply membrane

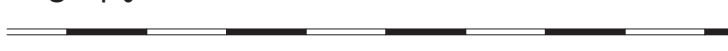

Interior gypsum board
Timber shiplap cladding

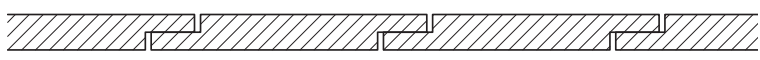

Corrugate metal cladding profile

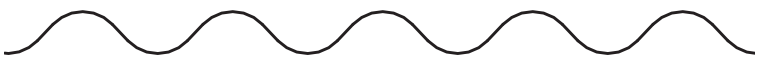

Standing seam metal cladding profile

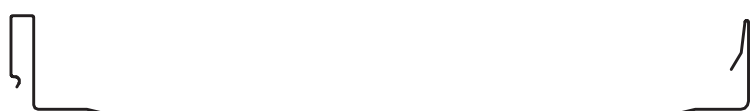

Metal bracket
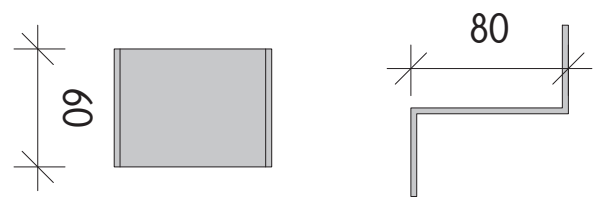

Timber framing

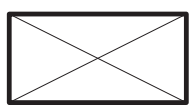
1.

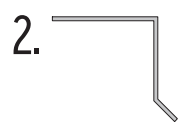
3. 4.

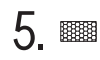
6.
7. ำmmin
8. $\mathbb{1}$
9. $\$ 0$

1. Metal batten

2. Metal flashing

3. Cavity closer (timber cladding)

4. Cavity closer (metal cladding)

5. Compressible foam air seal

6. Steel screw

7. Timber screw

8. Rivet

9. Backer rod and sealant

Figure 4.19. Detail key. 


\section{wall assembly}
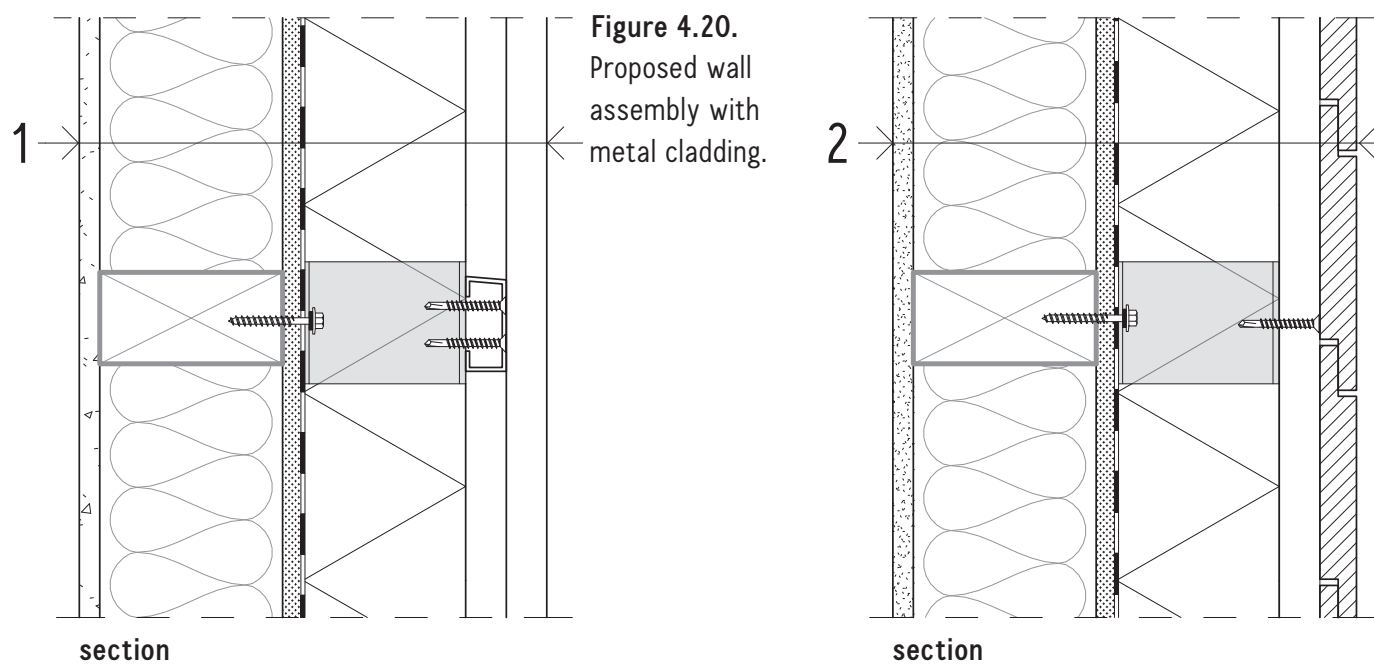

Figure 4.21.

Proposed wall assembly with timber cladding.

section

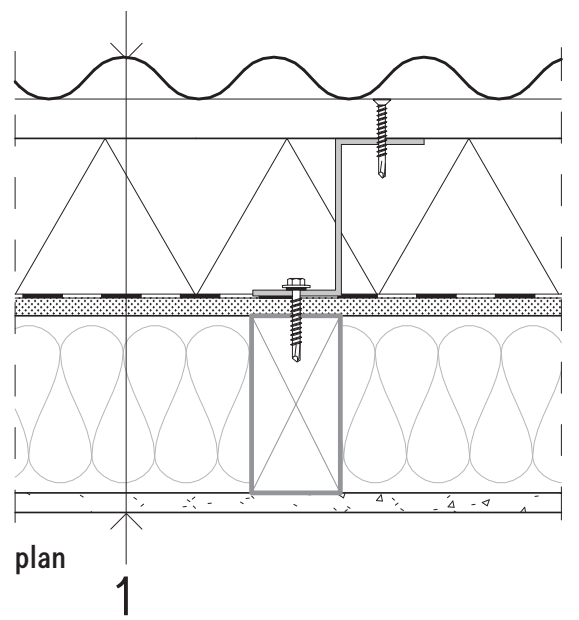

1. wall assembly

$10 \mathrm{~mm}$ gypsum board interior lining

$90 \mathrm{~mm} \times 45 \mathrm{~mm}$ timber framing with recycled fibreglass insulation

$12.7 \mathrm{~mm}$ gypsum sheathing with fibreglass coating class II vapour control layer (air barrier and drainage plane)

$60 \mathrm{~mm}$ metal brackets for batten attachment

$80 \mathrm{~mm}$ rigid rock fibre insulation

$20 \mathrm{~mm} \times 45 \mathrm{~mm}$ horizontal metal batten vertical metal corrugate cladding

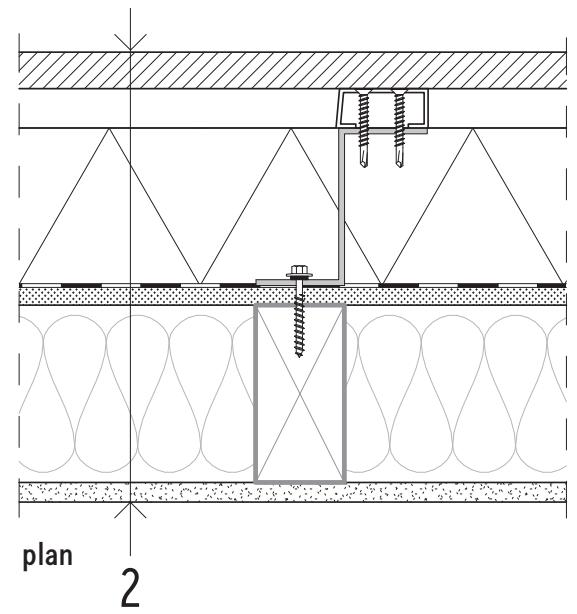

\section{2. wall assemlbly}

$10 \mathrm{~mm}$ gypsum board interior lining

$90 \mathrm{~mm} \times 45 \mathrm{~mm}$ timber framing with recycled fibreglass insulation

$12.7 \mathrm{~mm}$ gypsum sheathing with fibreglass coating class II vapour control layer (air barrier and drainage plane)

$60 \mathrm{~mm}$ metal brackets for batten attachment

$80 \mathrm{~mm}$ rigid rock fibre insulation

$20 \mathrm{~mm} \times 45 \mathrm{~mm}$ vertical metal batten horizontal timber panel cladding

Wall assembly notes applied to all drawings.

Recycled fibreglass cavity insulation must not exceed R-2.1. Class II vapour control layer self-adhered to fibreglass coated gypsum sheathing with minimum 100mm overlaps. Aluminium bracket fixed through to structure @600 centres followed by 80mm rock fibre insulation fixed back into structure. 20mm x 45mm metal batten fixed to aluminium brackets @600 centres. 


\section{roof assembly}
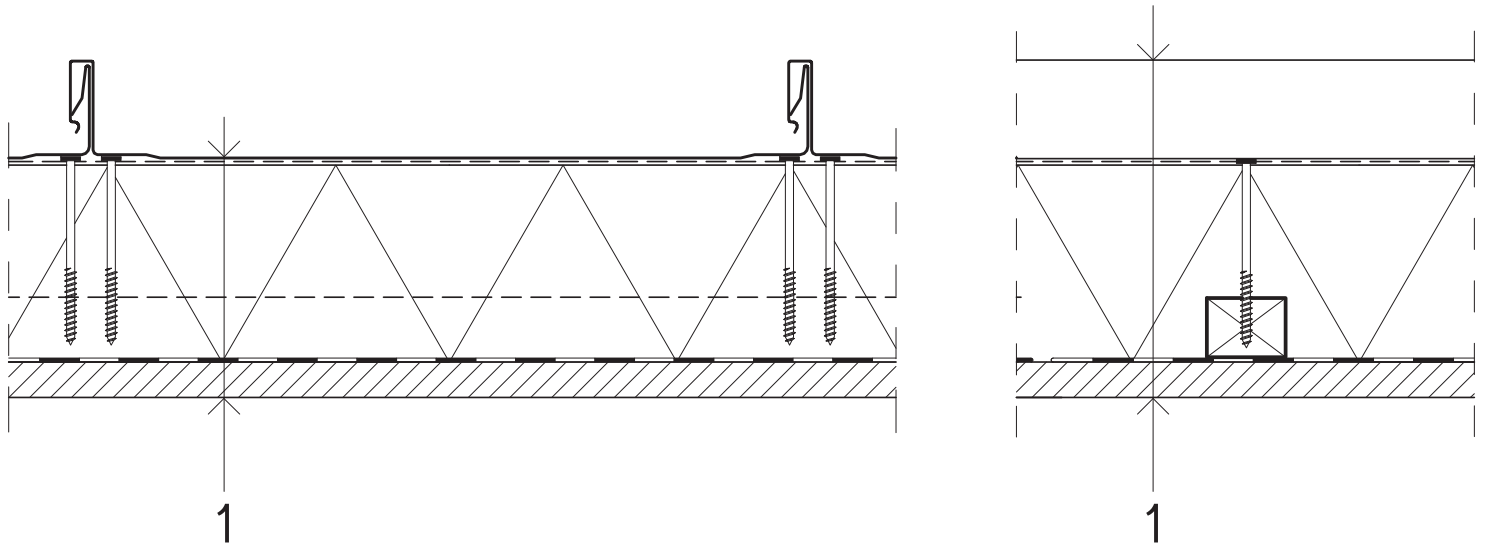

Figure 4.22. Proposed pitched roof assembly with metal cladding.

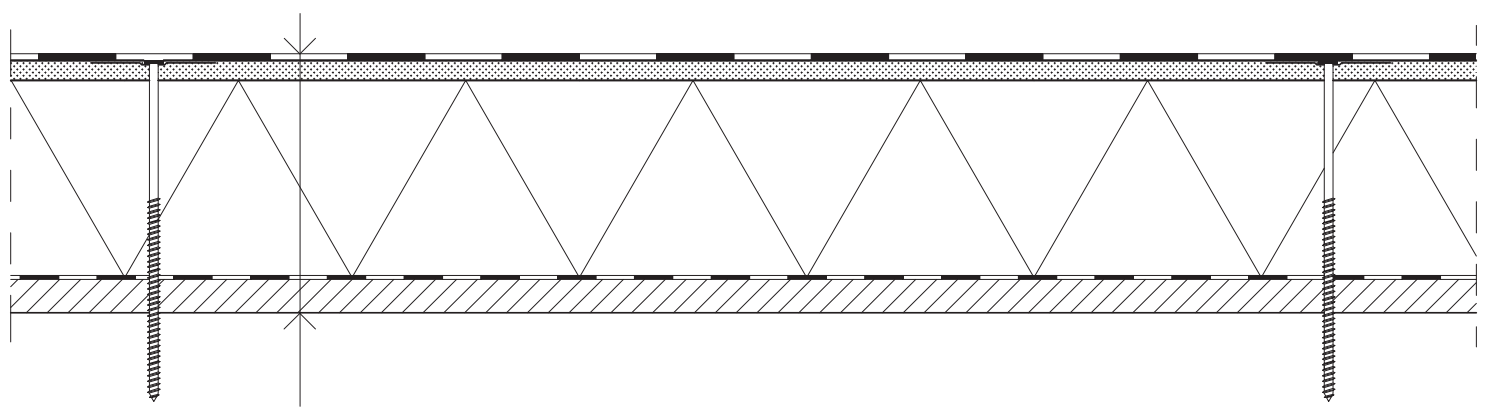

2

Figure 4.23. Proposed flat roof assembly with single ply membrane.

\section{1. roof assemlbly}

$18 \mathrm{~mm}$ plywood substrate

class I vapour control layer (air barrier)

$40 \mathrm{~mm} \times 45 \mathrm{~mm}$ timber battens fixed through to purlins

$100 \mathrm{~mm}$ rigid rock fibre insulation

roof underlay

hidden roofing clips fixed through to timber battens

standing seam metal cladding installed onto clips

\section{2. roof assemlbly}

$18 \mathrm{~mm}$ plywood substrate

class I vapour control layer (air barrier)

$100 \mathrm{~mm}$ rigid rock fibre insulation

$10 \mathrm{~mm}$ gypsum roof board fixed through to purlins single ply membrane adhered over roof board

Roof assembly notes applied to all drawings.

Class I vapour control layer is self-adhered to the plywood substrate in both roof assemblies. Timber battens in metal cladding assembly are fixed @800 centres through to the timber purlins. Single ply membrane must be correctly overlapped (shown on details). At every wall to roof junction the class I vapour control layer must overlap the class II vapour control layer of the wall assembly. 
3

\section{4}

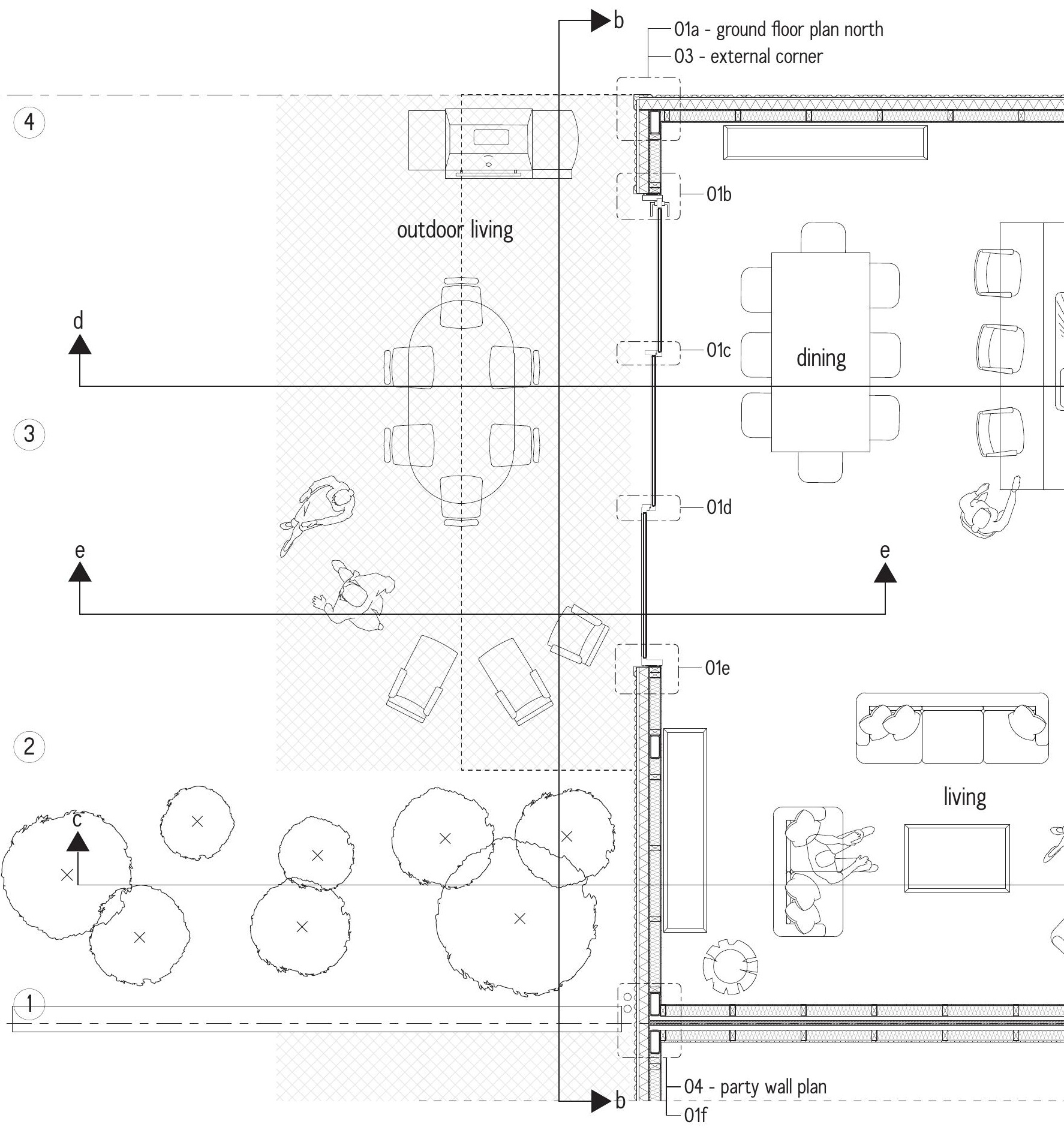

Figure 4.24. Ground floor plan 1:50. 


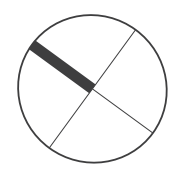

(C)

(D)

(E)

a

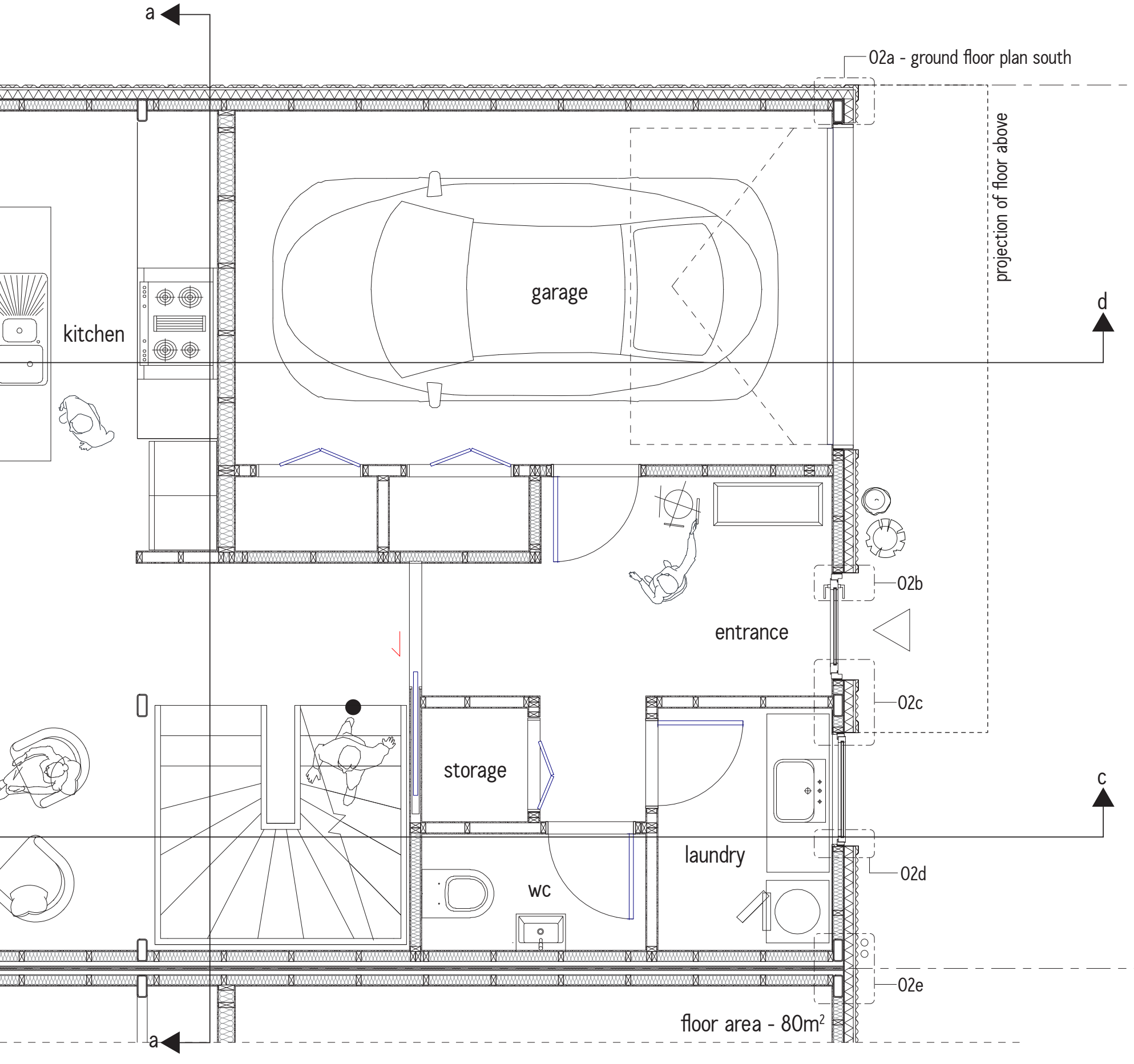




\section{1 - ground plan floor morth}

Envelope control layers are identified with the control layer identification key on 1:10 scale drawings. It is recommended that all building consent drawing sets should include at least one drawing which communicates location and continuity of envelope control layers.
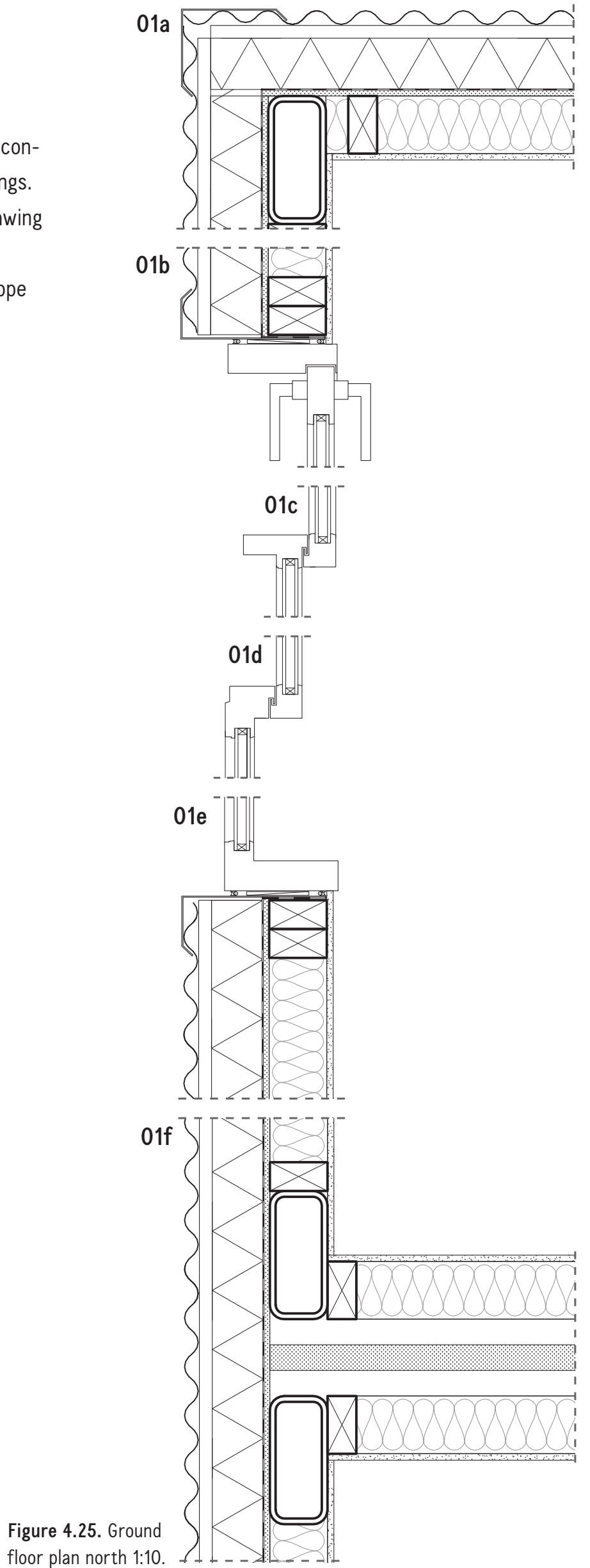

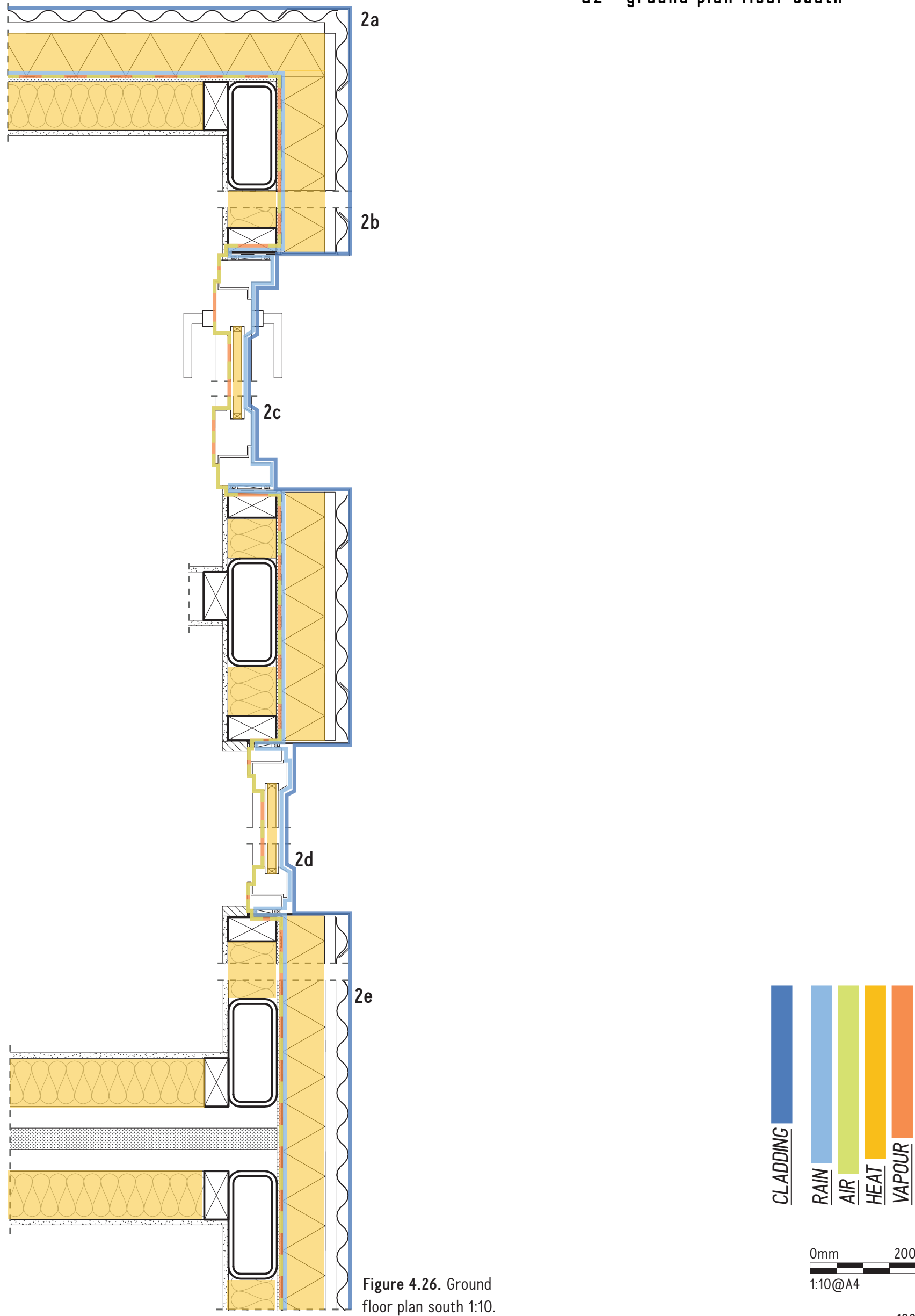


\section{3 - party wall plan}

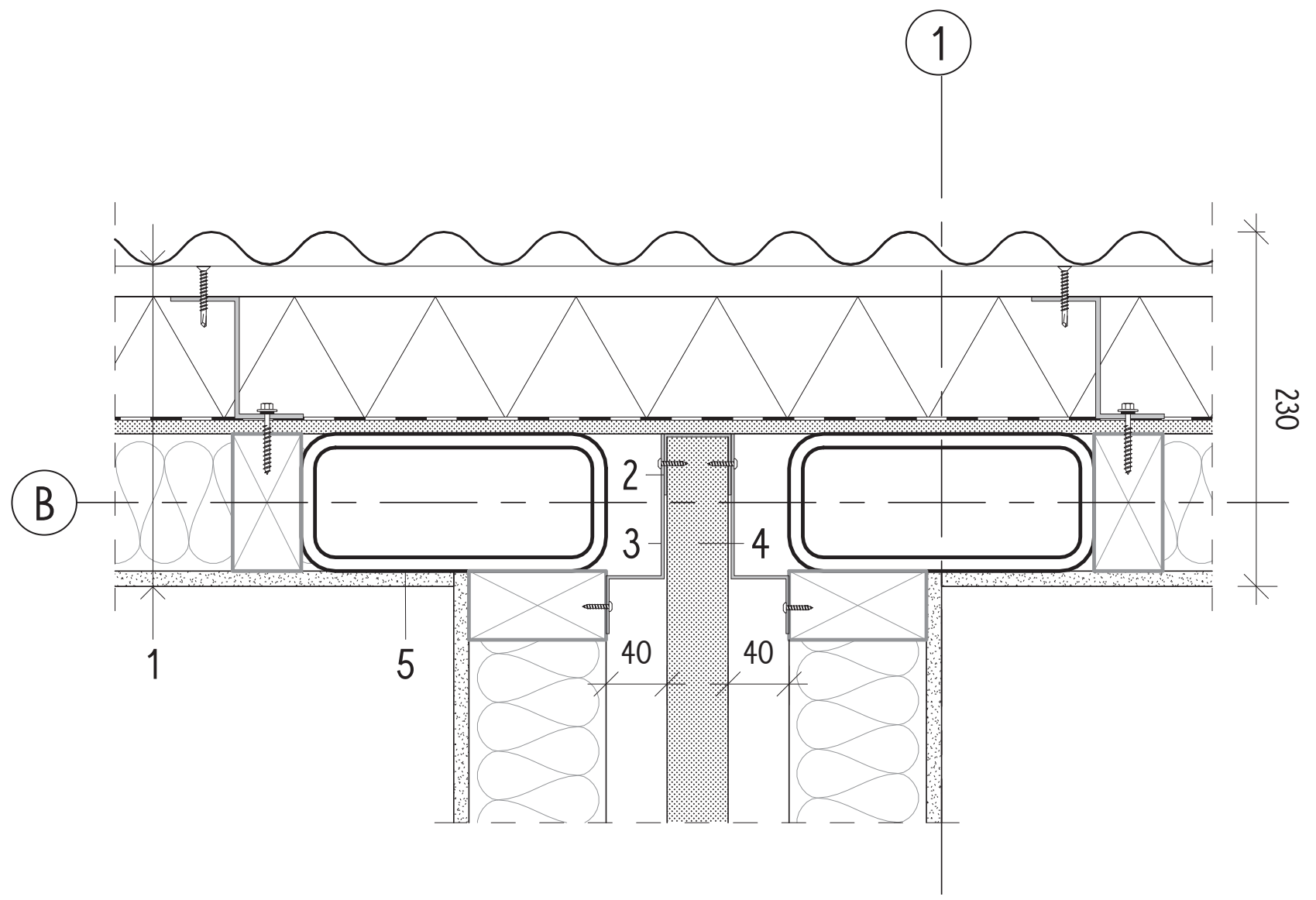

\section{1. wall assemlbly}

$10 \mathrm{~mm}$ gypsum board interior lining

$90 \mathrm{~mm} \times 45 \mathrm{~mm}$ timber framing with recycled fibreglass insulation

$12.7 \mathrm{~mm}$ gypsum sheathing with fibreglass coating class II vapour control layer (air barrier and drainage plane)

$80 \mathrm{~mm}$ rigid rock fibre insulation

$20 \mathrm{~mm} \times 45 \mathrm{~mm}$ horizontal metal batten

vertical metal corrugate cladding
2. party wall continuous metal capping

3. party wall metal brackets

4. party wall

5. $200 \mathrm{~mm} \times 90 \mathrm{~mm}$ hollow section steel column

notes:

Party wall to be installed to manufacturers specifications. 


\section{Q4 - external corner}

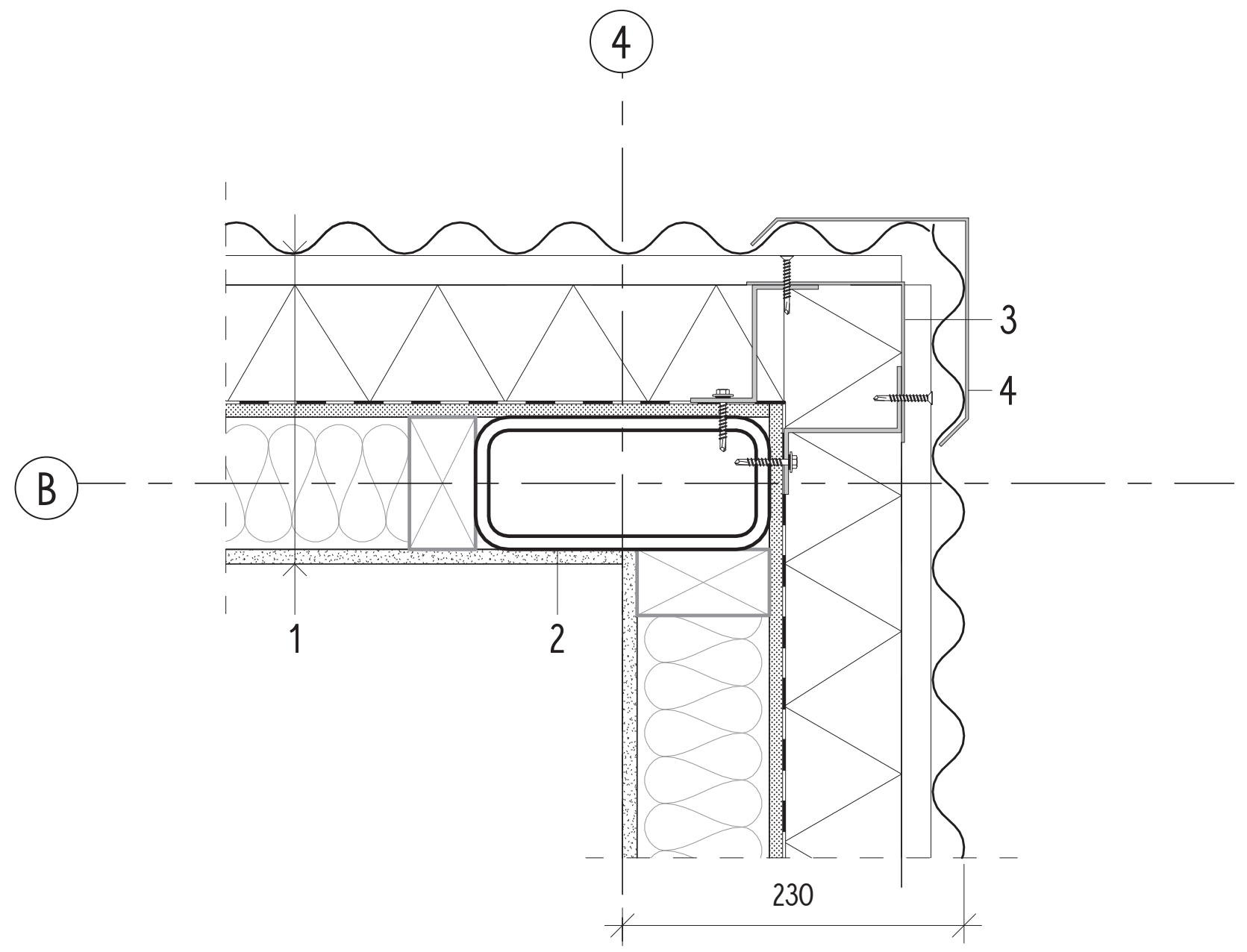

1. wall assemlbly

$10 \mathrm{~mm}$ gypsum board interior lining

$90 \mathrm{~mm} \times 45 \mathrm{~mm}$ timber framing with recycled fibreglass insulation

$12.7 \mathrm{~mm}$ gypsum sheathing with fibreglass coating class II vapour control layer (air barrier and drainage plane)

$80 \mathrm{~mm}$ rigid rock fibre insulation

$20 \mathrm{~mm} \times 45 \mathrm{~mm}$ horizontal metal batten

vertical metal corrugate cladding
2. $200 \mathrm{~mm} \times 90 \mathrm{~mm}$ hollow section steel column

3. external closure flashing fixed to metal brackets

4. external corner flashing 


\section{first floor plan}
A
B

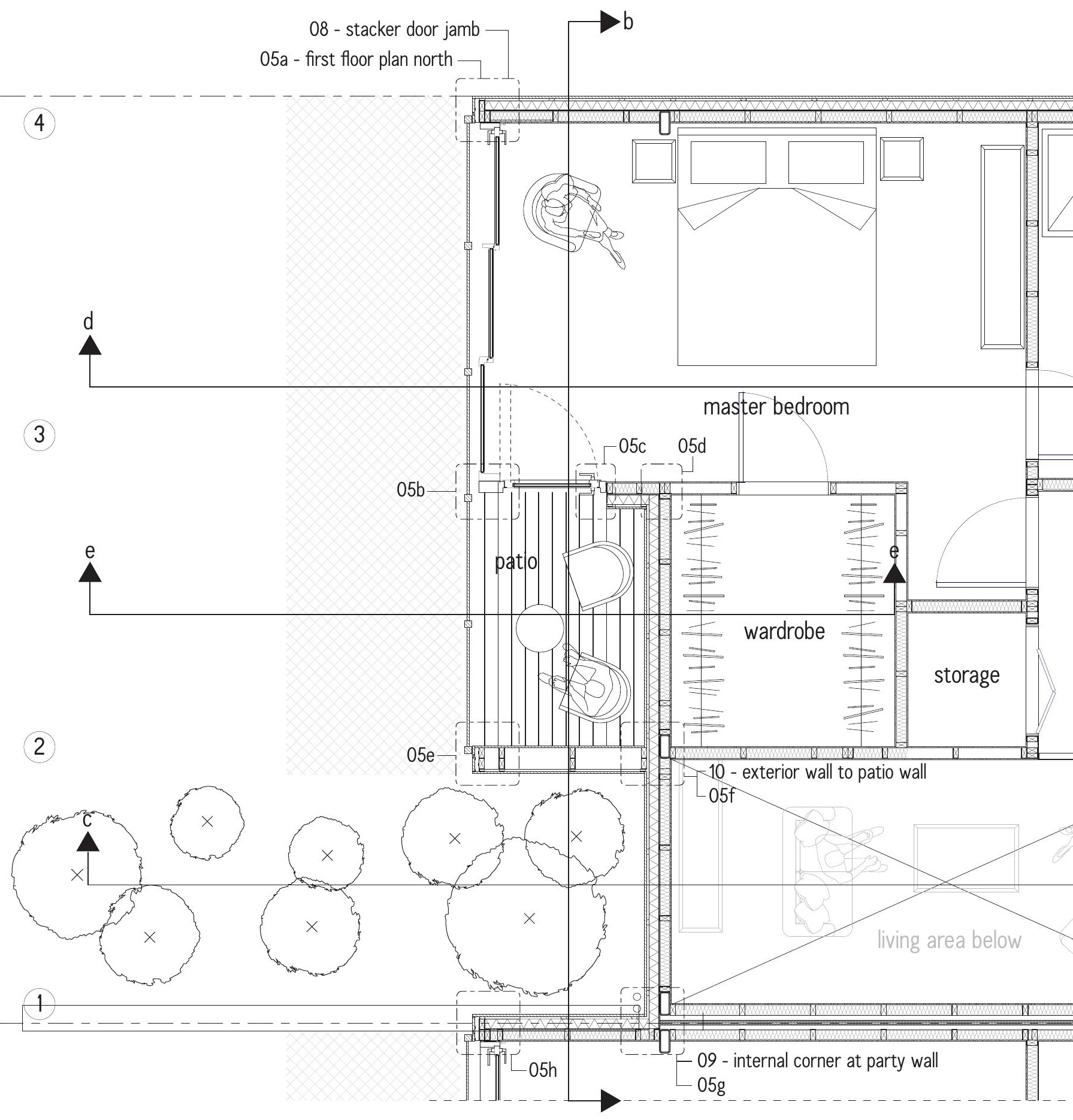

Figure 4.29. First floor plan 1:50. 


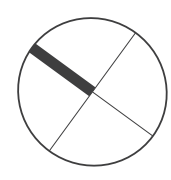

(C)

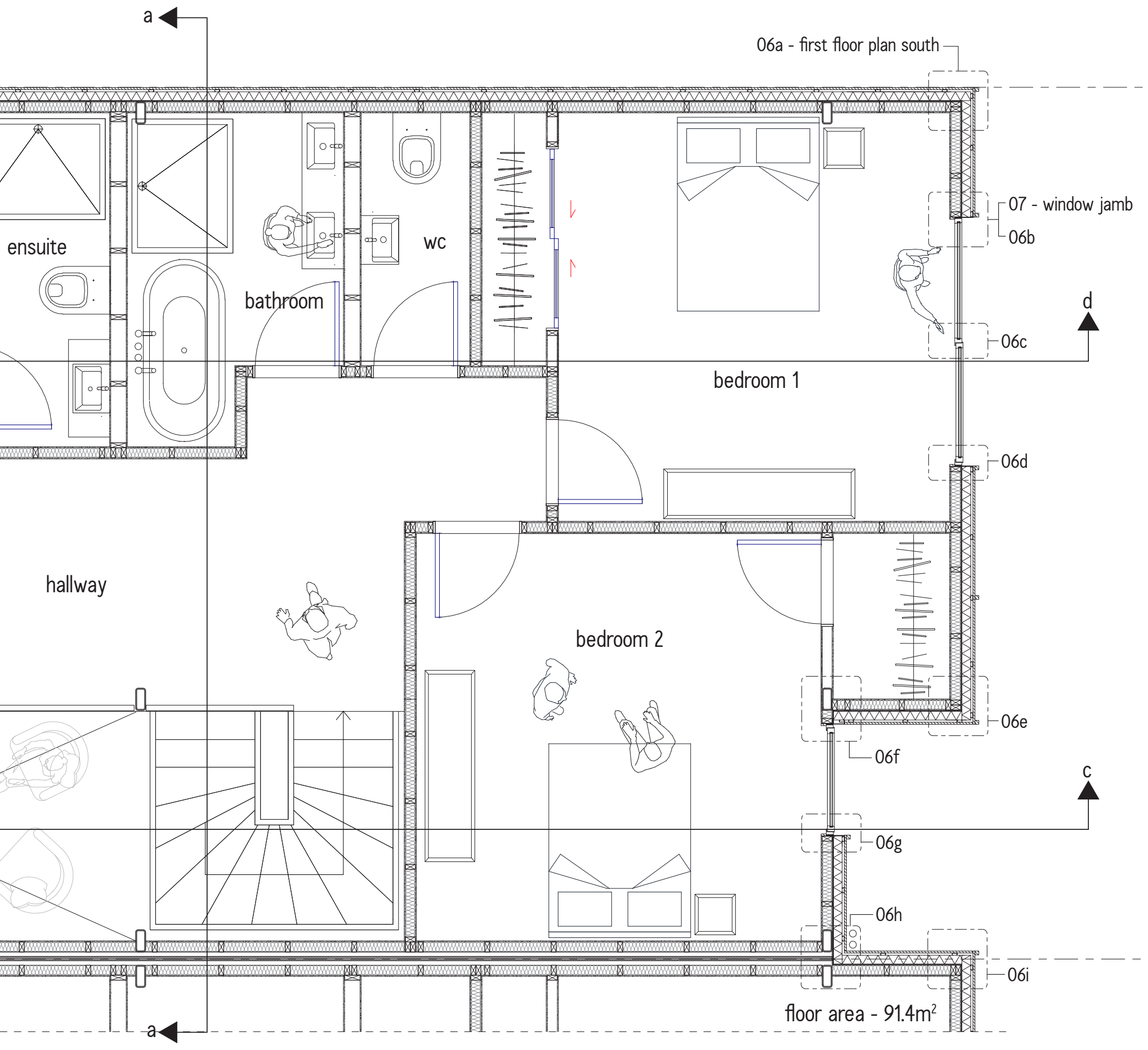


05 - first floor plan north

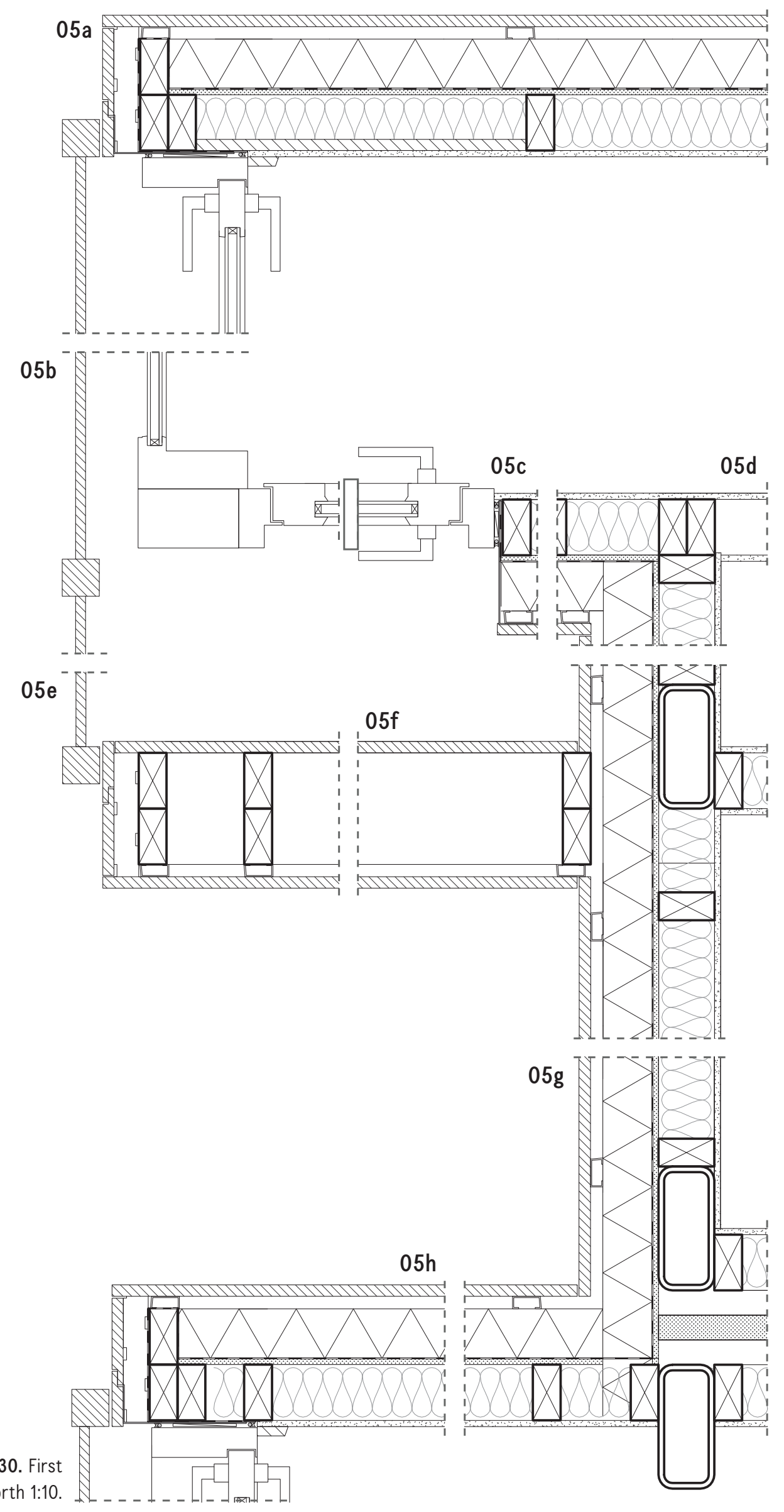


QG - first floor plan south

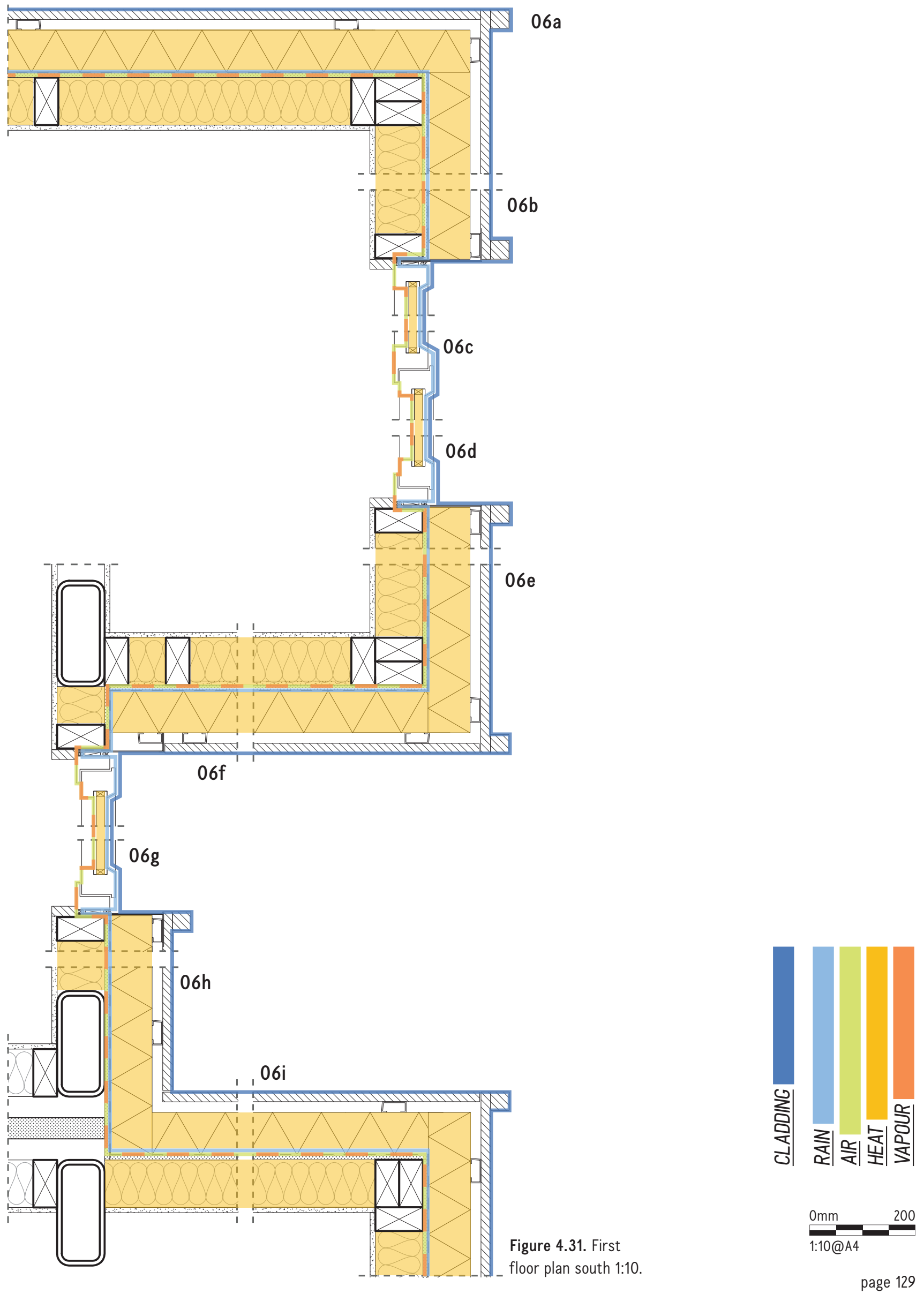




\section{7 - window jamb}

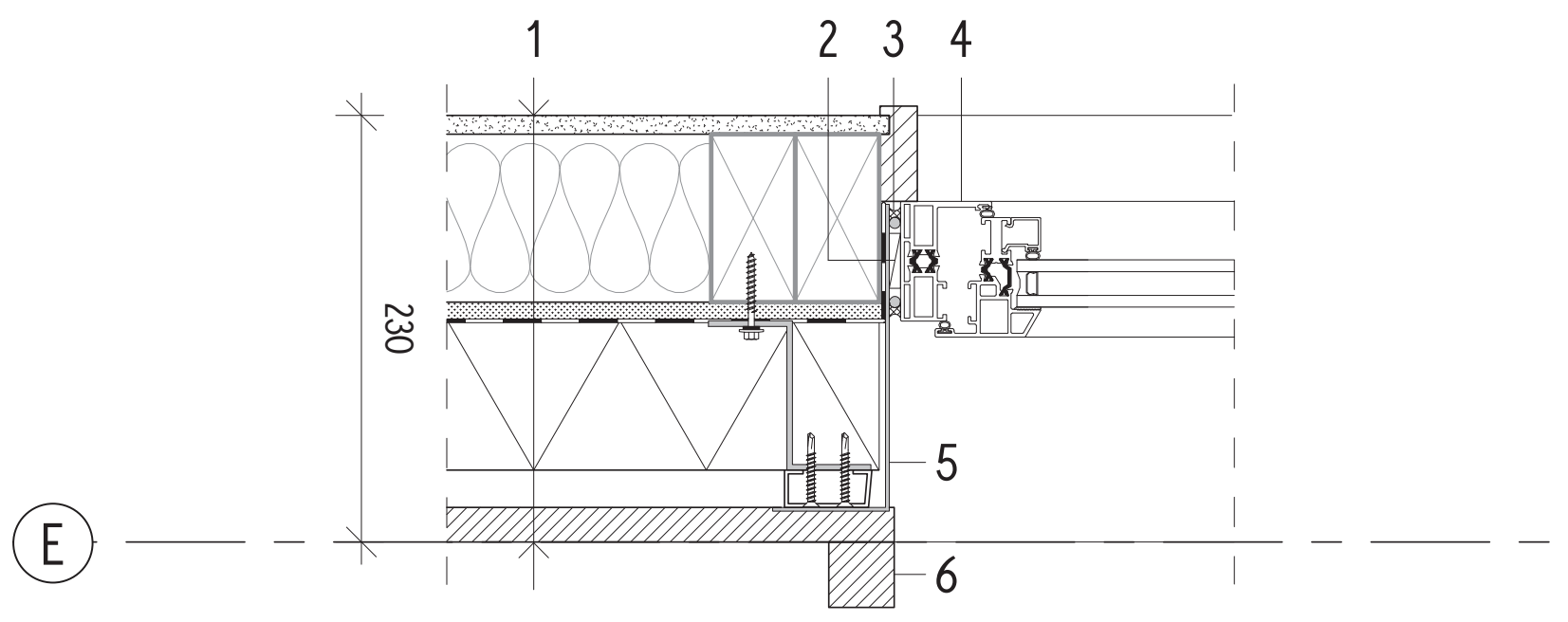

\section{1. wall assemlbly}

$10 \mathrm{~mm}$ gypsum board interior lining

$90 \mathrm{~mm} \times 45 \mathrm{~mm}$ timber framing with recycled fibreglass insulation

$12.7 \mathrm{~mm}$ gypsum sheathing with fibreglass coating class II vapour control layer (air barrier and drainage plane)

$80 \mathrm{~mm}$ rigid rock fibre insulation

$20 \mathrm{~mm} \times 45 \mathrm{~mm}$ vertical metal batten

horizontal shiplap timber cladding
2. timber packing

3. backer rod and sealant (air control continuity)

4. thermally broken aluminium window

5. metal jamb flashing fixed to front of vertical metal batten

6. vertical timber batten fixed to vertical metal batten 


\section{8 - stacker door jamb}

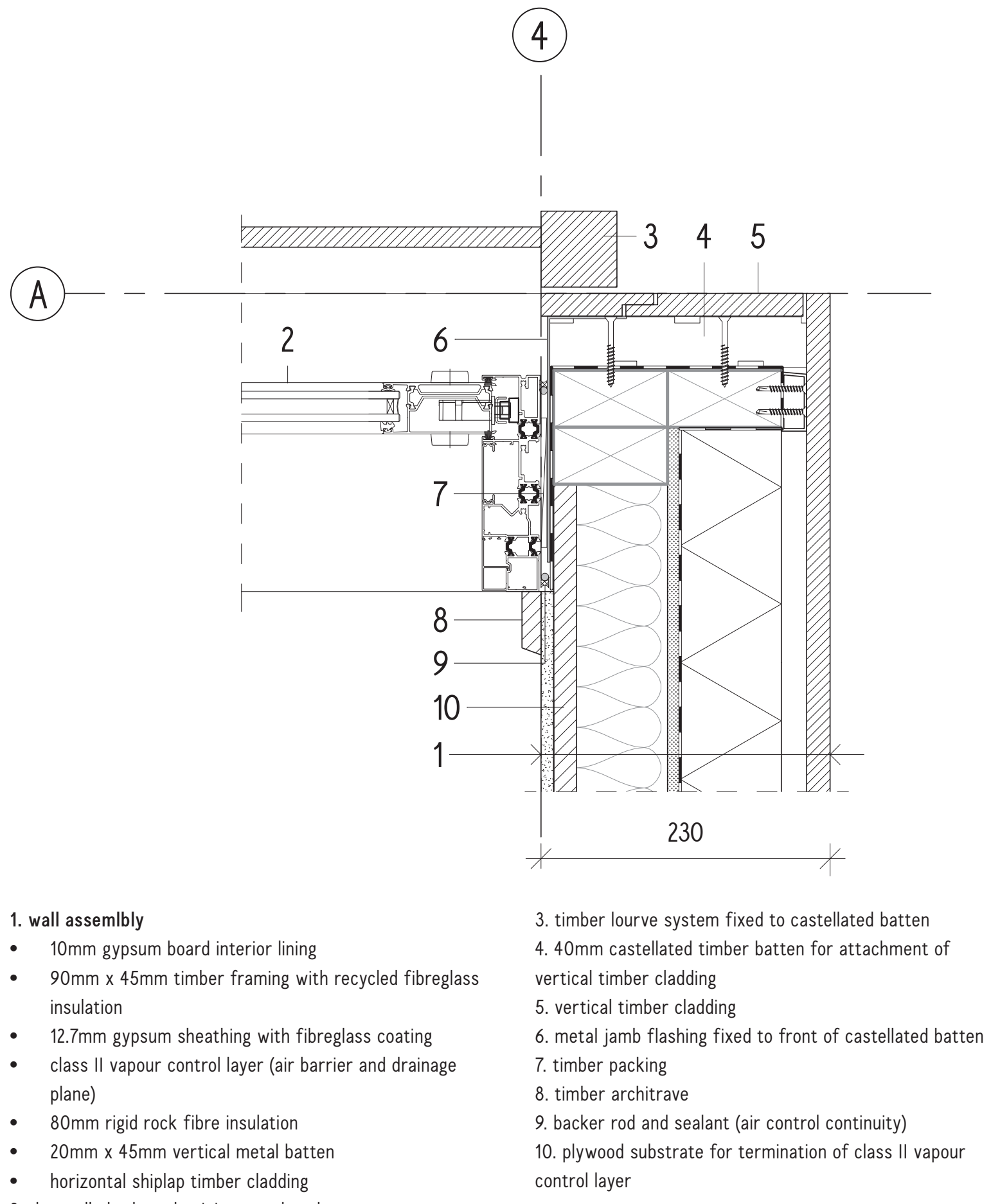

Figure 4.33. Detail 08 - stacker door jamb 1:5. 


\section{9 - internal corner at party wall}

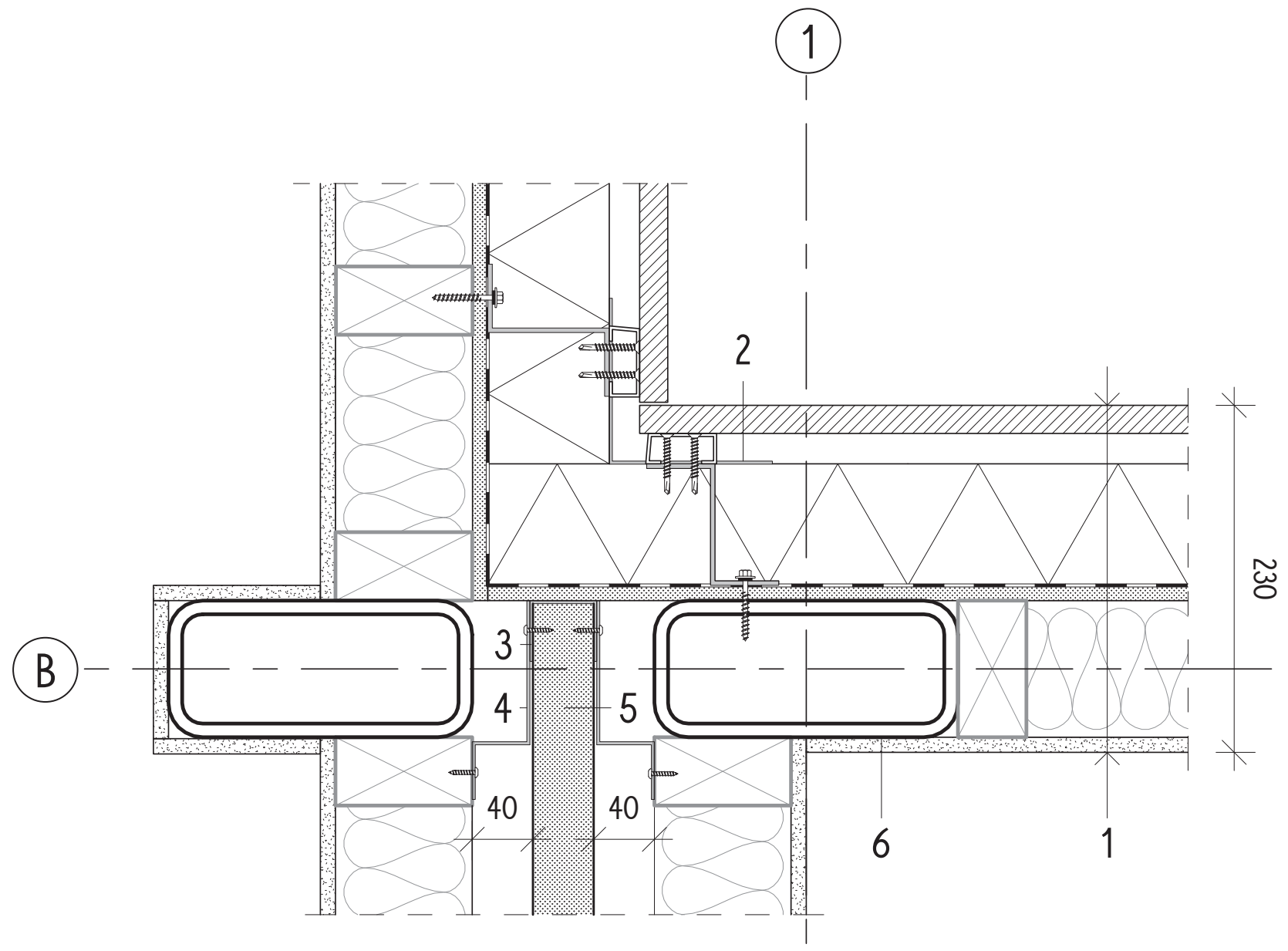

\section{1. wall assemlbly}

$10 \mathrm{~mm}$ gypsum board interior lining

$90 \mathrm{~mm} \times 45 \mathrm{~mm}$ timber framing with recycled fibreglass insulation

$12.7 \mathrm{~mm}$ gypsum sheathing with fibreglass coating class II vapour control layer (air barrier and drainage plane)

$80 \mathrm{~mm}$ rigid rock fibre insulation

$20 \mathrm{~mm} \times 45 \mathrm{~mm}$ vertical metal batten

horizontal shiplap timber cladding

2. internal closure flashing fixed to metal brackets
3. party wall continuous metal capping

4. party wall metal brackets

5. party wall

6. $90 \mathrm{~mm} \times 200 \mathrm{~mm}$ hollow rectangular steel section

notes.

Party wall to be installed to manufacturers specifications. 


\section{0 - exterior wall to patio wall}

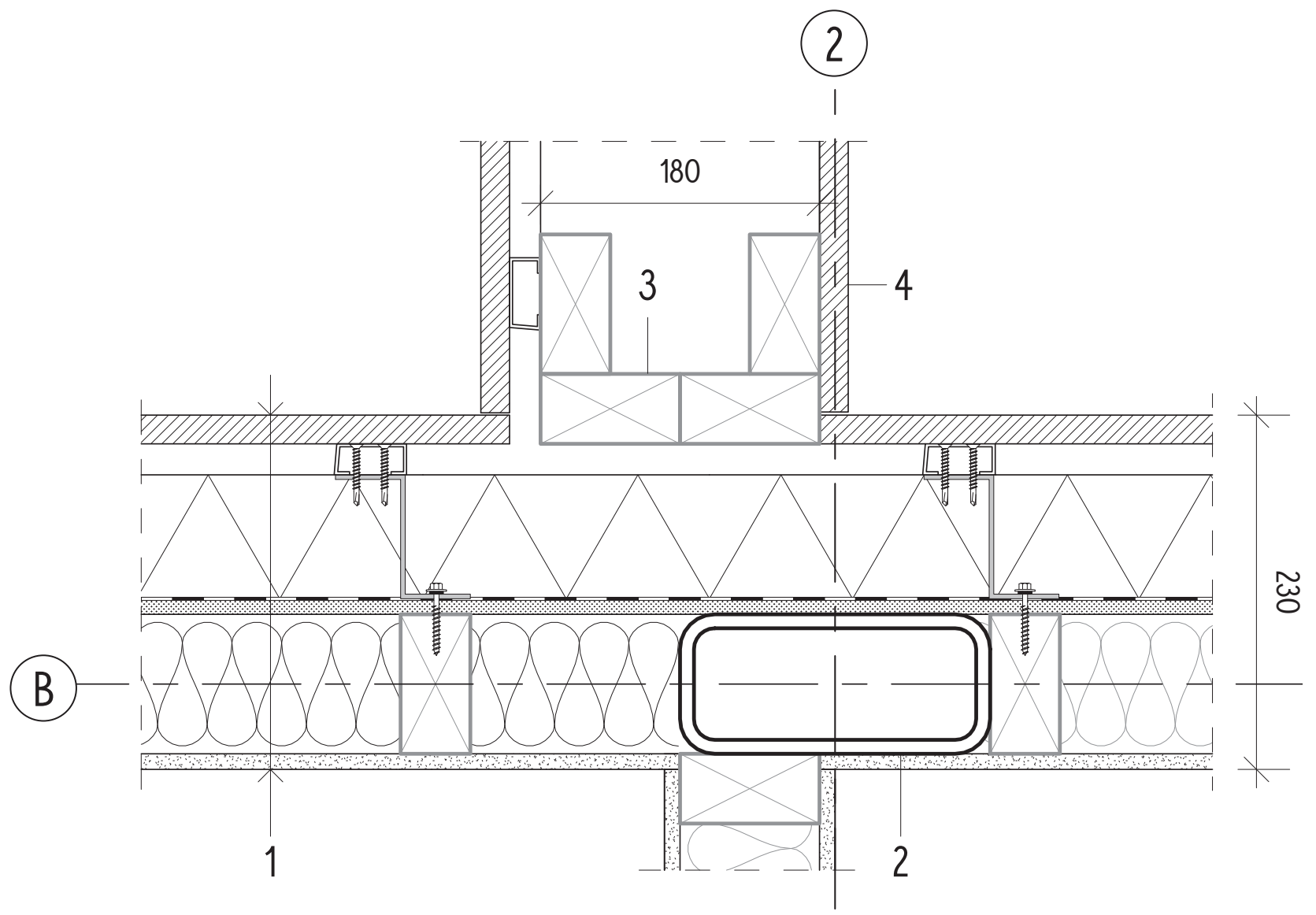

\section{1. wall assemlbly}

$10 \mathrm{~mm}$ gypsum board interior lining

$90 \mathrm{~mm} \times 45 \mathrm{~mm}$ timber framing with recycled fibreglass insulation

12.7mm gypsum board with fibreglass coating

class II vapour control layer (air barrier and drainage

plane)

$80 \mathrm{~mm}$ rigid rock fibre insulation

$20 \mathrm{~mm} \times 45 \mathrm{~mm}$ vertical metal batten

horizontal shiplap timber cladding

2. $90 \mathrm{~mm} \times 200 \mathrm{~mm}$ hollow rectangular steel section
3. $90 \mathrm{~mm} \times 45 \mathrm{~mm}$ timber framing

4. horizontal timber cladding fixed directy to timber framing

notes.

No requirement for air space at 4 as location is outside the building envelope. 


$$
\text { roof plan }
$$

A
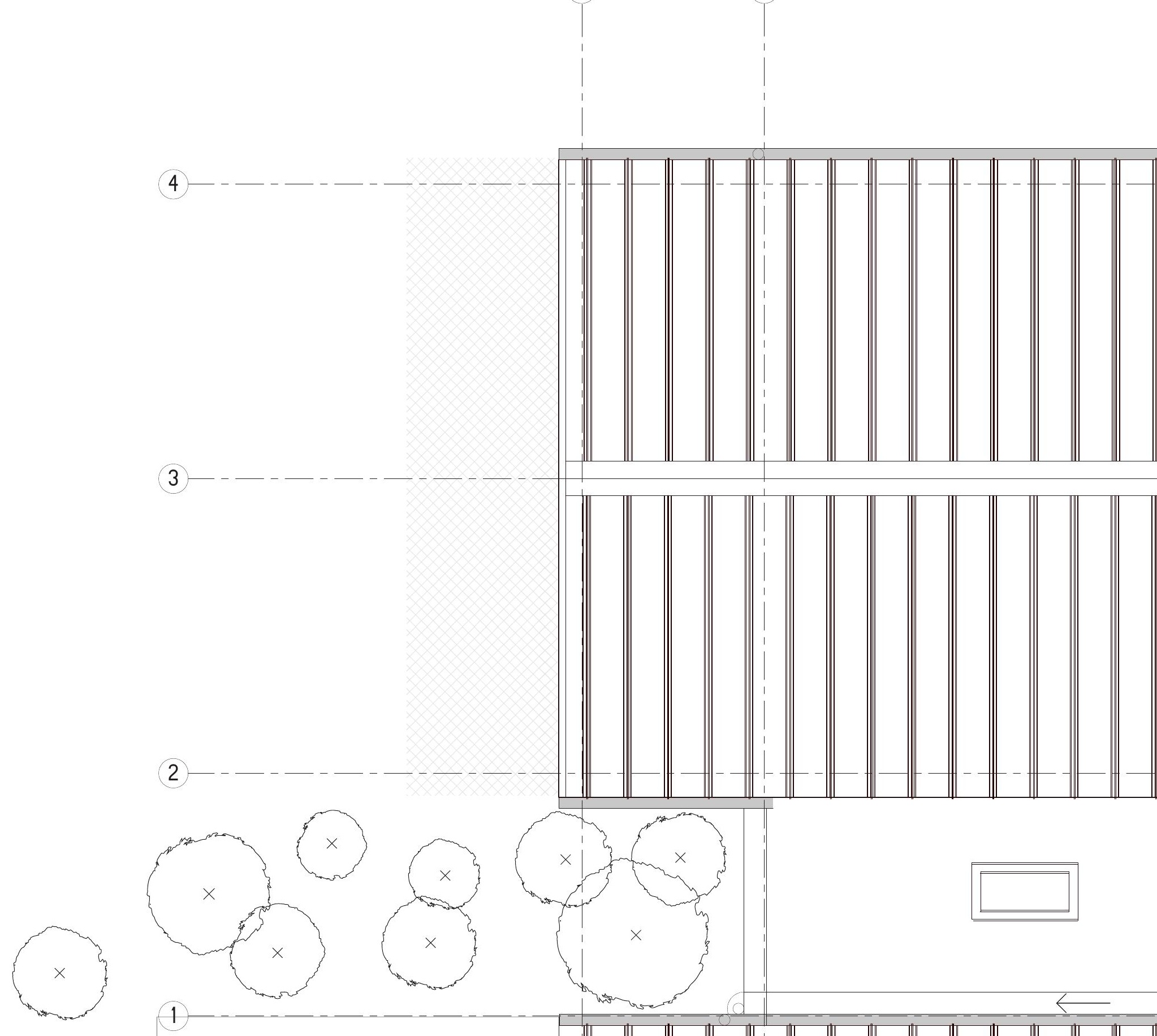

Figure 4.36. Roof plan 1:50. 
south elevation

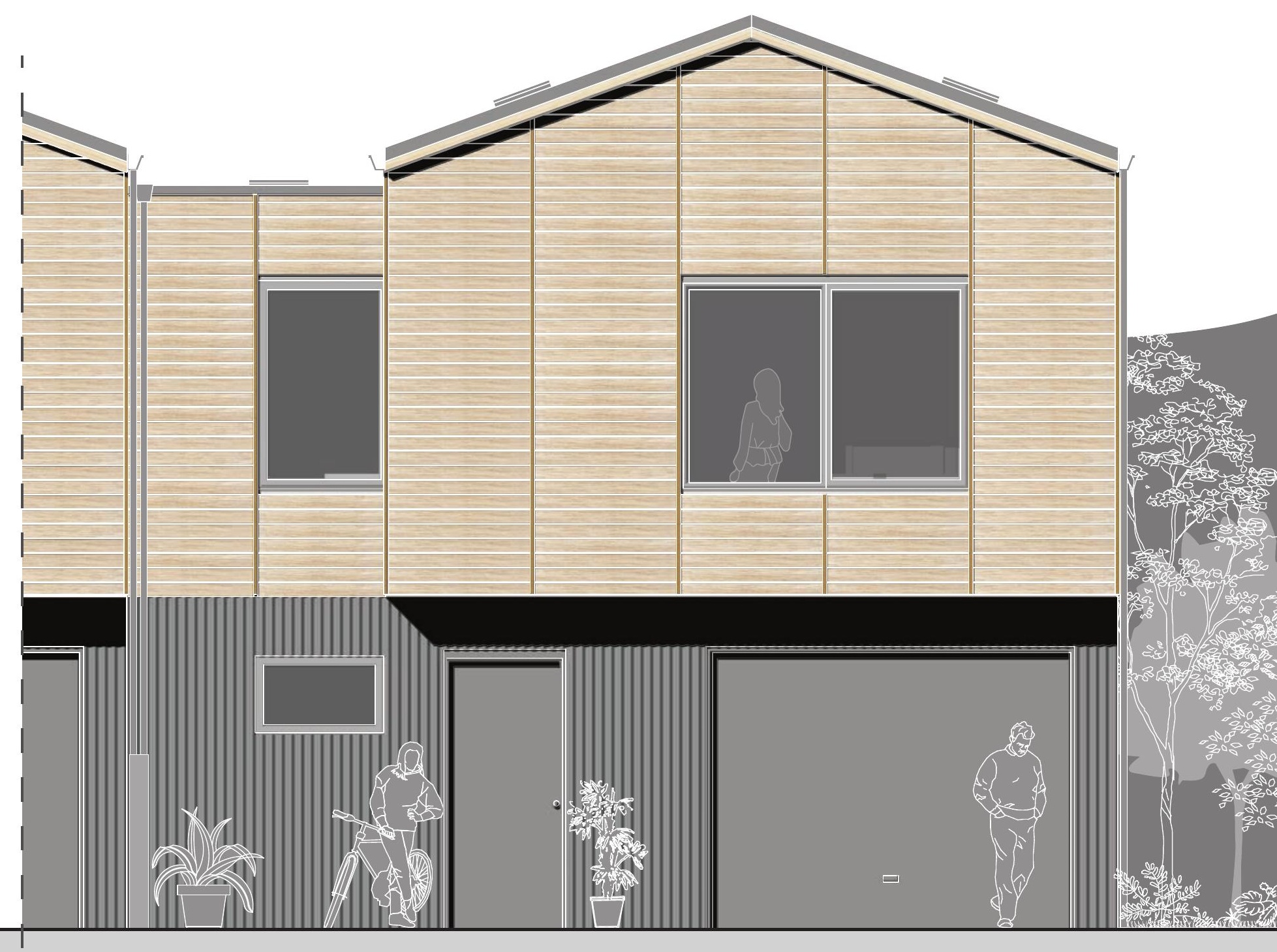




\section{section a-a}

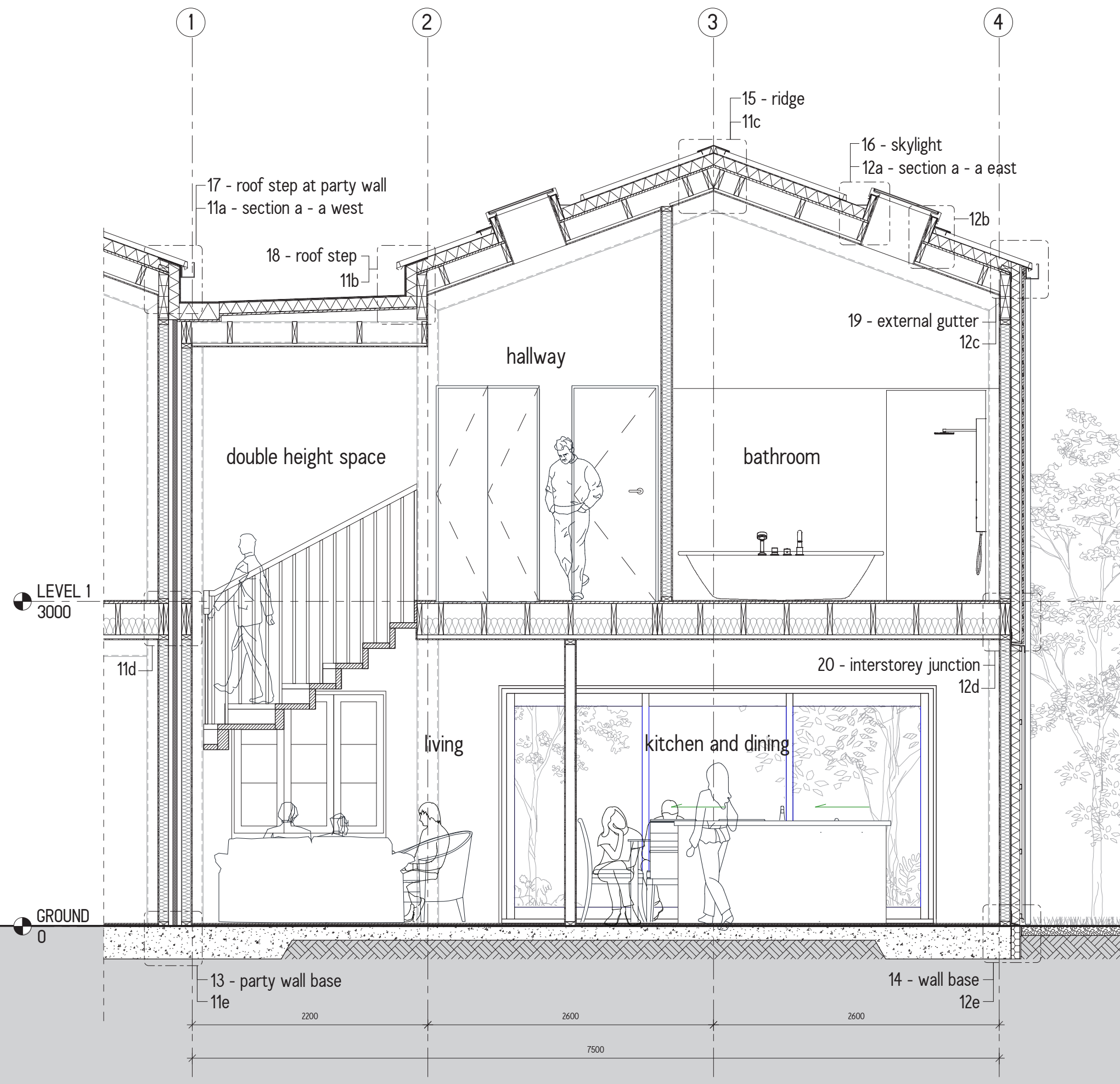

Figure 4.38. Section a - a 1:50.

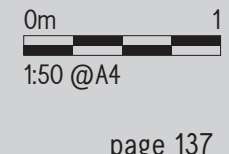




\section{II - section a - a west}
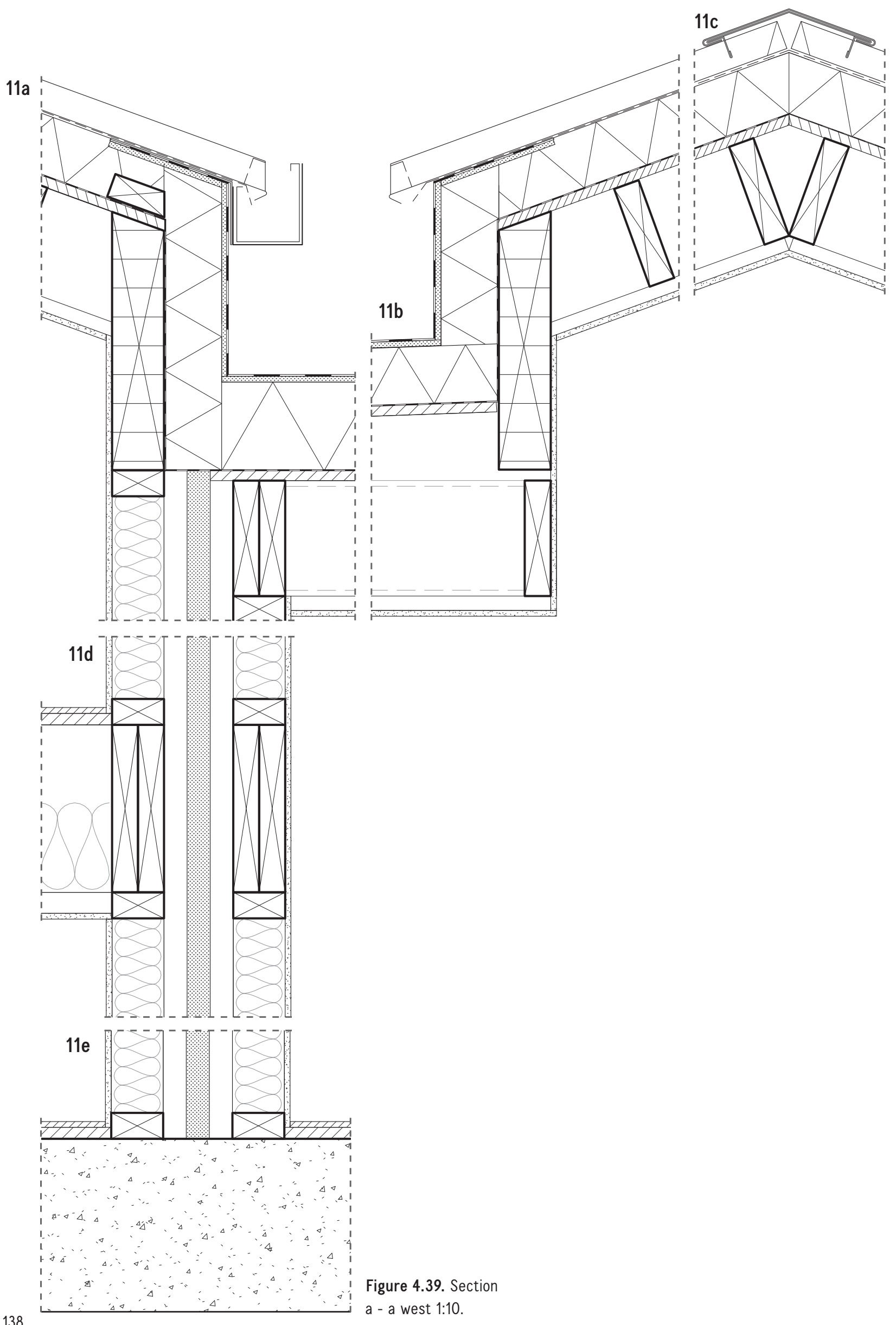
12 - sectiona - a east
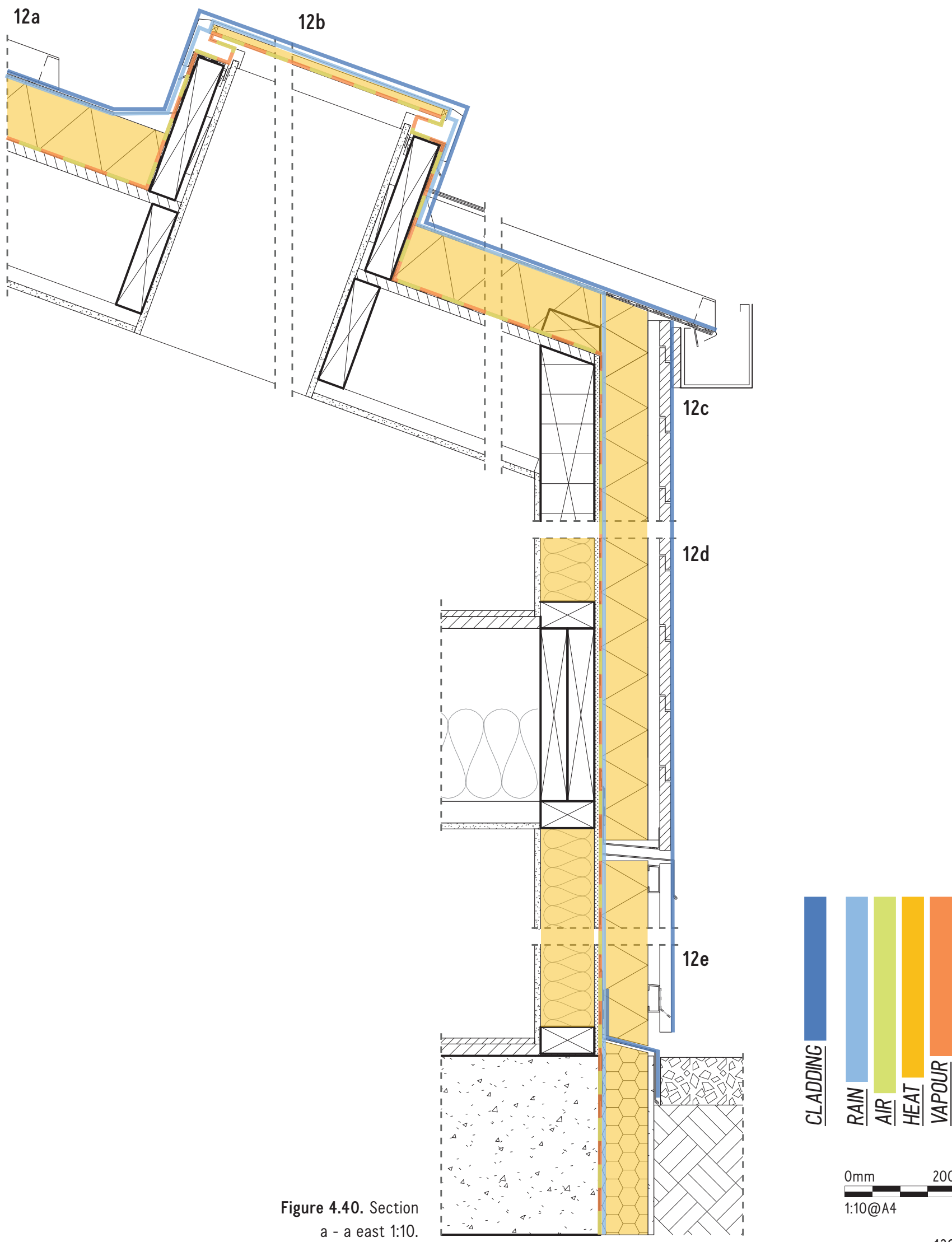


\section{3 - party wall base}

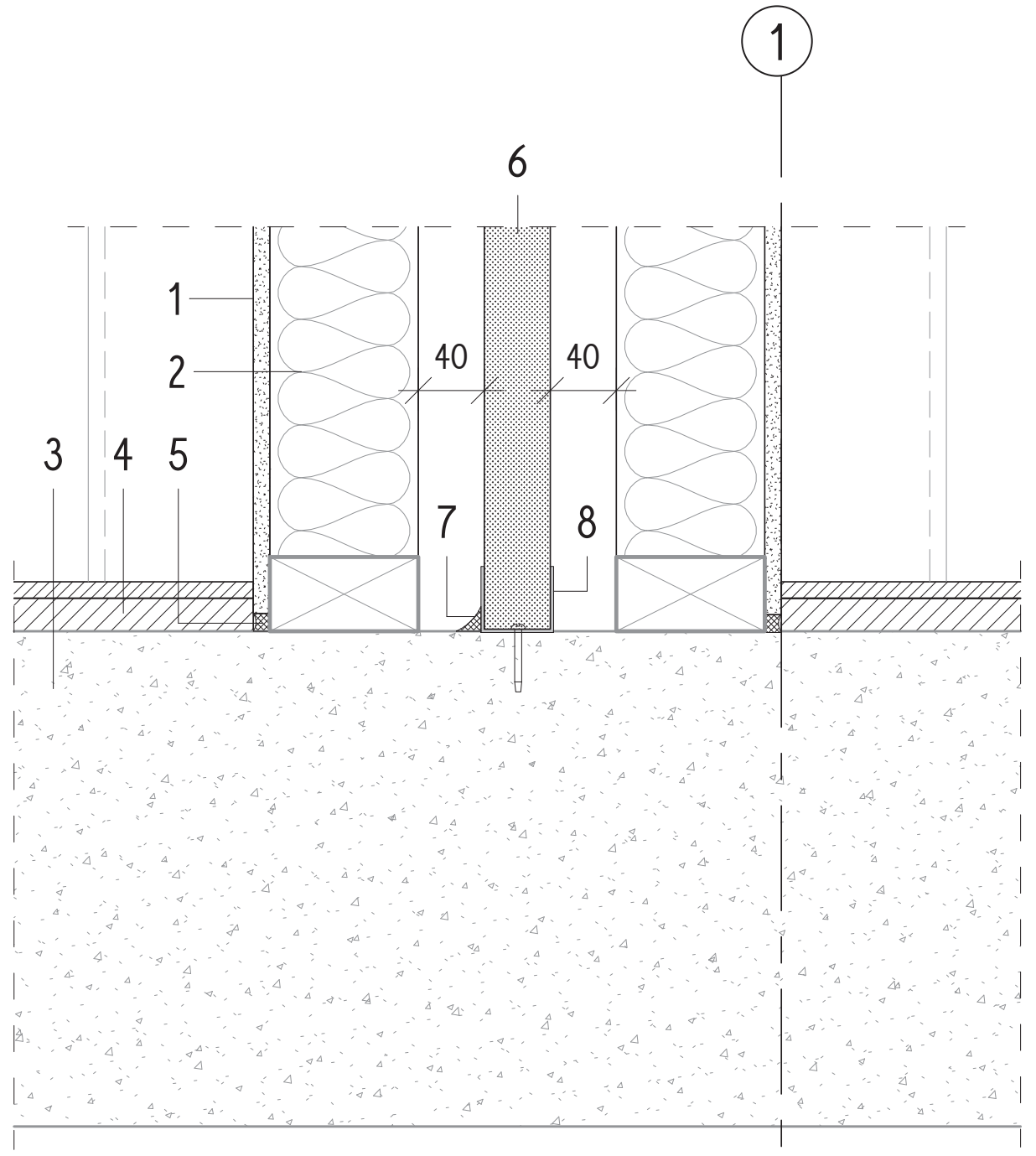

1. interior gypsum board lining

2. recycled fibreglass cavity insulation

3. concete slab

4. two layer timber flooring

5. sealant

6. party wall

7. party wall sealant

8. continuous party wall metal capping fixed into concrete

slab notes.

Party wall to be installed to manufacturers specifications. 


\section{4 - wall base}

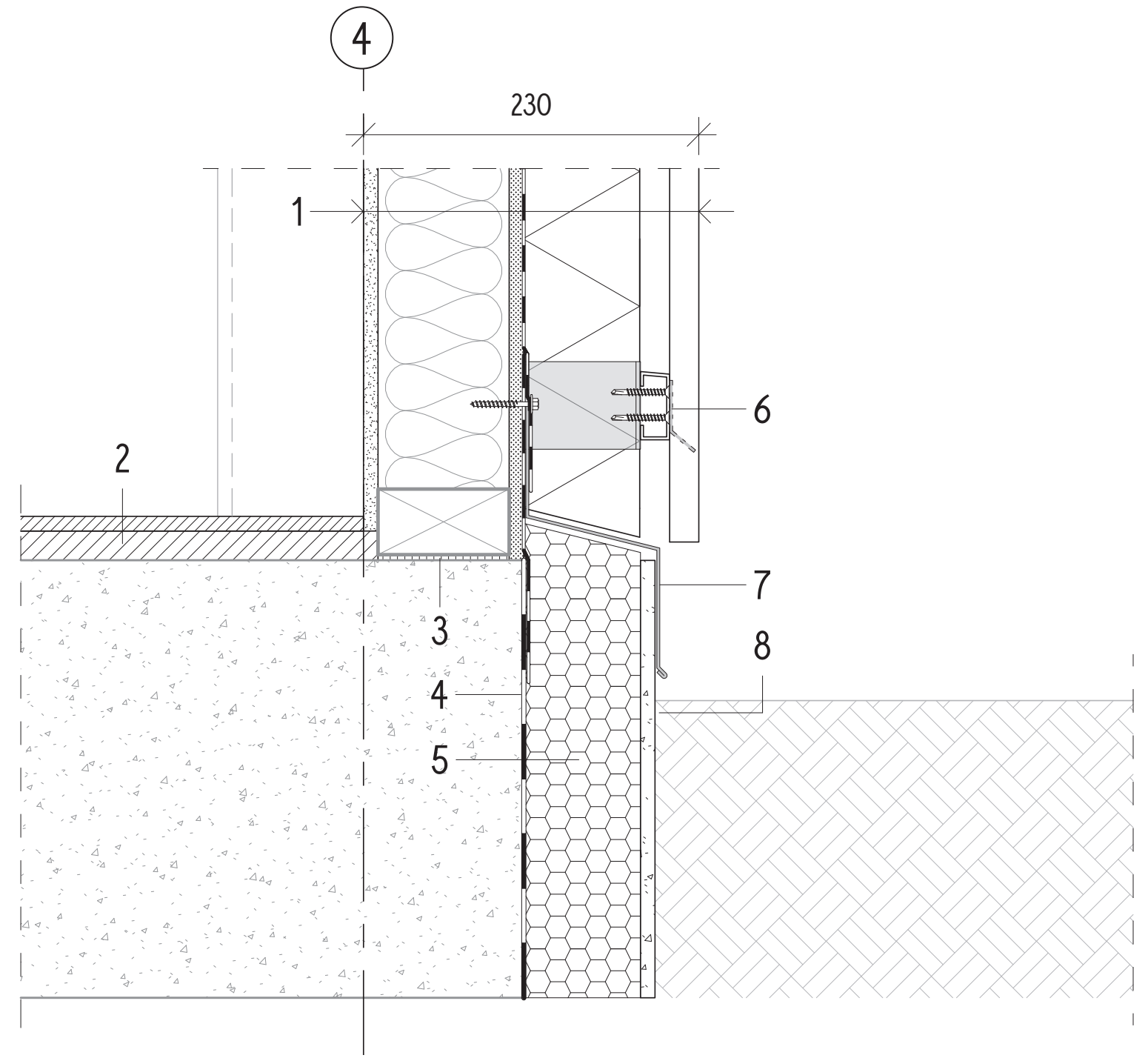

\section{1. wall assemlbly}

$10 \mathrm{~mm}$ gypsum board interior lining

$90 \mathrm{~mm} \times 45 \mathrm{~mm}$ timber framing with recycled fibreglass insulation

$12.7 \mathrm{~mm}$ gypsum board with fibreglass coating

class II vapour control layer (air barrier and drainage plane)

$80 \mathrm{~mm}$ rigid rock fibre insulation

$20 \mathrm{~mm} \times 45 \mathrm{~mm}$ horizontal metal batten

vertical corrugate metal cladding

2. two layer timber flooring
3. bottom plate seal
4. class I vapour control layer adhered to slad edge
5. extruded polystyrene
6. cavity closer
7. wall base metal flashing
8. concrete applied to face of extruded polystyrene

notes.

Class II vapour control layer to overlap class I vapour control layer. 
15 - ridge

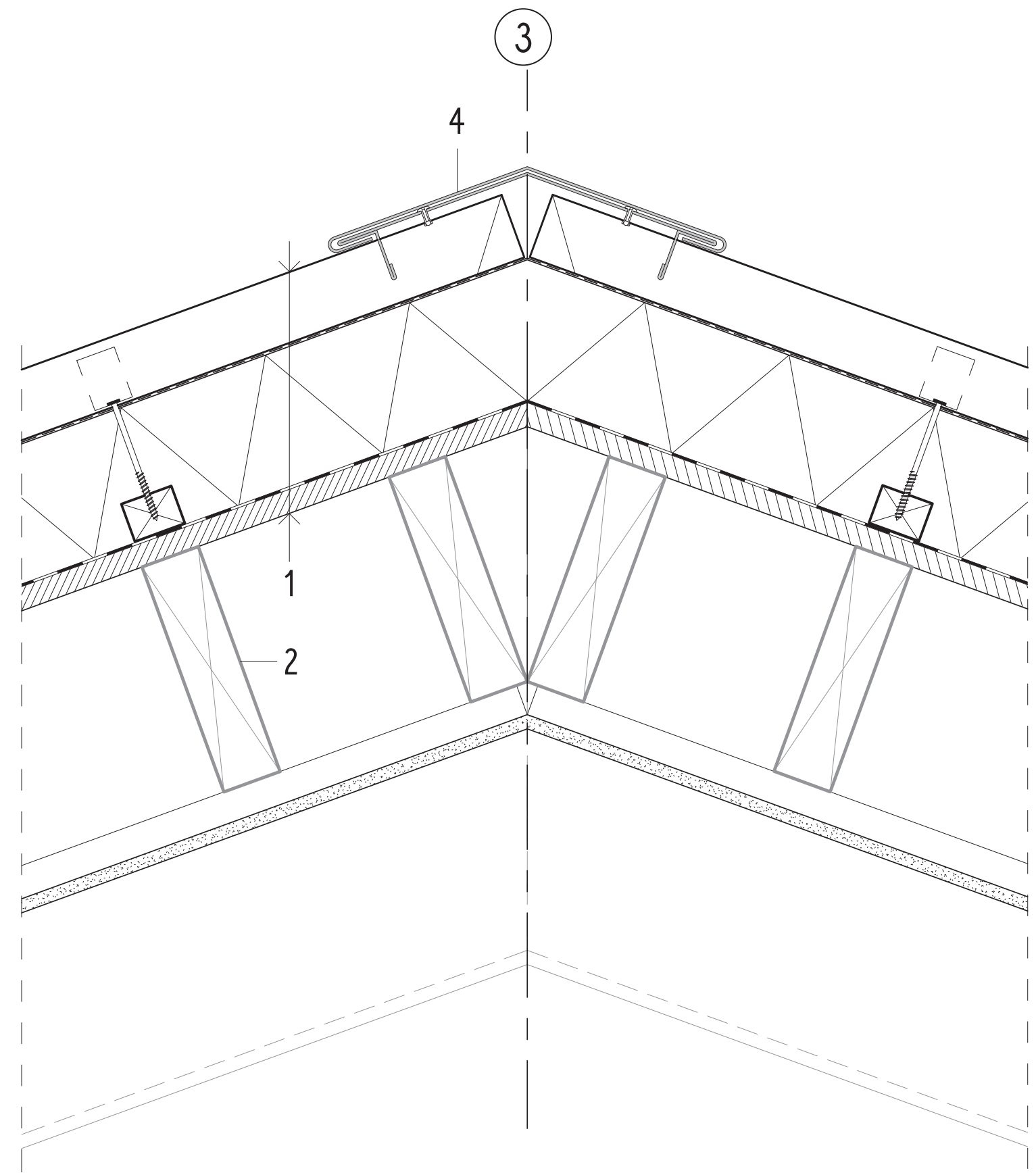

\section{1. roof assemlbly}

$18 \mathrm{~mm}$ plywood substrate

class I vapour control layer (air barrier)

$40 \mathrm{~mm} \times 45 \mathrm{~mm}$ timber battens fixed through to purlins

$100 \mathrm{~mm}$ rigid rock fibre insulation

roof underlay

hidden roofing clips fixed through to timber battens

standing seam metal cladding attached onto clips
2. $180 \mathrm{~mm} \times 45 \mathrm{~mm}$ timber purlins

3. ceiling (metal battens and gypsum baord)

4. metal ridge flashing with concealed hook flashing 


\section{I6- skylight}

\section{1. roof assemlbly}

$18 \mathrm{~mm}$ plywood substrate

class I vapour control layer (air barrier)

$40 \mathrm{~mm} \times 45 \mathrm{~mm}$ timber battens fixed through to purlins $100 \mathrm{~mm}$ rigid rock fibre insulation roof underlay

hidden roofing clips fixed through to timber battens standing seam metal cladding attached onto clips

2. fold back to recieve flashing
3. metal cricket flashing

4. thermally broken aluminium skylight

5. compressible foam seal (air control continuity)

6. metal skylight flashing

7. timber packing

8. metal apron flashing with concealed hook flashing

9. $80 \mathrm{~mm} \times 45 \mathrm{~mm}$ timber purlins

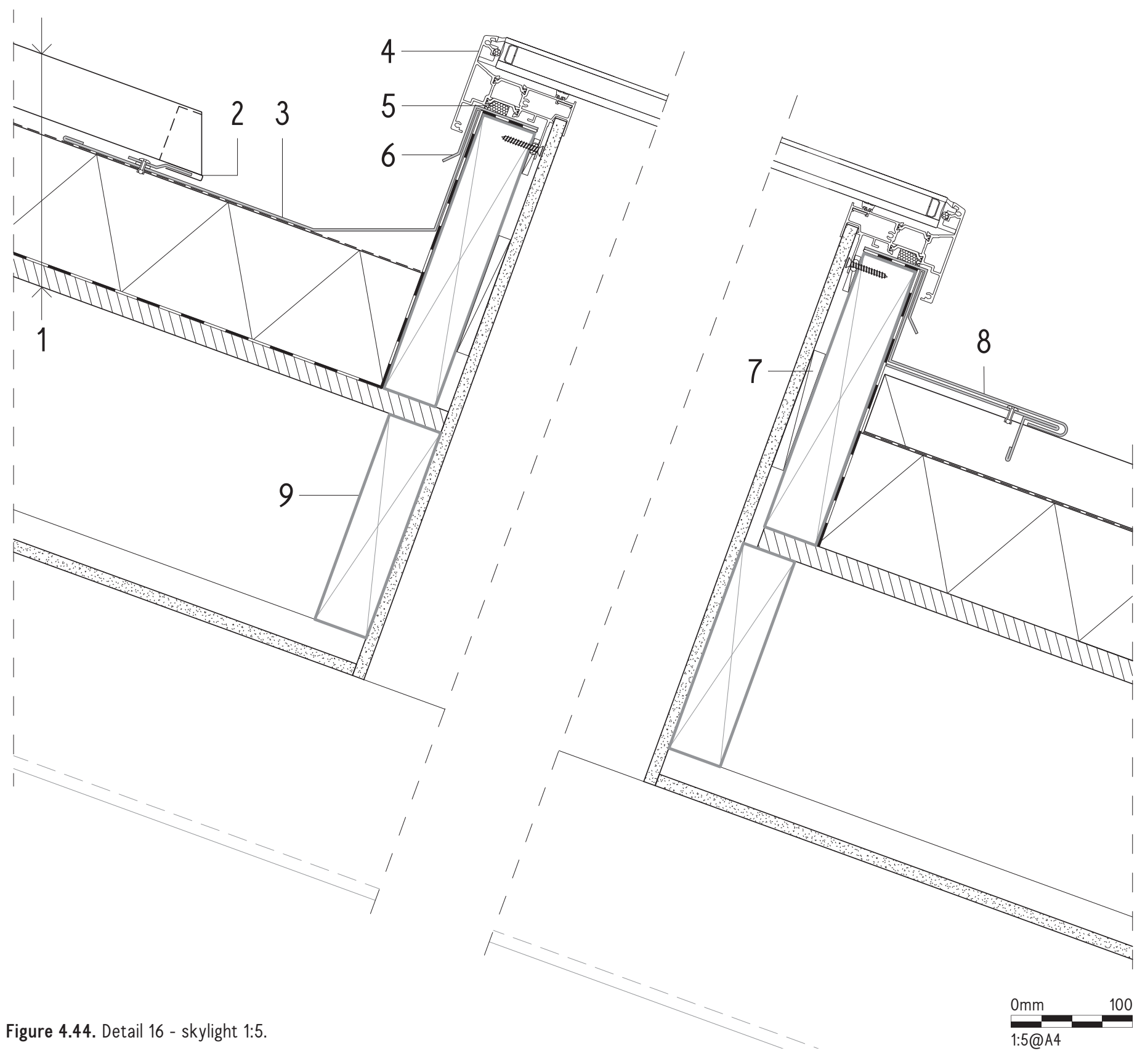




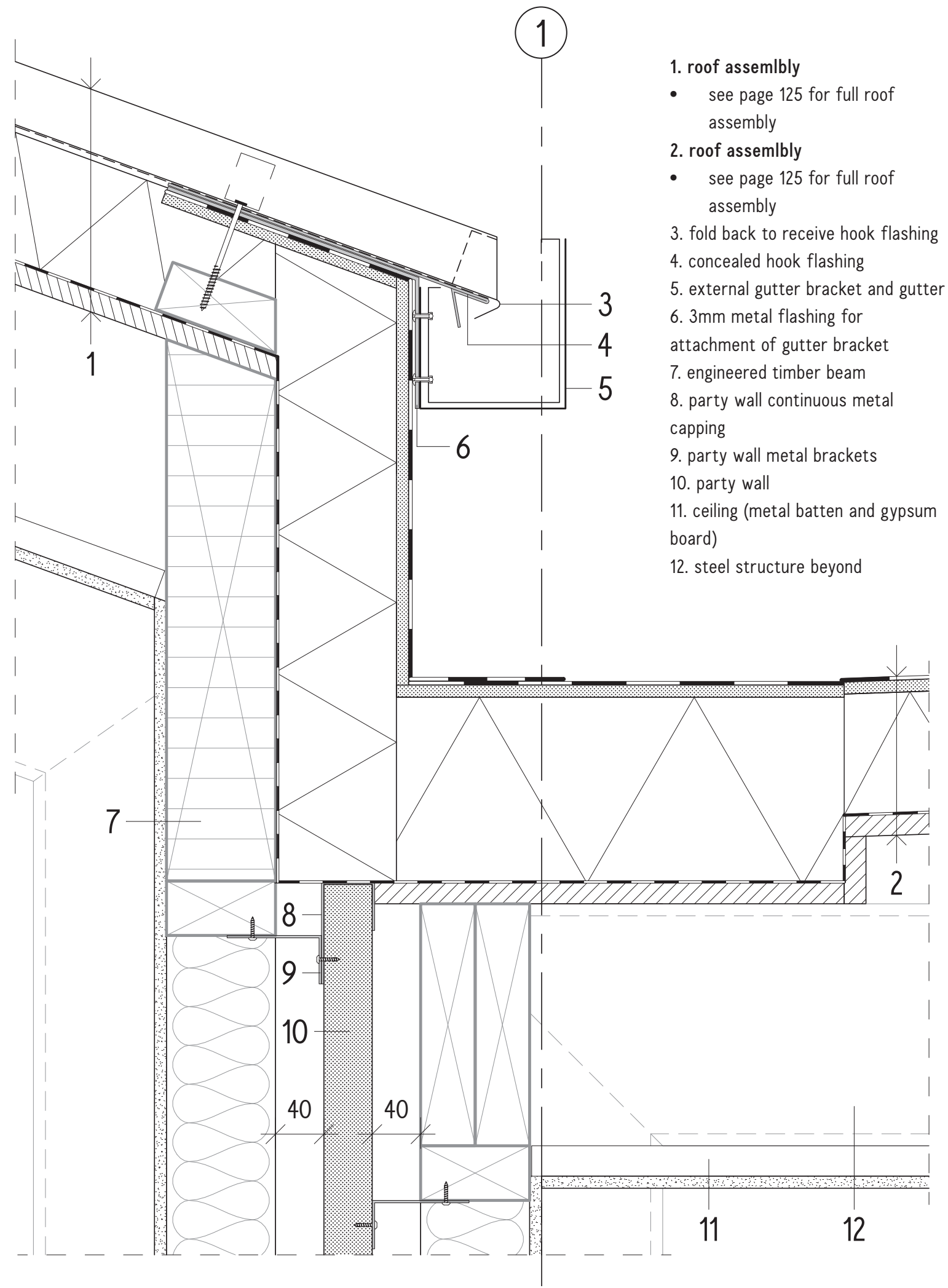

Figure 4.45. Detail 17 - roof step at party wall 1:5. 
$18-r a g f t e p$

1. roof assemlbly

see page 125 for full roof

assembly

2. roof assemlbly

see page 125 for full roof assembly

3. fold back to receive hook flashing

4. concealed hook flashing

5. engineered timber beam

6. $200 \mathrm{~mm} \times 45 \mathrm{~mm}$ timber purlins

7. ceiling (metal batten and gypsum board)

8. steel structure beyond

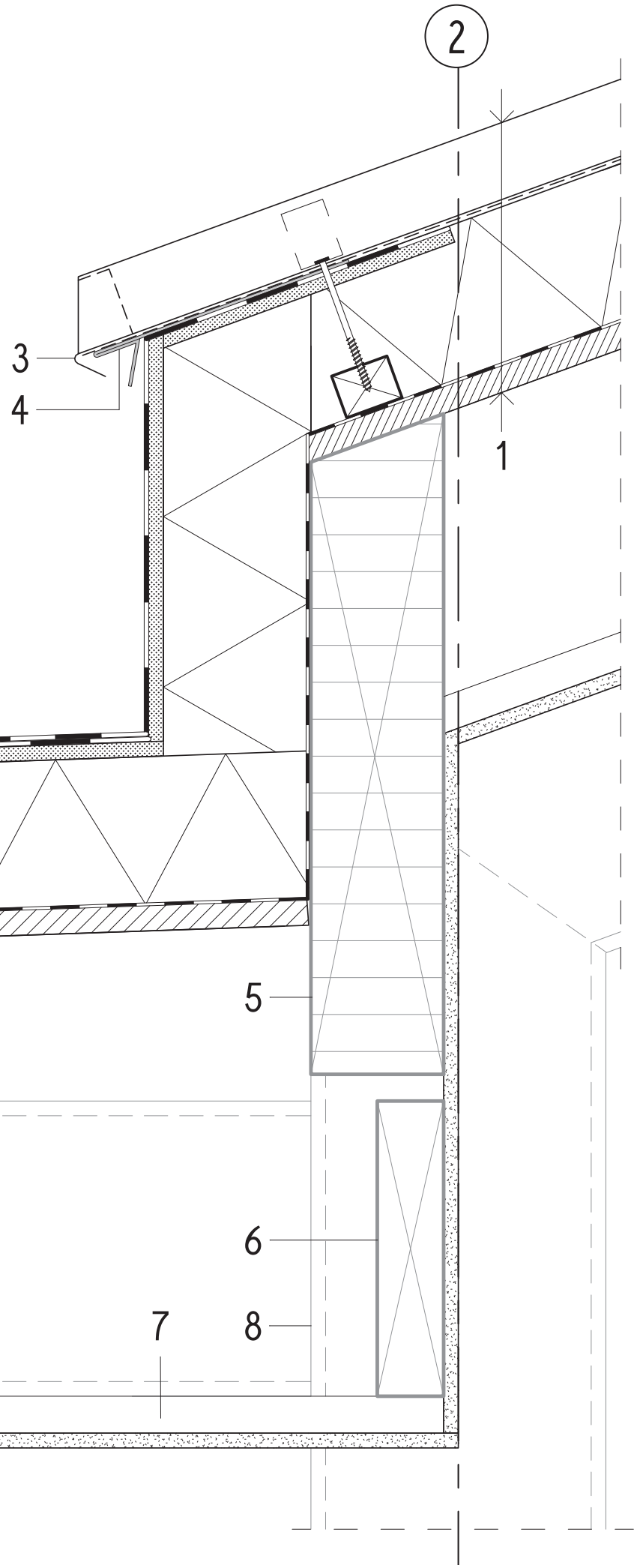

Figure 4.46. Detail 18 - roof step 1:5. 


\section{9 - external gutter}

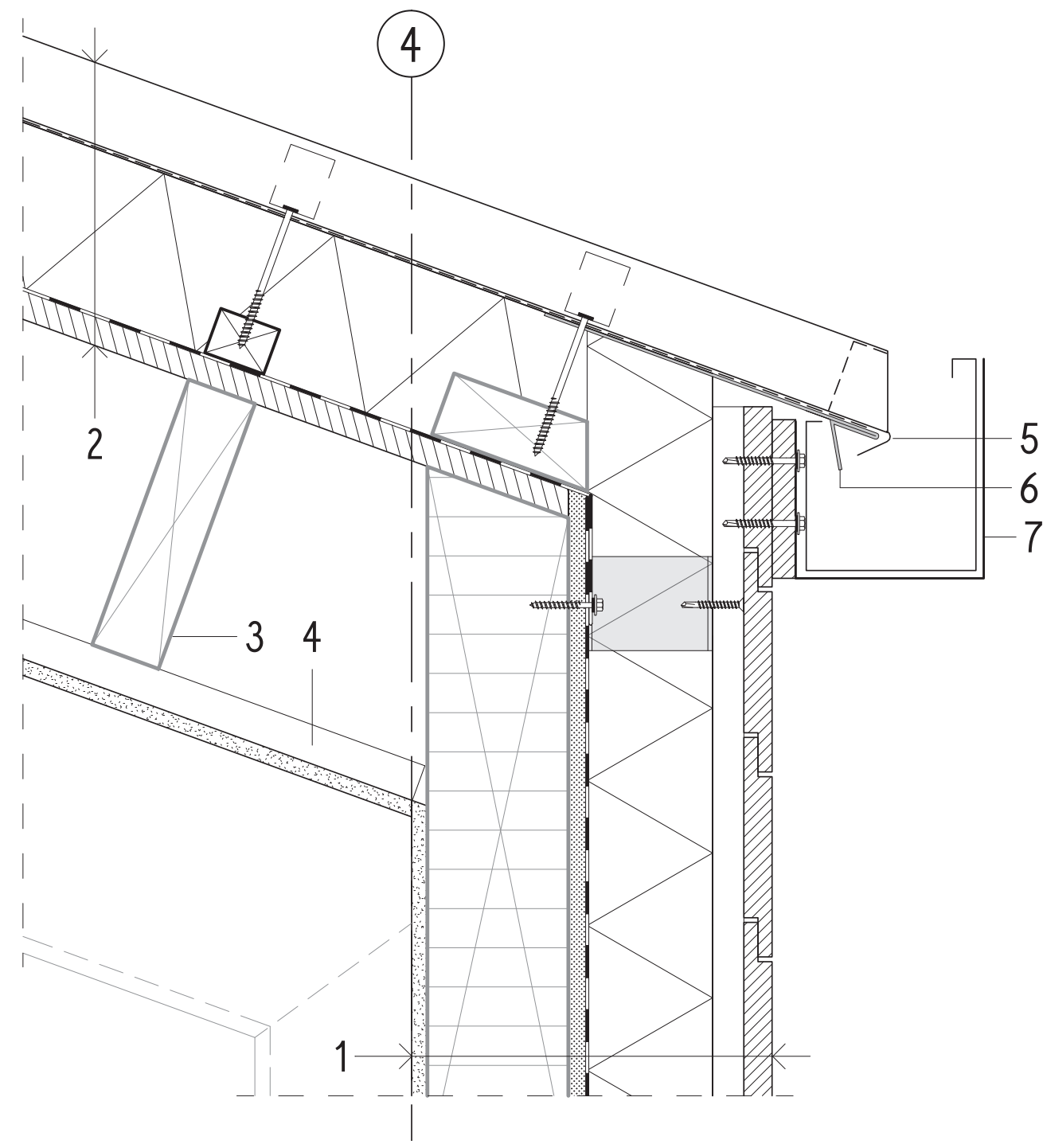

1. wall assemlbly

$10 \mathrm{~mm}$ gypsum board interior lining

$90 \mathrm{~mm} \times 45 \mathrm{~mm}$ timber framing with recycled fibreglass insulation

$12.7 \mathrm{~mm}$ gypsum sheathing with fibreglass coating class II vapour control layer (air barrier and drainage plane)

$80 \mathrm{~mm}$ rigid rock fibre insulation

$20 \mathrm{~mm} \times 45 \mathrm{~mm}$ vertical metal batten

horizontal shiplap timber cladding

\section{2. roof assemlbly}

$18 \mathrm{~mm}$ plywood substrate class I vapour control layer (air barrier)

$40 \mathrm{~mm} \times 45 \mathrm{~mm}$ timber battens fixed through to purlins $100 \mathrm{~mm}$ rigid rock fibre insulation roof underlay hidden roofing clips fixed through to timber battens standing seam metal cladding attached onto clips

3. $180 \mathrm{~mm} \times 45 \mathrm{~mm}$ timber purlins

4. ceiling (metal battens and gypsum board)

5. fold back to recieve flashing

6. concealed hook flashing

7. external gutter bracket and gutter 


\section{0 - interstorey junction}

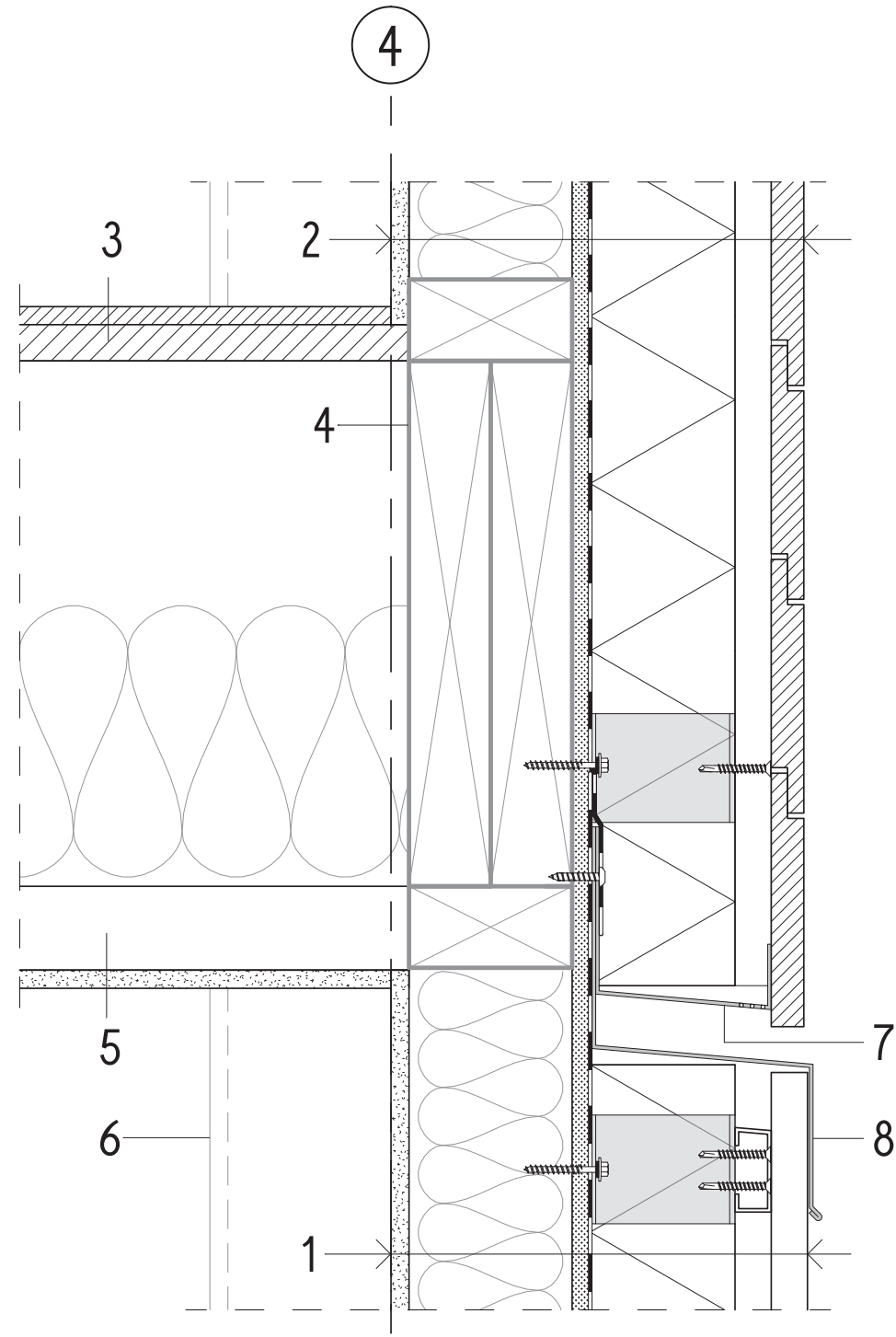

\section{1. wall assemlbly}

$10 \mathrm{~mm}$ gypsum board interior lining

$90 \mathrm{~mm} \times 45 \mathrm{~mm}$ timber framing with recycled fibreglass insulation

$12.7 \mathrm{~mm}$ gypsum sheathing with fibreglass coating class II vapour control layer (air barrier and drainage plane)

$80 \mathrm{~mm}$ rigid rock fibre insulation

$20 \mathrm{~mm} \times 45 \mathrm{~mm}$ vertical metal batten

horizontal shiplap timber cladding

\section{2. wall assembly}

same as 1 . wall assembly with vertical metal battens and horizontal shiplap timber cladding

3. two layer timber flooring

4. $290 \mathrm{~mm} \times 45 \mathrm{~mm}$ timber floor joists

5. ceiling (metal battens and gypsum board)

6. steel structure beyond

7. metal cavity closer fixed to front of metal batten

8. metal flashing 
north elevation

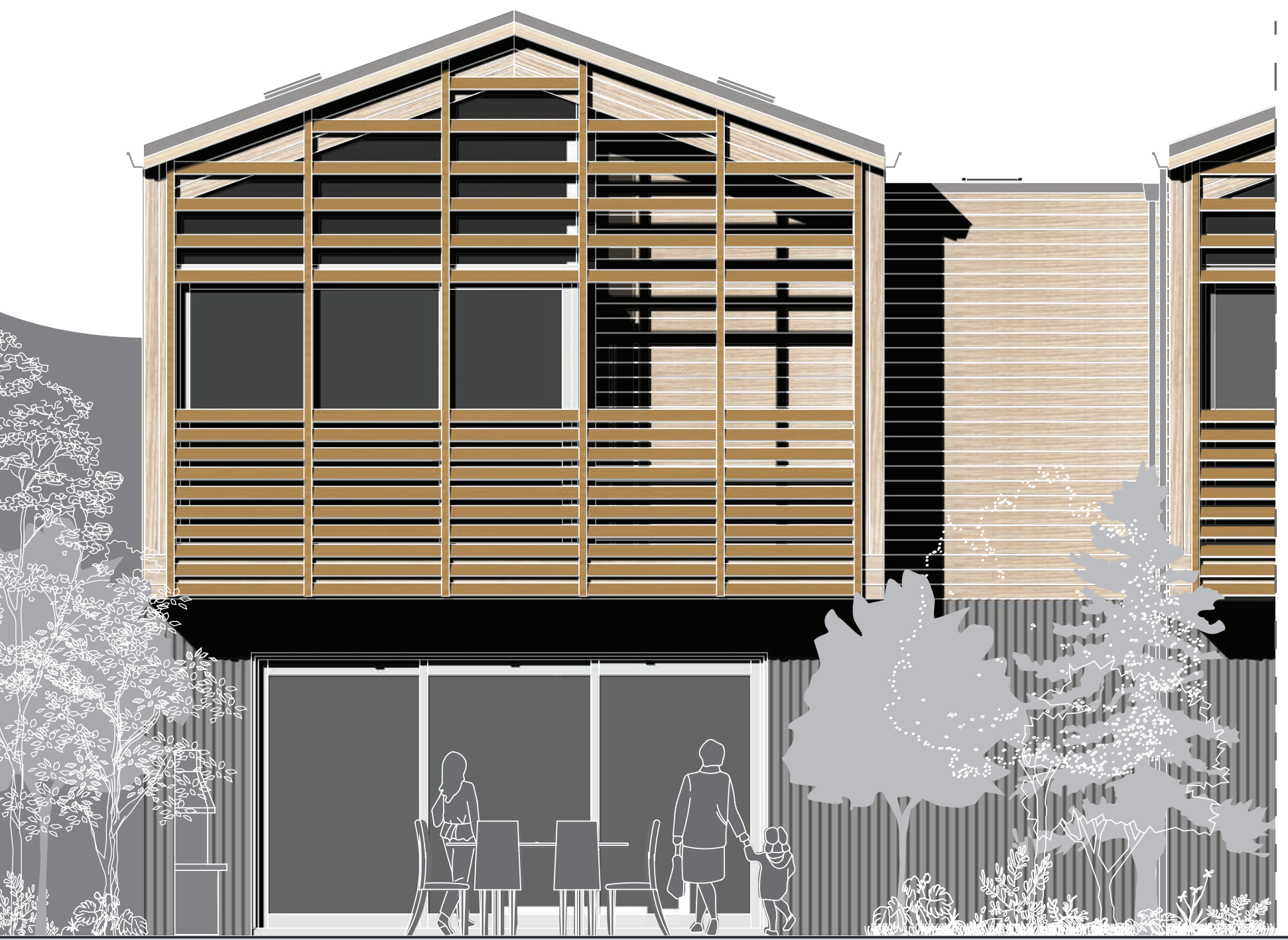





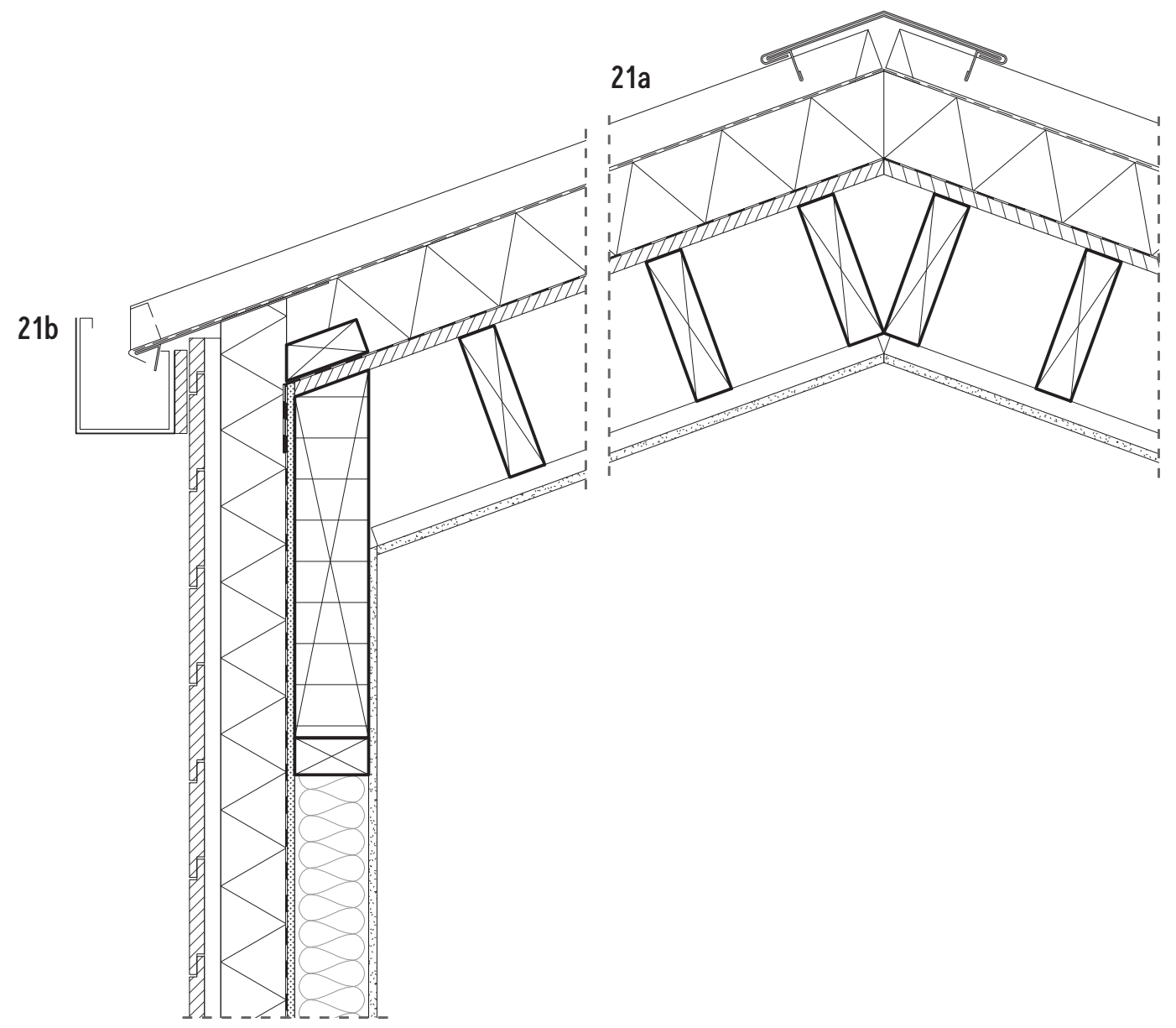

Figure 4.51. Section

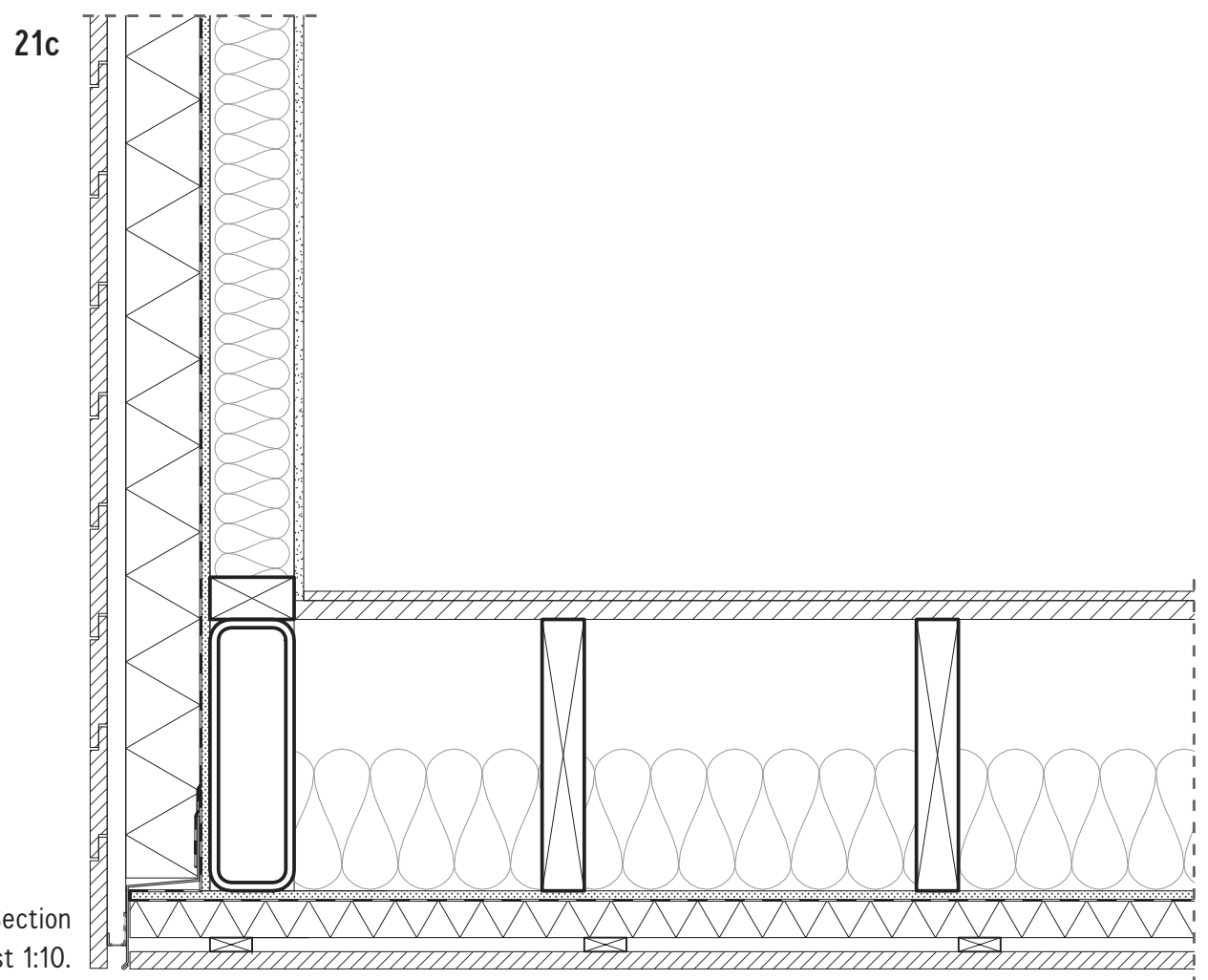



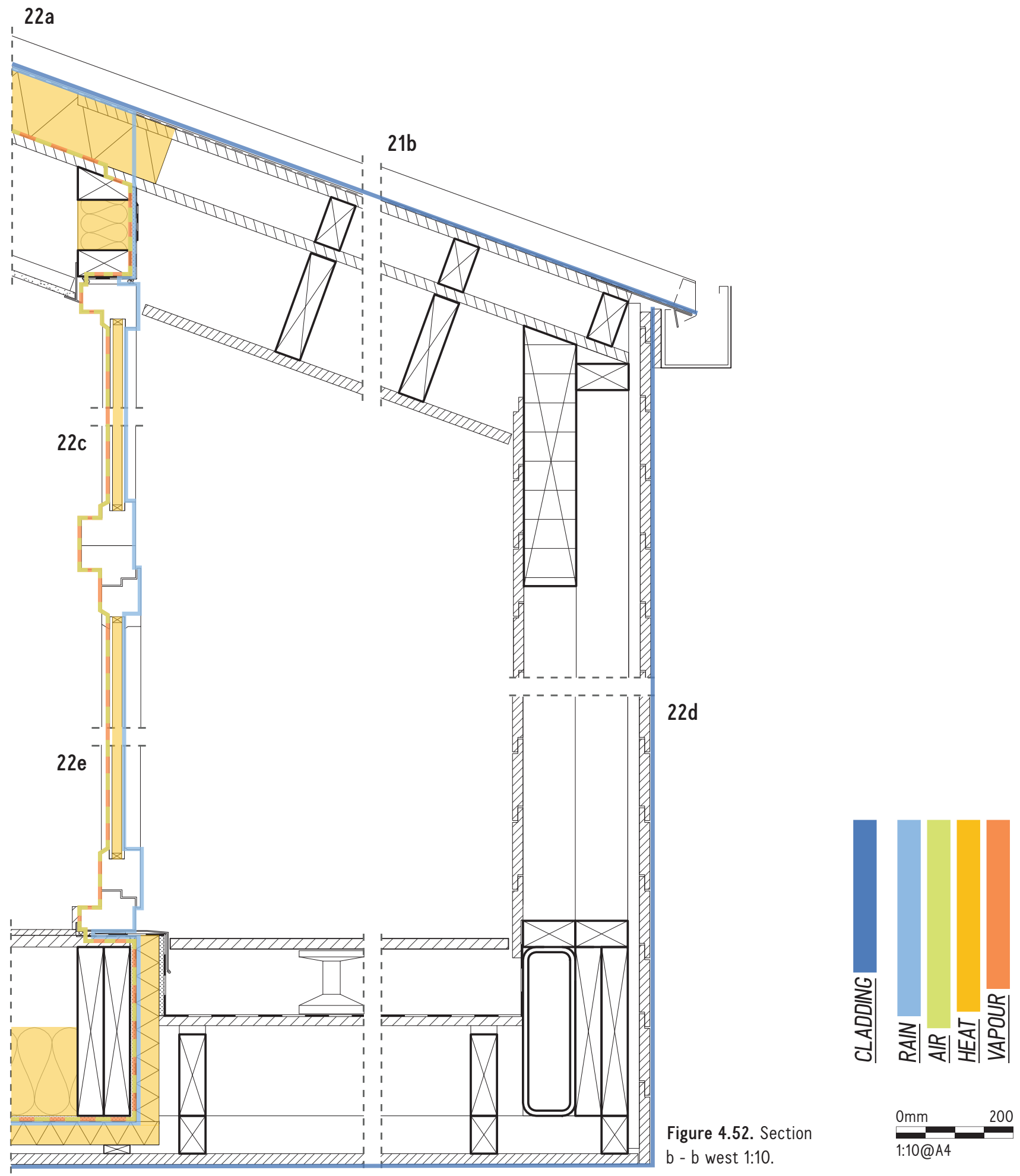

b - b west 1:10.

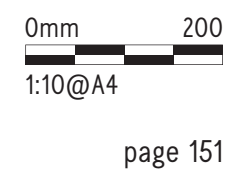




\section{3 - cantilever cormer}

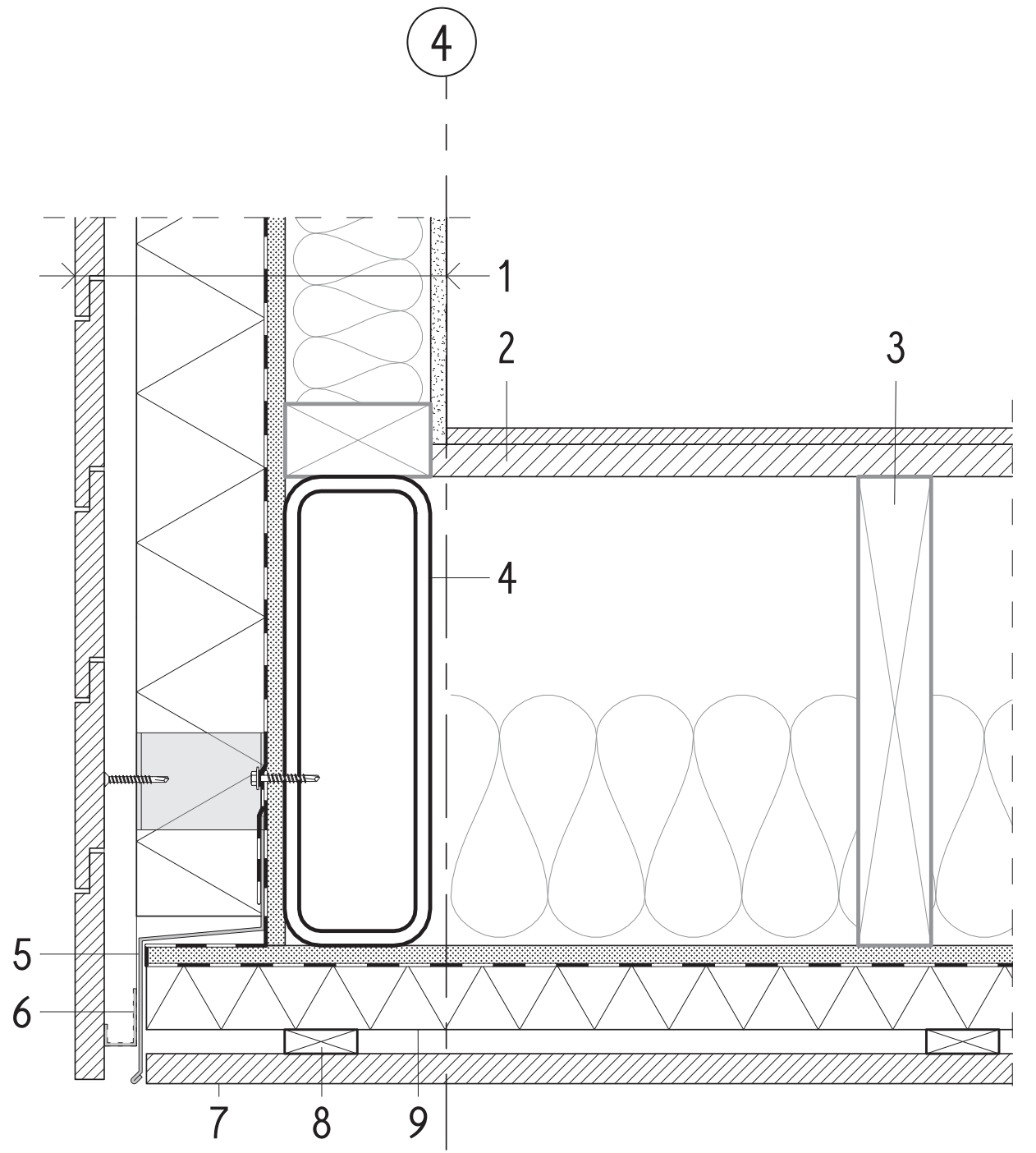

\section{1. wall assemlbly}

$10 \mathrm{~mm}$ gypsum board interior lining

$90 \mathrm{~mm} \times 45 \mathrm{~mm}$ timber framing with recycled fibreglass insulation

$12.7 \mathrm{~mm}$ gypsum sheathing with fibreglass coating class II vapour control layer (air barrier and drainage plane)

$80 \mathrm{~mm}$ rigid rock fibre insulation

$20 \mathrm{~mm} \times 45 \mathrm{~mm}$ vertical metal batten horizontal shiplap timber cladding

2. two layer timber flooring
3. $290 \mathrm{~mm} \times 45 \mathrm{~mm}$ cantilevered floor joists

4. cantilevered steel beam fixed to steel column

5. metal flashing

6. cavity closer

7. soffit timber cladding

8. timber strapping for attachment of soffit cladding.

9. $40 \mathrm{~mm}$ rock fibre insulation

notes.

Class II vapour control layer must be adhered over extruded sheathing to keep continuity. 


\section{4 - external door to patio}

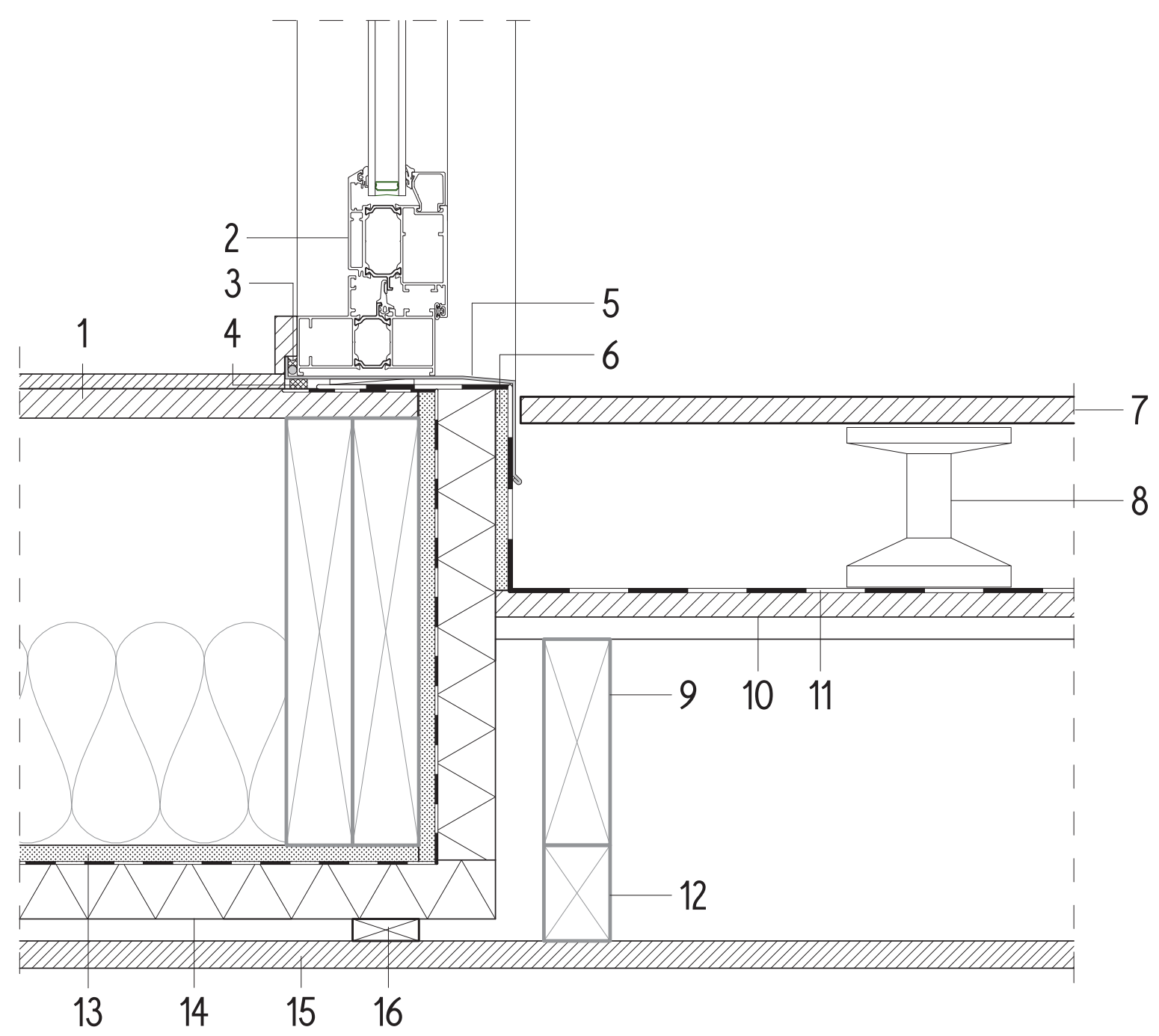

1. two layer timber flooring

3. thermally broken aluminium door joinery

4. compressible foam seal (air control continuity)

5. metal sill flashing

6. gypsum board for adhering of single ply membrane

7. timber decking

8. deck pedestals

9. $140 \mathrm{~mm} \times 45 \mathrm{~mm}$ cantilevered timber joists

10. plywood substrate for adhering of single ply membrane
11. single ply membrane

12. timber framing to match height of externally insulated soffit

13. $12.7 \mathrm{~mm}$ gypsum sheathing with fibreglass coating

15. soffit timber cladding

16. timber strapping for attachment of soffit cladding

14. $40 \mathrm{~mm}$ rock fibre insulation 


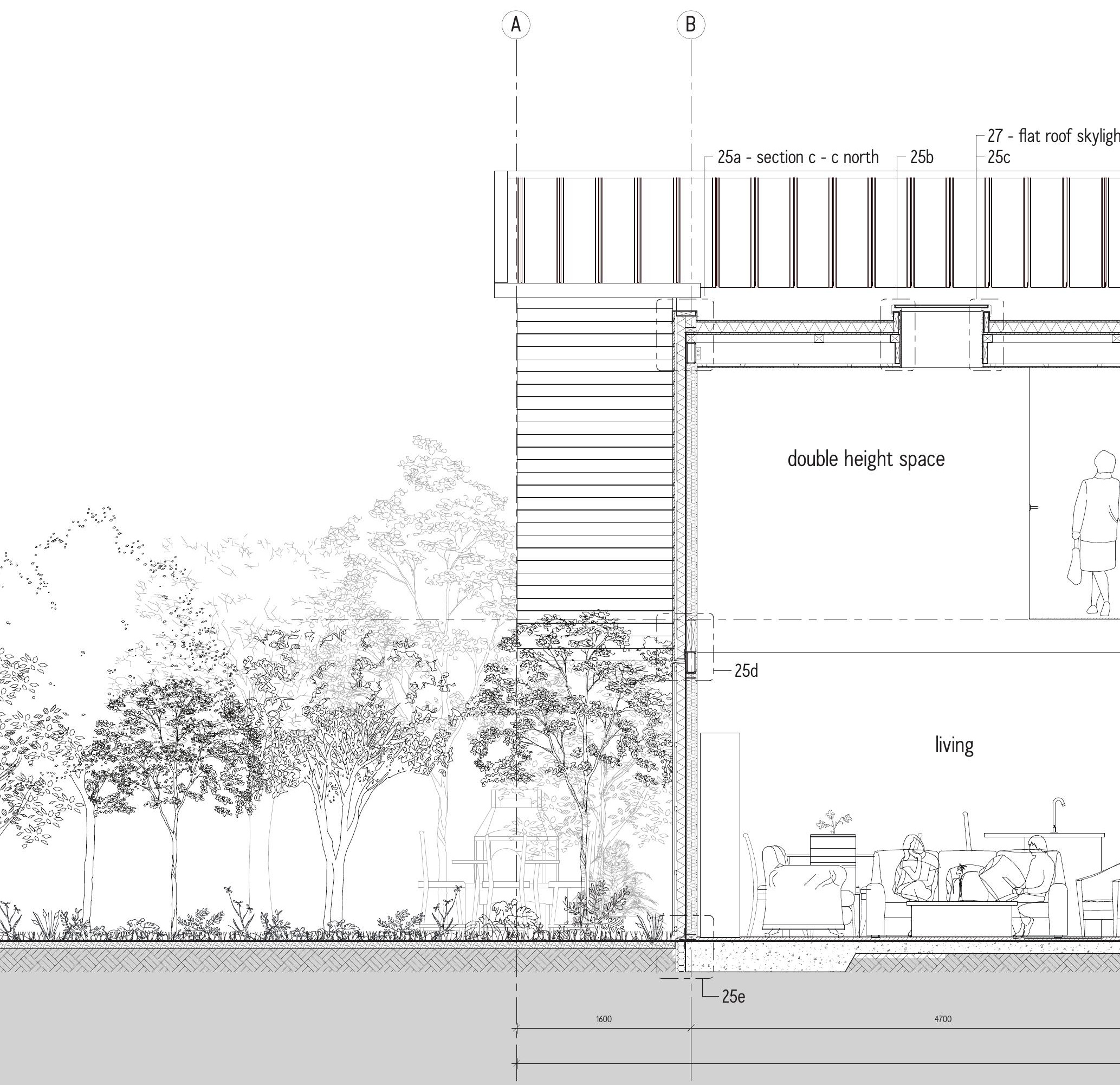




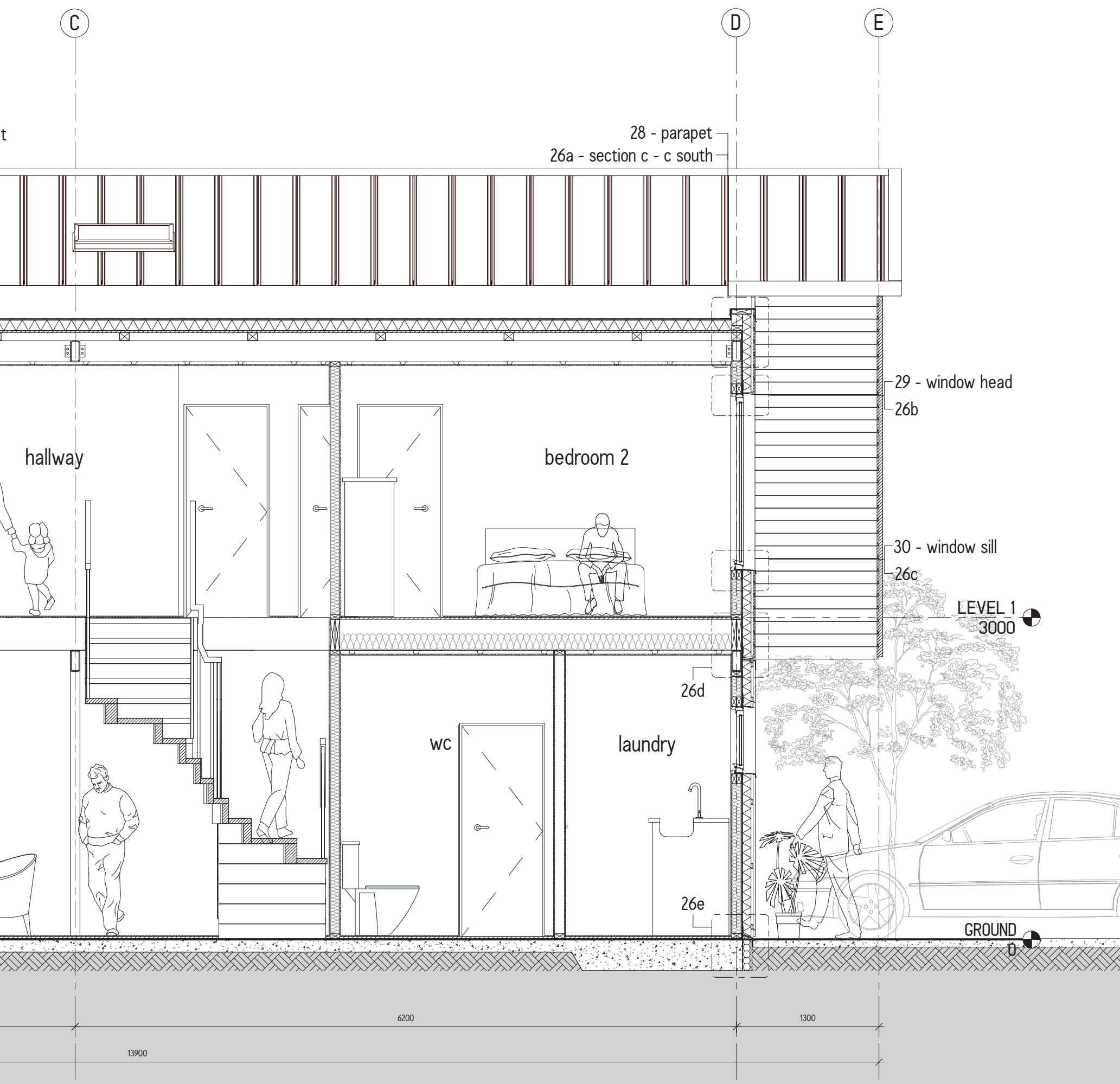


25 - section c - c north

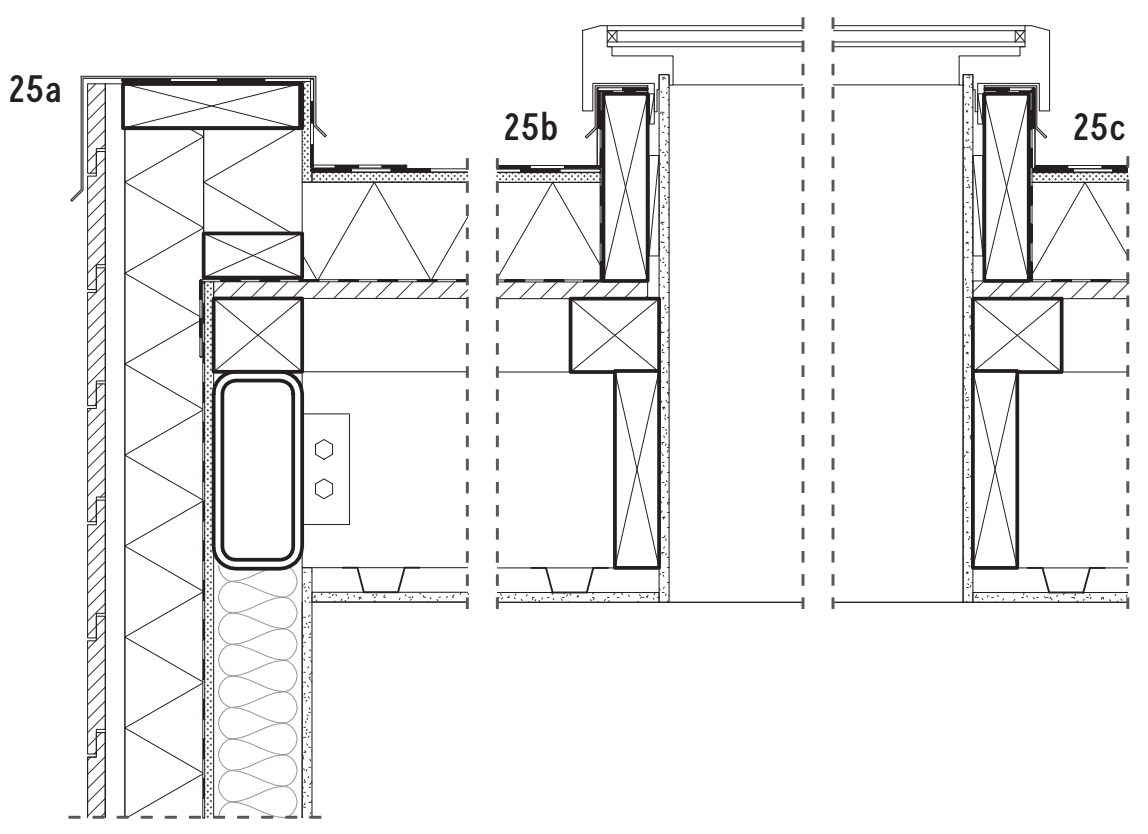

25d
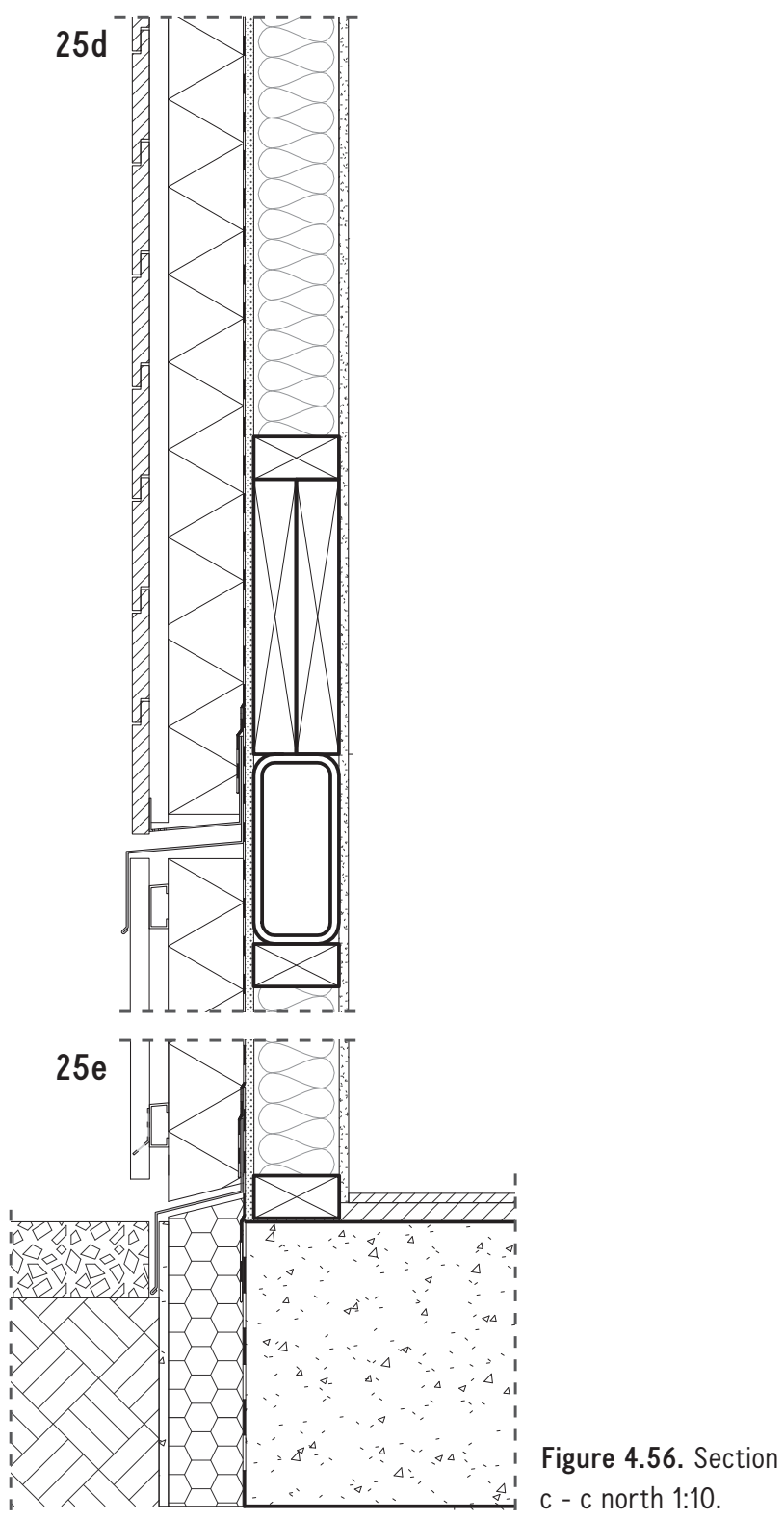
26 - section c - c south
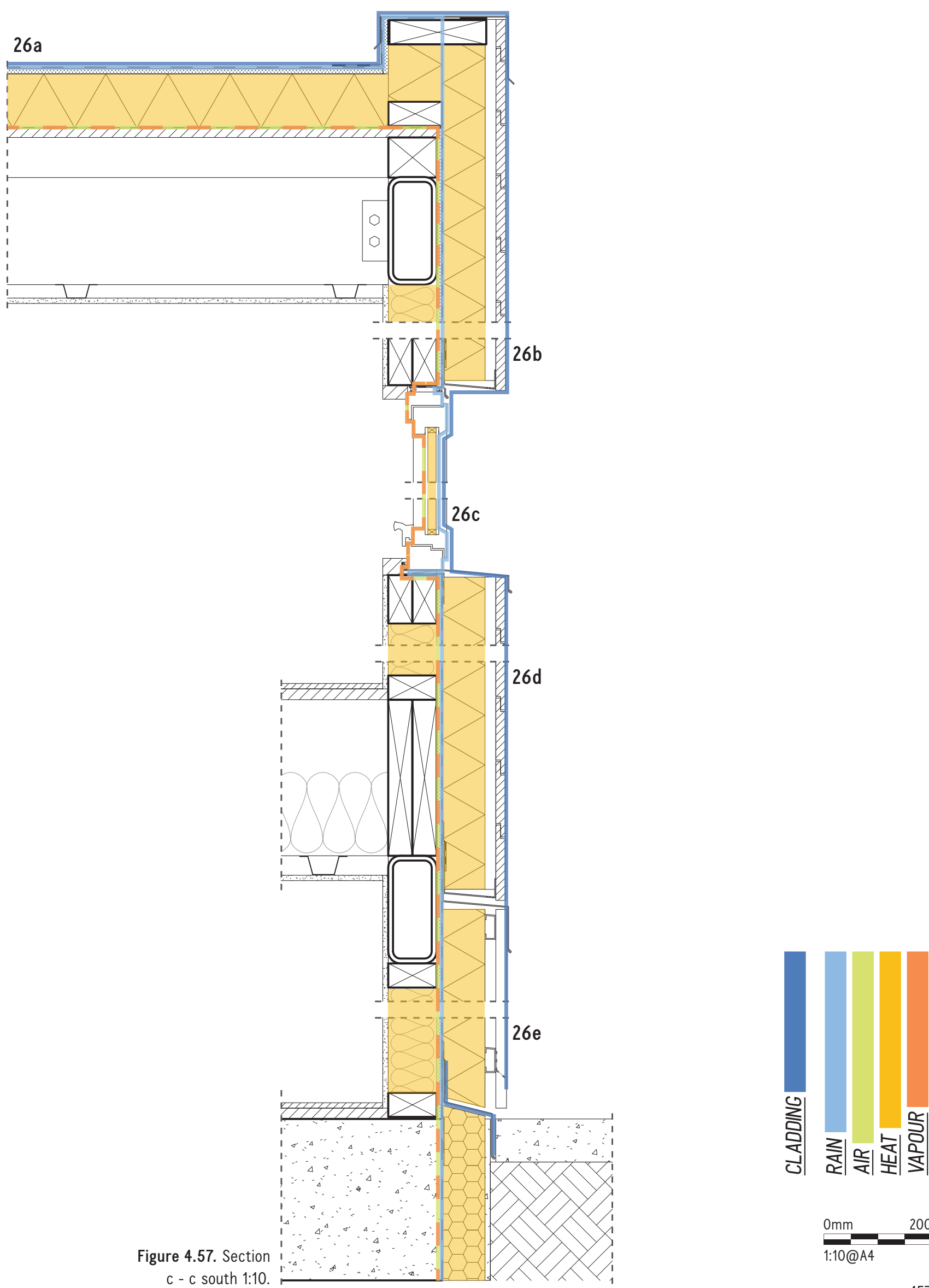


\section{7 - flat roof skylight}

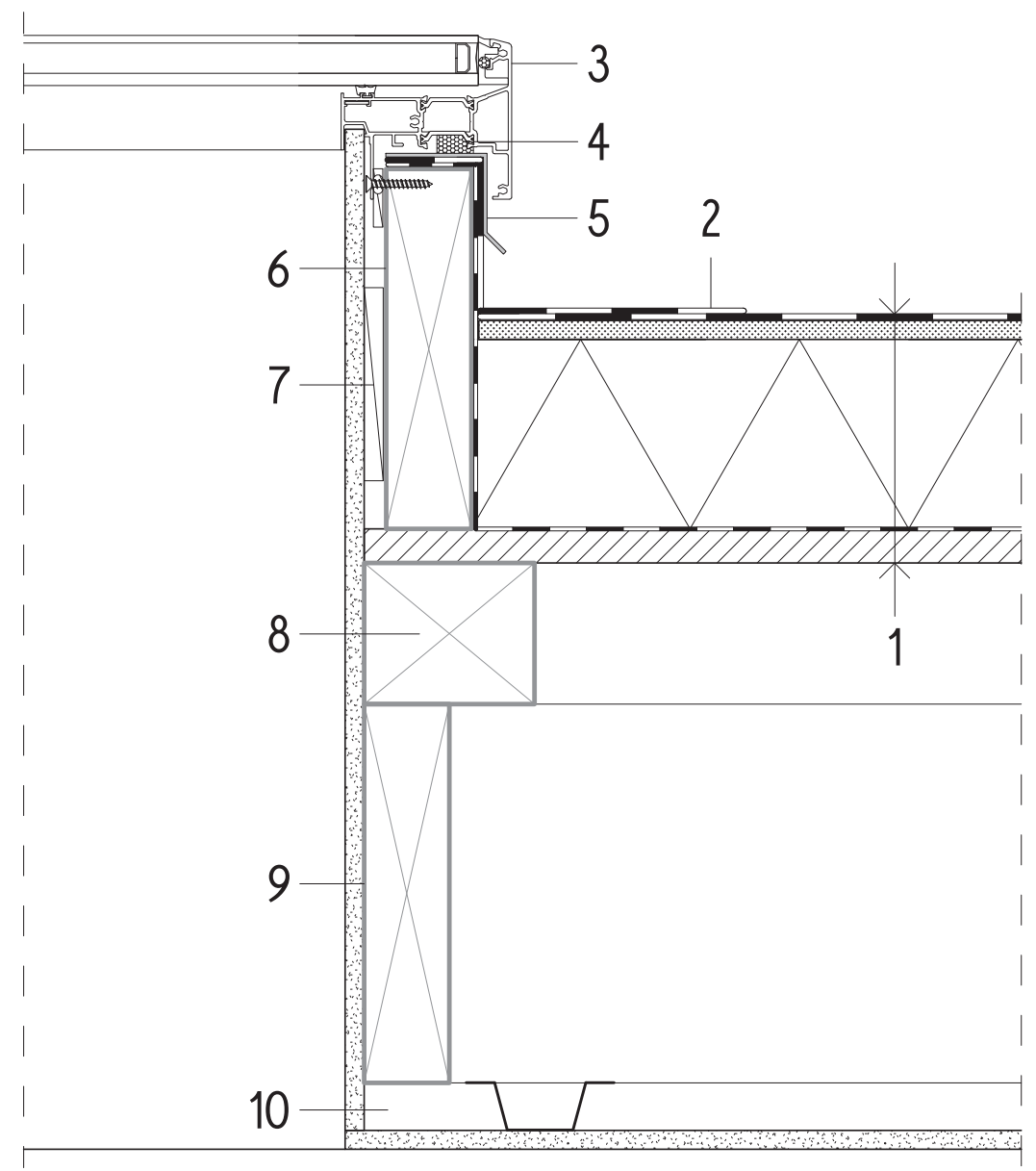

\section{1. roof assemlbly}

$18 \mathrm{~mm}$ plywood substrate

class I vapour control layer (air barrier)

$100 \mathrm{~mm}$ rigid rock fibre insulation

$10 \mathrm{~mm}$ gypsum roof board fixed through to purlins single ply membrane applied over roof board

2. single ply membrane flashed up under skylight joinery

3. thermally broken skylight
4. compressible foam air seal (air control continuity)

5. metal skylight flashing

6. timber blocking

7. timber packing

8. timber blocking to form $2^{\circ}$ slope

9. $200 \mathrm{~mm} \times 45 \mathrm{~mm}$ timber purlins

10. ceiling (metal battens and gypsum board) 


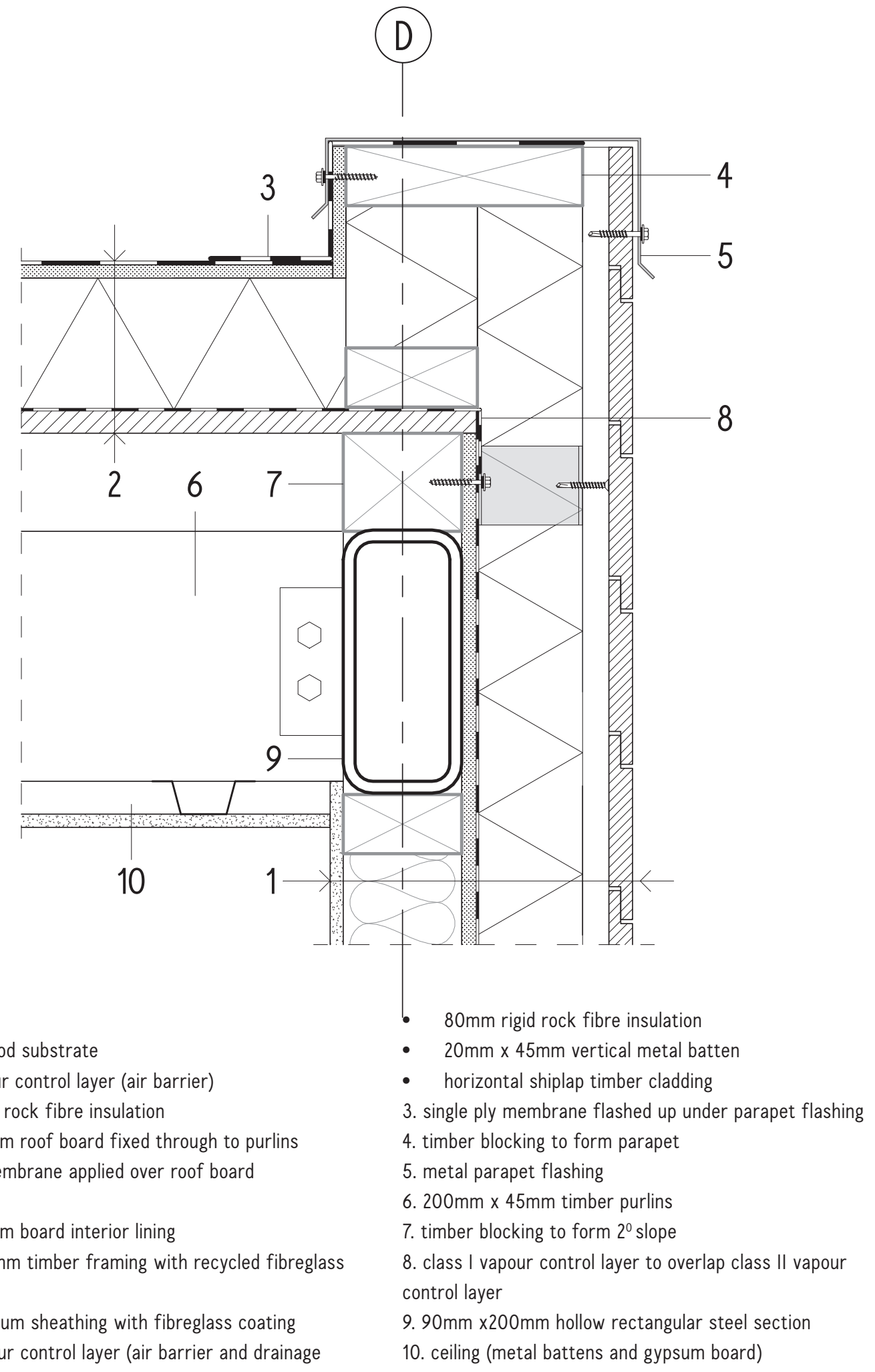

Figure 4.59. Detail 28 - parapet 1:5.

class I vapour control layer (air barrier)

$100 \mathrm{~mm}$ rigid rock fibre insulation

$10 \mathrm{~mm}$ gypsum roof board fixed through to purlins single ply membrane applied over roof board

\section{1. wall assemlbly}

$10 \mathrm{~mm}$ gypsum board interior lining

$90 \mathrm{~mm} \times 45 \mathrm{~mm}$ timber framing with recycled fibreglas insulation

$12.7 \mathrm{~mm}$ gypsum sheathing with fibreglass coating class II vapour control layer (air barrier and drainage plane) 


\section{9 - window head}

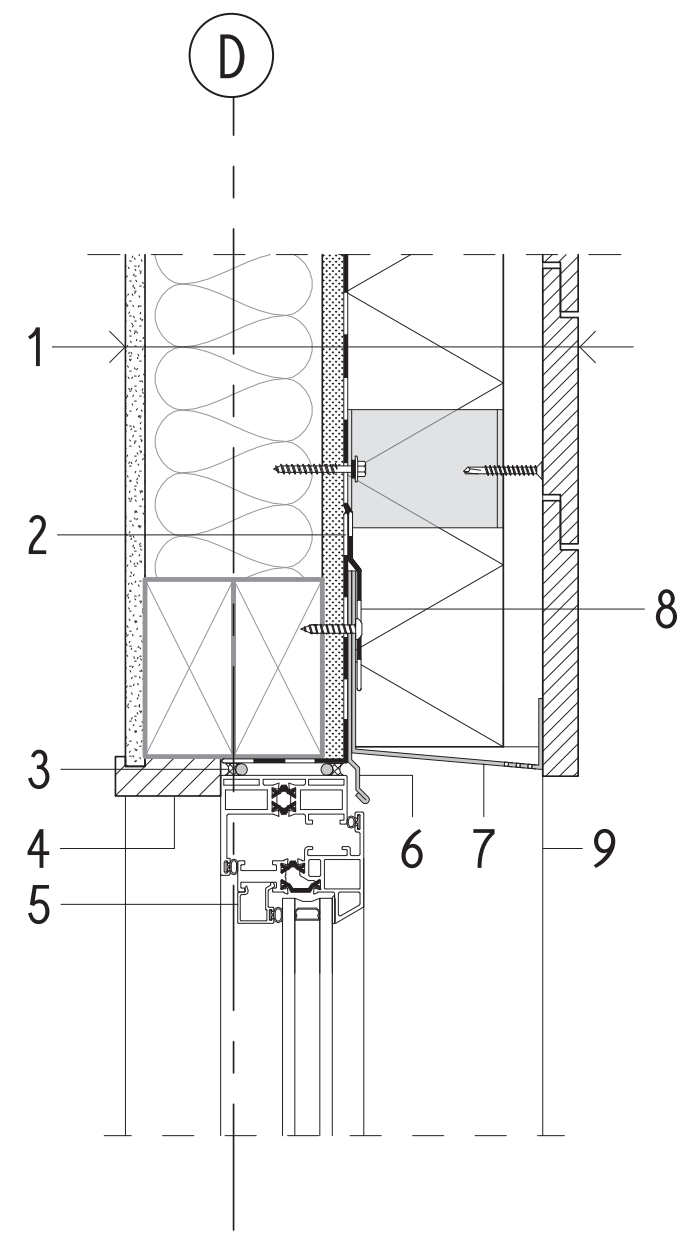

\section{1. wall assemlbly}

$10 \mathrm{~mm}$ gypsum board interior lining

$90 \mathrm{~mm} \times 45 \mathrm{~mm}$ timber framing with recycled fibreglass insulation

$12.7 \mathrm{~mm}$ gypsum sheathing with fibreglass coating class II vapour control layer (air barrier and drainage plane)

$80 \mathrm{~mm}$ rigid rock fibre insulation

$20 \mathrm{~mm} \times 45 \mathrm{~mm}$ vertical metal batten

horizontal shiplap timber cladding
2. class II vapour control layer flashed into window opening

3. backer rod and sealant (air control continuity)

4. timber architrave

5. thermally broken aluminium window

6. metal head flashing

7. metal cavity closure flashing fixed to front of metal batten

8. class II vapour control layer to overlap metal head flashing

9. jamb flashing beyond 
30 - window sill

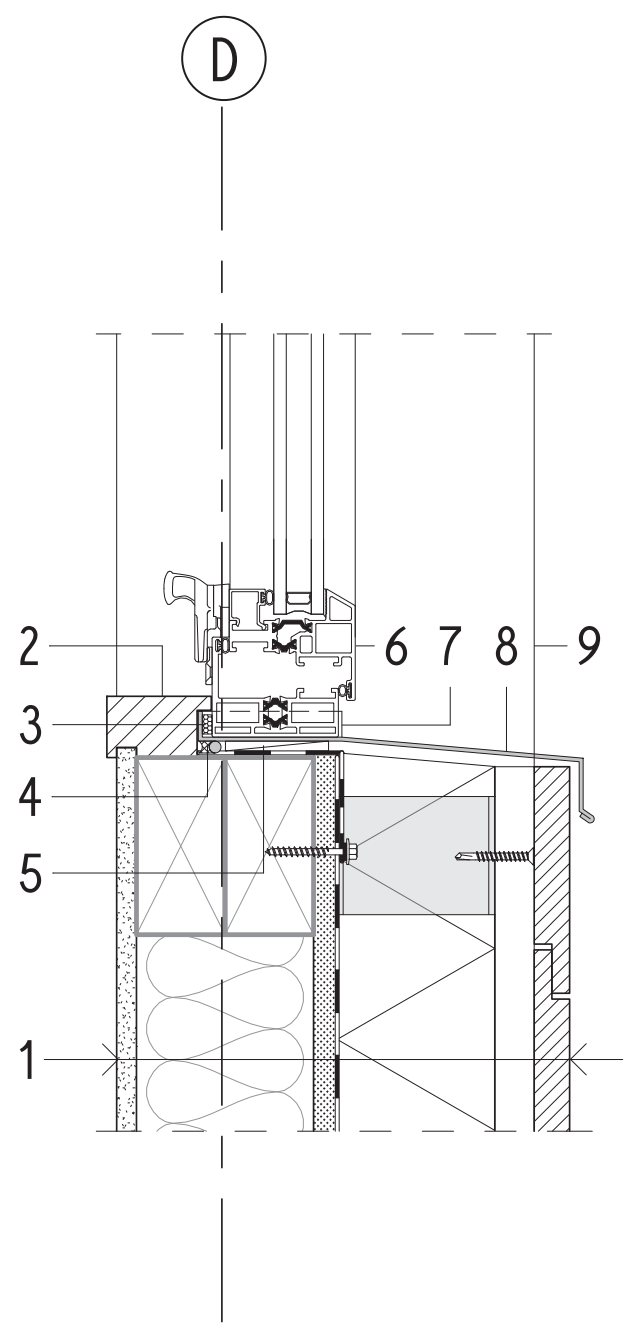

\section{1. wall assemlbly}

$10 \mathrm{~mm}$ gypsum board interior lining

$90 \mathrm{~mm} \times 45 \mathrm{~mm}$ timber framing with recycled fibreglass insulation

$12.7 \mathrm{~mm}$ gypsum sheathing with fibreglass coating class II vapour control layer (air barrier and drainage plane)

$80 \mathrm{~mm}$ rigid rock fibre insulation

$20 \mathrm{~mm} \times 45 \mathrm{~mm}$ vertical metal batten

horizontal shiplap timber cladding

\author{
2. timber architrave \\ 3. compressible foam air seal (air control continuity) \\ 4. backer rod and sealant (air control continuity) \\ 5. timber packing \\ 6. thermally broken aluminium window \\ 7. upstand to edges of sill tray flashing \\ 8. sill tray flashing \\ 9. jamb flashing beyond
}


section $d-d$

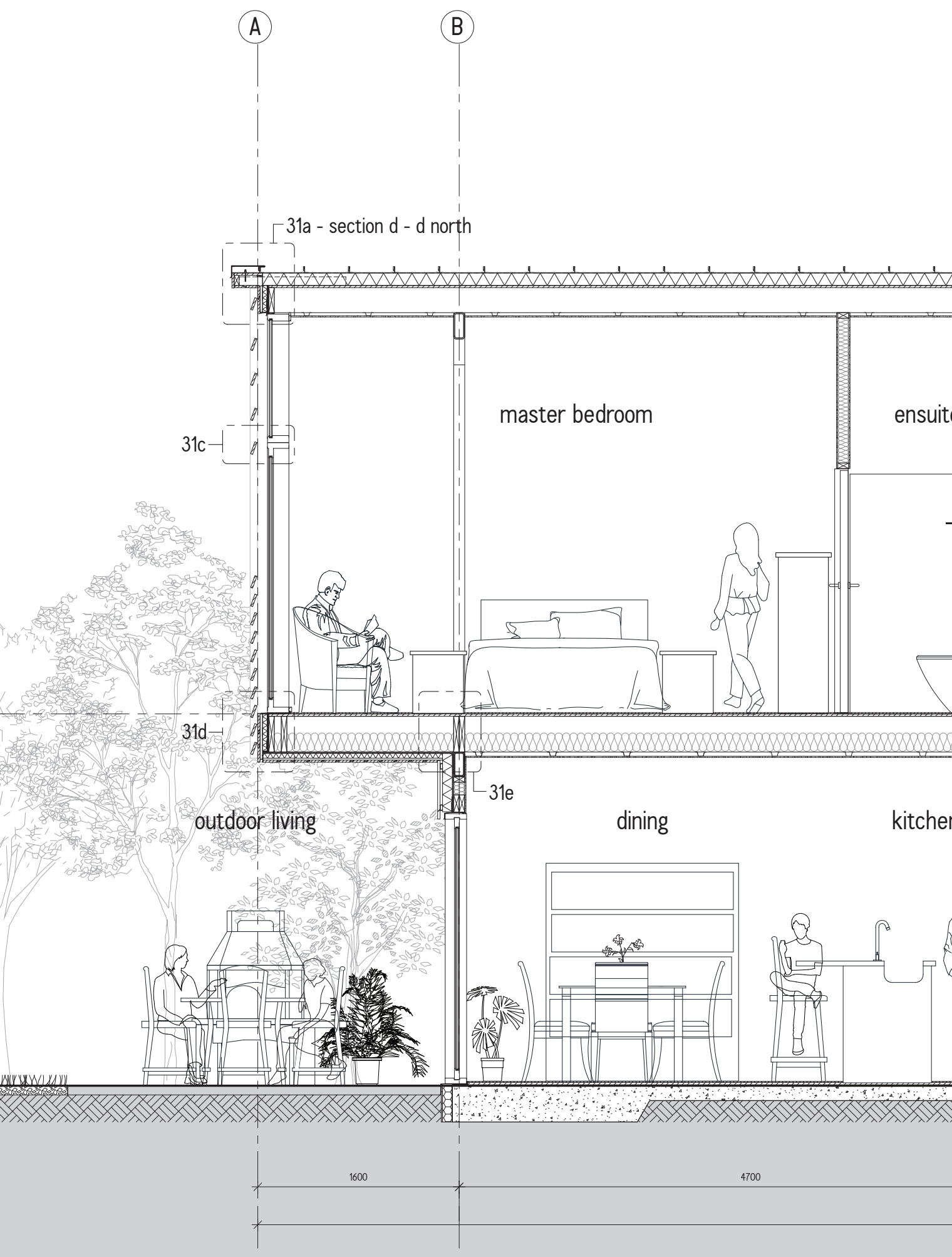




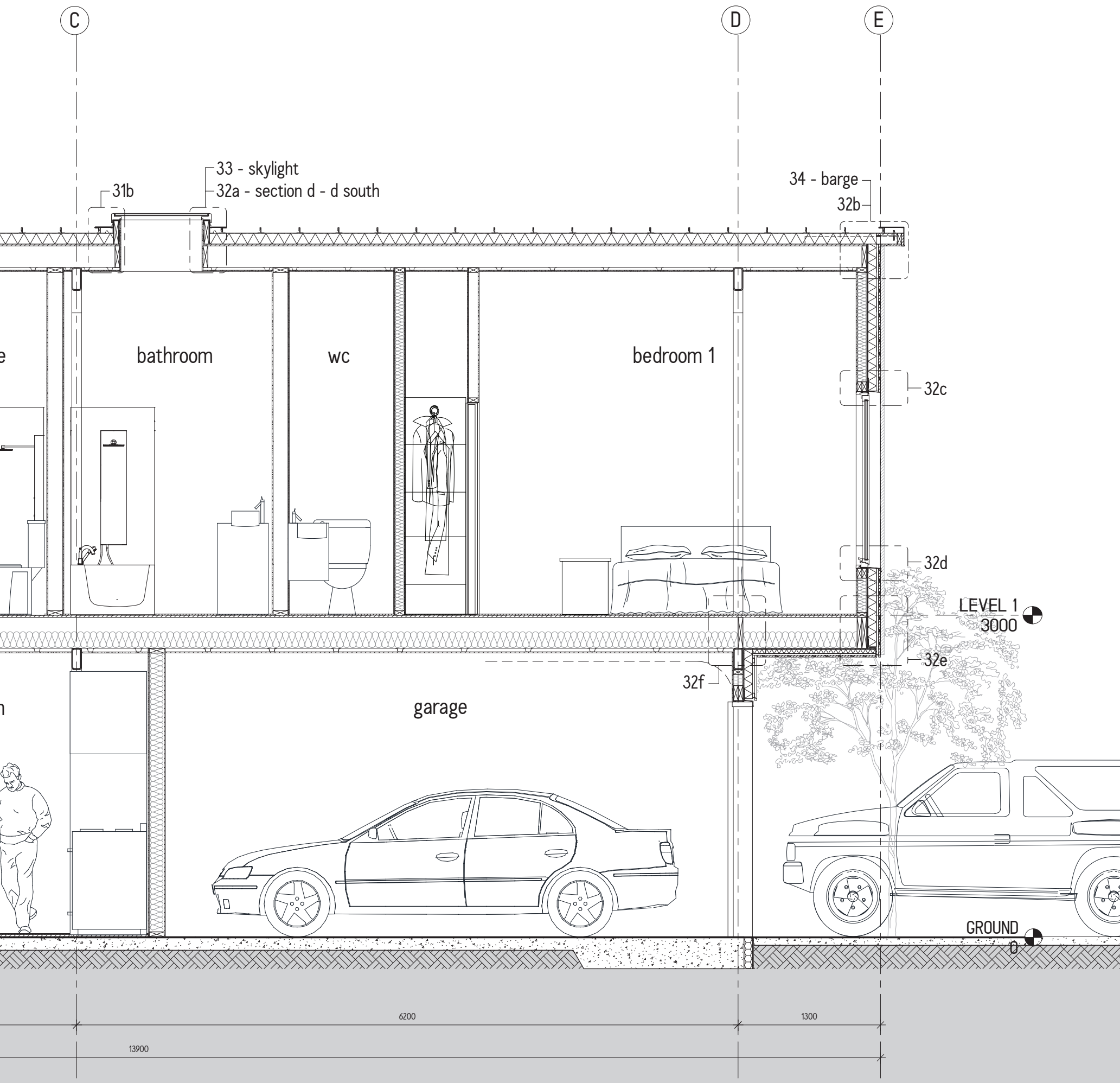


31 - section d-d north
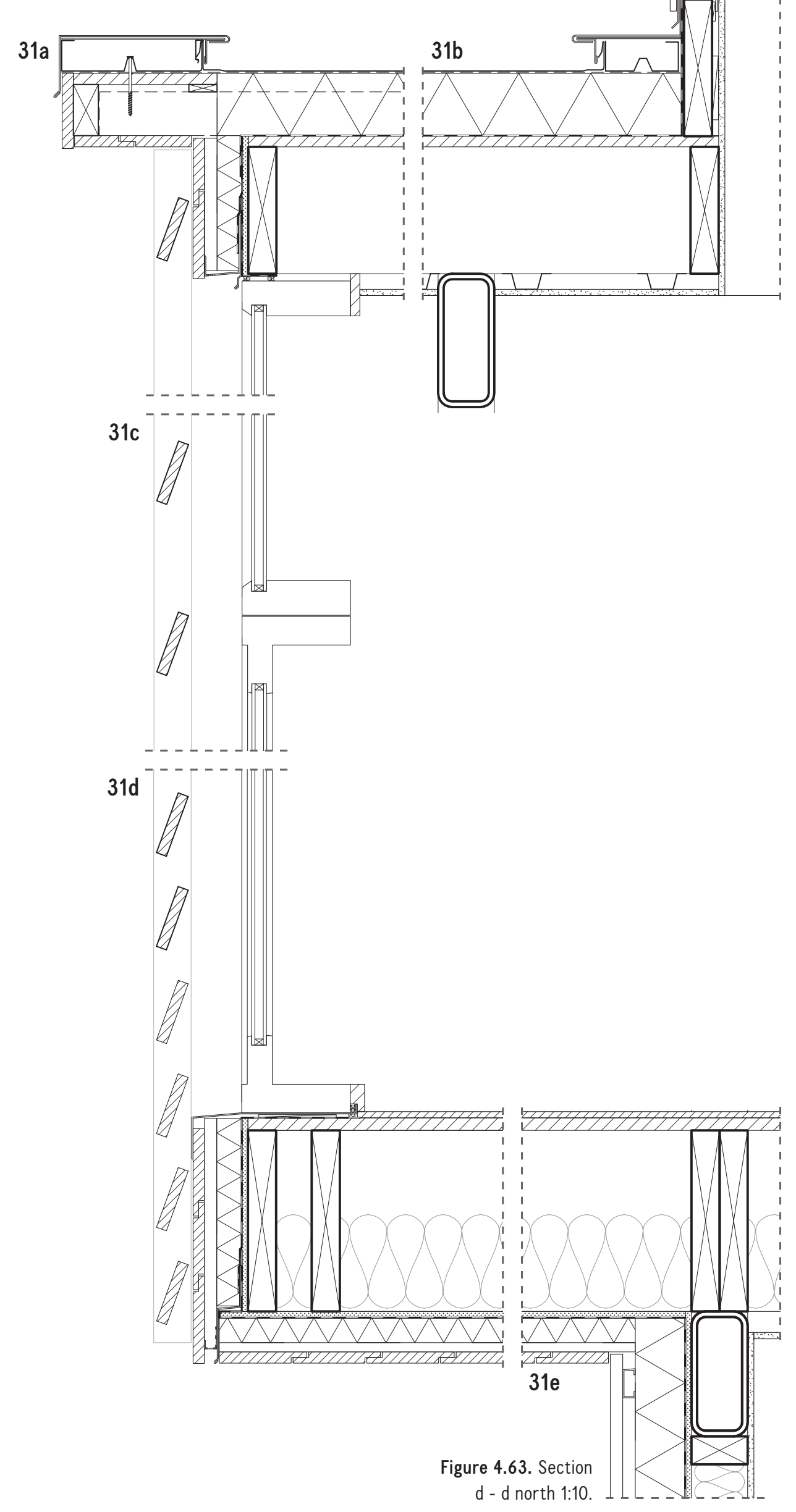


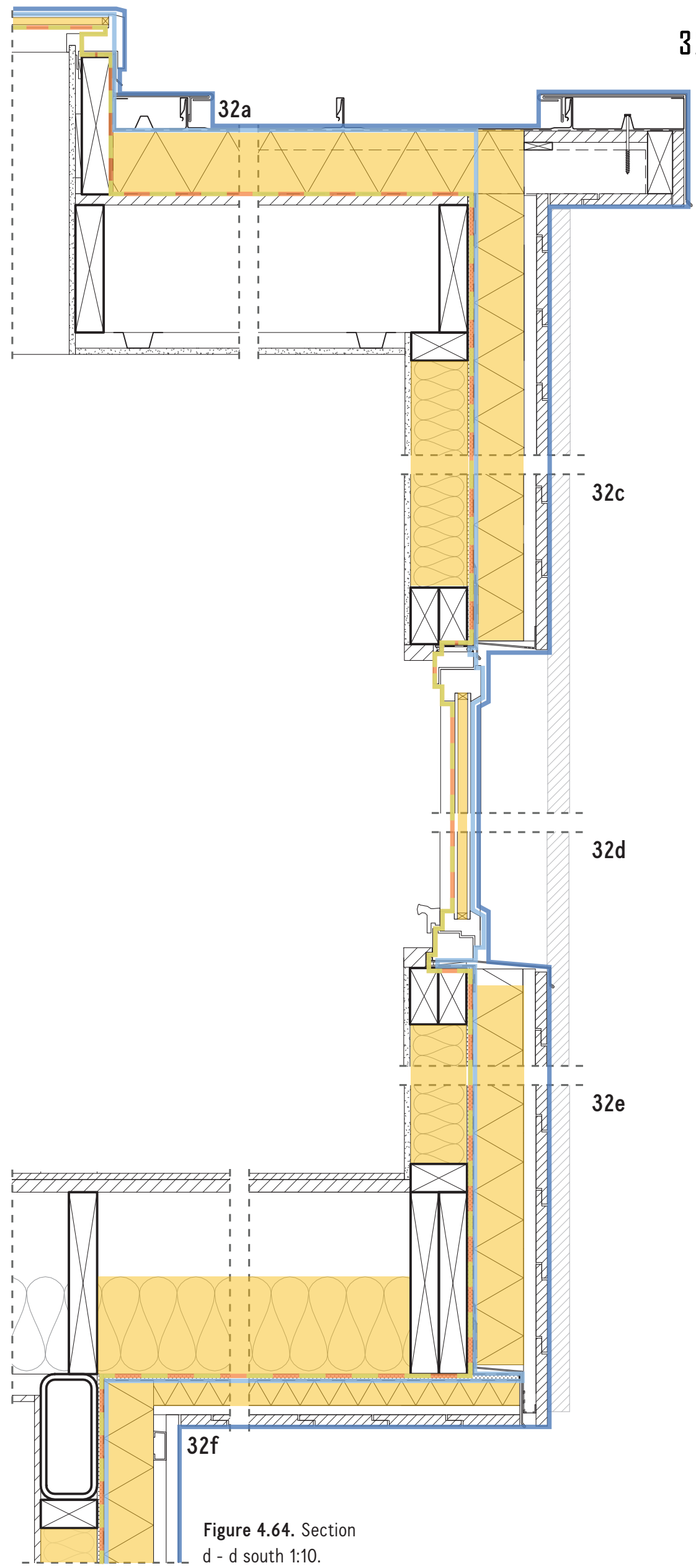
$32 b$ 


\section{3 - skylight}

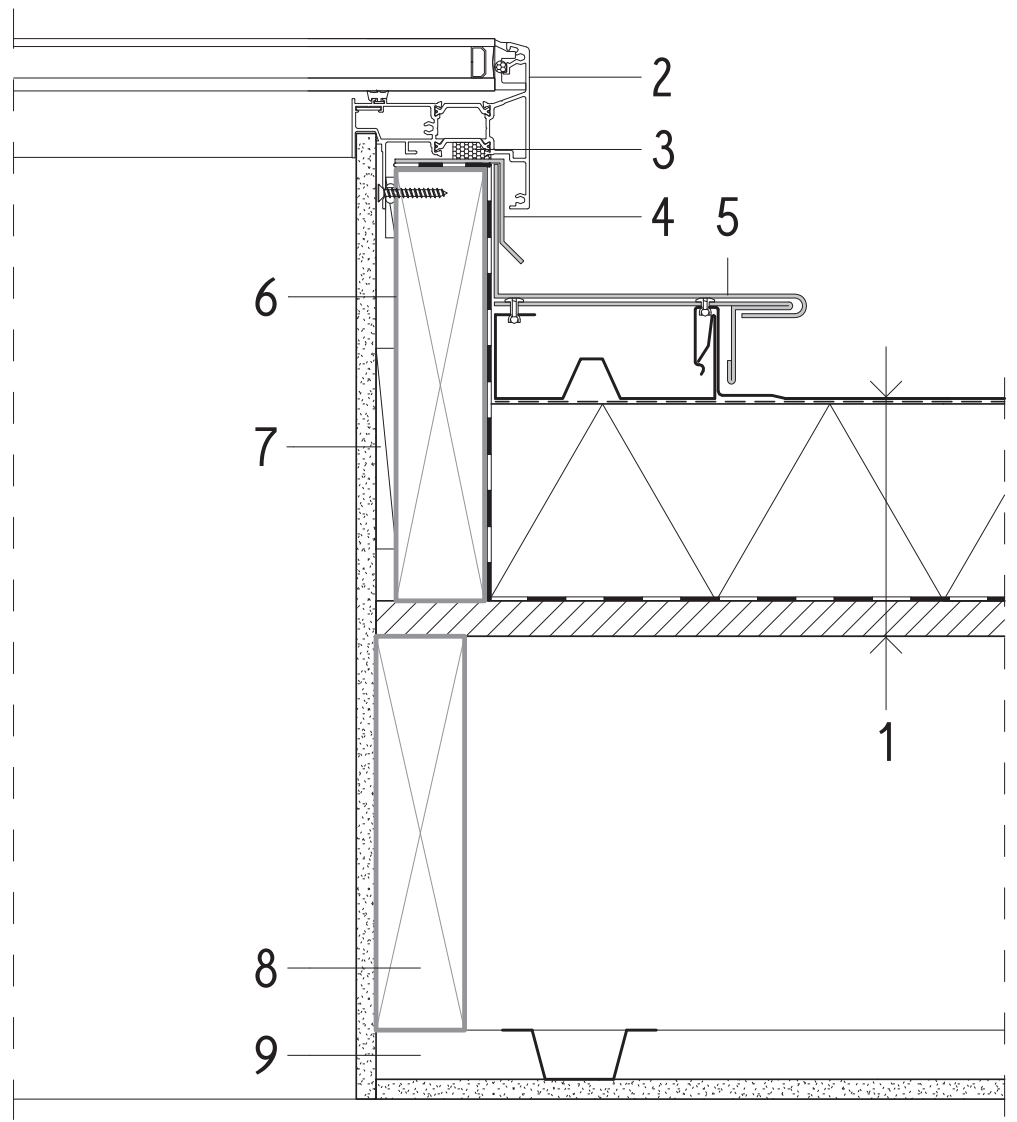

\section{1. roof assemlbly}

$18 \mathrm{~mm}$ plywood substrate

class I vapour control layer (air barrier)

$40 \mathrm{~mm} \times 45 \mathrm{~mm}$ timber battens fixed through to purlins $100 \mathrm{~mm}$ rigid rock fibre insulation

roof underlay

hidden roofing clips fixed through to timber battens standing seam metal cladding attached onto clips

2. thermally broken skylight
3. compressible foam air seal (air control continuity)

4. metal skylight flashing

5. metal apron flashing with concealed hook flashing

6. timber blocking

7. timber packing

8. $200 \mathrm{~mm} \times 45 \mathrm{~mm}$ timber purlins

9. ceiling (metal battens and gypsum board) 


\section{4 - barge}

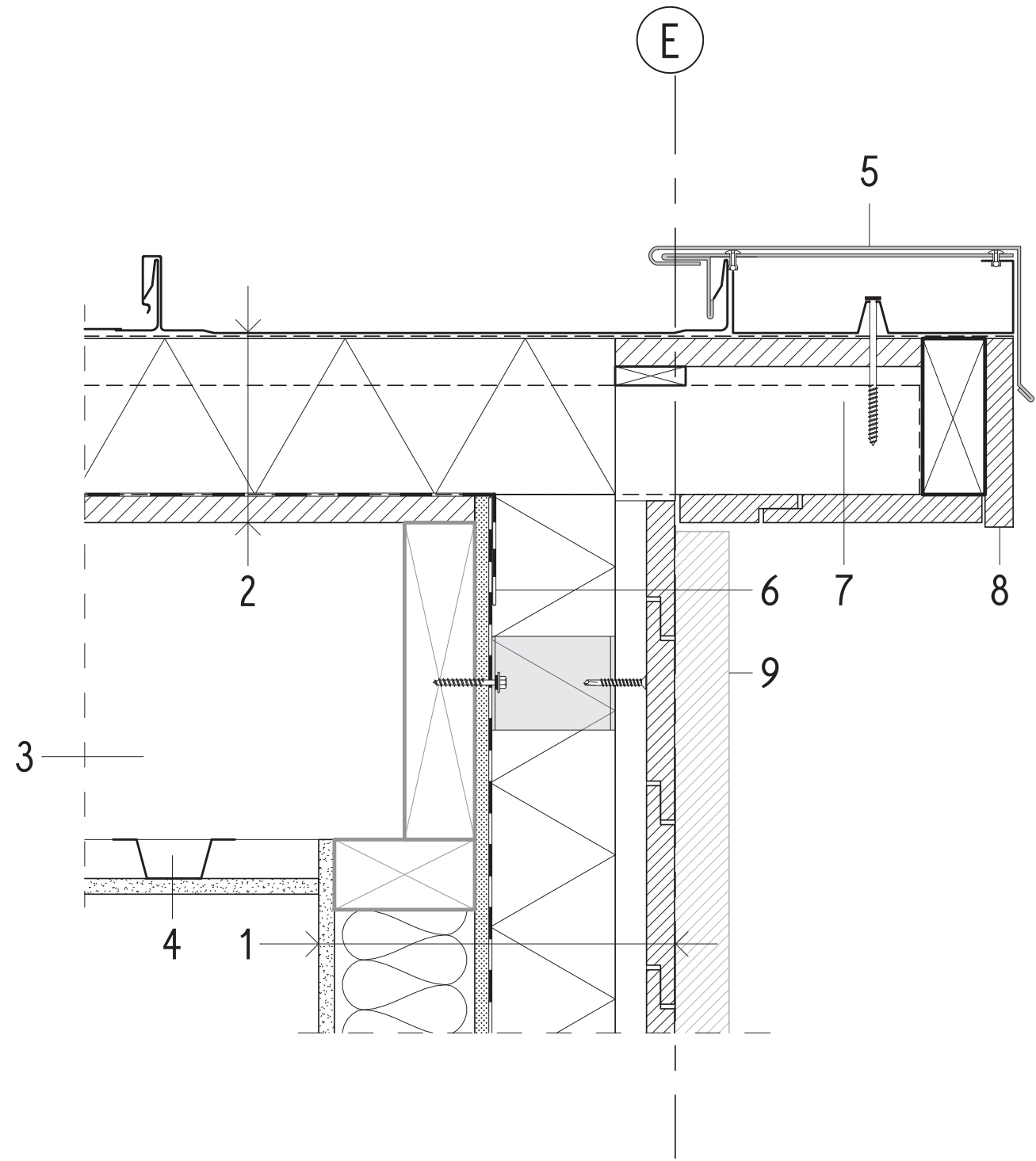

1. wall assemlbly

$10 \mathrm{~mm}$ gypsum board interior lining

$90 \mathrm{~mm} \times 45 \mathrm{~mm}$ timber framing with recycled fibreglass insulation

$12.7 \mathrm{~mm}$ gypsum sheathing with fibreglass coating class II vapour control layer (air barrier and drainage plane)

$80 \mathrm{~mm}$ rigid rock fibre insulation

$20 \mathrm{~mm} \times 45 \mathrm{~mm}$ vertical metal batten horizontal shiplap timber cladding

\section{2. roof assemlbly}

$18 \mathrm{~mm}$ plywood substrate

class I vapour control layer (air barrier)
$40 \mathrm{~mm} \times 45 \mathrm{~mm}$ timber battens fixed through to purlins $100 \mathrm{~mm}$ rigid rock fibre insulation roof underlay hidden roofing clips fixed through to timber battens standing seam metal cladding attached onto clips 3. $180 \mathrm{~mm} \times 45 \mathrm{~mm}$ cantilevered timber purlins 4. ceiling (metal battens and gypsum board) 5. metal barge flashing with concealed hook flashing 6. class I vapour control layer to overlap class II vapour control layer.

7. $70 \mathrm{~mm} \times 45 \mathrm{~mm}$ timber outriggers to form barge overhang 8. timber barge board

9. timber batten beyond 


\section{section e - e}

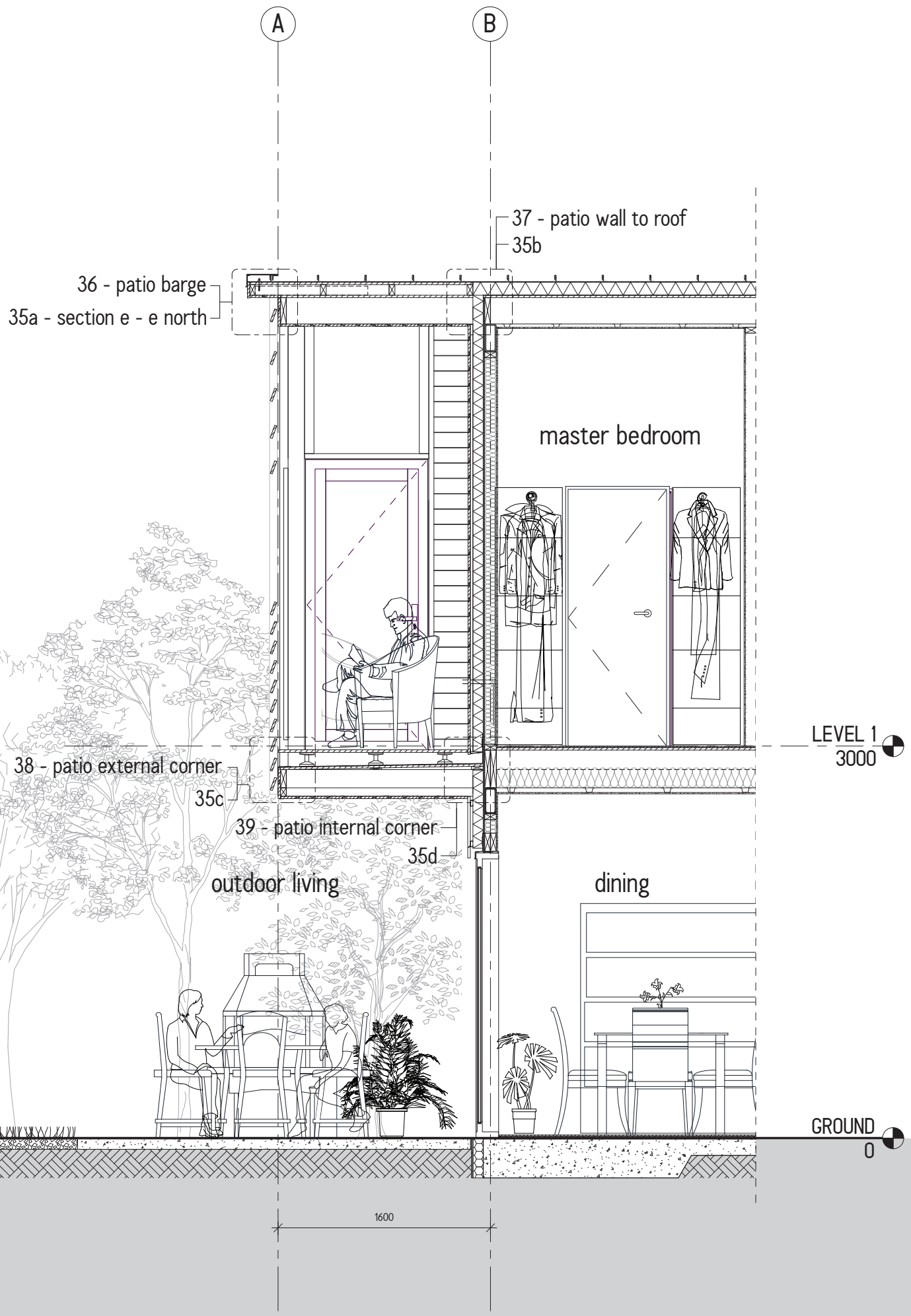


35 - section e - e north
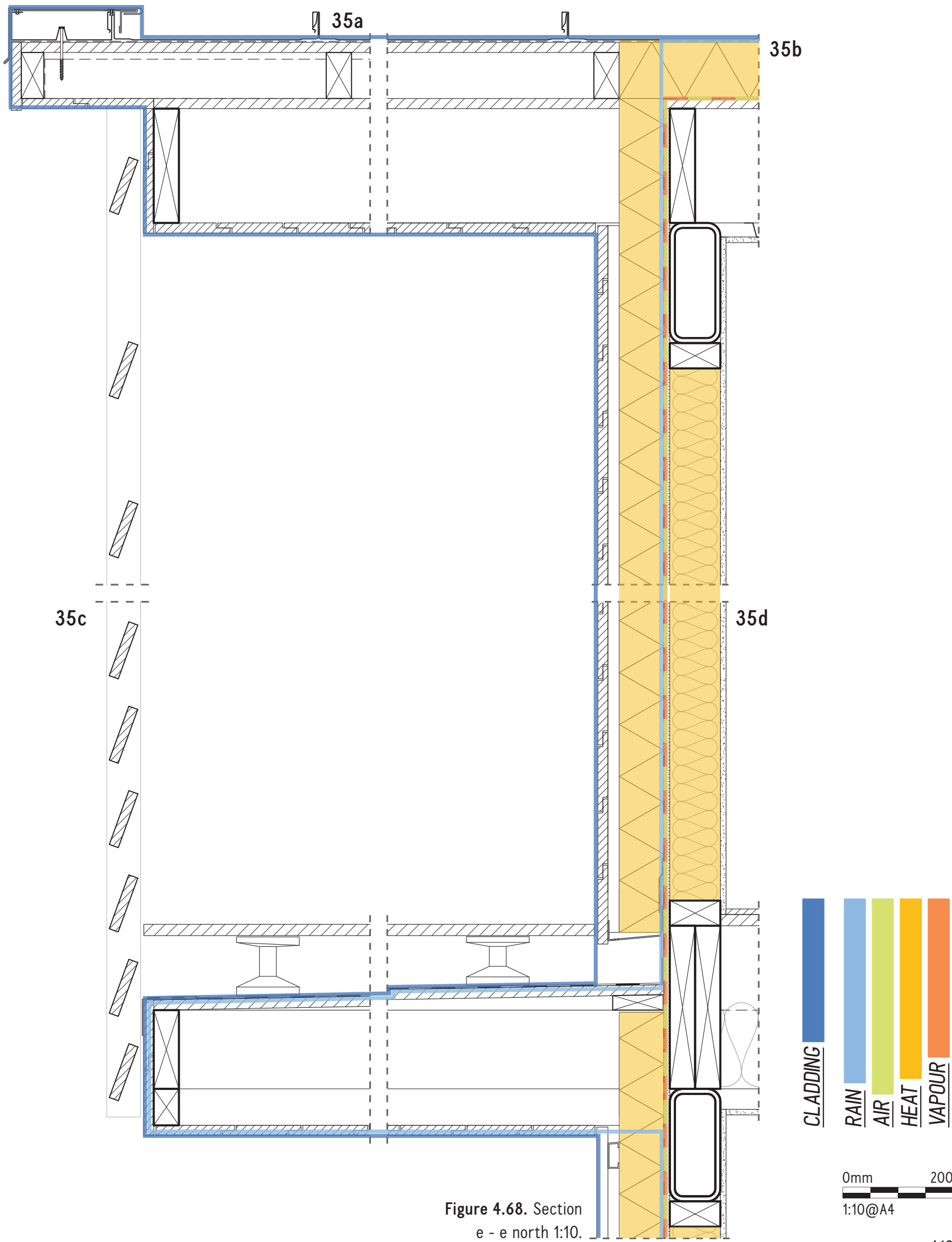


\section{6 - patio barge}

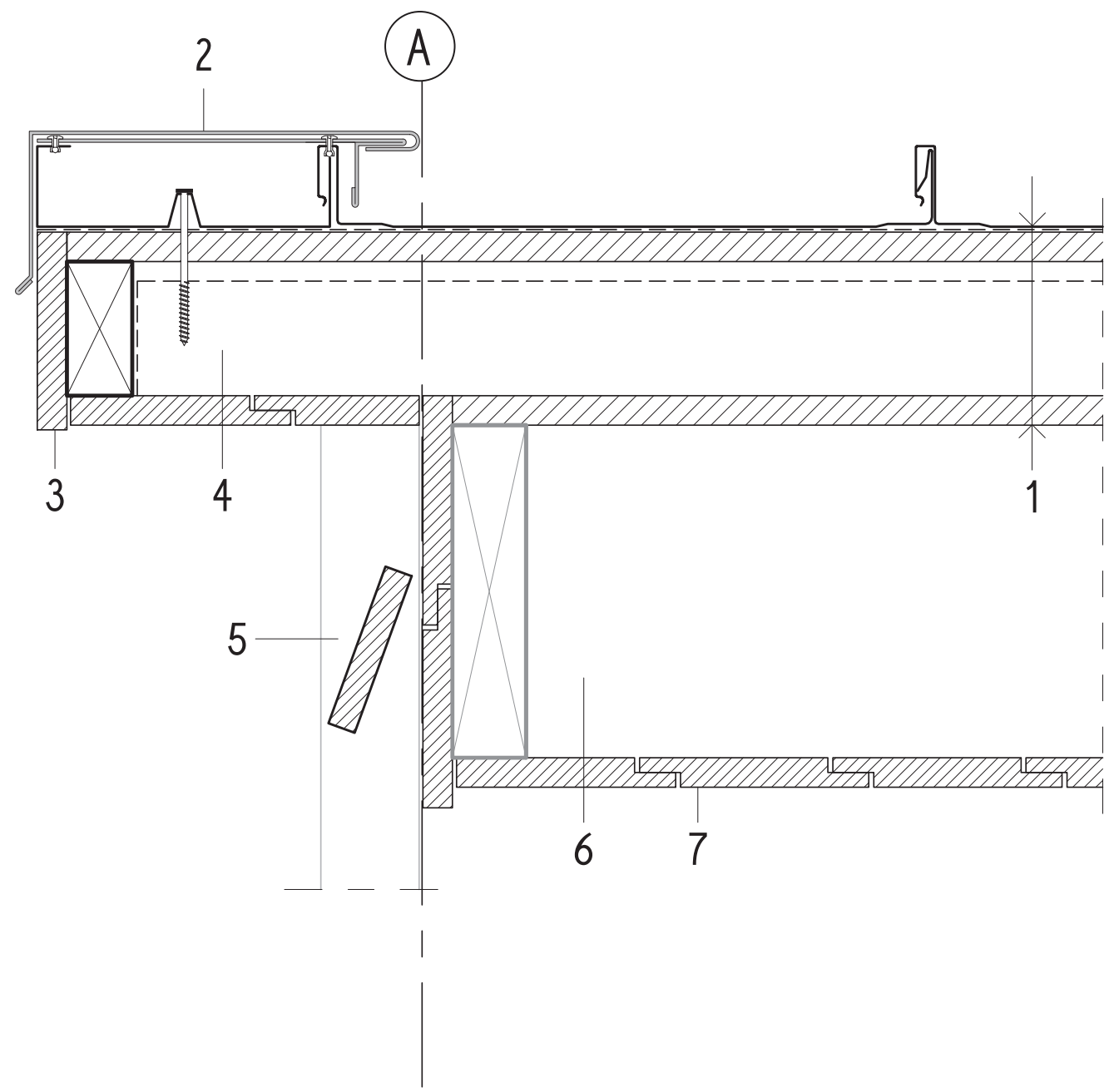

\section{1. patio roof assemlbly}

$18 \mathrm{~mm}$ plywood substrate

timber framing

$18 \mathrm{~mm}$ plywood substrate

roof underlay

hidden roofing clips fixed through to timber framing

standing seam metal cladding attached onto clips
2. metal barge flashing with concealed hook flashing

3. timber barge board

4. $70 \mathrm{~mm} \times 45 \mathrm{~mm}$ timber outriggers to form barge overhang

5. timber lourve system fixed to timber framing

6. $180 \mathrm{~mm} \times 45 \mathrm{~mm}$ cantilevered timber purlins

7. shiplap timber cladding 


\section{7 - patio wall to roof}

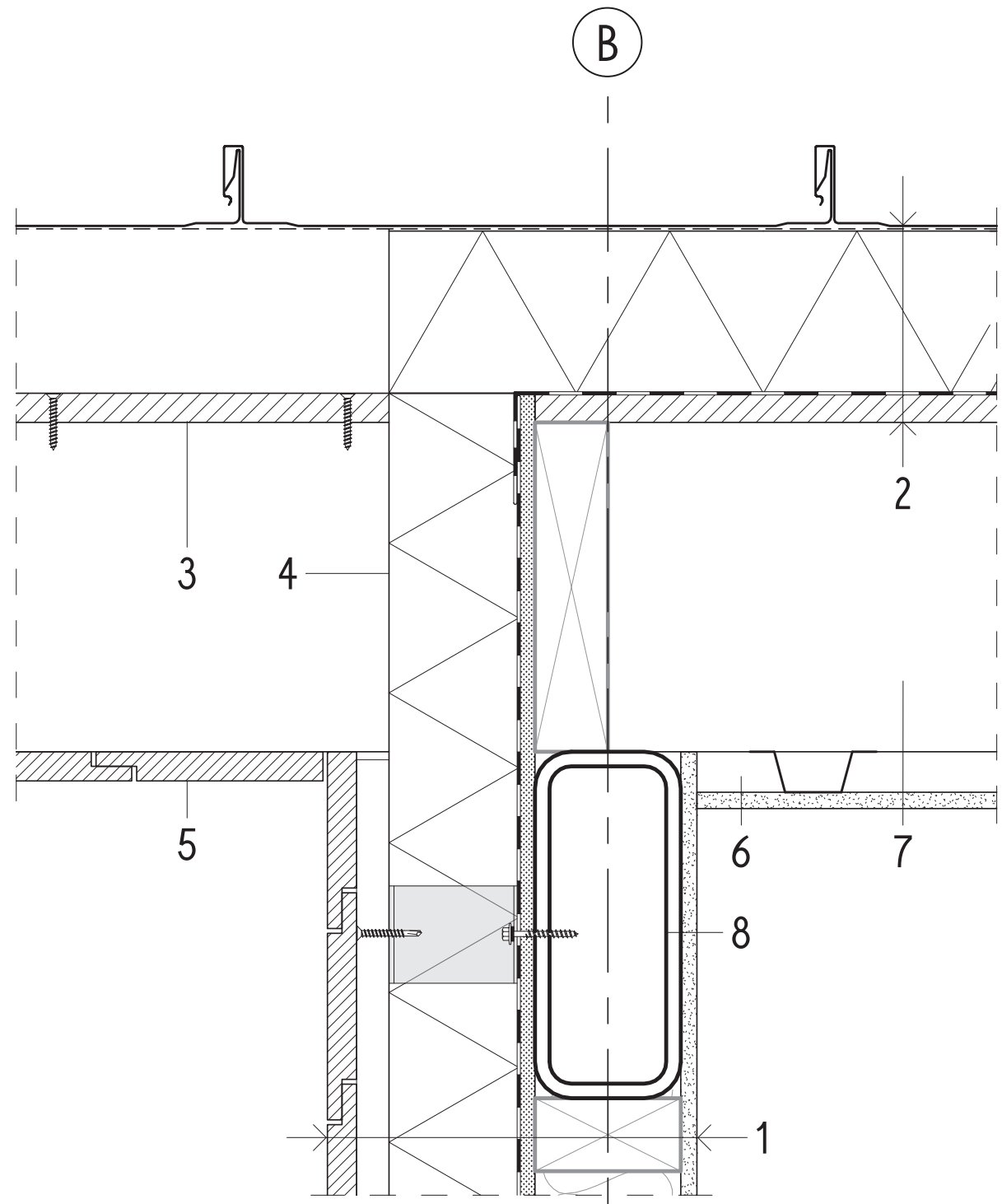

\section{1. wall assemlbly}

$10 \mathrm{~mm}$ gypsum board interior lining

$90 \mathrm{~mm} \times 45 \mathrm{~mm}$ timber framing with recycled fibreglass insulation

$12.7 \mathrm{~mm}$ gypsum sheathing with fibreglass coating class II vapour control layer (air barrier and drainage plane)

$80 \mathrm{~mm}$ rigid rock fibre insulation

$20 \mathrm{~mm} \times 45 \mathrm{~mm}$ vertical metal batten horizontal shiplap timber cladding

\section{2. roof assemlbly}

$18 \mathrm{~mm}$ plywood substrate

class I vapour control layer (air barrier)

$40 \mathrm{~mm} \times 45 \mathrm{~mm}$ timber battens fixed through to purlins $100 \mathrm{~mm}$ rigid rock fibre insulation roof underlay

hidden roofing clips fixed through to timber battens standing seam metal cladding attached onto clips

3. $18 \mathrm{~mm}$ plywood fixed to cantilevered timber purlins

4. rock fibre insulation in wall to be continuous with rock fibre insulation in roof

5. shiplap timber cladding

6. ceiling (metal battens and gypsum board)

7. $180 \mathrm{~mm} \times 45 \mathrm{~mm}$ cantilevered timber purlins

8. $90 \mathrm{~mm} \times 200 \mathrm{~mm}$ hollow rectangular steel section

notes.

Class I and II vapour control layers to be taped around cantilevered purlins for air control continuity. 


\section{8 - patio external corner}

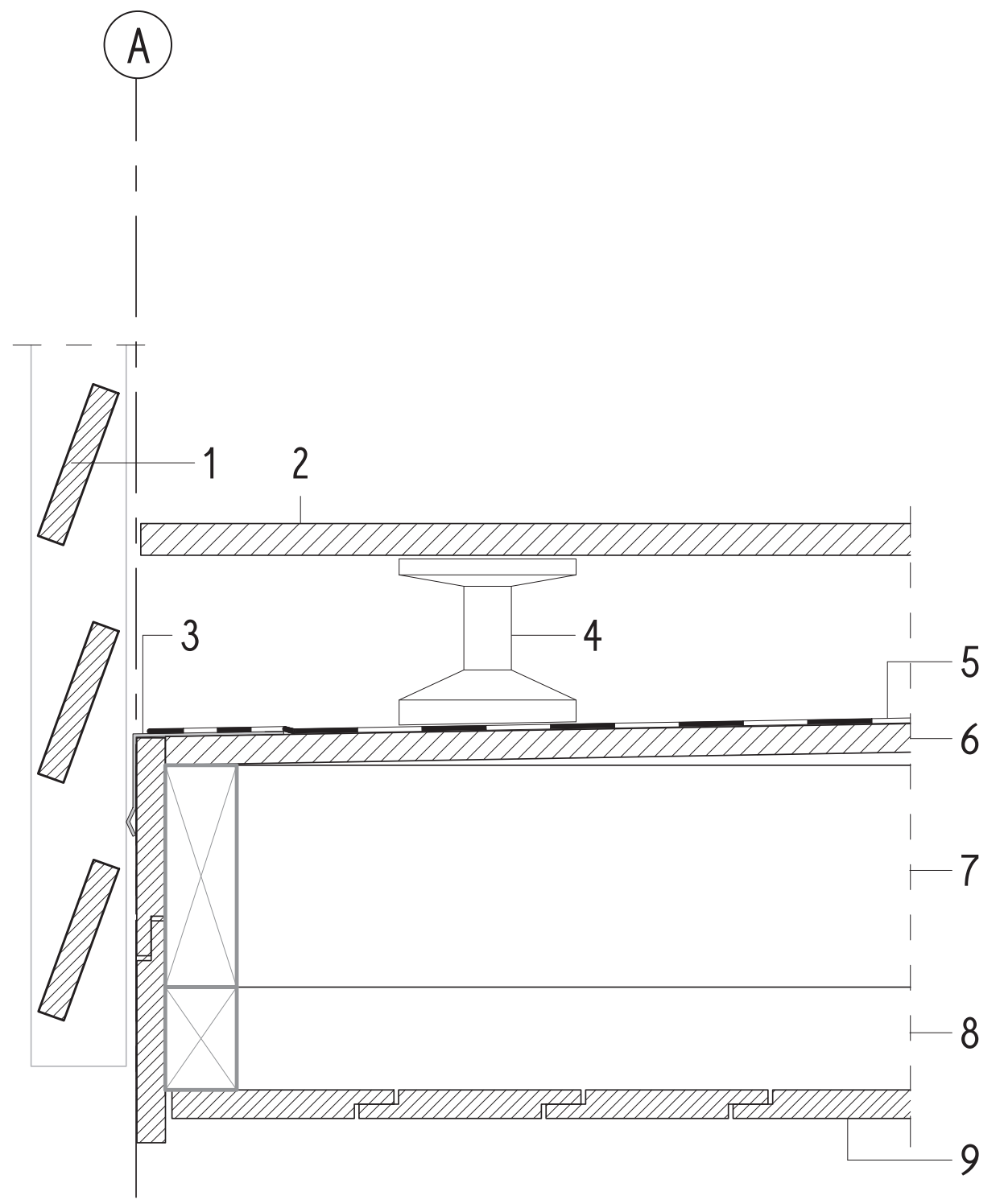

1. timber louvre system fixed to timber framing

2. timber decking

3. laminated metal flashing for adhereing of single ply membrane

4. deck pedestals

5. single ply membrane
6. plywood substrate forming $1^{0}$ slope

7. $140 \mathrm{~mm} \times 45 \mathrm{~mm}$ cantilevered timber joists

8. timber framing to match height of externally insulated soffit

9. timber soffit cladding 


\section{9 - patio internal согпег}

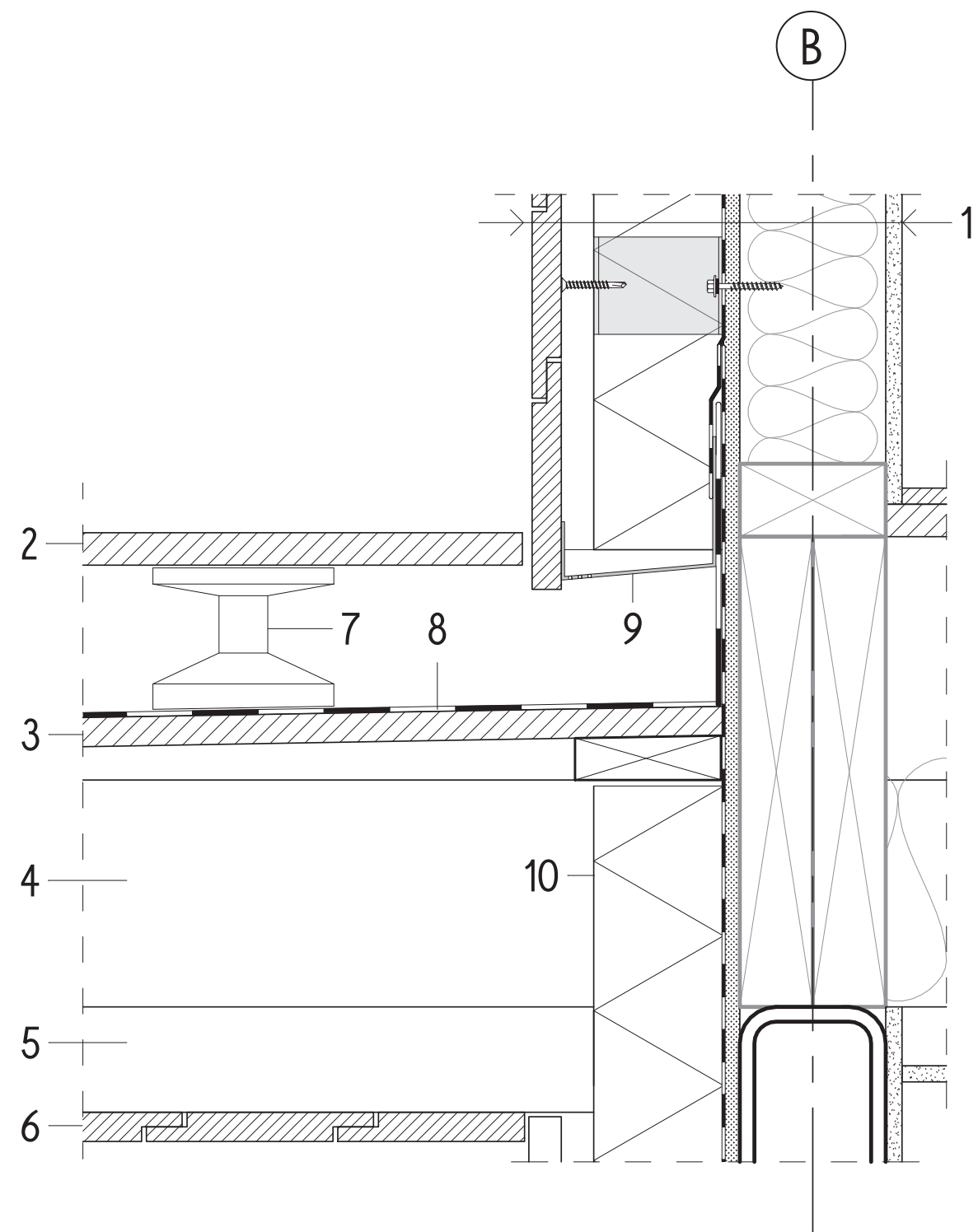

\section{1. wall assemlbly}

$10 \mathrm{~mm}$ gypsum board interior lining

$90 \mathrm{~mm} \times 45 \mathrm{~mm}$ timber framing with recycled fibreglass insulation

$12.7 \mathrm{~mm}$ gypsum sheathing with fibreglass coating class II vapour control layer (air barrier and drainage plane)

$80 \mathrm{~mm}$ rigid rock fibre insulation

$20 \mathrm{~mm} \times 45 \mathrm{~mm}$ vertical metal batten

horizontal shiplap timber cladding

2. timber decking
3. plywood substrate forming $1^{0}$ slope

4. $140 \mathrm{~mm} \times 45 \mathrm{~mm}$ cantilevered timber joists (class II vapour control layer to be flashed around joists for continuity) 5. timber framing to match depth of externally insulated soffit

6. timber soffit cladding

7. deck pedestals

8. single ply membrane

9. metal cavity closer

10. rock fibre insulation to continue past wall cladding to keep heat control layer continuity 


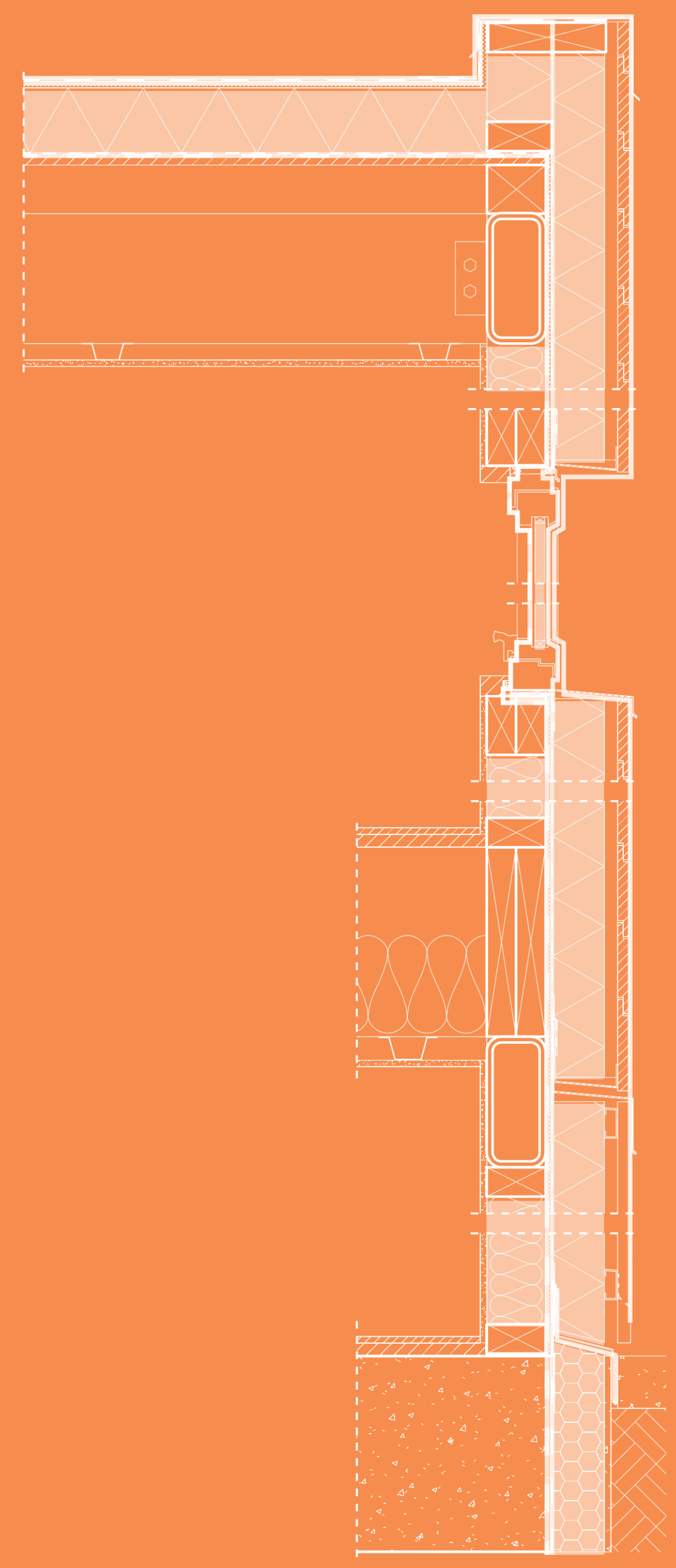




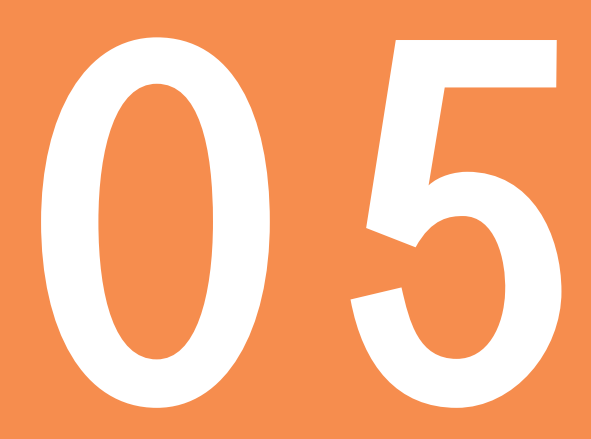

impliations and optimisation 


\section{1 implications}

This research could be used in a number of ways to contribute to better outcomes in the construction industry, particularly in relation to new timber framed house construction.

Education. The research that has been presented is intended to provide a basic working knowledge of the building envelope science principles in relation to rain control and hygrothermal load that should be considered in the design of a residential building envelope. Whilst an architect cannot be expected to be a building envelope science expert, a basic understanding of how to design a building envelope so that it manages the risk of condensation and mould is important if we are to design buildings that are healthy and durable. To achieve this the designer must understand that it is critical to design building envelopes as a complete system (a systems approach) where the individual components are designed to function effectively together. If individual components are specified with no understanding of their relationship to one another it is unlikely to perform well. A simple example of this would be in relation to the heat control layer. Insulation (and the more the better intuitively sounds like a good thing) but the location and permeability of the insulation layer relative to other control layers is important. As seen in the hygrothermal comparison, incorrect use of insulation leads to risk of interstitial condensation.

Adopting a "systems" approach is most important in relation to the envelope control layers. Understanding the role of each control layer within a building envelope, and how to ensure the roles are performed effectively, has been a focus of this research. An example of this is understanding the importance of the rain control layer - wall cladding is not, and should not, be considered the rain control layer as this can lead to basic weather-tightness failures. This research has emphasised that the wall's rain control layer is formed at the back of the air space (cavity) and must be detailed to be continuous. The importance of air control layer continuity has also been considered in detail, and the implications of air control discontinuity must be understood by all those involved in the construction process. For example, a flexible air control layer needs to be taped effectively to function (a blower door test is a good way to test performance of air control), and where these joints and overlaps occur should be clearly shown in detail drawings.

Control Layer Specification and identification. The research has focused on the correct specification, identification and installation of control layers. As mentioned above, designers should understand the building envelopes functionality in terms of the location and continuity of the four crucial control layers - rain, air, heat and vapour.

Designers can employ this research topic by ensuring that the construction details are precise and that they clearly identify the control layers and how the continuity of those control layers is to be maintained across the building envelope.

The control layers must be readable on the architectural details, provide clarity (for example, using a colour code) and be drawn with the appropriate scale. This contributes to the buildability theme and helps builders to construct the building envelope in a manner that ensures building performance objectives are achieved. 
Drawing quality affects outcomes. A strong argument can be made that the architectural details that relate to the design of the building envelope are the most important details to draw and get right. If this claim is correct then the implication should be that an increasing focus is placed on this aspect of the design. Getting the envelope aspect of a design wrong has consequences for public health, building durability and energy efficiency. The details that are drawn in relation to the building envelope have a direct impact on the health and well-being of the occupants of a building for the life of that building.

Improving building performance. The research has considered wall types that are currently acceptable under the New Zealand Building Code. The research has shown that Building Code compliant wall assemblies risk condensation, mould and rain control failures. At the most basic level this research is valuable in asking the simple question: are we happy to design buildings that do not manage condensation, become mouldy and have reduced durability? The research is therefore helpful in highlighting some of the limitations of the current building code and in offering some alternatives which will provide a consistently higher level of building performance.

Cost and performance. It is likely that implementing the building envelope solutions that have been proposed in this research would increase costs when compared to a traditional New Zealand roof or wall. While this may be true, the following considerations are important:

- The proposed wall can be built efficiently with single components being detailed to provide multiple functions within the wall assembly.
- Installing the proposed wall is potentially less expensive than trying to "tweak" traditional assemblies in an effort to get them to perform.

- The more common the proposed wall becomes, the lower the cost will become, in respect to both material and labour costs.

- Assessed in terms of life cycle cost, the proposed wall represents value. The system will result in buildings that are more energy efficient and more durable.

- The proposed wall will reduce the high social costs relating to unhealthy internal environments.

- Doing things right is less costly in the long run. The New Zealand construction industry is littered with examples of sub-standard outcomes that create cost to individual homeowners and to public institutions. The opportunity to consider solutions that provide long term benefit is one that should be carefully considered. 


\section{2 building envelope camparisan}

\section{facade section comparison}

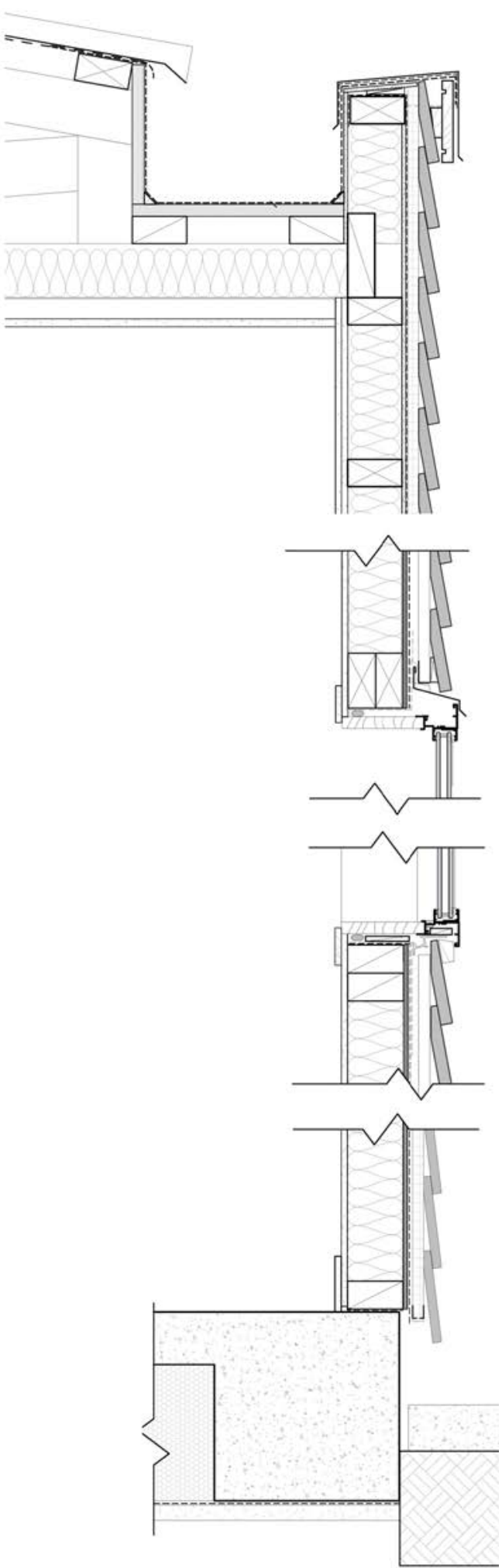

Figure 5.1. Typical NZ facade section. Public View Building Information, Search, Hutt City Council, 2020.

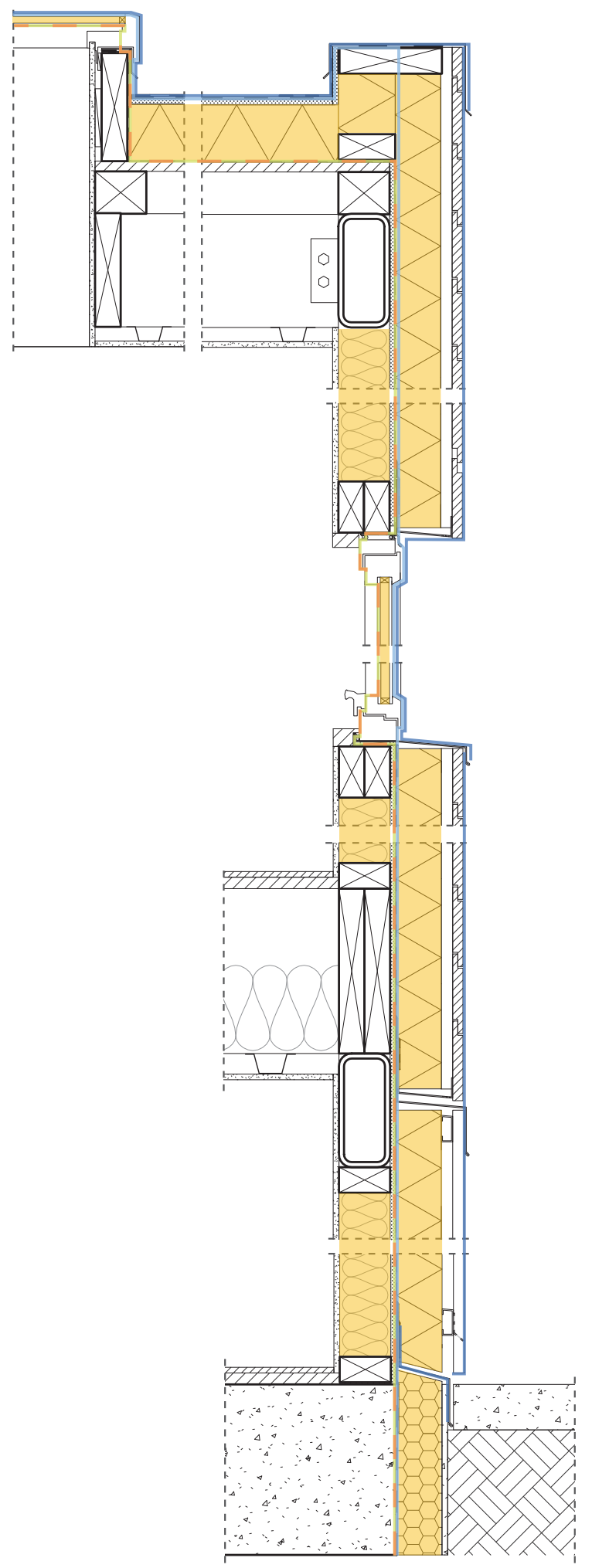

Figure 5.2. Proposed design facade section with control layer identification. 
The envelope design for the terrace housing that was presented in Chapter 4 is now compared and contrasted with typical New Zealand timber framed building envelopes that were first critiqued chapter 3.4. This comparison will assess the benefits of the research and findings that have informed the envelope design that was presented in chapter 4. The comparison addresses the key themes of performance, readability, and buildability and aims to demonstrate the fundamental differences in the performance and the clarity of communication between the envelope assemblies.

The envelope assemblies that have been chosen closely resemble the typologies that were used in the drawing critique in chapter 3 .

\section{Comparison between typical wall (figure 5.1) and proposed envelope design for terrace house (figure} 5.2).

Performance. The typical wall (figure 5.1) does not clearly identify the control layers or clearly show the continuity of the control layers, both which are critical to ensuring envelope performance. The proposed design for the terrace housing (figure 5.2) clearly identifies all control layers and articulates the continuity of those layers. Focusing on these control layers, a comparison between these two envelope assemblies can be made.

Rain control layer. In the typical assembly the rain control layer shows flashing tape overlapped incorrectly, most likely based on the assumption that the cladding is acting as the rain control layer. In the proposed assembly the rain control layer is detailed to provide a continuous drainage plane that effectively drains any water that penetrates the cladding. Correct overlapping of rain control layer elements is observed.

Air control layer. In the typical assembly the air control layer is shown as being continuous. However, the air control layer is installed on the outside of the timber framing with all thermal control within the timber framing. The hygrothermal calculations that have been presented show that this sequencing of control layers will create condensation risk. In the proposed assembly the air control layer is continuous and located on the interior side of the heat control layer to ensure the assembly performs hygrothermally.

The design of the membrane gutter in the typical assembly creates air control discontinuity where the wall and roof cladding met the internal membrane gutter. There is no evidence that suggests the roof underlay and wall underlay are effectively connected to form air control continuity.

Heat control layer. In the typical assembly the heat control is located within the structure. This means there will be multiple locations where the insulation will not be continuous. This discontinuity reduces the thermal efficiency of the envelope. The heat control layer in the typical assembly also terminates at the bottom plate meaning the slab edge is uninsulated.

The proposed assembly has continuous external insulation that increases thermal efficiency through eliminating thermal bridging. The location of the insulation on the exterior side of the rain-air-vapour control layers eliminates the risk of interstitial condensation within the timber framing. 
The proposed assembly has thermally broken windows that sit within the geometry of the heat control layer, increasing thermal performance. In the proposed assembly the heat control layer continues on the edge of the concrete slab increasing overall thermal performance.

The design of the parapet in the typical assembly results in large areas of thermal bridging. In contrast, the proposed assembly has continuous heat control at the wall to roof junction.

Vapour control layer. In the typical assembly no consideration is given to vapour control. In the proposed assembly continuous vapour control is detailed as part of the control layer design.

In addition to assessing the performance of the typical assembly through a consideration of the control layers, the readability of drawings and buildability should also be considered.

Readability. In the typical assembly there is no emphasis placed on identifying the control layers. In comparison, the coloured control layer identification on the proposed assembly provides visual clarification of location and sequencing of the control layers. The low-density cavity insulation and high-density rock fibre external insulation are drawn with different patterns reflecting their different physical properties.

The rain-air-vapour control layers are drawn as a solid element compared to the typical assembly which shows the air control layer as a dashed line. The solid element intuitively indicates to the reader that the material layer is, and must be, continuous.
Buildability. The typical wall is relatively simple to construct. However, if this typical assembly was retained, but the location of the control layers was adjusted to improve performance, the assembly would become considerably more difficult to construct. An example of this would be the need to locate and detail control layer/s on the interior side of the timber framing.

In the proposed wall all control layers are installed on the outside of the timber framing making continuity of control layers less problematic. 


\section{window head and sill comparison}

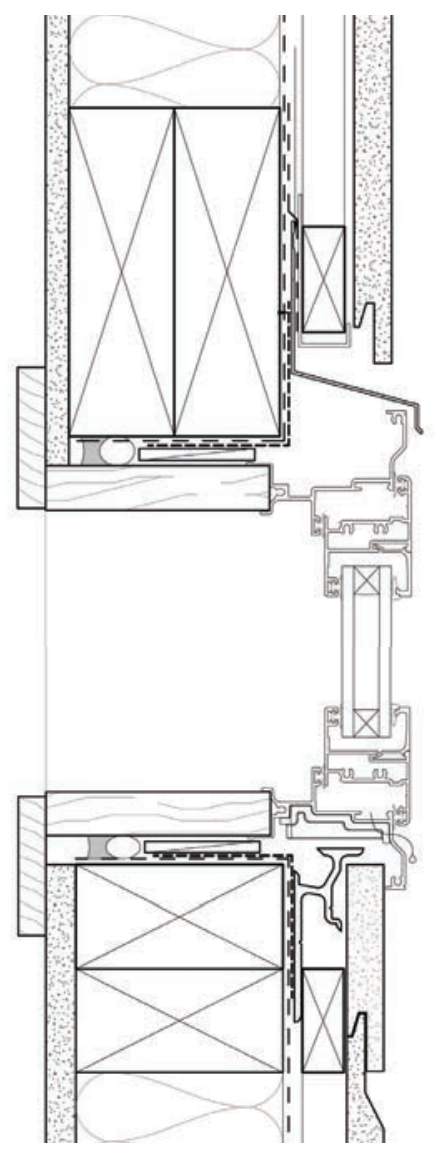

Figure 5.5. Typical NZ window head and sill. Public View Building Information, Search, Hutt City Council, 2020.

Window head and sill comparison. Increased thermal performance is observed in figure 5.6 compared to figure 5.1 due to it being thermally broken and its placement within the geometry of the building envelope. The set back of the window in figure 5.6 provides additional rain control as it creates creates an overhang.

The sill pan flashing in figure 5.6 allows for effective drainage of water when the windows leak. Figure 5.5 however, relies on flashing tapes to direct water to the exterior when windows leak.

The window head in figure 5.6 has air seals providing

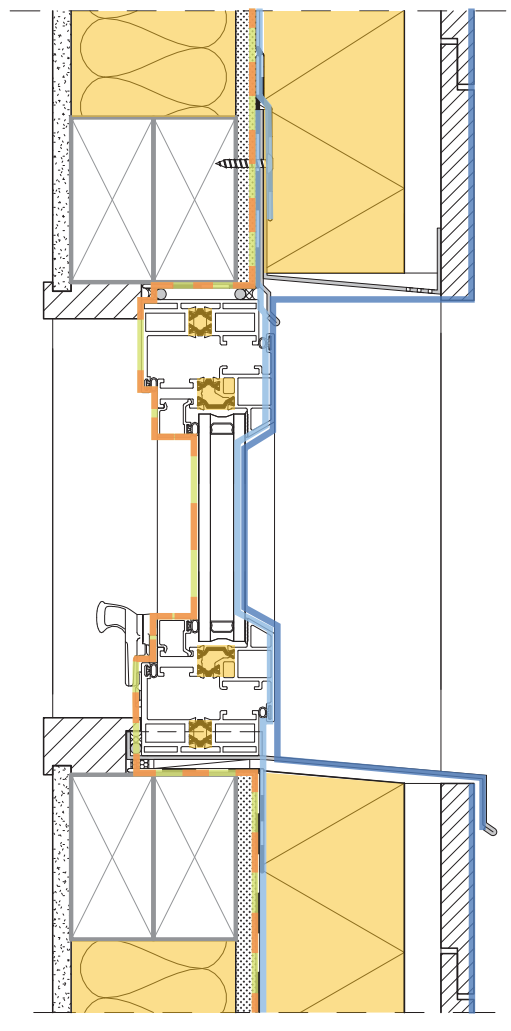

Figure 5.6. Proposed window head and sill with control layer identification.

an additional line of rain defense if one was to fail.

The dashed line represents the up turning of the pan flashing at either end. This ensures water draining down the jamb flashing is directed out to the exterior.

In the rare case where water would advance beyond the sill pan flashing, appropiately overlapped flashing tapes direct water to the drainage plane where it directed to the exterior. 


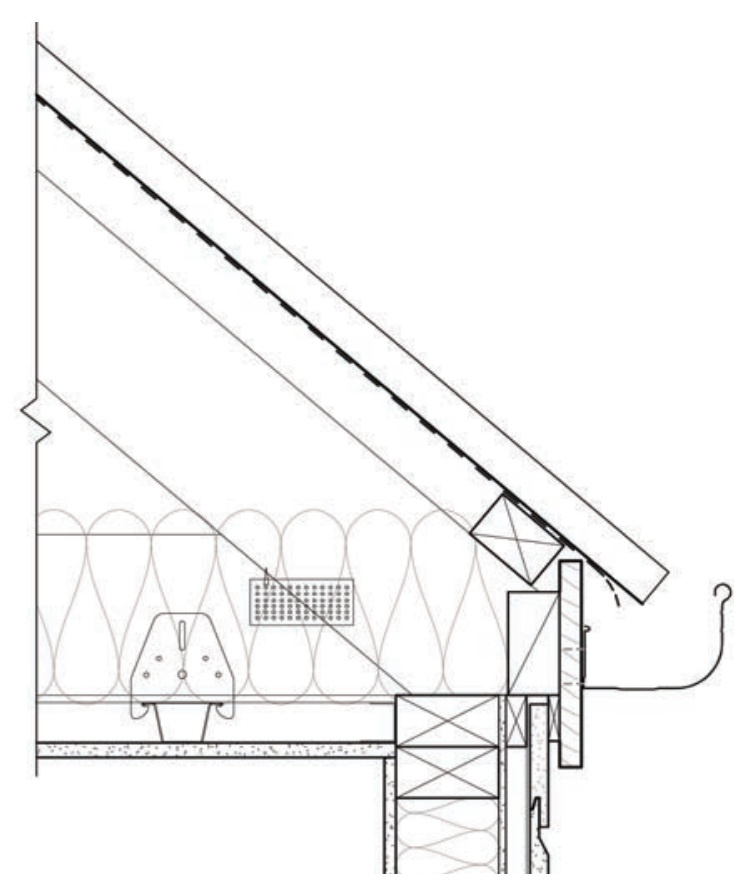

Figure 5.7. Typical NZ wall to roof junction. Public View Building Information, Search, Hutt City Council, 2020.

Roof to wall junction comparison. As mentioned in the chapter 3's drawing critique the wall to roof junction in typical NZ wall facades is often where control layer discontinuity occurs as seen in figure 5.7.

The proposed roof to wall junction (figure 5.8) has continuous control layers. This is made possible

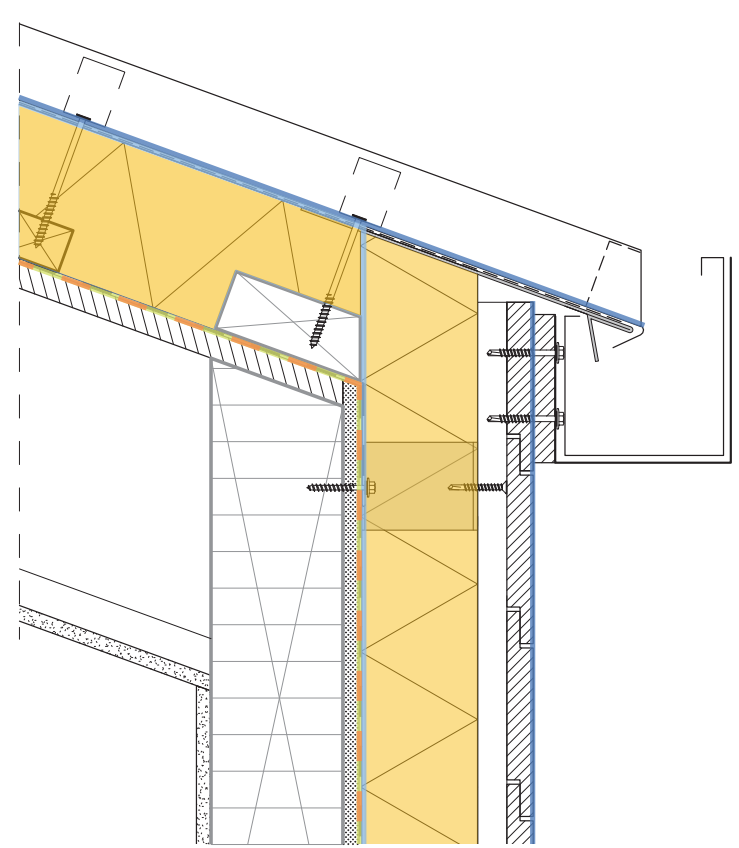

Figure 5.8. Proposed wall to roof junction with control layer identification.

by the location of the control layers outside the structure.

From a buildability perspective it as easier to install continuous control layers at junctions if control layers are on the exterior as there is no need to accommodate the timber framing elements that are present at junctions. 


\section{3 optimisation}

\section{1:I window mock up}

This 1:1 window mock up was created for the thesis presentation in order to demonstrate buildability of the proposed envelope assembly. The control layer

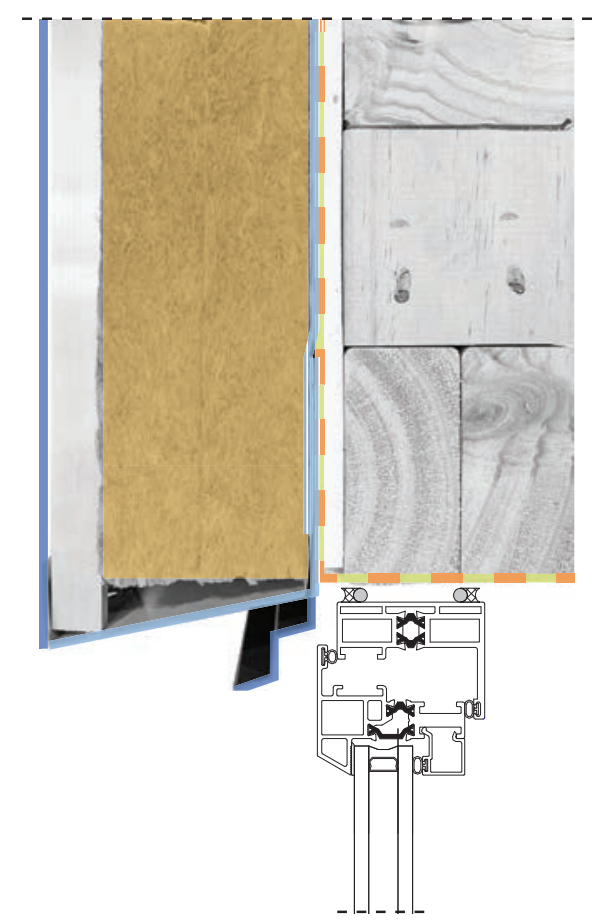

Figure 5.9. 1:1 window head mock up with control layer identification key applied. identification key was applied to window mock up model to show the presence of all the control layers and their continuity in the built reality.

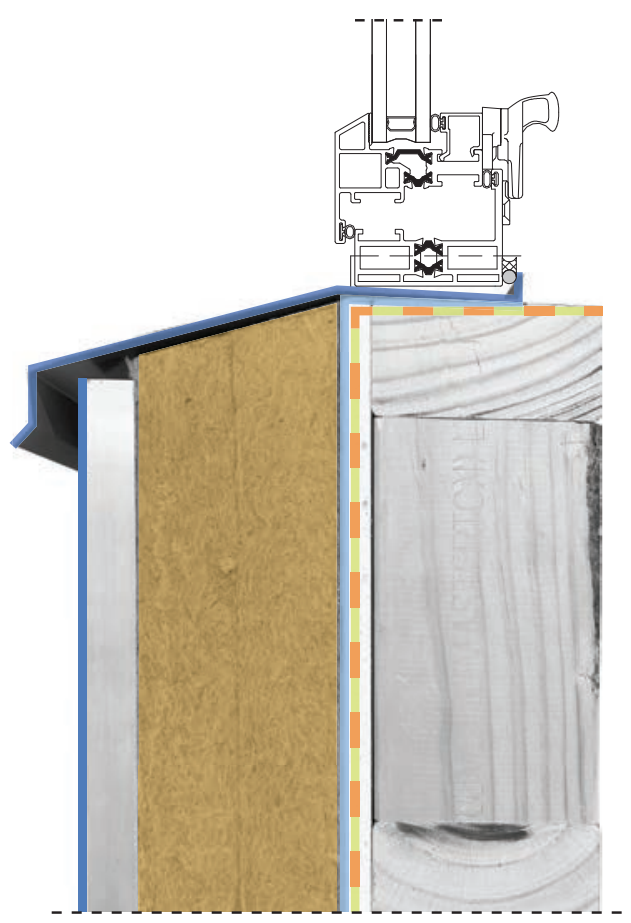

Figure 5.10. 1:1 window sill mock up with control layer identification key applied. 
I:I window mack up process photos
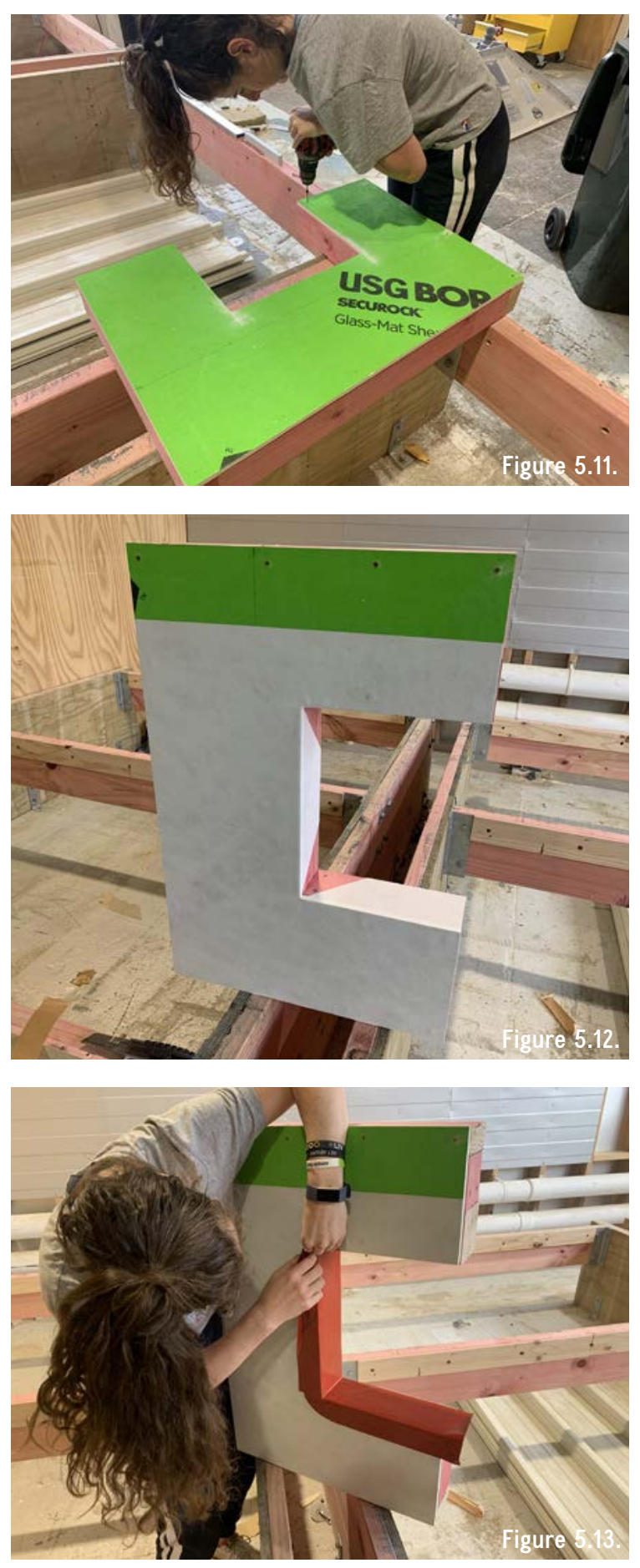
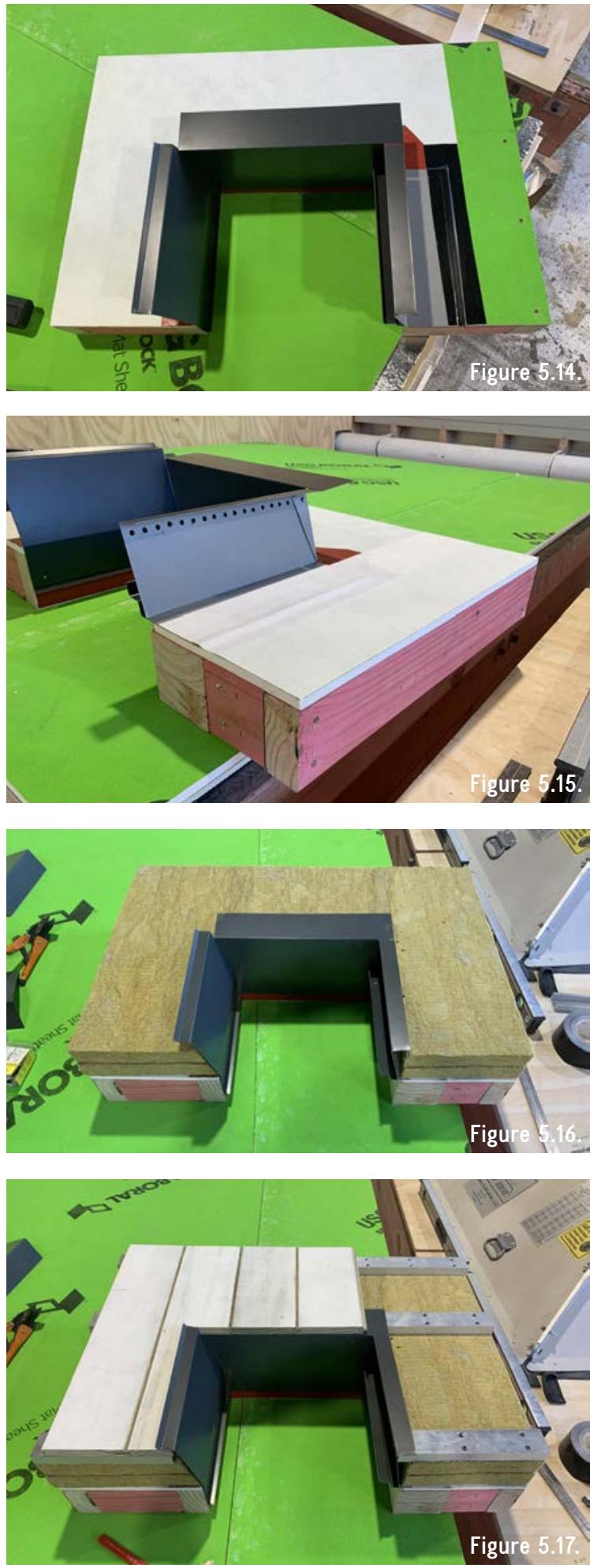

Figures 5.11 - 5.17. 1:1 window mock up process photos. 
I:I window mock up photos
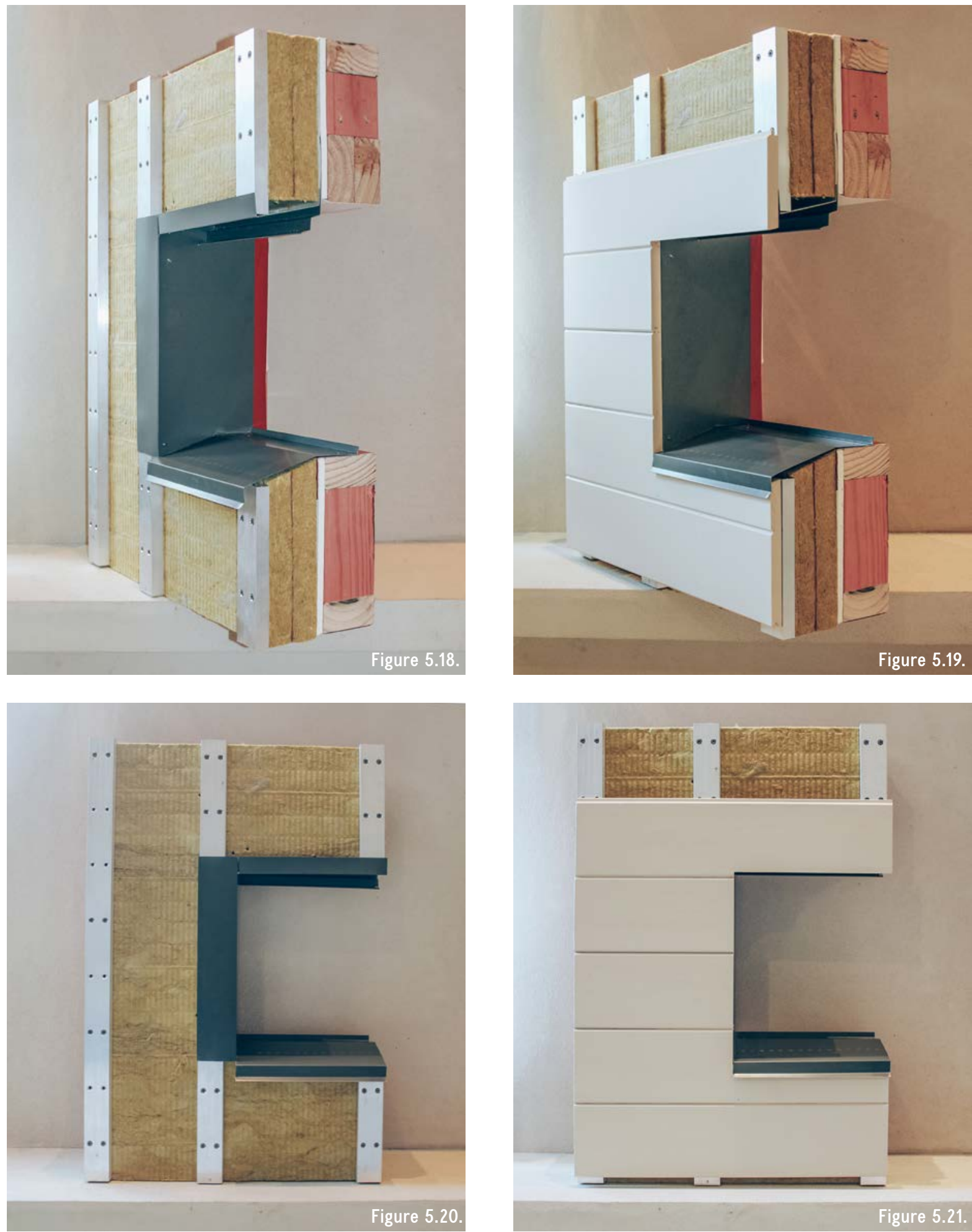

Figures 5.18 - 5.21. 1:1 window mock up photos. 


\section{optimisation}

This project has proposed ways in which building envelope performance, particularly in relation to timber framing terrace house design, can be improved. The project has also considered typical approaches to building envelope construction in New Zealand and the performance limitations associated with those approaches. On the basis of the building envelope science research, including hygrothermal comparison, a wall assembly is proposed that incorporates all crucial control layers, appropriately sequenced and installed on the outside of the timber framing. Through the drawing set it is demonstrated that control layer continuity can be achieved in timber framed building envelopes. This results in residential dwellings that are more healthy, more efficient and more durable.

Considering ways in which the research can be further developed and how the improvements that have been proposed can be implemented and measured are discussed below.

To achieve the desired outcomes, the wall construction that has been proposed has to be built well. This requires construction drawings that are readable and able to be effectively executed on site. It would be valuable to be able to interview builders and other practitioners and gain their feedback on the readability of the drawings. Are the drawings easy to understand? Are the envelope control layers clearly represented? Do the details provide sufficient clarity to enable the detail to be executed on site?

Ultimately, it would be fascinating to have the opportunity for builders to construct the wall assembly as it has been proposed and receive feedback in respect to the buildability of the wall and associated details.
The proposed wall assembly is compliant with the current "performance based" Building Code. However, it is not a common wall assembly in New Zealand. It would be helpful to engage in dialogue with building officials who are responsible for building consents to get feedback in respect to the clarity and intent of the drawings and details. As part of this process, it would be helpful to explain the proposed wall concept (and compare and contrast it to more common wall assemblies) with the use of hygrothermal analysis. It would also be interesting to engage in dialogue with the relevant industry organisations as to the role the New Zealand Building Code could play in assisting with implementing the findings of this research. Currently New Zealand has a performance based building code, and the author is not suggesting a fundamental change to this. However, it may be seen as an improvement to the NZBC if, when a building envelope design is submitted for consent, there was a requirement within the code to demonstrate that the design effectively mitigates condensation risk. The author is not suggesting that the way(s) to achieve effective condensation management should be prescribed in the code, but would argue that, however it is achieved, the designer must prove their envelope design achieves this.

The author sees great value in modifying the Building Code to ensure condensation risk is considered as part of envelope design, as proposed above. This research provides clear evidence that a wall or roof can be designed in accordance with the Building Code, receive consent and be built when it is inevitable that the design will result in significant condensation and mould forming in roof and wall cavities.

Furthermore, (as a much longer-term project) a 
residential dwelling could be constructed utilising the proposed envelope assembly. This would enable long term analysis to be undertaken to establish that the claimed levels of performance are, in reality, being achieved.

This research has been applied to a timber framed terrace house development. The building envelope research could equally be considered and applied in relation to other typologies. Further research could consider single dwellings, medium rise apartments and schools. 


\section{references and figures}

Allen, E. (2007). Architectural Detailing:

Function, Constructability, Aesthetics. John Wiley \& Sons.

Asthma and Respiratory Foundation NZ. (2018). Key Statistics. Retrieved from https://www. asthmafoundation.org.nz/research/key-statistics

Baird, G., Bennett, A., \& Easton, L. (2016).

Selected Papers from Building A Better New Zealand Conference. Shu-Kun Lin. Retrieved from https:// wWw.mdpi.com/books/pdfview/book/187

BC Housing. (2020). Building Enclosure Design Guide: Wood-Frame Multi-Unit Residential Buildings (2nd ed). Crown Publications, Queen's Printer.

Brand, R. (1990). Architectural Details for Insulated Buildings. Van Nostrand Reinhold.

BRANZ. (November, 2018). BRANZ Facts Roof Ventilation \#1: Roof Space Ventilation in New Zealand houses. Retrieved from https://www.branz. co.nz/pubs/branz-facts/roof-ventilation/1-roof-space/

BRANZ Research Now. (October, 2019). Indoor Air Quality \#1: An overview of indoor air contaminants in New Zealand houses. Retrieved from https://www.branz.co.nz/pubs/research-now/ iaq/1-overview-contaminants/

Building Science Corporation. (2003). BSC Information-310: Vapour Control Layer Recommendations. Building America. Retrieved from https://www. buildingscience.com/documents/information-sheets/ info-sheet-310-vapor-control-layer-recommendations

Burnett, E., \& Straube, J. (2005). Building Science for Building Enclosures. Building Science Press.

Douwes, J. (2008). Cold houses and impact on health. Science Media Centre. Retrieved from https://www.sciencemediacentre.co.nz/2008/06/18/ cold-houses-and-impact-on-health/

Howden-Chapmen, P., Viggers, H., Chapmen,
R., O'Sullivan, K., Telfar Barnard, L., \& Lloyd, B. (2012). Tackling cold housing and fuel poverty in New Zealand: A review of policies, research, and health impacts. Energy Policy Journal, 49, 134-142. https:// www.sciencedirect.com/science/article/abs/pii/ S0301421511007336

Hutt City Council. (2020). Public View Building Information Search. http://iportal.huttcity.govt. $\mathrm{nz} / ? \mathrm{tab}=34$

Jones, M., \& White, V. (2017). Warm, dry, healthy? Insights from the 2015 House Condition Survey on insulation, ventilation, heating and mould in New Zealand houses (BRANZ Study Report 372). Retrieved from https://d39d3mj7qi096p.cloudfront. net/media/documents/SR372_Warm_dry_healthy. pdf

Koenders, E., \& Knaack, U. (2018). Building Physics of the Envelope: Principles of Construction. Berlin, Germany: Walter de Gruyter GmbH. Latona, R., \& Pinon, J. (2013). Permeance of Steel Roof Decks and Effect on Hygrothermal Performance of Roofing System. ASHRAE.

Lothar, M., \& van Raamsdink, T. (2011). A

New Zealand Based Study on Airtightness and Moisture Management. Pro Clima. Retrieved from https:// proclima.co.nz/pro-clima-study/ 44(2):36-41

Lstiburek, J. (1999). Wood Durability (Research Report 0997). Building Science Press. Retrieved from https://www.buildingscience.com/documents/reports/rr-9910-wood-durability/view Lstiburek, J. (2000). Air Barriers vs. Vapour Barriers (Research Report 0004). Building Science Press. Retrieved from https://www.buildingscience. com/documents/reports/rr-0004-air-barriers-vs-vapor-barriers/view

Lstiburek, J. (2001). Moisture, Building 
Enclosures and Mould (Research Report 0101a). Building Science Press. Retrieved from https://www. buildingscience.com/documents/published-articles/ pa-moisture-building-enclosures-mold/view

Lstiburek, J. (2001). Unvented Roof Systems. (Research Report 0108). Building Science Press. Retrieved from https://www.buildingscience.com/ documents/reports/rr-0108-unvented-roof-systems/ view

Lstiburek, J. (2002). Moisture Control for Buildings. ASHRAE Journal, 44(2), 36-41. Retrieved from https://www.researchgate.net/publication/293128013_Moisture_control_for_buildings

Lstiburek, J. (2004). Insulations, Sheathings and Vapour Retarders (Research Report 0412). Building Science Press. Retrieved from https://www. buildingscience.com/documents/reports/rr-0412-insulations-sheathings-and-vapor-retarders/view

Lstiburek, J. (2004). Roof Design (Research Report 0404). Building Science Press. Retrieved from https://www.buildingscience.com/documents/reports/ rr-0404-roof-design/view

Lstiburek, J. (2004). Vapour Barriers and Wall Design (Research Report 0410). Building Science Press. Retrieved from https://www.buildingscience. com/documents/reports/rr-0410-vapor-barriers-andwall-design/view

Lstiburek, J. (2006). Understanding Air Barriers. (Building Science Digest 104). Building Science Press. Retrieved from https://www.buildingscience.com/documents/digests/bsd-104-understanding-air-barriers

Lstiburek, J. (2008). Energy Flow Across Enclosures. ASHRAE Journal, 50(8), 60-65. Retrieved from https://www.buildingscience.com/documents/ insights/bsi-028-energy-flow-across-enclosures

Lstiburek, J. (2010). Insight: The Perfect
Wall. Building Science Press. Retrieved from https:// www.buildingscience.com/documents/insights/bsi001-the-perfect-wall

Lstiburek, J. (2011). Understanding Vapour Barriers. (Building Science Digest 106). Building Science Press. Retrieved from https://www.buildingscience.com/documents/digests/bsd-106-understanding-vapor-barriers

Lstiburek, J. (2019). Insight Rain Control: Drained, Barrier and Mass. Building Science Press. Retrieved from https://www.buildingscience.com/documents/building-science-insights/bsi-117-rain-controldrained-barrier-and-mass

Ministry for Culture and Heritage. (2016). Thermal Insulation Required in NZ Homes. Retrieved from https://nzhistory.govt.nz/page/thermal-insulation-required-nz-homes

NIWA. (2020). Mean relative humidity. Retrieved from https://niwa.co.nz/education-and-training/schools/resources/climate/humidity

Page, I. (2009). Timber in New Buildings. BRANZ Build, Issue 111, 35. Retrieved from https:// www.buildmagazine.org.nz/index.php/articles/show/ timber-in-new-buildings

Powers, J. (2019). Heath and Housing in NZ. Retrieved from https://oculusltd.co.nz/housinghealth-in-nz/

Radford, A., \& Slater, R. (2012). Perceptions in the Australian Building Industry of Deficiencies in Architects' Design Documentation and the Effects on Project Procurement. Australian Journal of Construction Economics and Building, 8, 23. Retrieved from https://www.researchgate.net/ publication/287513265_Perceptions_in_the_Australian_Building_Industry_of_Deficiencies_in_Architects'_Design_Documentation_and_the_Effects_ on_Project_Procurement 
Rockwool. (2019). Wood Frame Construction up to 4 Storeys: Lightweight Cladding. Retrieved from https://p-cdn.rockwool.com/siteassets/o2-rockwool/ documentation/construction-details/residential/ constructiondetails-woodframe-construction-lightweight-horizontal-cladding.pdf? $f=20201024215323$

Roy, E. (2020). They allowed the perfect storm': UN expert damns New Zealand's housing crisis. The Guardian. Retrieved from https:// amp-theguardian-com.cdn.ampproject.org/c/s/amp. theguardian.com/world/2020/feb/19/they-allowedthe-perfect-storm-un-expert-damns-new-zealandshousing-crisis

Weather Spark. (2020). Average Weather in Wellington. Retrieved from https://weatherspark.com/y/144870/Average-Weather-in-WellingtonNew-Zealand-Year-Round

\section{figure list}

Figures not referecned are author's own

\section{1 research outline}

Figure 1.1. The increasing airtightness of New Zealand homes. McNeil, S. (Dec, 2015). Combating Internal Moisture. Build, 151, p.47. BRANZ. https:// www.buildmagazine.org.nz/index.php/articles/show/ combating-internal-moisture

Figure 1.2. Mould formed in timber framed envelope on building wrap and cavity insulation. Saltzman, R. (2012). This year, I'm thankful for closed-cell foam insulation. Yeah, that's right. Structure Tech. https://www.structuretech.com/ blog/basement-insulation/

Figure 1.5. Hospitalisations for asthma for year ending May 2007. Bpac NZ. (May, 2009). Inequalities in asthma prevalence, morbidity and mortality. Best Practice Journal, Special Edition Childhood Asthma, p.2. https://bpac.org.nz/BPJ/2009/ asthma/inequalities.aspx

\section{2 literature review}

Figure 2.1. The 'perfect wall' concept. Lstiburek, J. (2010). Insight: The Perfect Wall. Building Science Press.

Figure 2.2. The 'perfect wall' conceptually applied to the roof and slab assemblies. Lstiburek, J. (2010). Insight: The Perfect Wall. Building Science Press.

Figure 2.3. Water entry in New Zealand leaking buildings. Baird., Bennett., \& Easton. (2016). Selected Papers from Building A Better New Zealand (BBNZ 2014) Conference. Buildings (ISSN 20755309), p.60. https://www.mdpi.com/books/pdfview/ book/187

Figure 2.4. Multiple lines of defense against rain in a drained wall assembly. Burnett, E., \& Straube, J. (2005). Building Science for Building Enclosures. Building Science Press.

Figure 2.5. Experimental E2 Acceptable Solutions apron flashing between wall and roof revealing locations of water leakage past the cladding. Locations being between the flashing upstand and the cavity closer and up through the vent openings in the cavity closer. Baird., Bennett., \& Easton. (2016). Selected Papers from Building A Better New Zealand (BBNZ 2014) Conference. Buildings (ISSN 2075-5309), p.73. https://www.mdpi.com/books/pdfview/book/187

Figure 2.6. Water vapour transport in roof assembly, diffusion bridge is demonstrated where a vapour retarder is perforated.Slanina, P., \& Silarova, S. (2009). Moisture transport through perforated vapour retarders. Building and Environment, 44, p.1618. Elsevier Ltd.

Figure 2.7. Water vapour transport in roof assembly through diffusion. Slanina, P., \& Silarova, S. (2009). Moisture transport through perforated vapour retarders. Building and Environment, 44, p.1618.

Figure 2.8. Water vapour transpoted by air flow can create interstitial condensation on cold surfaces within walls. Burnett, E., \& Straube, J. (2005). 
Building Science for Building Enclosures. Building Science Press.

Figure 2.9. Thermal bridges and the effect of continuous exterior insulation on timber framed envelopes. Burnett, E., \& Straube, J. (2005). Building Science for Building Enclosures. Building Science Press.

Figure 2.10. Mould growing on roof framing timber and roofing underlay in a vented roof in an Auckland house. BRANZ. (November, 2018). BRANZ Facts Roof Ventilation \#1: Roof Space Ventilation in New Zealand houses. BRANZ. https://www.branz. co.nz/pubs/branz-facts/roof-ventilation/1-roof-space/

Figure 2.11. Hygrothermal Regions developed by building science coorporation. Building Science Corporation. (2003). BSC Information-310: Vapour Control Layer Recommendations. Building America.

Figure 2.14. Mareriality of control layers in 3D cutaway of interstorey junction. BC Housing. (2020). Building Enclosure Design Guide: Wood-Frame Multi-Unit Residential Buildings. Burnaby: British Columbia: Crown Publications, Queen's Printer.

Figure 2.15. Mareriality of control layers in 3D cutaway of cantilevered floor. BC Housing. (2020). Building Enclosure Design Guide: Wood-Frame MultiUnit Residential Buildings. Burnaby: British Columbia: Crown Publications, Queen's Printer.

Figure 2.16. Mareriality of control layers in 3D cutaway of insulated slab edge. BC Housing. (2020). Building Enclosure Design Guide: Wood-Frame Multi-Unit Residential Buildings. Burnaby: British Columbia: Crown Publications, Queen's Printer.

\section{3 envelape designand drawings}

Figure 3.20. Wall one, typical NZ facade design. Public View Building Information, Search, Hutt City Council, 2020.
Figure 3.21. Wall two, typical NZ facade design. Public View Building Information, Search, Hutt City Council, 2020.

Figure 3.22. Wall three, typical NZ facade design. Public View Building Information, Search, Hutt City Council, 2020.

Figure 3.23. Wall four, NZ facade design. Public View Building Information, Search, Hutt City Council, 2020.

Figure 3.24. Wall five, typical NZ facade design with internal air and vapour control. Public View Building Information, Search, Hutt City Council, 2020.

Figure 3.25. Wall 6, high perforamnce wall facade. Rockwool wood frame construction up to 4 storeys construction details, Rockwool, 2029.

\section{5 aptimisation and implications}

Figure 5.1. Typical NZ facade section. Public View Building Information, Search, Hutt City Council, 2020.

Figure 5.5. Typical NZ window head and sill. Public View Building Information, Search, Hutt City Council, 2020.

Figure 5.7. Typical NZ wall to roof junction. Public View Building Information, Search, Hutt City Council, 2020. 
Virtoria University Wellington 2021 